\title{
Cochrane
}

Library

Cochrane Database of Systematic Reviews

\section{Altered dietary salt intake for people with chronic kidney disease} (Review)

McMahon EJ, Campbell KL, Bauer JD, Mudge DW, Kelly JT

McMahon EJ, Campbell KL, Bauer JD, Mudge DW, Kelly JT.

Altered dietary salt intake for people with chronic kidney disease.

Cochrane Database of Systematic Reviews 2021, Issue 6. Art. No.: CD010070.

DOI: 10.1002/14651858.CD010070.pub3.

www.cochranelibrary.com 
TABLE OF CONTENTS

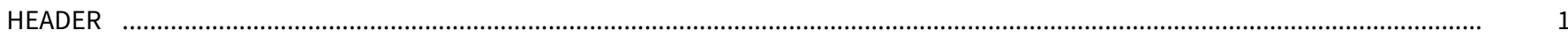

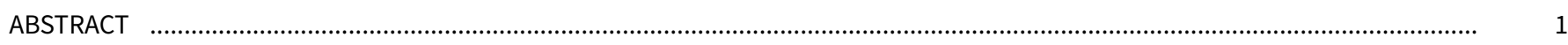

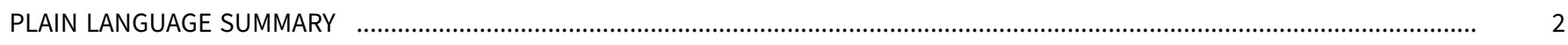

SUMMARY OF FINDINGS

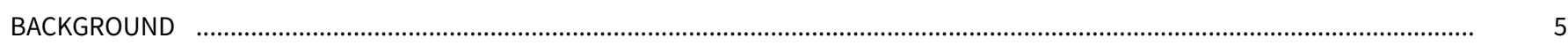

OBJECTIVES

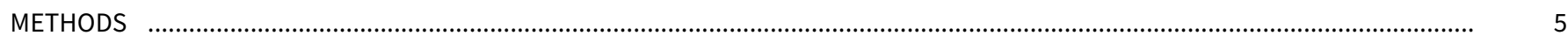

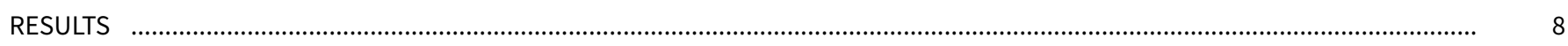

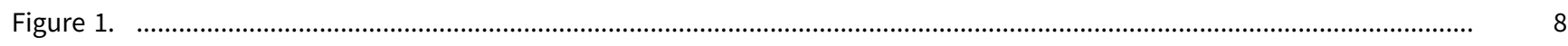

Figure 2.

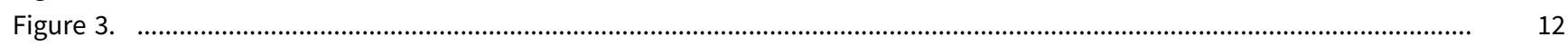

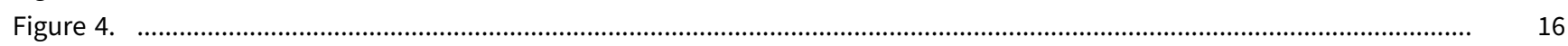

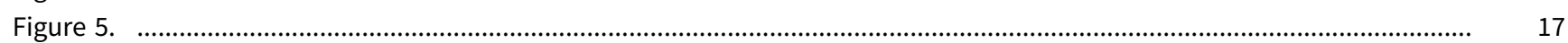

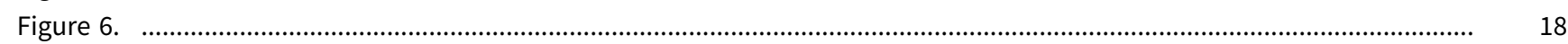

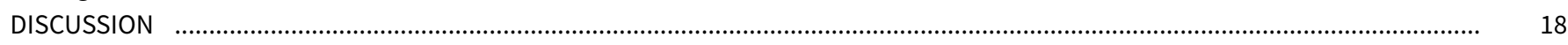

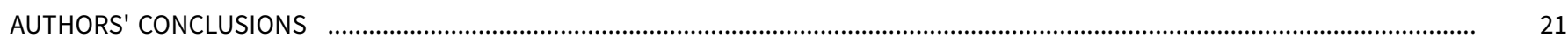

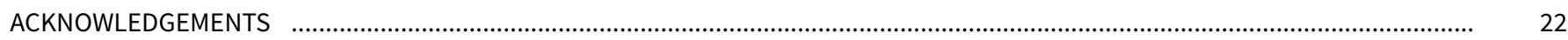

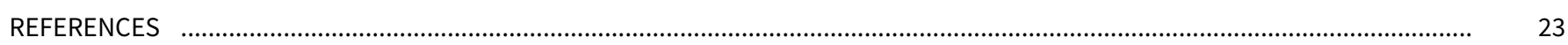

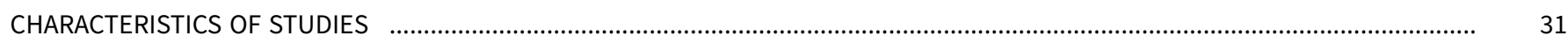

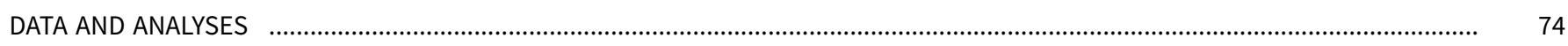

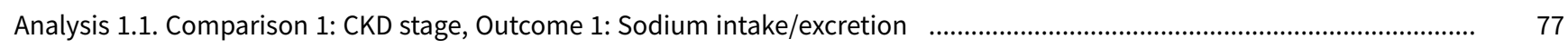

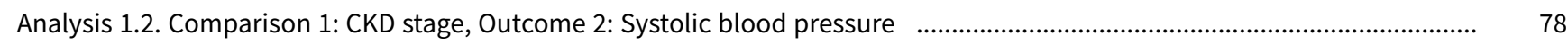

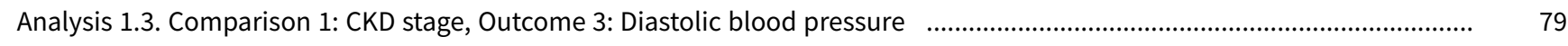

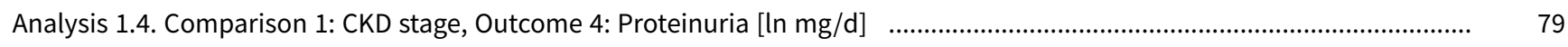

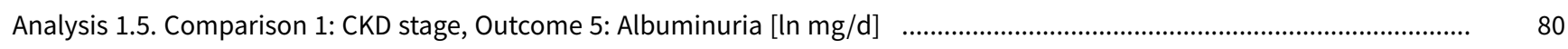

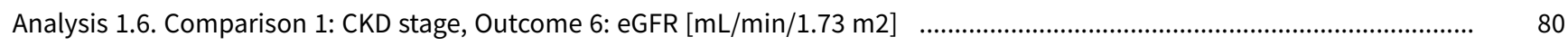

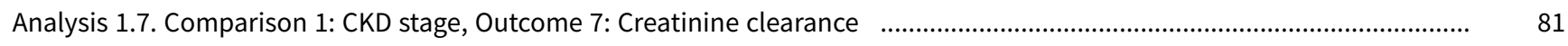

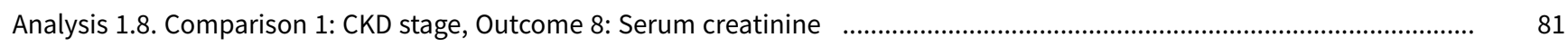

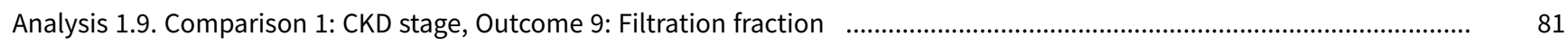

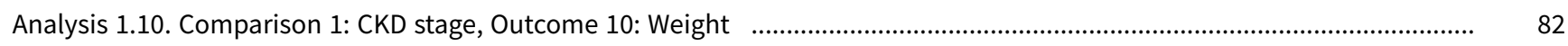

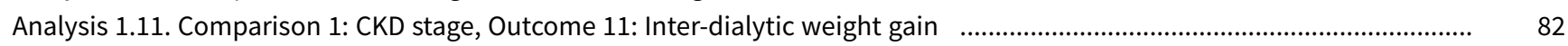

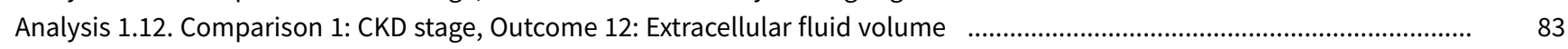

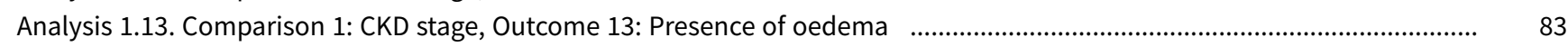

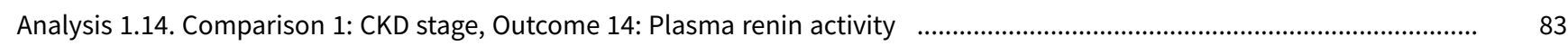

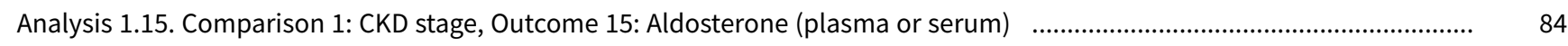

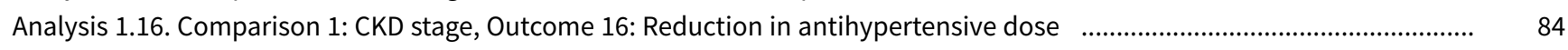

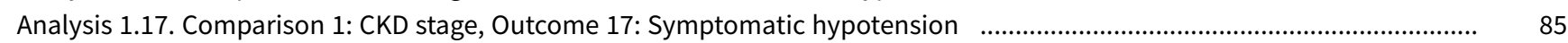

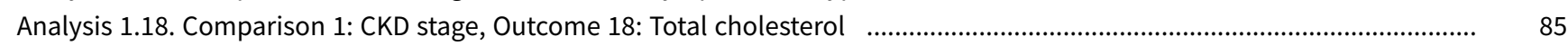

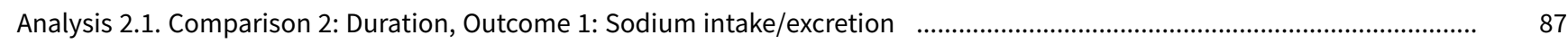

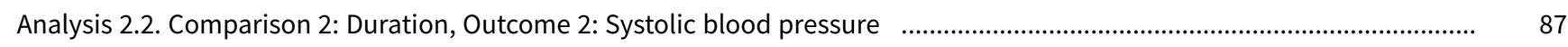

Analysis 2.3. Comparison 2: Duration, Outcome 3: Diastolic blood pressure ....................................................................... 88

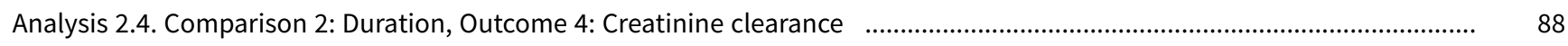

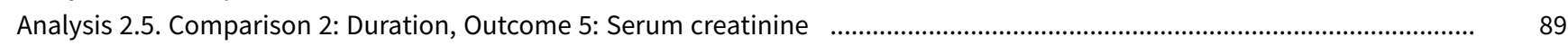

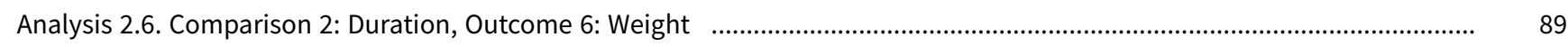

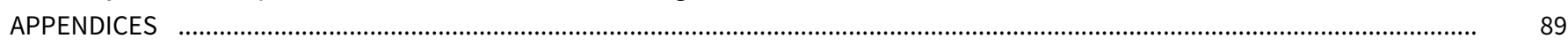

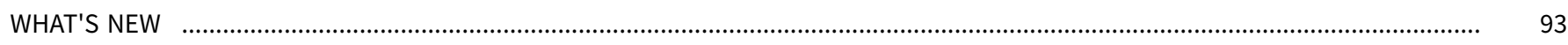

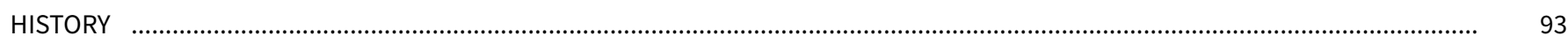

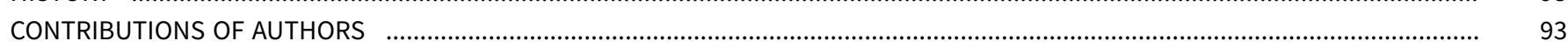

DECLARATIONS OF INTEREST

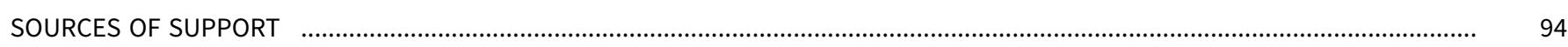

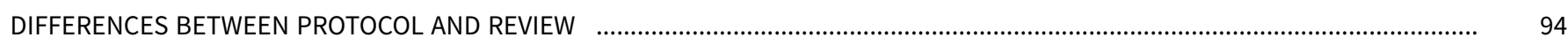

Altered dietary salt intake for people with chronic kidney disease (Review)

Copyright $\odot 2021$ The Cochrane Collaboration. Published by John Wiley \& Sons, Ltd. 
[Intervention Review]

\section{Altered dietary salt intake for people with chronic kidney disease}

Emma J McMahon ${ }^{1}$, Katrina L Campbell2,3, Judith D Bauer ${ }^{4}$, David W Mudge ${ }^{5}$, Jaimon T Kelly²

1Wellbeing and Preventable Chronic Diseases Division, Menzies School of Health Research, Charles Darwin University, Brisbane, Australia. ${ }^{2}$ Centre for Applied Health Economics, Menzies Health Institute Queensland, Griffith University, Nathan, Australia. ${ }^{3}$ Healthcare Excellence and Innovation, Metro North Hospital and Health Service, Herston, Australia. ${ }^{4}$ School of Human Movement and Nutrition Sciences, The University of Queensland, St Lucia, Australia. ${ }^{5}$ Department of Nephrology, University of Queensland at Princess Alexandra Hospital, Woolloongabba, Australia

Contact address: Emma J McMahon, e.j.mcmahon@outlook.com.

Editorial group: Cochrane Kidney and Transplant Group.

Publication status and date: New search for studies and content updated (conclusions changed), published in Issue 6, 2021.

Citation: McMahon EJ, Campbell KL, Bauer JD, Mudge DW, Kelly JT. Altered dietary salt intake for people with chronic kidney disease. Cochrane Database of Systematic Reviews 2021, Issue 6. Art. No.: CD010070. DOI: 10.1002/14651858.CD010070.pub3.

Copyright @ 2021 The Cochrane Collaboration. Published by John Wiley \& Sons, Ltd.

\section{A B S T R A C T}

\section{Background}

Evidence indicates that reducing dietary salt may reduce the incidence of heart disease and delay decline in kidney function in people with chronic kidney disease (CKD). This is an update of a review first published in 2015.

\section{Objectives}

To evaluate the benefits and harms of altering dietary salt for adults with CKD.

\section{Search methods}

We searched the Cochrane Kidney and Transplant Register of Studies up to 6 October 2020 through contact with the Information Specialist using search terms relevant to this review. Studies in the Register are identified through searches of CENTRAL, MEDLINE, and EMBASE, conference proceedings, the International Clinical Trials Register (ICTRP) Search Portal and ClinicalTrials.gov.

\section{Selection criteria}

Randomised controlled trials comparing two or more levels of salt intake in adults with any stage of CKD.

\section{Data collection and analysis}

Two authors independently assessed studies for eligibility, conducted risk of bias evaluation and evaluated confidence in the evidence using GRADE. Results were summarised using random effects models as risk ratios (RR) for dichotomous outcomes or mean differences (MD) for continuous outcomes, with $95 \%$ confidence intervals $(\mathrm{Cl})$.

\section{Main results}

We included 21 studies (1197 randomised participants), 12 in the earlier stages of CKD (779 randomised participants), seven in dialysis ( 363 randomised participants) and two in post-transplant (55 randomised participants). Selection bias was low in seven studies, high in one and unclear in 13. Performance and detection biases were low in four studies, high in two, and unclear in 15 . Attrition and reporting biases were low in 10 studies, high in three and unclear in eight.

Because duration of the included studies was too short (1 to 36 weeks) to test the effect of salt restriction on endpoints such as death, cardiovascular events or CKD progression, changes in salt intake on blood pressure and other secondary risk factors were examined. 
Reducing salt by mean $-73.51 \mathrm{mmol} /$ day $(95 \% \mathrm{Cl}-92.76$ to -54.27$)$, equivalent to $4.2 \mathrm{~g}$ or $1690 \mathrm{mg}$ sodium/day, reduced systolic/diastolic blood pressure by $-6.91 /-3.91 \mathrm{~mm} \mathrm{Hg}(95 \% \mathrm{Cl}-8.82$ to $-4.99 /-4.80$ to $-3.02 ; 19$ studies, 1405 participants; high certainty evidence). Albuminuria was reduced by $36 \%(95 \% \mathrm{Cl} 26$ to 44$)$ in six studies, five of which were carried out in people in the earlier stages of CKD (MD $-0.44,95 \% \mathrm{Cl}-0.58$ to $-0.30 ; 501$ participants; high certainty evidence). The evidence is very uncertain about the effect of lower salt intake on weight, as the weight change observed $(-1.32 \mathrm{~kg}, 95 \% \mathrm{Cl}-1.94$ to $-0.70 ; 12$ studies, 759 participants) may have been due to fluid volume, lean tissue, or body fat. Lower salt intake may reduce extracellular fluid volume in the earlier stages of CKD $(-0.87 \mathrm{~L}, 95 \% \mathrm{Cl}-1.17$ to -0.58 ; 3 studies; 187 participants; low certainty evidence). The evidence is very uncertain about the effect of lower salt intake on reduction in antihypertensive dose (RR 2.45, 95\% Cl 0.98 to 6.08; 8 studies; 754 participants). Lower salt intake may lead to symptomatic hypotension (RR 6.70, $95 \% \mathrm{Cl} 2.40$ to 18.69; 6 studies; 678 participants; moderate certainty evidence). Data were sparse for other types of adverse events.

\section{Authors' conclusions}

We found high certainty evidence that salt reduction reduced blood pressure in people with CKD, and albuminuria in people with earlier stage CKD in the short-term. If such reductions could be maintained long-term, this effect may translate to clinically significant reductions in CKD progression and cardiovascular events. Research into the long-term effects of sodium-restricted diet for people with CKD is warranted.

\section{PLAIN LANGUAGE SUMMARY}

\section{Altered dietary salt intake for adults with chronic kidney disease}

\section{What is the issue?}

People with chronic kidney disease (CKD) have a reduced kidney function that persists over time. People with CKD are at increased risk of heart disease and worsening kidney function which can lead to the need for dialysis or kidney transplantation to survive. High salt intake is linked to risk factors for both heart disease and worsening kidney function, including high blood pressure, excess protein in the urine and fluid overload. Therefore reducing salt intake may help reduce risk of heart disease and preserve kidney function. We aimed to assess the benefits and harms of reducing salt intake for people with CKD.

\section{What did we do?}

We searched the evidence up to October 2020 to find randomised controlled trials comparing two or more levels of salt intake in adults with CKD, including those in the earlier stages of CKD, those treated with dialysis, and those who had received a kidney transplant.

\section{What did we find?}

We found 21 studies that included 1197 adults with CKD (725 in low salt and 725 people in high salt group). Study participants included adults who were in the early stages of CKD (779 people in 12 studies), adults who were on dialysis (363 people in seven studies), and adult kidney transplant recipients ( 55 people in two studies). The average study duration was seven weeks, ranging from one to 36 weeks. We did not find any studies that measured the effect on the incidence of death, heart disease, or need for dialysis or kidney transplantation. Instead, we found studies that measured risk factors for these outcomes.

We found that lowering salt intake reduced blood pressure and protein in the urine in people with CKD. Lowering salt intake may reduce extracellular fluid volume in the earlier stages of CKD. The evidence is very uncertain about the effects on body weight and reductions in blood pressure medications. The effect on kidney function measures was mixed. Lower salt intake may increase dizziness due to low blood pressure.

\section{Conclusions}

We found that reducing salt intake reduced risk factors for heart disease and worsening kidney function in people with CKD in the short term. We could not find evidence of the longer term effects of reducing salt intake, which meant we were unable to determine the direct effects of salt intake on death, heart disease, or need for dialysis or kidney transplantation. We need more high quality research in these areas. 
SUMMARY OF FINDINGS

\section{Summary of findings 1 . Lower salt intake versus higher salt intake for participants with chronic kidney disease}

Lower salt intake versus higher salt intake for participants with CKD

Patient or population: participants with CKD

Setting: any

Intervention: lower salt intake

Comparison: higher salt intake

\begin{tabular}{|c|c|c|c|c|c|}
\hline \multirow[t]{2}{*}{ Outcomes } & \multicolumn{2}{|c|}{ Anticipated absolute effects ${ }^{\star}(95 \% \mathrm{Cl})$} & \multirow{2}{*}{$\begin{array}{l}\text { Relative effect } \\
(95 \% \mathrm{Cl})\end{array}$} & \multirow{2}{*}{$\begin{array}{l}\text { No. of partici- } \\
\text { pants } \\
\text { (studies) }\end{array}$} & \multirow{2}{*}{$\begin{array}{l}\text { Certainty of the } \\
\text { evidence } \\
\text { (GRADE) }\end{array}$} \\
\hline & Risk with higher salt intake & Risk with lower salt intake & & & \\
\hline $\begin{array}{l}\text { Diastolic blood } \\
\text { pressure }\end{array}$ & \multicolumn{2}{|c|}{$\begin{array}{l}\text { The mean DBP in the lower salt intake group was } 3.91 \mathrm{~mm} \mathrm{Hg} \text { lower ( } 4.8 \text { lower to } \\
3.02 \text { lower) than the higher salt intake group }\end{array}$} & - & $1257(19)$ & $\begin{array}{l}\oplus \oplus \oplus \oplus \\
\mathrm{HIGH}\end{array}$ \\
\hline Albuminuria & \multicolumn{2}{|c|}{$\begin{array}{l}\text { The mean albuminuria in the lower salt intake group was } 36 \% 1 \text { lower ( } 44 \% \text { lower } \\
\text { to } 26 \% \text { lower) than the higher salt intake group }\end{array}$} & - & $501(6)$ & $\begin{array}{l}\oplus \oplus \oplus \oplus \\
\mathrm{HIGH}\end{array}$ \\
\hline $\begin{array}{l}\text { Extracellular fluid } \\
\text { volume }\end{array}$ & \multicolumn{2}{|c|}{$\begin{array}{l}\text { The mean extracellular fluid volume in the lower salt intake group was } 0.87 \mathrm{~L} \\
\text { lower ( } 1.17 \text { lower to } 0.58 \text { lower) than the higher salt intake group }\end{array}$} & - & $187(3)$ & $\begin{array}{l}\oplus \oplus \ominus \ominus \\
\text { LOW } 23\end{array}$ \\
\hline Weight & \multicolumn{2}{|c|}{$\begin{array}{l}\text { The mean weight in the lower salt intake group was } 1.32 \mathrm{~kg} \text { lower } \\
\text { (1.94 lower to } 0.7 \text { lower) than the higher salt intake group }\end{array}$} & - & $759(12)$ & $\begin{array}{l}\oplus \ominus \ominus \ominus \\
\text { VERY LOW } 245\end{array}$ \\
\hline $\begin{array}{l}\text { Symptomatic hy- } \\
\text { potension }\end{array}$ & 8 per 1,000 & $\begin{array}{l}56 \text { per } 1,000 \\
(20 \text { to } 156)\end{array}$ & $\begin{array}{l}\text { RR } 6.70 \\
(2.40 \text { to } 18.69)\end{array}$ & $478(6)$ & $\begin{array}{l}\oplus \oplus \oplus \ominus \\
\text { MODERATE } 3\end{array}$ \\
\hline
\end{tabular}

${ }^{\star}$ The risk in the intervention group (and its $95 \% \mathrm{Cl}$ ) is based on the assumed risk in the comparison group and the relative effect of the intervention (and its $95 \% \mathrm{Cl}$ ).

CKD: chronic kidney disease; CI: confidence interval; SBP: systolic blood pressure; DBP: diastolic blood pressure; RR: risk ratio

GRADE Working Group grades of evidence

High certainty: We are very confident that the true effect lies close to that of the estimate of the effect

Moderate certainty: We are moderately confident in the effect estimate: The true effect is likely to be close to the estimate of the effect, but there is a possibility that it is

w substantially different 
Low certainty: Our confidence in the effect estimate is limited: The true effect may be substantially different from the estimate of the effect

Very low certainty: We have very little confidence in the effect estimate: The true effect is likely to be substantially different from the estimate of effect

1 Albuminuria was analysed as log-transformed ( $\mathrm{mg} /$ day) and expressed as a percentage reduction

2 Evidence certainty downgraded one level for uncertain or high risk of bias

3 Evidence certainty downgraded one level for few events and/or participants across all studies

4 Evidence certainty downgraded one level for moderate heterogeneity

5 Evidence certainty downgraded one levels for indirectness of outcome

6 Evidence certainty downgraded two levels for a high risk of bias

7 Evidence certainty downgraded one level for wide confidence interval range that include benefit or harm 


\section{B A C K G R O U N D}

\section{Description of the condition}

Chronic kidney disease (CKD) is a major global public health problem, affecting an estimated $10 \%$ of the global population (GBD 2019). According to the Global Burden of Disease, CKD was the 12th most common cause of death in 2017, accounting for 1.2 million deaths worldwide (GBD 2019). Overall CKD death increased by $34 \%$ from 2007 to 2017, making it one of the fastest rising major causes of death, alongside diabetes and dementia (GBD 2019). Diabetes and high blood pressure (BP) remain the two biggest risks for developing CKD, with $28 \%$ of CKD deaths being due to diabetes, and $28 \%$ due to high BP (GBD 2019).

CKD is a progressive condition, and risk of cardiovascular disease and death increases with declining glomerular filtration rate (GFR) (Go 2004). Healthcare costs of treating people with end-stage kidney disease (ESKD), where dialysis or kidney transplantation is required to survive, have been estimated at about 10 times greater than the cost of CKD management (Hunsicker 2004). Because both cardiovascular disease and progression to ESKD may be delayed, or possibly prevented, effective strategies to reduce these outcomes are needed to improve patients' prognoses and reduce healthcare costs.

\section{Description of the intervention}

Excessive salt (sodium) intake is related to many risk factors for cardiovascular disease and CKD progression (Jones-Burton 2006; Suckling 2010; Malta 2018). These include increased BP, fluid retention, proteinuria, inflammation, oxidative stress, and endothelial dysfunction (Al-Solaiman 2009; Ritz 2009). The World Health Organisation recommends adults consume less than $5 \mathrm{~g}$ of salt ( $2 \mathrm{~g}$ or $87 \mathrm{mmol}$ sodium) per day (WHO 2012). Data from populations around the world show that salt intakes far exceed this (Mozaffarian 2014; Trieu 2015). Estimates in people with CKD are commonly between 9 to $12 \mathrm{~g}$ (150 to $200 \mathrm{mmol}$ sodium) (McMahon 2012a). National salt reduction strategies have been established in 75 countries; most of these aim to reduce population salt intake through reducing salt content of food and/or consumer education to shift dietary behaviour (Trieu 2015). Intervention trials comparing two or more levels of salt intake usually achieve a difference in salt intake by dietary education (e.g., individual or group counselling, online support), providing meals to participants and/or using salt supplements (McMahon 2012a).

\section{How the intervention might work}

Sodium is an essential nutrient, and has vital roles in regulating fluid homeostasis, blood volume and osmotic pressure (Elliot 2006). Excess sodium increases serum osmolality, triggering the release of vasopressin (arginine vasopressin (AVP), also known as antidiuretic hormone) which initiative a cascade of metabolic actions including activation of the renin-angiotensin-aldosterone system (RAAS) causing blood vessels to constrict and increasing water reabsorption from the urine (Qian 2018). Chronic highsalt intake ( $>7$ days) leads to excessive AVP production and vasoconstriction. This can lead to kidney and cardiovascular damage through dysregulation of fluid volume homeostasis and BP. Non-osmotic storage of salt in the skin and the muscle is thought to be linked to increased risk of cardiovascular and kidney disease (Garofalo 2018; Qian 2018).
High BP is common in CKD, and sustained elevations in BP hasten CKD progression (Bakris 2000). Studies in the general population have consistently demonstrated a link between dietary salt intake and BP (He 2013; Svetkey 1999). A 2017 Cochrane review found that reducing salt from $11.5 \mathrm{~g} /$ day to $3.8 \mathrm{~g} /$ day reduced systolic $\mathrm{BP} /$ diastolic BP in people with normotension by $1 / 0 \mathrm{~mm} \mathrm{Hg}$, and in people with hypertension about approximately $5.5 / 3 \mathrm{~mm} \mathrm{Hg}$ (Graudal 2020). High salt intake may have a greater impact on BP in people with CKD than in those without CKD since CKD may reduce the ability to excrete the excess salt. A 2010 Cochrane review on reducing salt intake in people with diabetic kidney disease showed considerable BP reductions; systolic/diastolic BP was lowered by $7 / 3 \mathrm{~mm} \mathrm{Hg}$ (Suckling 2010).

It has also been suggested that salt has adverse effects independent of BP. Todd 2010 found arterial stiffness measured by pulse wave velocity was significantly decreased independently of BP changes in hypertensive people on a low salt diet. Increased pulse wave velocity is a predictor of all-cause and cardiovascular death (Guerin 2001). Proteinuria, a risk factor for both CKD progression and cardiovascular disease in people with CKD, has also shown to be reduced by salt restriction independent of BP (Verhave 2004).

\section{Why it is important to do this review}

Salt intake shows great promise as a modifiable risk factor for reducing cardiovascular risk and CKD progression even among people in the very early stages of the disease. However, clear consensus of the benefits of reducing salt for people with CKD and the optimal target salt intake for this population have yet to be established. This review updates a 2015 Cochrane review of altered dietary salt intake in people with CKD (McMahon 2015). Updating the review will ensure that best evidence is available for the benefits (and potential adverse effects) of reducing salt for people with CKD.

\section{OB JECTIVES}

This review evaluated the benefits and harms of altering dietary salt intake in adults with CKD.

\section{METHODS}

\section{Criteria for considering studies for this review}

\section{Types of studies}

We included randomised controlled trials (RCTs) and quasi-RCTs (RCTs in which allocation to treatment was obtained by alternation, use of alternate medical records, date of birth or other predictable methods) measuring the effect of low versus high salt intake in adults with CKD.

\section{Types of participants}

\section{Inclusion criteria}

Adults ( $\geq 18$ years) with CKD were included. For this review update, we defined CKD as those who are receiving any form of kidney replacement therapy, have a functioning kidney transplant, have impaired kidney function defined as a reduced GFR $(<60 \mathrm{~mL} /$ $\mathrm{min} / 1.73 \mathrm{~m}^{2}$ ) or the presence of other markers of kidney damage such as proteinuria (KDOQI stages 1-5) or an elevated serum creatinine (SCr > $120 \mathrm{mmol} / \mathrm{L}$ ) (KDIGO 2013), or as defined by study authors. This definition of CKD has been updated from that used in the initial review (McMahon 2015), where we defined CKD using 
the Kidney Disease Outcomes Quality Initiative (KDOQI) Clinical Practice Guidelines) at all disease stages (NKF 2002).

\section{Exclusion criteria}

- Pregnant women

- Children (aged up to 18 years).

\section{Types of interventions}

We planned to evaluate the following interventions.

- Comparing two or more differing levels of sodium intake

- Of at least one week duration

- Where concomitant interventions such as antihypertensive medication or other dietary modifications were used during the study period, providing that these interventions were constant throughout the low and high salt interventions.

In the initial review (2015), we included studies that evaluated sodium intake using 24-hour urinary sodium excretion (24-hour $\mathrm{UNa}$ ) with a minimum difference in 24-hour UNa of $34 \mathrm{mmol} /$ day ( $2 \mathrm{~g}$ salt/day) achieved between allocated interventions. No studies were excluded based on this criterion in the initial review. This eligibility criterion has been removed in this update, allowing the inclusion of studies measuring sodium intake using other methods (such as food records or 24-hour recalls) and allowing any magnitude of difference in sodium intake between the allocated interventions.

\section{Types of outcome measures}

\section{Primary outcomes}

1. Cardiovascular death

2. Death (any cause)

\section{Secondary outcomes}

1. Cardiovascular disease (coronary artery disease, heart failure, cerebrovascular disease, peripheral vascular disease)

2. Progression to ESKD requiring dialysis or transplantation

3. 24-hour UNa

4. Change in BP: clinic and 24-hour measurement

5. Change in arterial stiffness: pulse wave velocity and augmentation index)

6. Change in kidney function measures: creatinine clearance $(\mathrm{CrCl})$ $\mathrm{SCr}$, proteinuria, GFR

7. Change in markers of fluid overload: brain natriuretic peptide (NT-proBNP), weight, bio-impedance analysis

8. Change in markers of oxidative stress or inflammation: Creactive protein, adipokines

9. Adverse events: hypotensive episodes, undesirable change in blood lipids (low density lipoprotein, high-density lipoprotein).

\section{Search methods for identification of studies}

\section{Electronic searches}

We searched the Cochrane Kidney and Transplant Register of Studies up to 6 October 2020 through contact with the Information Specialist using search terms relevant to this review. The Register contains studies identified from the following sources:
1. Monthly searches of the Cochrane Central Register of Controlled Trials (CENTRAL)

2. Weekly searches of MEDLINE OVID SP

3. Searches of kidney and transplant journals, and the proceedings and abstracts from major kidney and transplant conferences

4. Searching of the current year of EMBASE OVID SP

5. Weekly current awareness alerts for selected kidney and transplant journals

6. Searches of the International Clinical Trials Register (ICTRP) Search Portal and ClinicalTrials.gov.

Studies contained in the Register are identified through searches of CENTRAL, MEDLINE, and EMBASE based on the scope of Cochrane Kidney and Transplant. Details of search strategies, as well as a list of handsearched journals, conference proceedings and current awareness alerts, are available on the Cochrane Kidney and Transplant website.

See Appendix 1 for search terms used in strategies for this review.

\section{Searching other resources}

1. Reference lists of review articles, relevant studies, and clinical practice guidelines

2. Contacting relevant individuals/organisations seeking information about unpublished or incomplete studies.

\section{Data collection and analysis}

\section{Selection of studies}

\section{1 update}

The search results were screened and studies included or excluded based on the selection criteria listed above. Excluded studies from the 2015 review were reassessed based on the updated eligibility criteria. Screening was done independently by two authors.

\section{5 review}

The search strategy described was used to obtain titles and abstracts of studies that may be relevant to the review. The titles and abstracts were screened independently by two authors, who discarded studies that were not applicable; however, studies and reviews that might have included relevant data or information on studies were retained initially. Two authors independently assessed the retrieved abstracts, and if necessary, the full text of these studies to determine which studies satisfied the inclusion criteria.

\section{Data extraction and management}

Data extraction for studies new to this 2021 update was done using standard data extraction forms. In the 2015 review, data extraction was carried out independently by two authors. Studies reported in non-English language journals were translated before assessment. Where more than one publication of one study exists, reports were grouped together and the publication with the most complete data was used in the analyses. Where relevant outcomes were only published in earlier versions these data were used. Any discrepancies between published versions were highlighted. 


\section{Assessment of risk of bias in included studies}

The following items were independently assessed by two authors using the risk of bias assessment tool (Higgins 2011) (see Appendix 2).

- Was there adequate sequence generation (selection bias)?

- Was allocation adequately concealed (selection bias)?

- Was knowledge of the allocated interventions adequately prevented during the study?

* Participants and personnel (performance bias)

* Outcome assessors (detection bias)

- Were incomplete outcome data adequately addressed (attrition bias)?

- Are reports of the study free of suggestion of selective outcome reporting (reporting bias)?

- Was the study apparently free of other problems that could put it at a risk of bias? Two additional domains were addressed:

* Carry-over effect

* Confounding factors (bias due to differences between groups other than sodium intake that are likely to impact the effect estimate (in either direction) including differential changes in diet/medication (potassium intake, body weight changes, anti-hypertensive medication dosage) and baseline differences in the outcome, where likely to impact the effect estimate)

\section{Measures of treatment effect}

For dichotomous outcomes (cardiovascular death, death (any cause), progression to ESKD, cardiovascular disease, symptomatic hypotension, reduction in anti-hypertensive dose) results were expressed as risk ratios (RR) with 95\% confidence intervals (CI). Where continuous scales of measurement were used to assess the effects of treatment (BP, pulse wave velocity, augmentation index, $\mathrm{CrCl}$, SCr, proteinuria, GFR, brain natriuretic peptide (NT-proBNP), weight, bio-impedance analysis, C-reactive protein, adipokines) the mean difference (MD) was used, or the standardised mean difference (SMD) if different scales were used. Studies analysing change scores were included in meta-analysis along with studies including endpoint data only.

\section{Unit of analysis issues}

For cross-over studies, we determined the mean difference in outcomes as the difference between the end of low salt and high salt periods. Standard deviations for cross-over studies were imputed from paired analysis $\mathrm{Cl}$ or $\mathrm{P}$ values. Where these were not reported, SD of the values at the end of each period was used.

For parallel studies, we calculated the treatment effect as the difference between treatment groups' change in outcomes from baseline. Where these were not reported, or could not be imputed from reported values, values at the end of the intervention were used.

\section{Dealing with missing data}

Any further information required from the original author was requested by written correspondence (e.g. emailing corresponding author) and any relevant information obtained in this manner was included in the review. Evaluation of important numerical data such as screened, randomised subjects as well as intention- to-treat, as-treated and per-protocol population were performed. Attrition rates, for example drop-outs, losses to follow-up and withdrawals were investigated. Issues of missing data and imputation methods (e.g. last-observation-carried-forward) were critically appraised (Higgins 2011).

\section{Assessment of heterogeneity}

We first assessed the heterogeneity by visual inspection of the forest plot. We then quantified statistical heterogeneity using the $1^{2}$ statistic, which describes the percentage of total variation across studies that is due to heterogeneity rather than sampling error (Higgins 2003). A guide to the interpretation of $\mathrm{I}^{2}$ values was as follows.

- $0 \%$ to $40 \%$ : might not be important

- $30 \%$ to $60 \%$ : may represent moderate heterogeneity

- $50 \%$ to $90 \%$ : may represent substantial heterogeneity

- $75 \%$ to $100 \%$ : considerable heterogeneity.

The importance of the observed value of $1^{2}$ depends on the magnitude and direction of treatment effects and the strength of evidence for heterogeneity (e.g. $\mathrm{P}$ value from the $\mathrm{Chi}^{2}$ test, or a $\mathrm{Cl}$ for $\mathrm{I}^{2}$ ) (Higgins 2011).

\section{Assessment of reporting biases}

If possible, funnel plots were to be constructed to assess for the potential existence of small study bias (Higgins 2011). There were insufficient data to enable construction of funnel plots for this review.

\section{Data synthesis}

Data were pooled using the random-effects model but the fixedeffect model was also used to ensure robustness of the model chosen and susceptibility to outliers.

\section{Subgroup analysis and investigation of heterogeneity}

Subgroup analysis was used to explore possible sources of heterogeneity. Heterogeneity among participants could be related to age, ethnicity, stage of CKD and presence of comorbidities (e.g. hypertension and diabetes).

\section{Sensitivity analysis}

Where necessary, we performed sensitivity analyses in order to explore the influence of the following factors on effect size.

- repeating the analysis excluding unpublished studies

- repeating the analysis taking account of risk of bias, as specified

- repeating the analysis excluding any very long or large studies to establish how much they dominate the results

- repeating the analysis excluding studies using the following filters: diagnostic criteria, language of publication, source of funding (industry versus other), and country.

\section{Summary of findings and assessment of the certainty of the evidence}

We presented the main results of the review in 'Summary of findings' tables. These tables present key information concerning the quality of the evidence, the magnitude of the effects of the interventions examined, and the sum of the available data 
for the main outcomes (Schunemann 2011a). The 'Summary of findings' tables also include an overall grading of the evidence related to each of the main outcomes using the GRADE (Grades of Recommendation, Assessment, Development and Evaluation) approach (GRADE 2008; GRADE 2011). The GRADE approach defines the quality of a body of evidence as the extent to which one can be confident that an estimate of effect or association is close to the true quantity of specific interest. The quality of a body of evidence involves consideration of within-trial risk of bias (methodological quality), directness of evidence, heterogeneity, precision of effect estimates and risk of publication bias (Schunemann 2011b). We presented the following outcomes in the 'Summary of findings' tables.

- Systolic BP

- Diastolic BP

- Albuminuria

- Extracellular fluid volume

- Weight

Figure 1. Study flow diagram

2015 review: 1066 reports

CENTRAL (317); EMBASE (717); Specialised Register (32)

Included studies: 8 (24 reports)
Excluded studies: 10 (13 reports)
- Not CKD (3); concomitant intervention (3); no
random allocation to low/high salt diet (2)
Ongoing studies: 3 (4 reports)
Studies awaiting assessment: 2 (2 reports)

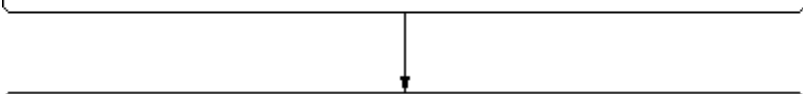

\section{1 review update}

Ongoing studies: 3 ongoing studies moved to included studies

Studies awaiting classification: 2 studies moved to included studies

Excluded studies: 5 studies deleted (not RCTs (3); wrong population (2))
- Reduction in antihypertensive dose

- Symptomatic hypotension.

\section{RES U L T S}

\section{Description of studies}

See Characteristics of included studies; Characteristics of excluded studies; Characteristics of studies awaiting classification; Characteristics of ongoing studies.

\section{Results of the search}

Figure 1 details the study search results. The initial version of this review (McMahon 2015) included eight studies (24 reports) with 224 participants in the low salt group and 218 participants in the high salt group (442 combined; 261 unique). Nine studies were excluded, four were ongoing, and two studies were awaiting assessment. None of the previously excluded studies were eligible when reassessed against the updated eligibility criteria.

\section{1 review update: 67 new reports}

Specialised register (60); additional handsearching (4); contact with study authors (3)

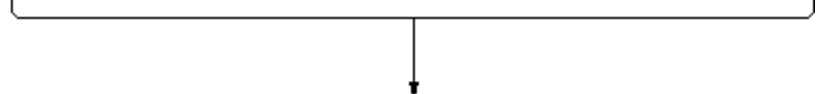

Included studies

New included studies: 8 (30 reports)

New reports of previously included studies: 5 studies (6 reports)

New reports of previous ongoing studies now included: 2 studies (7 reports)

\section{Excluded studies}

New excluded studies: 7 studies (14 reports)

New reports of previously excluded studies: 2 studies (4 reports)

\section{Ongoing studies}

New ongoing studies: 5 (6 reports)

2021 review update
Included studies: 21 studies (72 reports)
Excluded studies: 11 studies (26 reports)
- wrong population (2); wrong intervention (6);
$\quad$ duration < 1 week (2); study terminated (1)
Ongoing studies: 5 studies (6 reports)

For this update (2021), we identified 67 new reports. We included 13 new included studies (45 reports) (BalanceWise-HD 2013; BalanceWise-PD 2011; Catto 1973; de Vries 2016; Doulton 2007;
ESMO 2017; ESPECIAL 2014; Kwakernaak 2014; Mulhauser 1996; Power 2010; Rodrigues Telini 2014; Saran 2017; ViRTUE-CKD 2016); three of these were previously ongoing studies (BalanceWise-HD 
2013; Doulton 2007; Saran 2017). We also identified six new reports of five previously included studies; seven new excluded studies (14 reports); four new reports of two existing excluded studies; and six reports for five new ongoing studies. One study previously listed as ongoing was withdrawn in late 2015 and has been moved to excluded studies (Reyes 2013). All non-randomised studies and RCTs in non-CKD patients have been removed from this update.

A total of 21 studies ( 72 reports) have been included and 11 studies (26 reports) have been excluded from this review update. There are five ongoing studies ( 6 reports) which will be assessed in a future update of this review.

\section{Included studies}

See Characteristics of included studies.

We included 21 studies (1197 randomised participants), 12 in the earlier stages of CKD (779 randomised participants), seven in dialysis (363 randomised participants) and two in post-transplant (55 randomised participants). These studies reported the results of 725 participants in the low salt arm and 725 participants in the high salt arm. Power 2010 (31 participants) did not report the sample size for each group and therefore the results could not be included in the quantitative synthesis.

Six studies were conducted in the Netherlands (de Vries 2016; DUAAAL 2011; ESMO 2017; Kwakernaak 2014; ViRTUE-CKD 2016; Vogt 2008), four in the USA (BalanceWise-HD 2013; BalanceWisePD 2011; Fine 1997; Saran 2017), four in the UK (de Brito-Ashurst 2013; Catto 1973; Doulton 2007; Power 2010), and one study in Australia (LowSALT CKD 2012), Brazil (Rodrigues Telini 2014), Germany (Mulhauser 1996), Japan (Konishi 2001), Korea (ESPECIAL 2014), Spain (Ruilope 1992a), and Turkey (Keven 2006).

Of the 21 included studies, 12 were cross-over studies (Catto 1973; de Vries 2016; Doulton 2007; DUAAAL 2011; Fine 1997; Konishi 2001; Kwakernaak 2014; LowSALT CKD 2012; Ruilope 1992a; Saran 2017; ViRTUE-CKD 2016; Vogt 2008) and nine were parallel design studies (BalanceWise-HD 2013; BalanceWise-PD 2011 de Brito-Ashurst 2013; ESMO 2017; ESPECIAL 2014; Keven 2006; Mulhauser 1996; Power 2010; Rodrigues Telini 2014). Values from paired analyses were reported for most cross-over studies, although not always for all outcomes. Konishi 2001 and Ruilope 1992a did not report paired analyses and values from the end of the intervention were used. Four of the parallel studies (BalanceWise-HD 2013; BalanceWisePD 2011; de Brito-Ashurst 2013; ESPECIAL 2014) reported change from baseline for each group, and these data were used for analysis. Mulhauser 1996 reported change from baseline for BP but not for other outcomes. Four of the parallel studies (ESMO 2017; Keven 2006; Power 2010; Rodrigues Telini 2014) did not present data on change from baseline, and because there were no appropriate data available to impute values, values at the end of the intervention were used.

Nine studies enrolled participants with ESKD, seven in dialysis (haemodialysis (HD): BalanceWise-HD 2013; Catto 1973; Doulton 2007; Power 2010; Rodrigues Telini 2014; peritoneal dialysis (PD): BalanceWise-PD 2011; Fine 1997) and two post-transplant (Keven 2006; de Vries 2016). Twelve studies enrolled participants in earlier stages of CKD (de Brito-Ashurst 2013; DUAAAL 2011; ESMO 2017; ESPECIAL 2014; Konishi 2001; Kwakernaak 2014; LowSALT CKD

Altered dietary salt intake for people with chronic kidney disease (Review)

Copyright (c) 2021 The Cochrane Collaboration. Published by John Wiley \& Sons, Ltd.
2012; Mulhauser 1996; Ruilope 1992a; Saran 2017; ViRTUE-CKD 2016; Vogt 2008).

Median study duration was seven weeks, ranging from one to 36 weeks. A cut-off of four weeks was used to classify studies according to intervention duration (short-term: fewer than four weeks; longerterm: four weeks or more). Three studies were classified as shortterm, all of which were cross-over studies with two arms and enrolled participants in the earlier stages of CKD: Konishi 2001 and Ruilope 1992a had one-week interventions and LowSALT CKD 2012 had two-week interventions. We classified 15 studies as longerterm (range: four to 36 weeks); these included all ESKD studies (BalanceWise-HD 2013; BalanceWise-PD 2011; Catto 1973; de Vries 2016; Doulton 2007; Fine 1997; Keven 2006; Power 2010; Rodrigues Telini 2014) and nine studies in earlier CKD (de Brito-Ashurst 2013; DUAAAL 2011; ESMO 2017; ESPECIAL 2014; Kwakernaak 2014; Mulhauser 1996; Saran 2017; ViRTUE-CKD 2016; Vogt 2008).

Thirteen studies used dietary counselling to achieve a difference in sodium intake. Of these, 11 studies compared sodium restriction achieved through dietary counselling in the low salt intervention to usual diet or usual care in the high salt intervention (BalanceWisePD 2011; de Brito-Ashurst 2013; de Vries 2016; DUAAAL 2011; ESMO 2017; Keven 2006; Kwakernaak 2014; Rodrigues Telini 2014; Saran 2017; ViRTUE-CKD 2016; Vogt 2008). Two studies compared against a less intensive education strategy to reduce dietary sodium: ESPECIAL 2014 compared intensive education to reduce sodium in the high salt intervention versus brief education in the low salt intervention, and BalanceWise-HD 2013 provided individualised dietary counselling paired with personal digital assistant-based self-monitoring and feedback on sodium intake to participants in the low salt intervention and six educational modules to both groups (attention control for the high salt group). Six studies used sodium supplements to achieve difference in sodium intake with sodium supplements in the high salt group compared against placebo (Catto 1973; Doulton 2007; Fine 1997; LowSALT CKD 2012; Mulhauser 1996) or a lower dose of sodium supplementation (Ruilope 1992a) in the low salt group. Power 2010 did not specify means for achieving difference in sodium intake. Konishi 2001 provided all food for participants.

Five studies included concomitant interventions of medications that remained stable throughout the high and low salt phases. DUAAAL 2011 and Kwakernaak 2014 started all participants on lisinopril $40 \mathrm{mg} /$ day, ESPECIAL 2014 used olmesartan medoxomil $40 \mathrm{mg} /$ day, Ruilope 1992a used verapamil $240 \mathrm{mg}$ /day, and ViRTUECKD 2016 used ramipril 10 mg/day. The protocol for Konishi 2001 included cessation of all medications one week before the study.

\section{Outcome reporting in included studies}

Where multiple markers of sodium intake were collected, 24-hour UNa excretion was used preferentially in analyses. Fifteen studies reported 24-hour UNa excretion as a marker of sodium intake (de Brito-Ashurst 2013 ; de Vries 2016 ; DUAAAL 2011 ; ESMO 2017 ; ESPECIAL 2014 ; Fine 1997 ; Keven 2006 ; Konishi 2001 ; Kwakernaak 2014 ; LowSALT CKD 2012 ; Mulhauser 1996; Ruilope 1992a; Saran 2017; ViRTUE-CKD 2016; Vogt 2008). Fine 1997, whose participants were receiving PD, added 24-hour UNa excretion to 24hour dialysate sodium to achieve a total value for sodium excretion, and this value was used for analysis. Four studies collected self-reported dietary sodium intake measurements (values were converted to $\mathrm{mmol} /$ day prior to analysis); BalanceWise-HD 2013 
and BalanceWise-PD 2011 used three, 24-hour recalls, Rodrigues Telini 2014 used three-day diet records, while Catto 1973, Doulton 2007 and Power 2010 did not report sodium intake or excretion.

All studies except BalanceWise-HD 2013 and Power 2010 measured and reported BP. Where more than one BP measurement was reported, 24-hour ambulatory BP was used preferentially in analyses, and clinic-assessed BP was used preferentially over self-assessed BP measurements. Seven studies measured 24-hour ambulatory BP (de Brito-Ashurst 2013; Doulton 2007; ESMO 2017; Konishi 2001; LowSALT CKD 2012; Ruilope 1992a; Saran 2017), 10 used clinic-assessed BP (Catto 1973; de Vries 2016; DUAAAL 2011; ESPECIAL 2014; Keven 2006; Kwakernaak 2014; Mulhauser 1996; Rodrigues Telini 2014; ViRTUE-CKD 2016; Vogt 2008); BalanceWisePD 2011 and Fine 1997 used self-assessed BP. If more than one position was reported, standing BP was the first preference, except in BalanceWise-PD 2011 where sitting BPs were used due to there being more missing data for the standing measurements.

Eleven studies reported changes in urinary protein or albumin (de Vries 2016; DUAAAL 2011; ESMO 2017; ESPECIAL 2014; Konishi 2001; Kwakernaak 2014; LowSALT CKD 2012; Mulhauser 1996; Saran 2017; ViRTUE-CKD 2016; Vogt 2008). Pooled analyses were performed on log-transformed values $(\mathrm{mg} /$ day) to give log mean $(95 \% \mathrm{Cl}$ of log mean). The exponential of these values were also reported to indicate percentage change for ease of understanding (Bland 1996).

Nine studies reported 24-hour urinary protein excretion (de Vries 2016; DUAAAL 2011; ESMO 2017; Konishi 2001; Kwakernaak 2014; LowSALT CKD 2012; Mulhauser 1996; ViRTUE-CKD 2016; Vogt 2008). Three studies (DUAAAL 2011; Kwakernaak 2014; ViRTUE-CKD 2016) reported geometric mean $(95 \% \mathrm{Cl})$ which was transformed to log mean and SD using the methods specified in the Cochrane Handbook. Two studies (ESMO 2017; Vogt 2008) reported values as mean and standard error which were converted to log mean and SD using the methods specified in Higgins 2008. LowSALT CKD 2012 provided raw data and these were log-transformed. Two studies (de Vries 2016; Konishi 2001) reported data as median and inter-quartile range and could not be entered into pooled analysis. Mulhauser 1996 reported values as mean and range and from these values it appeared that the data were not normally distributed therefore could not be entered into pooled analysis.

Six studies reported 24-hour urinary albumin excretion (de Vries 2016; ESPECIAL 2014; Kwakernaak 2014; LowSALT CKD 2012; Saran
2017; ViRTUE-CKD 2016). de Vries 2016 and Saran 2017 reported values as change in log mean and $95 \% \mathrm{Cl}$. Two studies (Kwakernaak 2014; ViRTUE-CKD 2016) reported geometric mean (95\% Cl) which was transformed to log mean and SD using the methods specified in the Cochrane Handbook. Two studies (LowSALT CKD 2012; ESPECIAL 2014) provided raw data which were log-transformed for analysis.

Thirteen studies reported change in body weight (BalanceWise-HD 2013 de Brito-Ashurst 2013; de Vries 2016; Doulton 2007; DUAAAL 2011; ESMO 2017; Fine 1997; Kwakernaak 2014; LowSALT CKD 2012; Ruilope 1992a; Saran 2017; ViRTUE-CKD 2016; Vogt 2008).

Objective markers of fluid status were reported by six studies; three studies reported extracellular fluid volume (LowSALT CKD 2012; Rodrigues Telini 2014; Saran 2017), de Brito-Ashurst 2013 reported total body water, two studies reported presence of oedema (DUAAAL 2011; ViRTUE-CKD 2016), and three reported intradialytic weight gain (BalanceWise-HD 2013; Doulton 2007; Rodrigues Telini 2014). Doulton 2007 reported only mean values at the end of each intervention arm and the $P$ value for the mean difference for body weight and inter-dialytic weight gain, therefore SDs were imputed from $P$ values using the methods described in the Cochrane Handbook.

\section{Excluded studies}

We excluded 11 studies (26 reports) that did not meet our inclusion criteria. Reasons for exclusion were non-CKD population (Li 2013f; Suckling 2016), concomitant intervention that was not stable between interventions (DD 2017; Esnault 2005; Kauric-Klein 2012; HHK 2018) not comparing two or more levels of sodium intake (Chanwikrai 2012; Imanishi 1997), or less than one week duration (Clark-Cutaia 2016; De Nicola 2000).

\section{Ongoing studies}

Five studies are ongoing and will be assessed once they have been completed (NCT03373500; OxCKD1 2012; STICK 2015; SUBLIME 2020; SUPER 2016).

\section{Risk of bias in included studies}

Figure 2 and Figure 3 summarise risk of bias assessment for the included studies. 
Figure 2. Risk of bias summary: review authors' judgements about each risk of bias item for each included study.

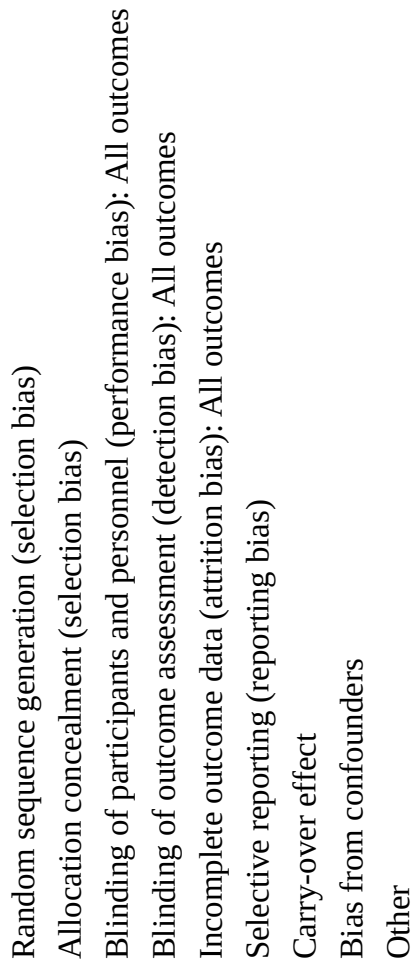

BalanceWise-HD 2013

BalanceWise-PD 2011

Catto 1973

de Brito-Ashurst 2013

de Vries 2016

Doulton 2007

DUAAAL 2011

ESMO 2017

ESPECIAL 2014

Fine 1997

Keven 2006

Konishi 2001

Kwakernaak 2014

LowSALT CKD 2012

Mulhauser 1996

Power 2010

Rodrigues Telini 2014

Ruilope 1992a

Saran 2017

ViRTUE-CKD 2016

Vogt 2008

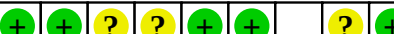

\begin{tabular}{|c|c|c|c|c|c|c|c|c|}
\hline & ? & ? & ? & ? & + & & & \\
\hline ? & ? & ? & ? & ? & ? & & ? & \\
\hline & $(-)$ & - & ? & 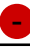 & ? & + & ? & \\
\hline & + & ? & $?$ & + & + & + & ? & \\
\hline & ? & ? & ? & + & + & & & \\
\hline
\end{tabular}


Figure 3. Risk of bias graph: review authors' judgements about each risk of bias item presented as percentages across all included studies. Studies were frequently assessed as having unclear or high risk of bias for the risk of bias study domains with selection bias, performance bias, detection bias, and confounding bias domains having the largest proportion of unclear/high risk of bias.

Random sequence generation (selection bias) Allocation concealment (selection bias) Blinding of participants and personnel (performance bias): All outcomes Blinding of outcome assessment (detection bias): All outcomes Incomplete outcome data (attrition bias): All outcomes Selective reporting (reporting bias)

Carry-over effect

Bias from confounders

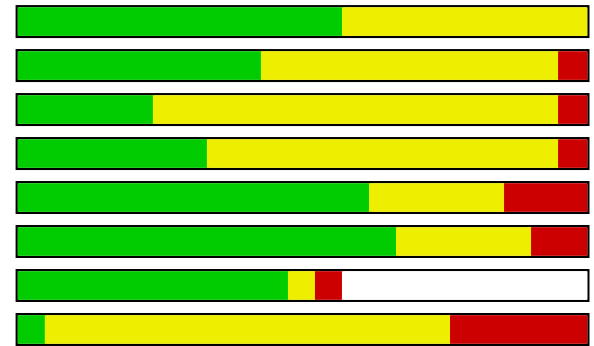

Other

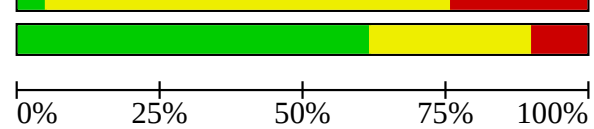

Low risk of bias

Unclear risk of bias

High risk of bias

\section{Allocation}

\section{Random sequence generation}

All included studies were randomised. Further details were provided about the method of randomisation for 12 studies and these studies were judged to be at low risk of bias (BalanceWise-HD 2013; BalanceWise-PD 2011; de Brito-Ashurst 2013; de Vries 2016; DUAAAL 2011; ESMO 2017; ESPECIAL 2014; Fine 1997; Kwakernaak 2014; LowSALT CKD 2012; Vogt 2008; ViRTUE-CKD 2016). The remaining nine studies were judged to have unclear risk of bias.

\section{Allocation concealment}

Allocation concealment was not described for 11 studies and these were judged to be low risk of bias (Catto 1973; de BritoAshurst 2013; de Vries 2016; DUAAAL 2011; Keven 2006; Konishi 2001; Kwakernaak 2014; Power 2010; Rodrigues Telini 2014; Ruilope 1992a; Vogt 2008). Saran 2017 was considered to be at high risk of bias due to allocation concealment. Randomisation was concealed using sealed envelopes but it was unclear how this process was monitored. This study had considerable violation of the protocol at one of the two study sites (6/21 given treatment in the reverse order for unknown reasons, 4/21 recommended to continue low salt instead of crossing over to high salt diet) (Saran 2017). The remaining nine studies were judged to have unclear risk of bias.

\section{Blinding}

Most outcomes were objective and therefore at lower risk of being influenced by performance bias. Five studies (Catto 1973; Doulton 2007, Fine 1997; LowSALT CKD 2012; Mulhauser 1996) were double blinded. Clinicians, but not participants, were blinded in ESPECIAL 2014. Investigators, but not participants or study coordinators, were blinded in Saran 2017, and the lack of blinding of study coordinators may have influenced the outcomes, as evidenced by the protocol deviations described previously.

Twelve studies had open-label dietary interventions (BalanceWiseHD 2013; BalanceWise-PD 2011; de Brito-Ashurst 2013; de Vries 2016; DUAAAL 2011; ESMO 2017; Keven 2006; Kwakernaak 2014; Power 2010; Rodrigues Telini 2014; ViRTUE-CKD 2016; Vogt 2008).
Konishi 2001 and Ruilope 1992a did not describe blinding.

\section{Incomplete outcome data}

There was a high risk of attrition bias due to incomplete outcome data for three studies; BalanceWise-PD 2011 reported 19\% attrition and data were missing for a large proportion of participants for BP, weight and urine outcomes; Power 2010 had 38\% attrition and did not report reasons or attrition by allocation; Saran 2017 had a proportion of participants with missing data for some outcomes (e.g. only 10/21 participants at one of the sites included in urinary albumin data, but $21 / 21$ included in urinary creatinine data), and reasons for this were not provided. The authors were contacted to provide further information, but none was provided.

Konishi 2001 and Ruilope 1992a did not report participant attrition. Doulton 2007 specified a target enrolment of 20 and reported 13 completers but did not report actual enrolment to determine attrition. Fine 1997 reported a large degree of attrition (12/32 participants; $37 \%$ ) that was even among the two groups, however may have introduced bias as some participants withdrew due to concern about values when self-measuring BP. Rodrigues Telini 2014 reported $26 \%$ attrition which was higher in the high salt (9/30; $30 \%)$ than the low salt group $(5 / 23 ; 21 \%)$.

\section{Selective reporting}

Risk of reporting bias was unclear for four studies for which trial registration or study protocol could not be located (Keven 2006; Konishi 2001; Ruilope 1992a) and for Saran 2017 with unexplained missing outcome data. Risk of reporting bias was high for two studies where most or all outcomes could not be meta-analysed due to the way that they were reported (Mulhauser 1996; Power 2010).

\section{Other potential sources of bias}

\section{Carry-over effect in cross-over studies}

Carry-over effect may have introduced bias in Konishi 2001 and Ruilope 1992a; both were of one week duration with no washout between interventions. Ruilope 1992a introduced a new 
antihypertensive medication at day 1 of the first intervention, increasing risk of treatment order effect.

\section{Bias from cofounders}

Bias from confounders was classified as unclear or high risk for nearly all studies, mostly due to lack of measurement or failing to adequately report or account for the impact of changes in medications and/or dietary changes such as potassium intake, protein intake and/or weight loss between interventions. Dietary changes were considered more likely to introduce bias in studies comparing a sodium restricted to usual diet, and less so those using sodium supplements to achieve differences in salt intake. Mean systolic/diastolic BP was 6-7/3 mm Hg higher in low salt versus high salt group at baseline in both Keven 2006 and Rodrigues Telini 2014. While this difference may not have been statistically significant, this may have impacted the clinical significance of the results, as both studies did not report results as change from baseline. This information was sought from authors but was not provided.

We assessed that two studies were at high risk of bias in relation to funding sources (Fine 1997; Saran 2017).

\section{Effects of interventions}

See: Summary of findings $\mathbf{1}$ Lower salt intake versus higher salt intake for participants with chronic kidney disease

Duration of the included studies was too short to test the efficacy of salt restriction on endpoints such as death, cardiovascular events, or progression to ESKD. Therefore, changes in salt intake on BP and risk factors for cardiovascular disease and ESKD were considered in evaluating the evidence for this review.

\section{Sodium intake/excretion}

Low salt intake resulted in sodium intake/excretion being reduced in included studies (Analysis 1.1 (18 studies, 1383 participants): MD $-73.51 \mathrm{mmol} /$ day, $95 \% \mathrm{Cl}-92.76$ to -54.27 ; high certainty evidence) although heterogeneity was high $\left(I^{2}=93 \%\right)$.

\section{CKD stage}

In the earlier stages of CKD, reducing salt intake reduced sodium intake/excretion (Analysis 1.1.1 (12 studies, 1048 participants): MD $-83.81 \mathrm{mmol} / \mathrm{day}, 95 \% \mathrm{Cl}-104.54$ to $\left.-63.08 ; \mathrm{I}^{2}=92 \%\right)$. In studies in dialysis patients, reducing salt intake reduced sodium intake/ excretion (Analysis 1.1.2 (4 studies, 259 participants): MD -27.17 $\mathrm{mmol} /$ day, $95 \% \mathrm{Cl}-48.59,-5.76 ; \mathrm{I}^{2}=70 \%$. In studies in posttransplant recipients, reducing salt intake reduced sodium intake/ excretion (Analysis 1.1.3 (2 studies, 76 participants): MD -96.99 $\mathrm{mmol} /$ day, $95 \% \mathrm{Cl}-148.10$ to $\left.-45.89 ; \mathrm{I}^{2}=55 \%\right)$.

The test for subgroup differences showed a difference between the earlier stages of CKD and dialysis patients $\left(\mathrm{Chi}^{2}=13.87, \mathrm{df}=1(\mathrm{P}=\right.$ $\left.0.0002), I^{2}=92.8 \%\right)$ and dialysis patients and transplant recipients $\left(\mathrm{Chi}^{2}=6.10, \mathrm{df}=1(\mathrm{P}=0.01), \mathrm{I}^{2}=83.6 \%\right)$ but not between the earlier stages of $C K D$ and transplant recipients $\left(\mathrm{Chi}^{2}=0.22, \mathrm{df}=1(\mathrm{P}=0.64)\right.$, $\left.\mathrm{I}^{2}=0 \%\right)$

\section{Duration}

In short-term studies $(<4$ weeks), reducing salt intake reduced sodium intake/excretion (Analysis 2.1.1 (3 studies, 142 participants): MD $-111.29 \mathrm{mmol} /$ day, $95 \% \mathrm{Cl}-134.25$ to -88.32 ; $\mathrm{I}^{2}$ $=77 \%$;). In longer-term studies ( $\geq 4$ weeks), reducing salt intake reduced sodium intake/excretion ( Analysis 2.1.2 (15 studies, 1241 participants): MD $-64.53 \mathrm{mmol} /$ day, $\left.95 \% \mathrm{Cl}-83.29,-45.78 ; \mathrm{I}^{2}=90 \%\right)$.

The test for subgroup differences showed a difference between short- and longer-term studies $\left(\mathrm{Chi}^{2}=248.56, \mathrm{df}=1(\mathrm{P}=0.00001)\right.$, $\left.I^{2}=93 \%\right)$.

\section{Blood pressure}

Reducing salt intake reduced both systolic (Analysis 1.2 (19 studies, 1261 participants): $\mathrm{MD}-6.91 \mathrm{~mm} \mathrm{Hg}, 95 \% \mathrm{Cl}-8.82$ to $-4.99 ; \mathrm{I}^{2}=50 \%$; high certainty evidence) and diastolic BP (Analysis 1.3 (19 studies, 1257 participants): $\mathrm{MD}-3.91 \mathrm{~mm} \mathrm{Hg}, 95 \% \mathrm{Cl}-4.80$ to $-3.02 ; \mathrm{I}^{2}=21 \%$; high certainty evidence).

Power 2010 reported intradialytic BP stability as being significantly improved when sodium restriction was combined with low dialysate $(P<0.05)$, but did not report results for sodium restriction alone.

\section{CKD stage}

In the earlier stages of CKD, reducing salt intake reduced both systolic (Analysis 1.2.1 (12 studies, 1036 participants): MD -6.10 mm $\mathrm{Hg}, 95 \% \mathrm{Cl}-8.11$ to $-4.08 ; \mathrm{I}^{2}=48 \%$ ) and diastolic BP (Analysis 1.3.1 (12 studies, 1032 participants): MD $-3.47 \mathrm{~mm} \mathrm{Hg}, 95 \% \mathrm{Cl}-4.28$ to $\left.-2.65 ; I^{2}=0 \%\right)$.

In dialysis patients, reducing salt intake reduced both systolic (Analysis 1.2.2 (5 studies, 149 participants): MD -6.32 mm Hg, 95\% $\mathrm{Cl}-11.04$ to $-1.60 ; \mathrm{I}^{2}=0 \%$ ) and diastolic BP (Analysis 1.3 .2 (5 studies, 149 participants): $\mathrm{MD}-3.46 \mathrm{~mm} \mathrm{Hg}, 95 \% \mathrm{Cl}-6.39$ to $\left.-0.54 ; \mathrm{I}^{2}=0 \%\right)$.

In post-transplant recipients, reducing salt intake reduced both systolic (Analysis 1.2.3 (2 studies, 76 participants): MD $-11.94 \mathrm{~mm}$ $\mathrm{Hg}, 95 \% \mathrm{Cl}-15.77$ to $-8.11 ; \mathrm{I}^{2}=12 \%$ ) and diastolic BP (Analysis 1.3 .2 (2 studies, 76 participants): $\mathrm{MD}-7.13 \mathrm{~mm} \mathrm{Hg}, 95 \% \mathrm{Cl}-9.46$ to -4.79 ; $\left.1^{2}=0 \%\right)$.

For systolic BP, the test for subgroup differences showed a difference between the earlier stages of CKD and post-transplant recipients (Test for subgroup differences: $\mathrm{Chi}^{2}=7.01, \mathrm{df}=1(\mathrm{P}=$ $0.008), I^{2}=85.7 \%$ ) but not between the earlier stages of CKD and dialysis patients $\left(\mathrm{Chi}^{2}=0.01, \mathrm{df}=1(\mathrm{P}=0.93), \mathrm{I}^{2}=0 \%\right)$ or dialysis patients and post-transplant recipients $\left(\mathrm{Chi}^{2}=3.28, \mathrm{df}=1(\mathrm{P}=0.07)\right.$, $\left.1^{2}=69.6 \%\right)$.

For diastolic BP, the test for subgroup differences showed a difference between earlier stages of CKD and post-transplant recipient $\left(\mathrm{Chi}^{2}=8.38, \mathrm{df}=1(\mathrm{P}=0.004), \mathrm{I}^{2}=88.1 \%\right)$, but not for earlier stages of $C K D$ and dialysis patients $\left(\mathrm{Chi}^{2}=0.00, \mathrm{df}=1(\mathrm{P}=1.00), \mathrm{I}^{2}=\right.$ $0 \%)$ or dialysis patients and post-transplant recipients $\left(\mathrm{Chi}^{2}=3.68\right.$, $\left.\mathrm{df}=1(\mathrm{P}=0.06), \mathrm{I}^{2}=72.8 \%\right)$.

\section{Duration}

In short-term studies ( $<4$ weeks), reducing salt intake reduced both systolic (Analysis 2.2.1 (3 studies, 144 participants): MD $-7.91 \mathrm{~mm}$ $\mathrm{Hg}, 95 \% \mathrm{Cl}-11.53$ to $-4.28 ; \mathrm{I}^{2}=0 \%$ ) and diastolic BP (Analysis 2.3.1 (3 studies, 144 participants): MD $-3.70 \mathrm{~mm} \mathrm{Hg}, 95 \% \mathrm{Cl}-5.74$ to -1.67 ; $1^{2}=0 \%$ ). In longer-term studies ( $\geq 4$ weeks), reducing salt intake reduced both systolic (Analysis 2.2.2 (16 studies, 1117 participants): MD $-6.82 \mathrm{~mm} \mathrm{Hg}, 95 \% \mathrm{Cl}-9.00$ to $-4.64 ; \mathrm{I}^{2}=56 \%$ ) and diastolic BP (Analysis 2.3.2 (16 studies, 1113 participants): MD $-3.99 \mathrm{~mm} \mathrm{Hg}, 95 \%$ $\mathrm{Cl}-5.03$ to $\left.-2.94 ; \mathrm{I}^{2}=32 \% ; .2\right)$. 
The tests for subgroup differences showed no difference between short- and longer-term studies for both systolic $\left(\mathrm{Chi}^{2}=0.25, \mathrm{df}=1\right.$ $\left.(\mathrm{P}=0.6155), \mathrm{I}^{2}=0 \%\right)$ and diastolic $\mathrm{BP}\left(\mathrm{Chi}^{2}=0.06, \mathrm{df}=1(\mathrm{P}=0.8073)\right.$, $\left.\mathrm{I}^{2}=0 \%\right)$

\section{Urinary protein excretion}

Reducing salt intake reduced 24-hour urinary protein excretion in the earlier stages of CKD (Analysis 1.4 (6 studies, 436 participants): MD $-0.41 \mathrm{ln} \mathrm{mg} /$ day, $95 \% \mathrm{Cl}-0.58$ to $-0.25 ; \mathrm{I}^{2}=78 \%$ ) corresponding to an average percentage difference of $-33.9 \%(95 \% \mathrm{Cl}-44.1$ to -21.9$)$ from the high salt to the low salt intervention.

Three studies could not be entered into the pooled analysis (de Vries 2016; Konishi 2001; Mulhauser 1996). Konishi 2001 reported a reduction in median protein excretion with salt restriction $(\mathrm{P}=$ $0.004,38$ CKD participants) equivalent to a $27 \%$ reduction. de Vries 2016 found no effect on urinary protein excretion $(P=0.9,22$ posttransplant participants). Mulhauser 1996 reported no significant difference in proteinuria between the low salt group and the high salt group $(P>0.05$ using analysis of covariance adjusted for baseline values), although the analysis method may have been inappropriate as it is likely that data were not normally distributed (mean (range) values g/day end of run-in low salt: 1 (0.06 to 1.92) High salt: 0.71 (0.06 to 2.31); end of intervention: low salt 0.79 (0.1 to 1.39 ) high salt 1.14 (0.1 to 5.06$)$ ).

Reducing salt intake reduced 24-hour urinary albumin excretion (Analysis 1.5 (6 studies, 501 participants): MD $-0.44 \operatorname{ln~} \mathrm{mg} /$ day, $95 \%$ $\mathrm{Cl}-0.58$ to $-0.3 ; \mathrm{I}^{2}=29 \%$; high certainty evidence) corresponding to an average percentage difference of $-35.6(95 \% \mathrm{Cl}-44.2$ to -25.7$)$ from the high salt to the low salt intervention.

All six studies reporting 24-hour urinary protein (520 participants) were in the earlier stages of CKD and all but one (LowSALT CKD 2012) were of longer-term duration.

Most studies reporting 24-hour urinary albumin were in the earlier stages of CKD (except de Vries 2016 which is in post-transplant) and most were of longer-term duration (except LowSALT CKD 2012).

\section{Measures of kidney function}

Measures of kidney function reported by the included studies included eGFR, $\mathrm{SCr}, \mathrm{CrCl}$, effective renal plasma flow, and filtration fraction. Mulhauser 1996 reported no significant effect on renal parameters including eGFR, $\mathrm{CrCl}$, effective renal plasma flow, filtration fraction or renal vascular resistance $(P>0.05$ using analysis of covariance adjusted for baseline values) but data could not be pooled as values were reported as mean and range.

\section{Estimated glomerular filtration rate}

Reducing salt intake made little or no difference to eGFR (Analysis 1.6 (7 studies, 559 participants): MD $-0.82 \mathrm{~mL} / \mathrm{min} / 1.73 \mathrm{~m}^{2}, 95 \% \mathrm{Cl}$ -2.31 to $\left.0.66 ; I^{2}=0 \%\right)$. Of the seven studies that reported eGFR, all but one (de Vries 2016, post-transplant) were in the earlier stages of CKD and all but one (LowSALT CKD 2012) were of longer-term duration. Results were similar if including only earlier stages of CKD or in longer-term studies only. Results did not change when analysed using fixed effects.

\section{Creatinine clearance}

Reducing salt intake reduced $\mathrm{CrCl}$ (Analysis 1.7 (7 studies, 529 participants): $\mathrm{MD}-4.70 \mathrm{~mL} / \mathrm{min}, 95 \% \mathrm{Cl}-6.94$ to $-2.47 ; \mathrm{I}^{2}=$ 0\%). DUAAAL 2011 (52 participants) analysed log-transformed $\mathrm{CrCl}$ and reported the results as geometric means with a significant reduction from 72 ( 62 to 84 ) $\mathrm{mL} / \mathrm{min}$ in high salt to 66 (57 to 76 ) mL/ min in low salt $(P=0.002)$.

The test for subgroup differences showed no difference between short- and longer-term studies in $\mathrm{CrCl}\left(\mathrm{Chi}^{2}=0.96, \mathrm{df}=1(\mathrm{P}=0.33)\right.$, $\mathrm{I}^{2}=0 \%$ ). Results did not change when analysed using fixed versus random effects.

\section{Serum creatinine}

Reducing salt intake increased SCr (Analysis 1.8 (7 studies, 519 participants): $M D 4.46 \mu \mathrm{mol} / \mathrm{L}, 95 \% \mathrm{Cl} 0.08$ to $8.83 ; 1^{2}=24 \%$ ). de Vries 2016 analysed log transformed $\mathrm{SCr}$ and found no effect with salt restriction ( $\mathrm{MD} \ln -0.02 \mathrm{mg} / \mathrm{dL}, 95 \% \mathrm{Cl}-0.03$ to $0.07 \mathrm{P}=0.4$ ). LowSALT CKD 2012 reported a significant increase in $\mathrm{SCr}(\mu \mathrm{mol} / \mathrm{L})$ from median 149 (IQR 135-230) with high salt intake to 172 (157-276) with low salt intake $(P<0.05)$.

\section{Effective renal plasma flow}

Konishi 2001 (41 participants) reported no significant difference in effective renal plasma flow between low and high salt intake.

\section{Filtration fraction}

Reducing salt intake may make little or no difference to filtration fraction in the earlier stages of CKD (Analysis 1.9 (2 studies, 160 participants): $\mathrm{MD}-0.40 \%, 95 \% \mathrm{Cl}-0.87$ to 0.07 ; studies $=2$; participants $=160 ;\left.\right|^{2}=0 \%$ ).

\section{Body weight}

The evidence is very uncertain about the effect of reducing salt intake on body weight (Analysis 1.10 (12 studies, 759 participants): MD $-1.32 \mathrm{~kg}, 95 \% \mathrm{Cl}-1.94$ to $-0.70 ; \mathrm{I}^{2}=54 \%$; very low certainty evidence).

\section{CKD stage}

In the earlier stages of CKD, reducing salt intake reduced body weight (Analysis 1.10 .1 (8 studies, 634 participants): MD $-1.47 \mathrm{~kg}$, $95 \% \mathrm{Cl}-2.42$ to $\left.-0.53 ; \mathrm{I}^{2}=62 \%\right)$. In studies in dialysis patients, reducing salt intake may make little or no difference to body weight (Analysis 1.10 .2 (3 studies, 81 participants): MD -0.67 kg, $95 \% \mathrm{Cl}-1.37$ to $\left.0.04 ;\left.\right|^{2}=0 \%\right)$. In post-transplant recipients de Vries 2016 reported reducing salt intake reduced body weight (Analysis $1.10,3$ (44 participants): MD $-2.00 \mathrm{~kg}, 95 \% \mathrm{Cl}-3.00$ to -1.00 ). The test for subgroup differences showed no differences between the stages of $\mathrm{CKD}\left(\mathrm{Chi}^{2}=5.01, \mathrm{df}=2(\mathrm{P}=0.0819), \mathrm{I}^{2}=60 \%\right)$.

\section{Duration}

In both short-term studies (< 4 weeks) (Analysis 2.6 .1 ( 2 studies, 68 participants): MD $-0.41 \mathrm{~kg}, 95 \% \mathrm{Cl}-0.81$ to $\left.-0.01 ; \mathrm{I}^{2}=0 \%\right)$ and longer-term studies ( $\geq 4$ weeks) (Analysis 2.6 .2 (10 studies, 691 participants): $\mathrm{MD}-1.53 \mathrm{~kg}, 95 \% \mathrm{Cl}-2.02$ to $-1.04 ; \mathrm{I}^{2}=11 \%$ ) reducing salt intake reduced body weight. The test for subgroup differences showed no difference between short- and longer-term studies for body weight $\left(\mathrm{Chi}^{2}=12.09, \mathrm{df}=1(\mathrm{P}=0.0005), \mathrm{I}^{2}=91.7 \%\right)$ 


\section{Fluid status}

Reducing salt intake may reduce extracellular fluid volume in the earlier stages of CKD (Analysis 1.12 (3 studies, 187 participants): MD $-0.87 \mathrm{~L}, 95 \% \mathrm{Cl}-1.17$ to $-0.58 ; \mathrm{I}^{2}=0 \%$; low certainty evidence). de Brito-Ashurst 2013 reported a significant reduction in mean total body water in the low salt group of $0.50 \mathrm{~L}(\mathrm{P}<0.01)$ and no change in the control group ( $0.26 \mathrm{~L}$, not statistically significant).

Reducing salt intake did not change interdialytic weight gain (Analysis 1.11 (2 studies, 187 participants): MD $-0.11 \mathrm{~kg}, 95 \% \mathrm{Cl}$ -0.28 to $0.06 ; I^{2}=0 \%$ ). Power 2010 reported intradialytic weight gain was significantly reduced when sodium restriction was combined with low dialysate but did not report results for sodium restriction alone. Catto 1973 did not report intradialytic weight gain; however differences between mean pre- and post-dialysis weights taken over 15 dialysis sessions were similar in the low salt $(2.17 \mathrm{~kg})$ and the high salt $(2.21 \mathrm{~kg})$ arms.

Reducing salt intake reduced oedema in the earlier stages of CKD (Analysis 1.13 (2 studies, 191 participants): RR $0.52,95 \% \mathrm{Cl} 0.31$ to $\left.0.90 ; 1^{2}=0 \%\right)$.

\section{Renin-angiotensin-aldosterone system and $\mathrm{N}$-terminal pro- brain natriuretic peptide stimulation}

RAAS stimulation was reported as plasma renin activity, plasma renin, plasma aldosterone and serum aldosterone.

In the earlier stages of CKD reducing salt intake increased plasma renin activity (Analysis 1.14 (2 studies, 142 participants): MD 1.08 $\mathrm{ng} / \mathrm{mL} / \mathrm{h}, 95 \% \mathrm{Cl} 0.51$ to 1.65 ; studies = 2; participants = $142 ;$ $\mathrm{I}^{2}=0 \%$ ) and increased aldosterone (plasma or serum) (Analysis 1.15 (2 studies, 142 participants): MD $6.20 \mathrm{ng} / \mathrm{dL}, 95 \% \mathrm{Cl} 3.82$ to $\left.8.58 ; I^{2}=0 \%\right)$. Some data on renin and aldosterone could not be pooled; de Vries 2016 reported a significant increase in log transformed plasma aldosterone (MD 0.5 In pmol/L; $95 \% \mathrm{Cl} 0.3$ to $0.8 ; \mathrm{P}<0.001$ ), corresponding to a percentage difference in geometric mean of $65 \%$ (35\% to $123 \%$ ) and no significant effect on plasma renin (MD $0.2 \mathrm{ln} \mathrm{IU} / \mathrm{mL} ; 95 \% \mathrm{Cl}-0.1$ to $0.5 ; \mathrm{P}=0.1$ ) in posttransplant recipients. LowSALT CKD 2012 reported an increase in plasma renin of median $48 \mathrm{pmol} / \mathrm{L}$ (interquartile range (IQR) 23.5 to 70.5 ) and plasma aldosterone by $53.8 \mathrm{mU} / \mathrm{L}$ (IQR 4.8 to 74.7 ) with salt restriction $(P<0.001$ for both analyses) in the earlier stages of CKD.

NT-proBNP results could not be pooled. Two studies in earlier stages of CKD reported a significant reduction in NT-proBNP with salt restriction; LowSALT CKD 2012 reported that salt restriction reduced NT-proBNP by $125 \mathrm{pg} / \mathrm{mL}$ from median 330 (IQR 167$793)$ to $205(124-528) \mathrm{pg} / \mathrm{mL}(\mathrm{P}<0.05)$; Vogt 2008 reported salt restriction significantly decreased NT-proBNP from geometric mean $91 \mathrm{pg} / \mathrm{mL}$ (IQR 60 - 137) 62 (IQR 41 - 93) to ( $=0.005)$. de Vries 2016 reported no significant effect of salt restriction on logtransformed NT-proBNP $(-0.1 \mathrm{ln} n g / L, 95 \% \mathrm{Cl}-0.4$ to $0.1 ; \mathrm{P}=0.3)$ in post-transplant participants.

\section{Change in antihypertensive regimen}

Seven studies (664 participants) reported incidence of reduction in antihypertensives with salt restriction (de Vries 2016; DUAAAL 2011; ESPECIAL 2014; Keven 2006; LowSALT CKD 2012; Saran 2017; ViRTUE-CKD 2016). Three of these reported no changes in either low

Altered dietary salt intake for people with chronic kidney disease (Review)

Copyright (c) 2021 The Cochrane Collaboration. Published by John Wiley \& Sons, Ltd. salt or high salt groups (DUAAAL 2011; ESPECIAL 2014; ViRTUE-CKD 2016).

The evidence is very uncertain about the effect of reducing salt intake on antihypertensive medication dosage (Analysis 1.16 (7 studies, 664 participants): $\mathrm{RR} 2.45,95 \% \mathrm{Cl} 0.98$ to $6.08 ; \mathrm{I}^{2}=12 \%$; very low certainty evidence). Antihypertensive medication dosage were reported by four studies (228 participants; de Vries 2016; Keven 2006; LowSALT CKD 2012; Saran 2017). This may have reduced the effect size of sodium restriction on BP in these studies. There were 20 instances of reduction in antihypertensive dosage in low salt group versus eight in the high salt group. Six of the eight instances in the high salt arm occurred in Saran 2017, and these were mostly in the second arm of the cross-over study. Saran 2017 also experienced protocol violations with respect to treatment order; 10 of the 56 patients were not receiving the correct treatment in the second arm (six in the first arm), therefore this may have impacted anti-hypertensive dose. If Saran 2017 is excluded from the analysis, the effect size is larger (RR $5.38,95 \% \mathrm{Cl} 1.45$ to 20.0112 events in low salt and two in high salt arms).

ESMO 2017 reported the number of antihypertensive medications was not significantly changed with salt restriction (MD $0.095 \%$ -0.3 to 0.2 ) but did not report change in dosage. Rodrigues Telini 2014 reported there was no significant difference in the number of antihypertensive medications between the groups at follow-up.

Some studies did not report change in antihypertensive medications but it is reasonable to assume medication changes did not occur due to their study protocols; the study protocols for Kwakernaak 2014 and Vogt 2008 specified keeping medications stable; Konishi 2001 refrained from the use of antihypertensive medications during the study; Ruilope 1992a specified that no medications were given during run-in and it is likely that this continued (besides the co-intervention of $240 \mathrm{mg}$ verapamil); Mulhauser 1996 excluded participants taking antihypertensive medications.

Fine 1997 reported that there were no increases to medication in the 10 hypertensive patients during the high salt intervention, but it is unclear whether changes occurred in the low salt intervention or in the other 10 participants. de Brito-Ashurst 2013 study protocol included salt restriction "in addition to standard hypertension medication management" therefore there may have been changes to medications but measurement of this was not specified. Power 2010 measured antihypertensive dosage but did not report results.

\section{Adverse effects}

Potential adverse effects reported included symptomatic hypotension, cramps, and serum cholesterol.

Reducing salt intake may increase symptomatic hypotension (Analysis 1.17 (4 studies, 478 participants): RR $6.70,95 \% \mathrm{Cl} 2.40$ to $18.69 ; I^{2}=0 \%$; moderate certainty evidence). These were mostly considered mild (ViRTUE-CKD 2016) or were resolved by lowering the dose of antihypertensive medication (de Vries 2016; LowSALT CKD 2012). This is a potential adverse effect associated with salt restriction, although one that could be rectified by reducing the antihypertensive dose.

Power 2010 reported that sodium restriction increased frequency, but not severity, of cramps by $21 \%(P=0.04)$. Catto 1973 reported that administration of slow sodium during dialysis (versus placebo) 
resulted in a $26 \%$ reduction in the frequency $(P<0.05)$ and $30 \%$ in the severity $(P<0.02)$ of muscle cramps recorded over 15 dialysis sessions.

Reducing salt intake did not change total cholesterol (Analysis 1.18 ( 7 studies, 473 participants): MD $-0.11 \mathrm{mmol} / \mathrm{L}, 95 \% \mathrm{Cl}-0.31$ to $\left.0.10 ; 1^{2}=0 \%\right)$

\section{Sensitivity analysis}

The funnel plots of analyses for sodium intake/excretion (Figure 4), systolic BP (Figure 5) and diastolic BP (Figure 6) were investigated. Studies giving rise to asymmetry for systolic BP (BalanceWisePD 2011) and diastolic BP (BalanceWise-PD 2011; Rodrigues Telini 2014) were removed with no change in direction or effect size.

Figure 4. Funnel plot of comparison: 1 CKD stage, outcome: 1.1 Sodium intake/excretion [mmol/d].

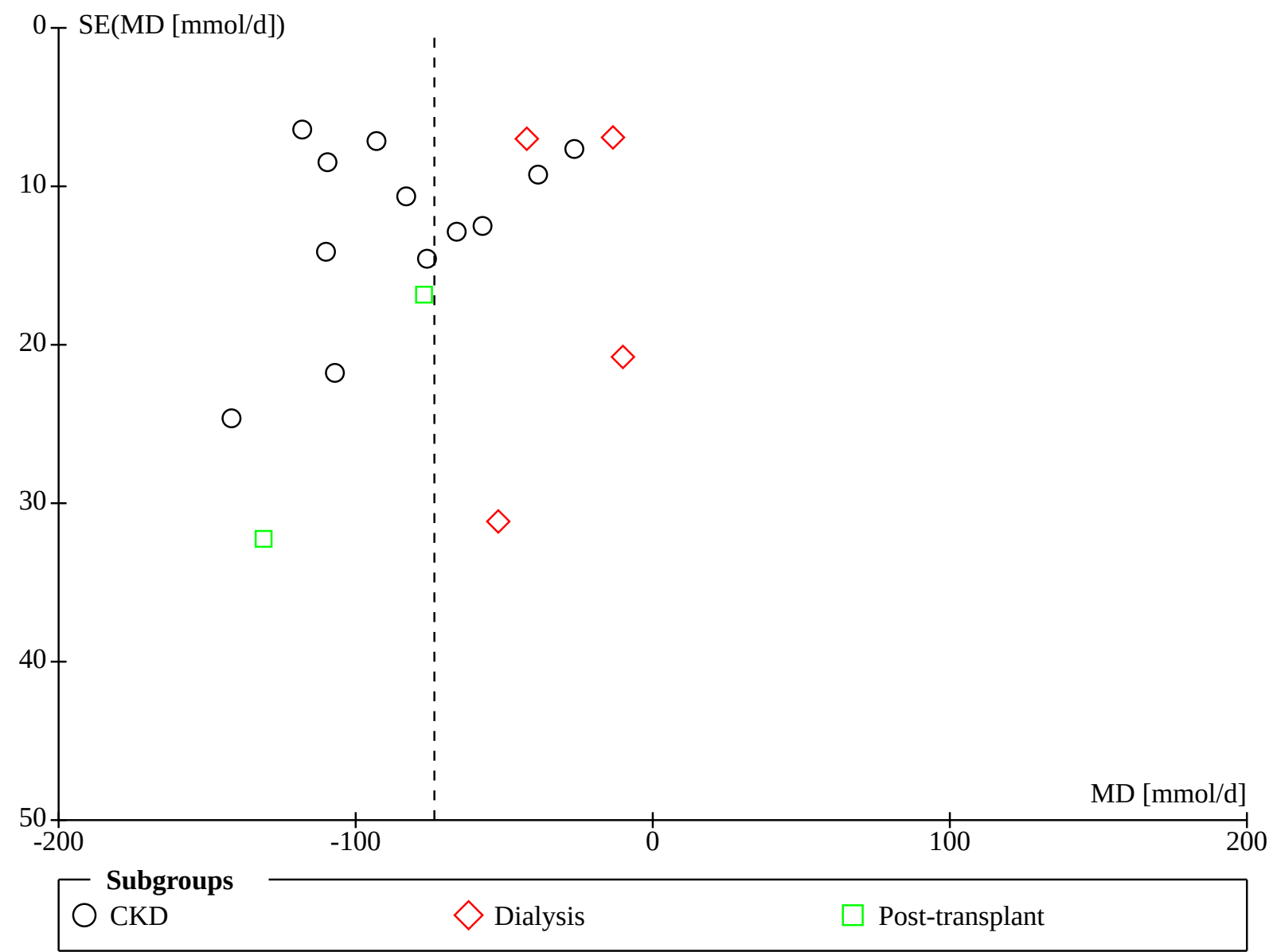


Figure 5. Funnel plot of comparison: 1 CKD stage, outcome: 1.2 Systolic blood pressure [mm Hg].

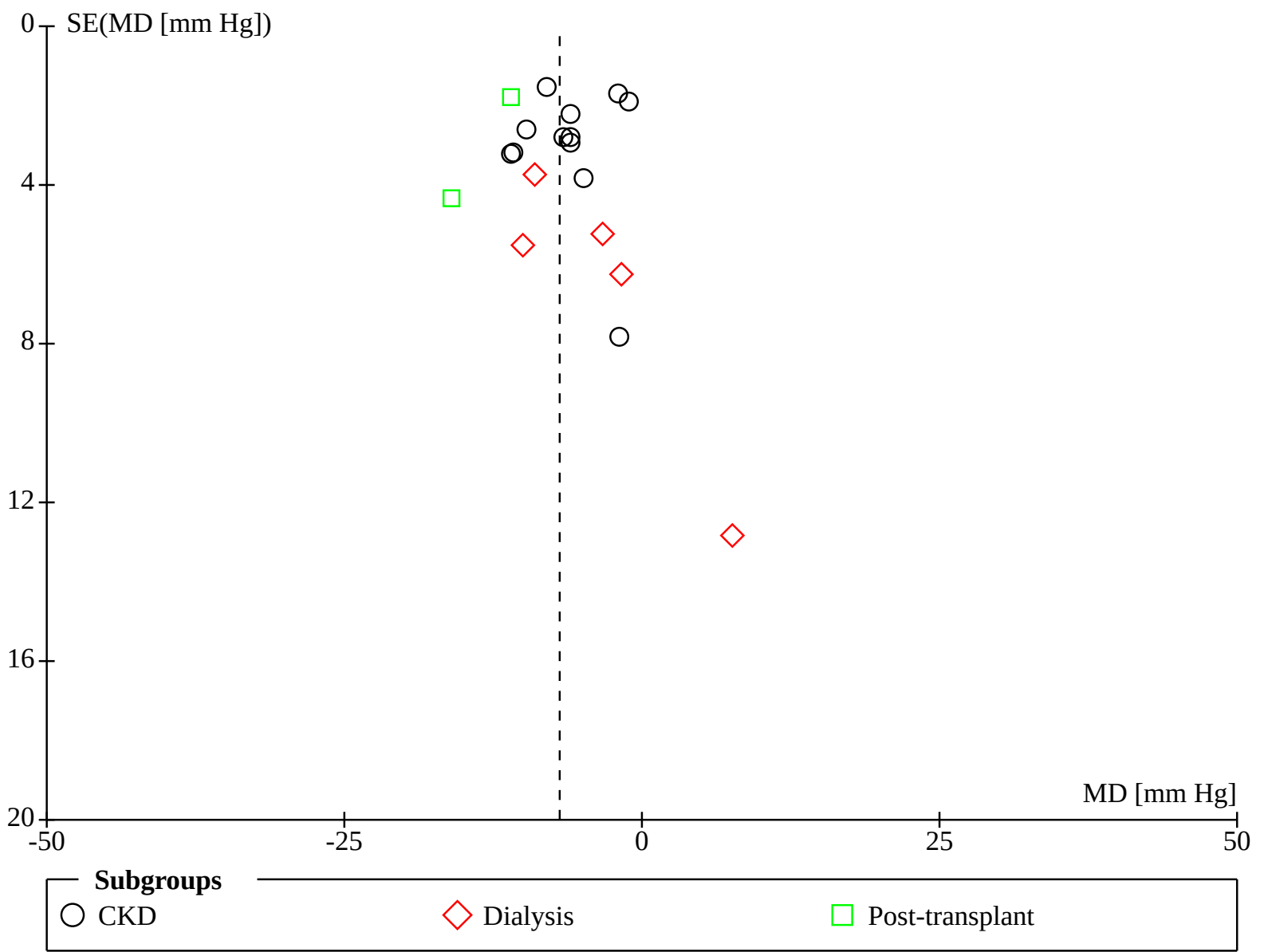


Figure 6. Funnel plot of comparison: 1 CKD stage, outcome: 1.3 Diastolic blood pressure [mm $\mathbf{~ g g}$ ].

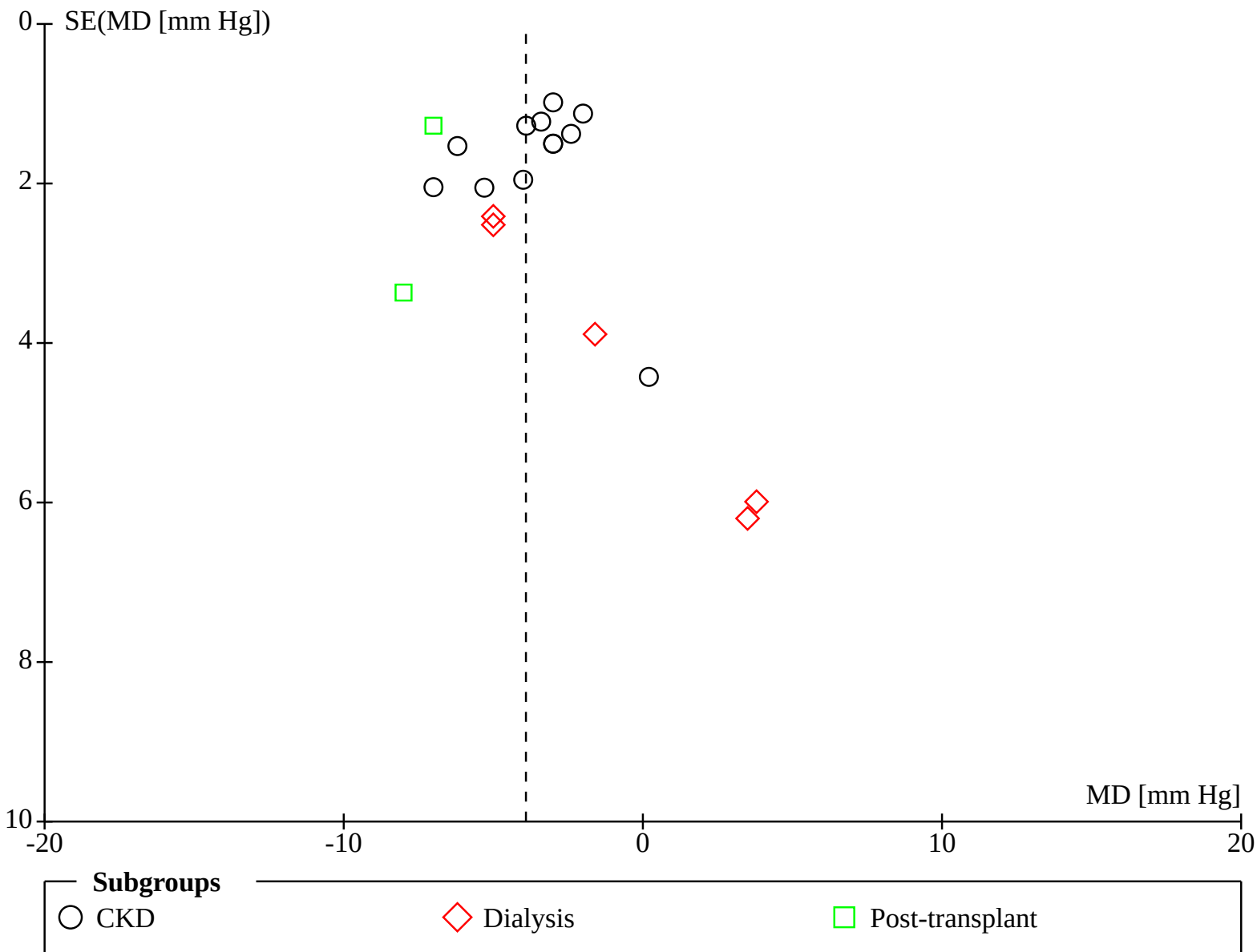

Studies with high risk of bias in more than one domain (BalanceWise-PD 2011; Saran 2017) were removed. The differences in analyses were mostly minimal except when Saran 2017 was eliminated from antihypertensive dosage reduction analysis as discussed previously (analyses not shown).

\section{DISCUSSION}

\section{Summary of main results}

We included 21 studies (1197 randomised participants), 12 in the earlier stages of CKD (779 randomised participants), seven in dialysis (363 randomised participants) and two in post-transplant (55 randomised participants). Included studies had a median study duration of seven weeks (range 1 to 36 weeks) and compared two levels of sodium intake achieved via dietary counselling to reduce salt (13 studies); sodium supplements (six studies) providing food (one study) or unspecified methods (one study).

Reducing salt reduced BP in all stages of CKD. We found that reducing salt intake by approximately $4.2 \mathrm{~g} /$ day $(73.52 \mathrm{mmol}$ or $1690 \mathrm{mg}$ sodium) lowered BP by $7 / 4 \mathrm{~mm} \mathrm{Hg}$ in people with CKD and proteinuria/albuminuria by $34 \%$ to $36 \%$ in people in the earlier stages of CKD. This is a clinically significant reduction in $\mathrm{BP}$, comparable to expectations of administering a single antihypertensive drug (Law 2009).
In non-dialysed, non-transplanted people with CKD, reducing salt intake by $4.8 \mathrm{~g} /$ day $(84 \mathrm{mmol}$ or $1930 \mathrm{mg}$ sodium) for a median of six weeks duration reduced BP by $6.1 / 3.5 \mathrm{~mm} \mathrm{Hg}$. In dialysed people with CKD reducing salt by $1.6 \mathrm{~g} /$ day ( $27 \mathrm{mmol}$ or $620 \mathrm{mg}$ sodium) for a median of 16 weeks duration reduced BP by $6.3 / 3.5 \mathrm{~mm} \mathrm{Hg}$. In people who had undergone transplantation (two studies 6 and 12 week duration), reducing salt by $5.6 \mathrm{~g} /$ day $(97 \mathrm{mmol}$ or $2230 \mathrm{mg}$ sodium) reduced $\mathrm{BP}$ by $11.9 / 7.1 \mathrm{~mm} \mathrm{Hg}$.

In studies of less than four weeks duration, reducing salt by $6.4 \mathrm{~g} /$ day ( $111 \mathrm{mmol}$ or $2550 \mathrm{mg}$ sodium) reduced BP by $7.9 / 3.7 \mathrm{~mm} \mathrm{Hg}$. In studies of four weeks or more duration, reducing salt by $3.7 \mathrm{~g} /$ day (64.53 mmol or $1480 \mathrm{mg}$ sodium) reduced BP by $6.8 / 4.0 \mathrm{~mm} \mathrm{Hg}$.

The evidence is very uncertain about the effect of lower salt intake on weight. We found body weight was reduced by $1.3 \mathrm{~kg}$ with salt reduction, with a larger reduction in studies over 4 weeks $(1.5$ $\mathrm{kg}$ ) than studies under 4 weeks duration $(0.4 \mathrm{~kg})$. However, it was not possible to determine the extent to which this weight loss was due to fluid volume, lean tissue, or body fat. Salt restriction resulted in reduced extracellular fluid volume by $0.87 \mathrm{~L}$ and a $48 \%$ reduced risk of oedema in non-transplanted people with CKD. Reducing salt intake did not significantly change inter-dialytic weight gain. Evidence for effects on fluid status was not available for transplanted people with CKD. Reductions in body weight were seen in all stages of CKD with $1.5 \mathrm{~kg}$ weight loss in non- 
dialysed, non-transplanted CKD, $0.7 \mathrm{~kg}$ in dialysed CKD and $2 \mathrm{~kg}$ in transplanted CKD.

Reducing salt intake reduced 24-hour urinary protein excretion in the earlier stages of CKD by $-0.41 \mathrm{ln} \mathrm{mg} /$ day $(95 \% \mathrm{Cl}-0.58$ to $-0.25)$ which corresponded to an average percentage difference of $-33.9 \%(95 \% \mathrm{Cl}-44.1$ to -21.9$)$. Reducing salt intake may reduce extracellular fluid volume and oedema in the earlier stages of CKD but did not alter interdialytic weight gain.

It was found that eGFR was not significantly changed by salt restriction, but salt restriction decreased $\mathrm{CrCl}$ by $4.7 \mathrm{ml} / \mathrm{min}$ and increased SCr by $4.5 \mu \mathrm{mol} / \mathrm{L}$. These effects were more pronounced in studies under four weeks duration than those four or more weeks duration, but the difference by duration was not statistically significant.

While reduced salt intake may increase symptomatic hypotension, the evidence is very uncertain about the effect of reducing salt intake on antihypertensive medication dosage.

\section{Overall completeness and applicability of evidence}

We aimed to evaluate the benefits and harms of altering dietary salt intake for people with CKD. We could not assess the effect of restricting salt intake on endpoints such as death, cardiovascular events of progression to ESKD in people with CKD because there were no RCTs of adequate size or duration to examine these outcomes. This limitation has been noted in previous reviews in non-CKD populations (Hooper 2002; Suckling 2010), and may be also in part due to the resources and practical aspects of providing the ongoing and regular support that is needed to achieve long-term adherence to a sodium-restricted diet (McMahon 2012a). In practice, supporting patients to achieve this requires an individualised approach tailored to support patients to improve their motivation, knowledge and develop personal coping skills to prevent behaviour change decay over time. More research on these elements are needed. In this review, we identified some ongoing studies with longer intervention durations meaning that we may be able to assess the longer-term effects on salt restriction in people with CKD in future updates of this review.

While nearly all included studies reported effects of salt restriction on dietary salt intake/excretion and BP, there were limited evidence for effects on kidney function, proteinuria/albuminuria, and fluid status. Subgroup analyses were not possible for many outcomes due to the small number of studies reporting these outcomes. We examined results by stage of CKD and study duration; we were unable to explore other potential sources of heterogeneity such as presence of diabetes mellitus or albuminuria/proteinuria, primary kidney disease, or antihypertensive regimen.

There was a substantial degree of heterogeneity among study results for some outcomes, including sodium intake/excretion, systolic BP, and weight, although this was reduced in subgroup analyses in most cases. A contributor to heterogeneity was inclusion of people across the stages of CKD, including early stage CKD (non-dialysis), dialysis, and transplant populations. Sodium handling in people with mild CKD is likely to differ considerably from those with severe kidney dysfunction, people on dialysis, and kidney transplant recipients. We analysed outcomes by CKD stage where possible, however this subgroup analysis was limited due to the small number of included studies, particularly in the more advanced stages of CKD. Only two studies included posttransplant participants and seven in dialysis (two with people receiving $\mathrm{PD}$, four with people receiving $\mathrm{HD}$, one dialysis modality not specified). Other salt restriction studies have been conducted in people undergoing dialysis, but these are either observational (Kayikcioglu 2009), non-randomised (Ang 1999; Osanai 2002) or used a concomitant intervention in the sodium restricted group (Rupp 1978) and were not eligible for inclusion in this review.

There were important differences in methodology between short(fewer than four weeks) and longer-term studies (four weeks and more) that limited subgroup analysis according to study duration. Short-term studies achieved a larger reduction in salt ( $6.4 \mathrm{~g} /$ day; $111 \mathrm{mmol}$ or $2550 \mathrm{mg}$ sodium) than studies of four weeks or longer reducing salt by $(3.7 \mathrm{~g} /$ day; $64.53 \mathrm{mmol}$ or 1480 mg sodium) but achieved similar reductions in BP (8/4 and $7 / 4$ $\mathrm{mm} \mathrm{Hg}$ respectively). However short-term studies used either supplemental sodium (Konishi 2001; LowSALT CKD 2012) or full meal provision (Ruilope 1992a), therefore dietary confounders may have been more tightly controlled than in longer-term studies which most commonly compared dietary education to reduce salt versus usual diet. A limitation in two of the three short-term studies was that neither employed a washout period (Konishi 2001; Ruilope 1992a). Considering that these studies had intervention durations of only one week, carry-over effect may have influenced study results. Ruilope 1992a, a short-term study, began a new antihypertensive medication on day one of the study, further increasing risk of carry-over effect.

It is likely that differing magnitude of salt restriction impacted heterogeneity. A previous analysis showed a dose-response relationship between salt reduction and BP reduction (He 2003). We could not examine differential effects by magnitude of sodium reduction achieved as studies did not report results separately by level of sodium reduction achieved.

\section{Quality of the evidence}

We assessed the quality of study evidence using standard risks of bias domains within the Cochrane tool together with GRADE methodology. Confidence in evidence was high for systolic and diastolic BP and albuminuria. Confidence in evidence was low for sodium intake/excretion (substantial heterogeneity), extracellular fluid volume (uncertain or high risk of bias; few participants across all studies) and symptomatic hypotension (few participants across all studies; wide confidence interval range that include benefit or harm). Confidence in evidence was very low for weight (uncertain or high risk of bias; moderate heterogeneity; indirectness of outcome) and reduction in antihypertensive dose (high risk of bias; wide confidence interval range that include benefit or harm).

Potential bias from confounders were mostly due to lack of measurement or failing to adequately report or account for the impact of changes in medications and/or dietary changes such as potassium intake, protein intake and/or weight loss between interventions. Reduction in anti-hypertensive medications may have led to underestimations of the effect of salt restriction on BP and proteinuria. Studies that provided supplementary sodium (Catto 1973; Doulton 2007; Fine 1997; LowSALT CKD 2012; Mulhauser 1996; Ruilope 1992a) to manage sodium intake were at lower risk of bias from dietary confounders because other dietary factors were likely to remain stable over the study period (McMahon 2012a). Previous research has found that when dietary advice is 
given about reducing sodium intake, other factors such as energy and potassium intake can also change (Korhonen 2000). This means that studies relying on dietary advice to manage sodium intake (BalanceWise-HD 2013; BalanceWise-PD 2011; de Brito-Ashurst 2013; de Vries 2016; DUAAAL 2011; ESMO 2017; ESPECIAL 2014; Keven 2006; Kwakernaak 2014; Rodrigues Telini 2014; Saran 2017; ViRTUE-CKD 2016; Vogt 2008) may be at a higher risk of bias from dietary confounders.

It is widely accepted that potassium intake affects BP. Nine of the 19 studies that reported BP as an outcome measured change in potassium intake either directly or indirectly and reported the findings. Seven studies (de Brito-Ashurst 2013; de Vries 2016; ESMO 2017; Kwakernaak 2014; LowSALT CKD 2012; Mulhauser 1996; ViRTUE-CKD 2016) reported potassium intake/ excretion as unchanged with sodium restriction. DUAAAL 2011 and Ruilope 1992a reported small, but significant, reductions in urinary potassium excretion in the sodium-restricted groups (3 to $4 \mathrm{mmol}$ ) day), which is likely to reflect reduction in urinary volume.

Body weight has also been reported to affect BP and proteinuria (Siebenhofer 2016). Given that most studies did not report change in fluid status, we could not determine the degree to which body weight change observed in included studies was due to reduction in fluid volume or body fat. The latter could introduce bias by overestimating the effect of salt restriction on $\mathrm{BP}$ and proteinuria.

Saran 2017 had high risk of bias across several domains due to protocol violation meaning that a large proportion of participants did not receive treatments in the allocated order or did not receive both treatments, incomplete outcome data and potential conflict of interest (due to two study authors holding stock in a company that makes the tool used for primary outcome measurement). Results for were similar when Saran 2017 was excluded for all outcomes anti-hypertensive dosage reduction; the magnitude of effect was increased when Saran 2017 was excluded.

\section{Potential biases in the review process}

This review was conducted according to a pre-specified protocol and used a highly sensitive search strategy. Inclusion/exclusion and risk of bias was conducted by two independent review authors and we considered evidence certainty in interpretation of the results. All efforts were made to minimise bias inherent in the review process. Study inclusion and risk of bias assessment were carried out by two authors working independently.

In the 2015 review, we contacted all study authors for additional information to inform our risk of bias assessment and received further information for five of the eight included studies (de BritoAshurst 2013; DUAAAL 2011; Konishi 2001; LowSALT CKD 2012; Vogt 2008). Of the 13 additional studies included in this review update, we did not require further information for one study (Kwakernaak 2014); we could not find current contact details to request further information for three studies (Catto 1973; Doulton 2007; Mulhauser 1996); and we contacted study authors of the remaining nine studies and received further information for five studies (BalanceWise-HD 2013; BalanceWise-PD 2011; ESMO 2017; ESPECIAL 2014; ViRTUE-CKD 2016).

We applied a search strategy to include both published and unpublished studies, and were able to include one study where main findings were unpublished (BalanceWise-PD 2011) and two studies where main findings were published as conference abstracts only (Doulton 2007; Power 2010).

\section{Agreements and disagreements with other studies or reviews}

\section{Previous version of this review}

This review update included 21 studies with 725 participants in the low salt group and 725 in the high salt group. This is a considerable increase compared with our 2015 review which included eight studies with 224 participants in the low salt group and 218 in the high salt group (McMahon 2015), and we were able to include additional outcomes in this update (proteinuria, albuminuria, interdialytic weight gain). A further difference from the 2015 review is that we included results from paired analyses where available which in most instances led to narrower confidence intervals than when results from unpaired analyses were included. Some key differences in the results of this update compared to the 2015 review are discussed below.

Our 2015 review included six studies in the earlier stages of CKD, one in dialysis, and one post-transplant. This update includes an additional six studies in the earlier stages of CKD (12 studies total), six in dialysis (seven studies total) and one post-transplant (two studies total). The additional studies in ESKD in this update improves generalisability of the findings to participants at this stage of kidney disease.

We found a smaller reduction on sodium intake/excretion in included studies in this update (mean $74 \mathrm{mmol} /$ day) compared with the 2015 review (mean $106 \mathrm{mmol} /$ day). This is likely due to an increase in the number of studies examining effectiveness of behavioural and education-based approaches to reducing salt intake, rather than the efficacy of salt reduction in a controlled setting. Included studies also had a longer intervention duration in this update compared with the 2015 review. Four of the eight included studies in the 2015 review used education to reduce sodium intake compared to 13 of the 21 studies in this update. Of these studies, those in the 2015 review tended to have higher baseline sodium intakes (mean values ranging from 177 to 261 $\mathrm{mmol} / \mathrm{day}$ ) than those added in this update (mean values ranging from 98 to $175 \mathrm{mmol} /$ day), however target sodium intakes for the low salt group were similar, ranging between 50 to $100 \mathrm{mmol} /$ day. This likely contributed to the smaller reduction in sodium seen in this review update versus the 2015 review. The inclusion of studies with lower sodium reduction also likely explains the slightly lower effect on systolic BP. We originally demonstrated that reducing salt intake by approximately $6 \mathrm{~g} /$ day $(100 \mathrm{mmol}$ or $2300 \mathrm{mg}$ sodium/ day) lowered BP by $9 / 4 \mathrm{~mm} \mathrm{Hg}$ in people with CKD. In this update, we found that reducing salt intake by approximately $4.2 \mathrm{~g} /$ day (73.52 mmol or $1690 \mathrm{mg}$ sodium) lowered BP by $7 / 4 \mathrm{~mm} \mathrm{Hg}$.

In the 2015 review, we did not meta-analyse the effects on proteinuria and albuminuria due to heterogeneity in outcome reporting. Instead we reported the range of effect in the four studies reporting proteinuria and one reporting albuminuria. In this update, we meta-analysed the effect of salt restriction on proteinuria (six studies) and albuminuria (six studies) mostly in the earlier stages of CKD, and our findings were consistent with those we reported in the 2015 review. 
This update included three additional studies (four total) reporting on extracellular fluid, one (two total) reporting on presence of oedema and four (four total) reporting on intra-dialytic weight gain. We found significant reductions on extracellular fluid volume and presence of oedema which is an important finding as fluid overload is a strong predictor of cardiovascular events and kidney function decline in CKD (Essig 2008). We also found significant changes in $\mathrm{CrCl}$ and body weight in this update, while these were not significantly altered in the 2015 review, although these changes are likely due to changes in BP, proteinuria/albuminuria and fluid status and are unlikely to be clinically significant.

\section{Other reviews in CKD}

There have been three reviews of trials of salt restriction in people with CKD published since the 2015 review, including: 1) a narrative review of seven RCTs in non-dialysed, non-transplanted CKD participants (Nerbass 2018); 2) a systematic review of 12 randomised and non-randomised trials achieving at least one gram salt reduction in dialysis participants, and meta-analysis of the four RCTs (Cole 2019); and 3) a systematic review and meta-analysis of 11 RCTs in non-dialysed CKD patients (Garofalo 2018). Agreements and disagreements with the findings of the meta-analyses are discussed below.

Cole 2019 reported that salt restriction in four RCTs in dialysis reduced systolic/diastolic BP by $8 / 4 . \mathrm{mm} \mathrm{Hg}$. This is slightly higher than the difference in BP in our meta-analysis of five RCTs in dialysis $(8 / 3 \mathrm{~mm} \mathrm{Hg})$, likely due to our inclusion of the BalanceWise-PD 2011 Study which did not achieve a significant reduction in sodium intake or BP.

Garofalo 2018 reported that a mean $80 \mathrm{mmol} /$ day reduction in sodium excretion reduced ambulatory BP by $6 / 2 \mathrm{~mm} \mathrm{Hg}$ and clinicassessed BP by $5 / 3$ in 11 RCTs in non-dialysed CKD patients, similar to our findings of a $6 / 3$ reduction in 12 RCTs in the earlier stages of CKD, and resulted in a $29 \%$ mean reduction in proteinuria, similar to our results (34\% reduction), and $14 \%$ reduction in albuminuria, whereas we found a $37 \%$ reduction in our analysis of the same five studies. These are likely due to differences in meta-analysis methods. We analysed albuminuria as log-transformed values (which in some cases was made possible only by provision of raw data by study authors), because these data are usually not normally distributed and effect is highly dependent on their baseline values. Garofalo 2018 converted medians and inter-quartile ranges to means and SD and pooled log-transformed with untransformed data. Three studies were weighted very low due to wide $\mathrm{Cl}$ suggesting no effect on albuminuria (Kwakernaak 2014; LowSALT CKD 2012; ViRTUE-CKD 2016); however these studies all reported clinically and statistically significant effects on albuminuria $(P<$ 0.001). It is likely that the study by Saran 2017 was weighted heavily because log-transformed values were used, leading to narrower confidence intervals.

\section{Other reviews in non-CKD}

Previous reviews investigating the effect of salt restriction have been conducted in people with normal kidney function, and these consistently show that reducing dietary sodium intake reduces BP, although magnitudes vary (Graudal 2020; He 2013; Hernandez 2018; Hooper 2002). Across these reviews, dietary salt reduction generally has a greater effect on people who are hypertensive (Graudal 2020; He 2013; Hooper 2002). We could not conduct subgroup analyses by hypertensive status as most participants in the included studies were hypertensive and it was rare to report findings separately for hypertensive and normotensive participants. We found a reduction in BP of approximately $7 / 4$ $\mathrm{mm} \mathrm{Hg}$ with salt reduction of approximately $74 \mathrm{mmol}$. This is a similar to that found in hypertensive people without CKD; Graudal 2020 reported mean reduction of $6 / 3 \mathrm{~mm} \mathrm{Hg}$ with median salt reduction of $145 \mathrm{mmol}$; Hernandez 2018 found that low-sodium salt substitutes decreased systolic BP by $8 / 4 \mathrm{~mm} \mathrm{Hg}$, with a 27 mmol decrease in urinary sodium and $13 \mathrm{mmol}$ increase in urinary potassium.

Graudal 2020 also identified that increased serum cholesterol level was an adverse effect in a meta-analysis of sodium restriction. We found no significant change in total cholesterol in relation to salt restriction in people with CKD.

In a pooled meta-analysis of people with diabetes, Suckling 2010 reported that $\mathrm{CrCl}$ was significantly reduced $(-6.33 \mathrm{~mL} / \mathrm{min}, 95 \%$ $\mathrm{Cl}-10.47$ to -2.19$)$ with salt restriction; eGFR was not significantly changed (MD -1.92; 95\% Cl -4.49 to 0.64). Our update found similar, with $\mathrm{CrCl}$ significantly reducing by 4.46 and that eGFR did not change significantly with salt restriction. It is thought that reductions in $\mathrm{CrCl}$ with salt restriction occur as a result of hyperfiltration paradoxically decreasing risk of kidney disease (Allen 1997).

Suckling 2010 found mixed results for the effects of salt restriction on proteinuria in people with diabetes. Aburto 2013 reported urinary protein excretion and albuminuria was reduced with lower sodium intake in a systematic review including two studies in the general population. Our review demonstrated proteinuria to significantly reduce by $34 \%$ following salt restriction; this difference was expected as people with CKD are more susceptible to proteinuria.

\section{AUTHORS' CONCLUSIONS}

\section{Implications for practice}

We found a strong case for the benefits of salt restriction in people with CKD. We found that reducing dietary salt considerably reduced BP in people with CKD. We found consistent evidence that dietary salt restriction reduced proteinuria in people with earlier stage (non-dialysed, non-transplanted) CKD by $34 \%$ to $36 \%$. If such reductions were maintained long-term, this may translate to clinically significant reductions in ESKD and cardiovascular events.

Reduced salt intake may increase symptomatic hypotension. Data were sparse for other types of adverse events.

Current evidence-based clinical guidelines recommend a sodium intake target of less than $6 \mathrm{~g}$ of salt $(100 \mathrm{mmol} ; 2300 \mathrm{mg}$ sodium) per day for people with CKD, although achieving longerterm adherence to this target can be challenging for patients without regular and ongoing support to improve their motivation, knowledge and prevent behaviour change decay. These findings were based on studies with intervention durations up to 6 months. There are ongoing studies with longer intervention durations which will strengthen the evidence for longer-term effects.

\section{Implications for research}

We found that salt reduction in people with CKD reduced BP considerably and consistently reduced proteinuria over a time- 
frame of up to 6 months. We found a critical evidence gap in longterm effects of salt restriction in people with CKD that meant we were unable to determine the direct effects of sodium restriction on critical outcomes such as death and progression to ESKD. If the reductions we found in short-term studies could be maintained long-term, these benefits may translate to clinically significant reductions in ESKD incidence and cardiovascular events. Research into longer-term effects of dietary sodium restriction for people with CKD is warranted, along with investigation of adherence to a low salt diet.

Despite consistent data from observational and non-randomised studies showing that salt restriction reduced fluid volume in people with CKD, high quality RCTs are lacking. Further research on the effect of salt restriction on other cardiac and vascular abnormalities such as arterial stiffness, left ventricular hypertrophy, inflammation and oxidative stress is warranted.

Future studies investigating salt restriction should employ methods that limit risk of bias due to dietary confounders where possible and should take care to adequately measure dietary intake of not only sodium, but other nutrients that may confound study results. Research into long-term adherence to a sodium-restricted diet may assist in translating these results into a practical setting.

\section{ACKNOWLEDGEMENTS}

We would like to acknowledge the Cochrane Kidney and Transplant for providing administrative and support for the conduct of this review, and Brydee Johnston and Rabia Khalid for providing support with data extraction. We would also like to acknowledge the ongoing support from Menzies School of Health Research, University of Queensland, the Princess Alexandra Hospital and the Queensland Government. Emma McMahon is currently supported by a cofunded NHMRC/Australian Heart Foundation Early Career Fellowship (100085) and previously received support from the Australian Government through an Australian Postgraduate Award scholarship. The information and opinions contained in this paper are solely the responsibility of the authors and do not necessarily reflect the views or policy of NHMRC, Australian Heart Foundation, Menzies School of Health Research, University of Queensland, Griffith University, the Princess Alexandra Hospital and the Queensland Government.

The authors are grateful to the following peer reviewers for their time and comments: Ronald L. Koretz, M.D. Emeritus Professor of Clinical Medicine, David Geffen-UCLA School of Medicine, Los Angeles, California, USA; Retired Chief, Division of Gastroenterology, Olive View-UCLA Medical Center, Sylmar, California, USA; Colin H Jones, Consultant Physician and Nephrologist, York Teaching Hospital NHS Foundation Trust. 


\section{R E F E R E N C E S}

\section{References to studies included in this review}

BalanceWise-HD 2013 \{published and unpublished data\}

Clark-Cutaia MN, Ren D, Hoffman LA, Burke LE, Sevick MA. Adherence to hemodialysis dietary sodium recommendations: influence of patient characteristics, self-efficacy, and perceived barriers. Journal of Renal Nutrition 2014;24(2):92-9. [MEDLINE: 24462498]

Clark-Cutaia MN, Ren D, Hoffman LA, Snetselaar L, Sevick MA. Psychometric validation of the self-efficacy for restricting dietary salt in hemodialysis scale. Topics in Clinical Nutrition 2013;28(4):384-91. [EMBASE: 2013726385]

Clark-Cutaia MN, Sevick MA, Thurheimer-Cacciotti J, Hoffman LA, Snetselaar L, Burke LE, et al. Perceived barriers to adherence to hemodialysis dietary recommendations. Clinical Nursing Research 2019;28(8):1009-29. [MEDLINE: 29732932]

Hu L, St-Jules DE, Popp CJ, Sevick MA. Determinants and the role of self-efficacy in a sodium-reduction trial in hemodialysis patients. Journal of Renal Nutrition 2019;29(4):328-32. [MEDLINE: 30579673]

Sevick MA, Piraino BM, St-Jules DE, Hough LJ, Hanlon JT, Marcum ZA, et al. No difference in average interdialytic weight gain observed in a randomized trial with a technologysupported behavioral intervention to reduce dietary sodium intake in adults undergoing maintenance hemodialysis in the United States: primary outcomes of the BalanceWise study. Journal of Renal Nutrition 2016;26(3):149-58. [MEDLINE: 26868602]

Stark S, Snetselaar L, Piraino B, Stone RA, Kim S, Hall B, et al. Personal digital assistant-based self-monitoring adherence rates in 2 dialysis dietary intervention pilot studies: BalanceWise-HD and BalanceWise-PD. Journal of Renal Nutrition 2011;21(6):492-8. [MEDLINE: 21420316]

St-Jules DE, Woolf K, Pompeii ML, Sevick MA. Exploring problems in following the hemodialysis diet and their relation to energy and nutrient intakes: the BalanceWise study. Journal of Renal Nutrition 2016;26(2):118-24. [MEDLINE: 26586249]

\section{BalanceWise-PD 2011 \{published and unpublished data\}}

Koprucki M, Piraino B, Bender F, Snetselaar L, Hall B, Stark S, et al. RCT of Personal Digital Assistant (PDA) supported dietary intervention to reduce sodium intake in PD [abstract no: 162]. American Journal of Kidney Diseases 2010;55(4):A72. [EMBASE: 70124819]

* Sevick MA. BalanceWise-PD final progress report redacted (as supplied 14 June 2019). Data on file.

Stark S, Snetselaar L, Piraino B, Stone RA, Kim S, Hall B, et al. Personal digital assistant-based self-monitoring adherence rates in 2 dialysis dietary intervention pilot studies: BalanceWise-HD and BalanceWise-PD. Journal of Renal Nutrition 2011;21(6):492-8. [MEDLINE: 21420316]
Catto 1973 \{published data only\}

Catto GR, Smith FW, MacLeod M. Treatment of muscle cramps during maintenance haemodialysis. BMJ 1973;3(5876):389-90. [MEDLINE: 4581080]

de Brito-Ashurst 2013 \{published and unpublished data\} De Brito-Ashurst I, Dobbie H, Raftery MJ, Yaqoob MM. Are hypertensive chronic kidney disease patients salt-sensitive? A randomised controlled study [abstract no: PUB722]. Journal of the American Society of Nephrology 2009;20(Abstract Suppl):990A.

* de Brito-Ashurst I, Perry L, Sanders TA, Thomas JE, Dobbie H, Varagunam $M$, et al. The role of salt intake and salt sensitivity in the management of hypertension in South Asian people with chronic kidney disease: a randomised controlled trial. Heart 2013;99(17):1256-60. [MEDLINE: 23766446]

de Brito-Ashurst I, Perry L, Sanders TA, Thomas JE, Dobbie H, Yaqoob MM. A dietitian's role in the management of blood pressure: results of a randomised controlled trial in British Bangladeshi chronic kidney disease patients [abstract no: PP077-MON]. Clinical Nutrition Supplements 2012;7(1):168-9. [EMBASE: 70903810]

de Vries 2016 \{published data only (unpublished sought but not used)\}

de Vries LV, Dobrowolski LC, Krediet CTP, Bemelman FJ, Bakker SJ, Navis G. Effect of dietary sodium restriction on blood pressure and urinary protein excretion in renal transplant recipients on RAAS-blockade [abstract no: FR-P01030]. Journal of the American Society of Nephrology 2015;26(Abstract Suppl):605a.

* de Vries LV, Dobrowolski LC, van den Bosch JJ, Riphagen IJ, Krediet CT, Bemelman FJ, et al. Effects of dietary sodium restriction in kidney transplant recipients treated with renin-angiotensin-aldosterone system blockade: a randomized clinical trial. American Journal of Kidney Diseases 2016;67(6):936-44. [MEDLINE: 26803690]

\section{Doulton 2007 \{published data only\}}

* Doulton TW, Cassidy A, Wood M, Markandu ND, MacGregor GA. Reducing salt intake by 5 grams a day decreases thirst, interdialytic weight gain and blood pressure in haemodialysis patients [abstract]. In: Renal Association Annual Conference; 2007; Brighton, UK. 2007:152.

DUAAAL 2011 \{published and unpublished data\}50137410

Humalda JK, Lambers Heerspink HJ, Kwakernaak AJ, Slagman MC, Waanders F, Vervloet MG, et al. Fibroblast growth factor 23 and the antiproteinuric response to dietary sodium restriction during renin-angiotensin-aldosterone system blockade. American Journal of Kidney Diseases 2015;65(2):259-66. [MEDLINE: 25278093]

Kwakernaak AJ, Lambert G, Slagman MC, Waanders F, Laverman GD, Petrides F, et al. Proprotein convertase subtilisinkexin type 9 is elevated in proteinuric subjects: relationship 
with lipoprotein response to antiproteinuric treatment. Atherosclerosis 2013;226(2):459-65. [MEDLINE: 23261172]

Kwakernaak AJ, Waanders F, Slagman MC, Dokter MM, Laverman GD, de Boer RA, et al. Sodium restriction on top of renin-angiotensin-aldosterone system blockade increases circulating levels of $\mathrm{N}$-acetyl-seryl-aspartyl-lysyl-proline in chronic kidney disease patients. Journal of Hypertension 2013;31(12):2425-32. [MEDLINE: 24029871]

* Slagman MC, Waanders F, Hemmelder MH, Woittiez AJ, Janssen WM, Lambers Heerspink HJ, et al. Moderate dietary sodium restriction added to angiotensin converting enzyme inhibition compared with dual blockade in lowering proteinuria and blood pressure: randomised controlled trial. $B M J$ 2011;343:d4366. [MEDLINE: 21791491]

\section{ESMO 2017 \{published and unpublished data\}}

* Meuleman Y, Hoekstra T, Dekker FW, Navis G, Vogt L, van der Boog PJ, et al. Sodium restriction in patients with CKD: a randomized controlled trial of self-management support. American Journal of Kidney Diseases 2017;69(5):576-86. [MEDLINE: 27993433]

\section{ESPECIAL 2014 \{published and unpublished data\}}

Ahn SY, Kim DK, Han SS, Park JH, Choi B, Lim CS, et al. Weight loss has an additive effect on the anti-proteinuric effects of angiotensin II receptor blockers in hypertensive patients with CKD [abstract no: FR-P0502]. Journal of the American Society of Nephrology 2017;28(Abstract Suppl):531. [EMBASE: 633703439]

Ahn SY, Kim DK, Han SS, Park JH, Shin SJ, Lee SH, et al. Weight loss has an additive effect on the proteinuria reduction of angiotensin II receptor blockers in hypertensive patients with chronic kidney disease. Kidney Research \& Clinical Practice 2018;37(1):49-58. [MEDLINE: 29629277]

Ahn SY, Kim DK, Park JH, Shin SJ, Lee SH, Choi BS, et al. Long-term effects of intensive low-salt diet education on deterioration of glomerular filtration rate among non-diabetic hypertensive patients with chronic kidney disease. Kidney \& Blood Pressure Research 2019;44(5):1101-14. [MEDLINE: 31533093]

An JN, Hwang JH, Lee JP, Chin HJ, Kim S, Kim DK, et al. The decrement of hemoglobin concentration with angiotensin II receptor blocker treatment Is correlated with the reduction of albuminuria in non-diabetic hypertensive patients: posthoc analysis of ESPECIAL trial. PLOS ONE [Electronic Resource] 2015;10(6):e0128632. [MEDLINE: 26098847]

Baek SH, Kim S, Kim DK, Park JH, Shin SJ, Lee SH, et al. A low-salt diet increases the estimated net endogenous acid production in nondiabetic chronic kidney disease patients treated with angiotensin receptor blockade. Nephron 2014;128(3-4):407-13. [MEDLINE: 25531146]

ESPECIAL study investigators. Individual participant data urinary albumin (as supplied 30 May 2019). Data on file.

Han SS, Bae E, Ahn SY, Kim S, Park JH, Shin SJ, et al. Urinary adiponectin and albuminuria in non-diabetic hypertensive patients: an analysis of the ESPECIAL trial. BMC Nephrology 2015;16:123. [MEDLINE: 26232133]

* Hwang JH, Chin HJ, Kim S, Kim DK, Kim S, Park JH, et al. Effects of intensive low-salt diet education on albuminuria among nondiabetic patients with hypertension treated with olmesartan: a single-blinded randomized, controlled trial. Clinical Journal of the American Society of Nephrology: CJASN 2014;9(12):2059-69. [MEDLINE: 25332317]

Lee A, Chin HJ. Long term effects of intensive low salt diet education on deterioration of glomerular filtration rate among non-diabetic hypertensive patients with CKD [abstract no: FR-P0389]. Journal of the American Society of Nephrology 2017;28(Abstract Suppl):501. [EMBASE: 633700111]

Lim CS, Hwang JH, Chin HJ, Kim DK, Kim S, Park JH, et al. Effects of low sodium intake on the antiproteinuric efficacy of olmesartan in hypertensive patients with albuminuria (ESPECIAL): a randomized clinical trial [abstract no: MP146]. Nephrology Dialysis Transplantation 2014;29(Suppl 3):iii376. [EMBASE: 71492549]

Lim CS, Hwang JH, Chin HJ, Kim S, Choi BS. Effects of low sodium intake on the anti-proteinuric efficacy of olmesartan in hypertensive patients with albuminuria [abstract no: SA-PO155]. Journal of the American Society of Nephrology 2013;24(Abstract Suppl):659A.

Yu MY, Kim DK, Park JH, Shin SJ, Lee SH, Choi BS, et al. Albuminuria during treatment with angiotensin type II receptor blocker is a predictor for GFR decline among non-diabetic hypertensive CKD patients. PLOS ONE [Electronic Resource] 2018;13(8):e0202676. [MEDLINE: 30148871]

\section{Fine 1997 \{published data only\}}

* Fine A, Fontaine B, Ma M. Commonly prescribed salt intake in continuous ambulatory peritoneal dialysis patients is too restrictive: results of a double-blind crossover study. Journal of the American Society of Nephrology 1997;8(8):1311-4. [MEDLINE: 9259359]

Fine A. CAPD patients can take more salt in diet than usually prescribed [abstract]. Nephrology Dialysis Transplantation 1997;12(9):A183. [CENTRAL: CN-00261430]

Keven 2006 \{published and unpublished data\}

* Keven K, Yalcin S, Canbakan B, Kutlay S, Sengul S, Erturk S, et al. The impact of daily sodium intake on posttransplant hypertension in kidney allograft recipients. Transplantation Proceedings 2006;38(5):1323-6. [MEDLINE: 16797292]

Konishi 2001 \{published and unpublished data\}

Konishi Y, Imanishi M, Morikawa T, Teramoto K, Okada N, Okumura M, et al. Relationship of impairment of the reninangiotensin system and sodium sensitivity of blood pressure in immunoglobulin A (IgA) nephropathy [abstract no: FC2-04]. Nephrology 2003;8(Suppl 1):A16. [CENTRAL: CN-01657789]

Konishi Y, Morikawa T, Yasu T, Teramoto K, Okada N, Yoshioka K, et al. Blunted response of the renin-angiotensin system and nitric oxide synthesis related to sodium sensitivity in 
immunoglobulin A nephropathy. Hypertension Research Clinical \& Experimental 2004;27(1):7-13. [MEDLINE: 15055250]

Konishi Y, Nishiyama A, Morikawa T, Kitabayashi C, Shibata M, Hamada M, et al. Relationship between urinary angiotensinogen and salt sensitivity of blood pressure in patients with IgA nephropathy. Hypertension 2011;58(2):205-11. [MEDLINE: 21670416]

* Konishi Y, Okada N, Okamura M, Morikawa T, Okumura M, Yoshioka K, et al. Sodium sensitivity of blood pressure appearing before hypertension and related to histological damage in immunoglobulin A nephropathy. Hypertension 2001;38(1):81-5. [MEDLINE: 11463764]

\section{Kwakernaak 2014 \{published data only\}}

Binnenmars SH, Corpeleijn E, Kwakernaak AJ, Touw DJ, Kema IP, Laverman GD, et al. Impact of moderate sodium restriction and hydrochlorothiazide on iodine excretion in diabetic kidney disease: data from a randomized cross-over trial. Nutrients 2019;11(9):2204. [MEDLINE: 31547438]

Humalda JK, Keyzer CA, Binnenmars SH, Kwakernaak AJ, Slagman MC, Laverman GD, et al. Concordance of dietary sodium intake and concomitant phosphate load: Implications for sodium interventions. Nutrition Metabolism \& Cardiovascular Diseases 2016;26(8):689-96. [MEDLINE: 27266988]

Humalda JK, Seiler-Muler S, Kwakernaak AJ, Vervloet MG, Navis G, Fliser D, et al. Response of fibroblast growth factor 23 to volume interventions in arterial hypertension and diabetic nephropathy. Medicine 2016;95(46):e5003. [MEDLINE: 27861335]

Humalda JK, Seiler S, Kwakernaak AJ, Vervloet MG, Navis G, Heine $\mathrm{GH}$, et al. Response of fibroblast growth factor 23 to sodium interventions in diabetic nephropathy and arterial hypertension [abstract no: PUB535]. Journal of the American Society of Nephrology 2015;26(Abstract Suppl):1012A.

* Kwakernaak AJ, Krikken JA, Binnenmars SH, Visser FW, Hemmelder $\mathrm{MH}$, Woittiez AJ, et al. Effects of sodium restriction and hydrochlorothiazide on RAAS blockade efficacy in diabetic nephropathy: a randomised clinical trial. Lancet Diabetes \& Endocrinology 2014;2(5):385-95. [MEDLINE: 24795252]

LowSALT CKD 2012 \{published and unpublished data\}

Campbell KL, Johnson DW, Bauer JD, Hawley CM, Isbel NM, Stowasser $\mathrm{M}$, et al. A randomized trial of sodium-restriction on kidney function, fluid volume and adipokines in CKD patients. BMC Nephrology 2014;15(1):57. [MEDLINE: 24708818]

LowSALT CKD study Investigators. Individual patient data (as supplied 24 May 2019). Data on file.

McMahon E, Bauer J, Hawley C, Isbel N, Stowasser M, Johnson D, et al. Effect of sodium restriction on blood pressure, fluid status and proteinuria in CKD patients: results of a randomised crossover trial and 6-month follow-up [abstract no: 004]. Nephrology 2013;18(Suppl 1):15-6. [CENTRAL: CN-01062204] [EMBASE: 71356987]

* McMahon EJ, Bauer JD, Hawley CM, Isbel NM, Stowasser M, Johnson DW, et al. A randomized trial of dietary sodium restriction in CKD. Journal of the American Society of Nephrology 2013;24(12):2096-103. [MEDLINE: 24204003]

McMahon EJ, Bauer JD, Hawley CM, Isbel NM, Stowasser M, Johnson DW, et al. The effect of lowering salt intake on ambulatory blood pressure to reduce cardiovascular risk in chronic kidney disease (LowSALT CKD study): protocol of a randomized trial. BMC Nephrology 2012;13(1):137. [MEDLINE: 23082956]

\section{Mulhauser 1996 \{published data only\}}

* Mulhauser I, Prange K, Sawicki PT, Bender R, Dworschak A, Schaden W, et al. Effects of dietary sodium on blood pressure in IDDM patients with nephropathy. Diabetologia 1996;39(2):212-9. [MEDLINE: 8635674]

Power 2010 \{published data only (unpublished sought but not used)\}

Power AJ, Singh S, Edwards C, Tandaric D, Taube D, Duncan ND. A randomized controlled trial of low dialysate and dietary sodium on blood pressure in hemodialysis [abstract no: F-FC320]. Journal of the American Society of Nephrology 2010;21(Abstract Suppl):73A.

Rodrigues Telini 2014 \{published data only (unpublished sought but not used)\}

Rodrigues Telini LS, de Carvalho BG, Caramori JC, Castro JH, Martin LC, Barretti P. Effect of dietary sodium restriction on body water, blood pressure, and inflammation in hemodialysis patients: a prospective randomized controlled study. International Urology \& Nephrology 2014;46(1):91-7. [MEDLINE: 23340794]

\section{Ruilope 1992a \{published data only\}}

Ruilope LM, Casal MC, Guerrero L, Alcázar JM, Férnandez ML, Lahera $V$, et al. Sodium intake does not influence the effect of verapamil in hypertensive patients with mild renal insufficiency. Drugs 1992;44 Suppl 1:94-8. [MEDLINE: 1283591]

\section{Saran 2017 \{published data only (unpublished sought but not} used)\}

* Saran R, Padilla RL, Gillespie BW, Heung M, Hummel SL, Derebail VK, et al. A randomized crossover trial of dietary sodium restriction in stage 3-4 CKD. Clinical Journal of the American Society of Nephrology: CJASN 2017;12(3):399-407. [MEDLINE: 28209636]

Saran R, Sands RL, Gillespie BW, Heung M, Hummel SL, Derebail VK, et al. A crossover trial of lowering dietary sodium $(\mathrm{Na})$ in chronic kidney disease (CKD) [abstract no: FR-OR118]. Journal of the American Society of Nephrology 2012;23(Abstract Suppl):56A.

Saran R, Sands RL, Gillespie BW, Heung M, Hummel SL, Derebail VK, et al. Baseline observations from a randomized crossover trial of lowering sodium intake in chronic kidney disease (CKD)-LOSALT study [abstract no: TH-PO357]. Journal of the American Society of Nephrology 2011;22(Abstract Suppl):195A. 
ViRTUE-CKD 2016 \{published and unpublished data\}

De Borst MH, Keyzer CA, van Breda F, Vervloet MG, Laverman GD, Hemmelder $\mathrm{MH}$, et al. Vitamin D receptor activation and dietary sodium restriction to reduce residual albuminuria in chronic kidney disease [abstract no: SA-PO1106]. Journal of the American Society of Nephrology 2015;26(Abstract Suppl):B7.

de Jong MA, Keyzer CA, van Breda F, Vervloet MG, Laverman GD, Hemmelder $\mathrm{MH}$, et al. Baseline 25-hydroxyvitamin D level and the anti-albuminuric response to vitamin $D$ receptor activation in patients with chronic kidney disease [abstract no: TH-PO515]. Journal of the American Society of Nephrology 2016;27(Abstract Suppl):210A-1A.

de Jong MA, Keyzer CA, van Breda F, Vervloet MG, Navis G, Bakker SJ, et al. Effect of vitamin $D$ receptor activation and sodium restriction on calcification propensity and fibroblast growth factor 23: the Virtue-CKD trial [abstract no: TH-PO516]. Journal of the American Society of Nephrology 2016;27(Abstract Suppl):211A.

Keyzer CA, de Jong MA, van Breda GF, Vervloet MG, Laverman GD, Hemmelder M, et al. Vitamin D receptor activator and dietary sodium restriction to reduce residual urinary albumin excretion in chronic kidney disease (ViRTUE study): rationale and study protocol. Nephrology Dialysis Transplantation 2016;31(7):1081-7. [MEDLINE: 25744274]

* Keyzer CA, van Breda GF, Vervloet MG, de Jong MA, Laverman GD, Hemmelder MH, et al. Effects of vitamin D receptor activation and dietary sodium restriction on residual albuminuria in CKD: the ViRTUE-CKD trial. Journal of the American Society of Nephrology 2016;28(4):1296-305. [MEDLINE: 27856633]

\section{Vogt 2008 \{published and unpublished data\}}

Gant CM, Laverman GD, Vogt L, Slagman MC, Heerspink HJ, Waanders F, et al. Renoprotective RAAS inhibition does not affect the association between worse renal function and higher plasma aldosterone levels. BMC Nephrology 2017;18(1):370. [MEDLINE: 29262813]

Krikken JA, Waanders F, Dallinga-Thie GM, Dikkeschei LD, Vogt L, Navis GJ, et al. Antiproteinuric therapy decreases LDL-cholesterol as well as HDL-cholesterol in non-diabetic proteinuric patients: relationships with cholesteryl ester transfer protein mass and adiponectin. Expert Opinion on Therapeutic Targets 2009;13(5):497-504. [MEDLINE: 19397474]

Mahmoodi BK, Mulder AB, Waanders F, Spronk HM, Mulder R, Slagman MC, et al. The impact of antiproteinuric therapy on the prothrombotic state in patients with overt proteinuria. Journal of Thrombosis \& Haemostasis 2011;9(12):2416-23. [MEDLINE: 21972946]

Slagman MC, Kwakernaak AJ, Yazdani S, Laverman GD, van den Born J, Titze J, et al. Vascular endothelial growth factor $C$ levels are modulated by dietary salt intake in proteinuric chronic kidney disease patients and in healthy subjects. Nephrology Dialysis Transplantation 2012;27(3):978-82. [MEDLINE: 21778278]
Slagman MC, Nguyen TQ, Waanders F, Vogt L, Hemmelder MH, Laverman GD, et al. Effects of antiproteinuric intervention on elevated connective tissue growth factor (CTGF/CCN-2) plasma and urine levels in nondiabetic nephropathy. Clinical Journal of the American Society of Nephrology: CJASN 2011;6(8):1845-50. [MEDLINE: 21784839]

Slagman MC, Sinkeler SJ, Hemmelder MH, Waanders F, Vogt L, Kluin-Nelemans HC, et al. Erythropoietin is reduced by combination of diuretic therapy and RAAS blockade in proteinuric renal patients with preserved renal function. Nephrology Dialysis Transplantation 2010;25(10):3256-60. [MEDLINE: 20339099]

Slagman MC, Waanders F, Vogt L, Damman K, Hemmelder M, Navis $\mathrm{G}$, et al. Elevated $\mathrm{N}$-terminal pro-brain natriuretic peptide levels predict an enhanced anti-hypertensive and antiproteinuric benefit of dietary sodium restriction and diuretics, but not angiotensin receptor blockade, in proteinuric renal patients. Nephrology Dialysis Transplantation 2012;27(3):983-90. [MEDLINE: 21862455]

Vogt L, de Zeeuw D, Waanders F, Navis G. Independent and added effects of low sodium and diuretic on renoprotective effect of All antagonist in non-diabetic proteinuric patients [abstract no: TH-FC171]. Journal of the American Society of Nephrology 2005;16:37A. [CENTRAL: CN-00644129]

* Vogt L, Waanders F, Boomsma F, de Zeeuw D, Navis G. Effects of dietary sodium and hydrochlorothiazide on the antiproteinuric efficacy of losartan. Journal of the American Society of Nephrology 2008;19(5):999-1007. [MEDLINE: 18272844]

Waanders F, Vaidya VS, van Goor H, Leuvenink H, Damman K, Hamming I, et al. Effect of renin-angiotensin-aldosterone system inhibition, dietary sodium restriction, and/or diuretics on urinary kidney injury molecule 1 excretion in nondiabetic proteinuric kidney disease: a post hoc analysis of a randomized controlled trial. American Journal of Kidney Diseases 2009;53(1):16-25. [MEDLINE: 18823687]

\section{References to studies excluded from this review}

\section{Chanwikrai 2012 \{published data only\}}

Chanwikrai Y, Satirapod B. A randomized controlled trial of dietary and lifestyle modification based on the empowerment approach among chronic kidney disease patients [abstract no: 311]. Kidney Research \& Clinical Practice 2012;31(2):A95-6. [EMBASE: 70815020]

\section{Clark-Cutaia 2016 \{published data only\}}

Clark-Cutaia MN, Reisinger N, Anache MR, Ramos K, Sommers MS, Townsend RR, et al. Feasibility of assessing sodium-associated body fluid composition in end-stage renal disease. Nursing Research 2019;68(3):246-52. [MEDLINE: 31033867]

Clark-Cutaia MN, Sommers MS, Anderson E, Townsend RR. Design of a randomized controlled clinical trial assessing dietary sodium restriction and hemodialysis-related symptom 
profiles. Contemporary Clinical Trials Communications 2016;3:70-3. [MEDLINE: 27822564]

\section{DD 2017 \{published data only\}}

Bovee DM, Danser AH, Zietse R, Hoorn EJ. Dietary sodium restriction versus diuretics for salt-sensitive hypertension in chronic kidney disease [abstract no: 053]. Hypertension 2018;72(Suppl 1). [EMBASE: 626089737]

Bovee DM, Danser AH, Zietse R, Hoorn EJ. Dietary sodium restriction versus diuretics for salt-sensitive hypertension in CKD [abstract no: TH-OR052]. Journal of the American Society of Nephrology 2017;28(Abstract Suppl):14. [EMBASE: 633699948]

Bovee DM, Visser WJ, Middel I, De Mik-van EA, Greupink R, Masereeuw $\mathrm{R}$, et al. A randomized trial of distal diuretics versus dietary sodium restriction for hypertension in chronic kidney disease. Journal of the American Society of Nephrology 2020;31(3):650-62. [MEDLINE: 31996411]

\section{De Nicola 2000 \{published data only\}}

De Nicola L, Bellizzi V, Minutolo R, Cioffi M, Giannattasio P, Terracciano V, et al. Effect of dialysate sodium concentration on interdialytic increase of potassium. Journal of the American Society of Nephrology 2000;11(12):2337-43. [MEDLINE: 11095656]

\section{Esnault 2005 \{published data only\}}

Ekhlas Eid A, Nguyen J, Delcroix C, Moutel M, Esnault VL. Effect of diuretics after dual blockade of renin-angiotensinaldosterone system on severe proteinuria [abstract]. In: 41st Congress. European Renal Association. European Dialysis and Transplantation Association; 2004 May 15-18; Lisbon, Portugal. 2004:434-5. [CENTRAL: CN-00509172]

Esnault VL, Ekhlas A, Delcroix C, Moutel MG, Nguyen JM. Diuretic and enhanced sodium restriction results in improved antiproteinuric response to RAS blocking agents. Journal of the American Society of Nephrology 2005;16(2):474-81. [MEDLINE: 15615822]

Esnault VL, Ekhlas A, Nguyen JM, Delcroix C, Moutel MG. Angiotensin converting enzyme inhibitors (ACEI), angiotensin receptor blockers (ARB) and diuretics for refractory proteinuria [abstract no: SU-PO1030]. Journal of the American Society of Nephrology 2003;14(Nov):762A. [CENTRAL: CN-00583888]

\section{HHK 2018 \{published data only\}}

Sevick MA, Woolf K, Mattoo A, Katz SD, Li H, St-Jules DE, et al. The Healthy Hearts and Kidneys (HHK) study: Design of a $2 \times 2$ RCT of technology-supported self-monitoring and social cognitive theory-based counseling to engage overweight people with diabetes and chronic kidney disease in multiple lifestyle changes. Contemporary Clinical Trials 2018;64:265-73. [MEDLINE: 28867396]

\section{Imanishi 1997 \{published data only\}}

Imanishi M, Yoshioka K, Okumura M, Konishi Y, Tanaka S, Fujii S, et al. Mechanism of decreased albuminuria caused by angiotensin converting enzyme inhibitor in early diabetic nephropathy. Kidney International - Supplement 1997;51(63):S198-200. [MEDLINE: 9407458]

\section{Kauric-Klein 2012 \{published data only\}}

Kauric-Klein Z, Peters RM, Yarandi HN. Self-efficacy and blood pressure self-care behaviors in patients on chronic hemodialysis. Western Journal of Nursing Research 2017;39(7):886-905. [MEDLINE: 27456461]

Kauric-Klein Z. Blood pressure knowledge in hypertensive hemodialysis patients. Cannt Journal 2012;22(4):18-25. [MEDLINE: 23413535]

Kauric-Klein Z. Improving blood pressure control in end stage renal disease through a supportive educative nursing intervention. Nephrology Nursing Journal 2012;39(3):217-28. [MEDLINE: 22866361]

\section{Li 2013f $\{$ published data only\}}

Jardine A, Li NY, Ninomiya T, Feng X, Zhang J, Shi J, et al. A sustained dietary sodium reduction program reduces albuminuria: a large cluster randomised trial [abstract no: SA-OR079]. Journal of the American Society of Nephrology 2014;25(Abstract Suppl):99a.

Jardine MJ, Li N, Ninomiya T, Feng X, Zhang J, Shi J, et al. Dietary sodium reduction reduces albuminuria: a cluster randomized trial. Journal of Renal Nutrition 2019;29(4):276-84. [MEDLINE: 30591358]

Li N, Yan LL, Niu W, Labarthe D, Feng X, Shi J, et al. A large-scale cluster randomized trial to determine the effects of communitybased dietary sodium reduction--the China Rural Health Initiative Sodium Reduction Study. American Heart Journal 2013;166(5):815-22. [MEDLINE: 24176436]

\section{Reyes 2013 \{published data only\}}

Cuff L, Padilla RL, Verma TP, Gillespie BW, Peterman D, Heung M, et al. Barriers to dietary sodium restrictions among patients on hemodialysis [abstract no: SA-P0961]. Journal of the American Society of Nephrology 2014;25(Abstract Suppl):862A.

Rao PS, Padilla RL, Cuff L, Verma TP, Peterman D, Heung M, et al. Salt taste sensitivity, sodium intake, and fluid status in hemodialysis [abstract no: TH-PO804]. Journal of the American Society of Nephrology 2015;26(Abstract Suppl):275a.

Reyes J, Williams CM, Raimann JG, Sheppard PF, Thijssen S, Levin NW, et al. Association of dietary sodium restriction and thirst in hemodialysis patients [abstract no: FR-PO447]. Journal of the American Society of Nephrology 2013;24(Abstract Suppl):468A.

\section{Suckling 2016 \{published data only\}}

Suckling R, He F, Markandu N, MacGregor G. Modest salt reduction in impaired glucose tolerance and type 2 diabetes lowers blood pressure and urinary albumin excretion [abstract no: Su139]. NDT Plus 2010;3(Suppl 3):iii349. [EMBASE: 70484357]

Suckling R, He F, Markandu N, MacGregor G. Modest salt reduction lowers blood pressure and urinary albumin excretion in impaired glucose tolerance and type 2 diabetes [abstract no: SA.01]. Journal of Hypertension 2010;28(Suppl A):e219. [EMBASE: 70214893] 
Suckling RJ, He F, Markandu N, MacGregor G. Modest reduction in salt intake lowers blood pressure and urinary albumin excretion in individuals with impaired glucose tolerance and type II diabetes [abstract no: PE.02]. Journal of Human Hypertension 2010;24(10):708. [EMBASE: 70273931]

Suckling RJ, He FJ, Markandu ND, MacGregor GA. Modest salt reduction lowers blood pressure and albumin excretion in impaired glucose tolerance and type 2 diabetes mellitus: a randomized double-blind trial. Hypertension 2016;67(6):1189-95. [MEDLINE: 27160199]

\section{References to ongoing studies}

NCT03373500 \{published data only\}

Swift P. Effect of dietary salt reduction on blood pressure in kidney transplant recipients. clinicaltrials.gov/show/ nct03373500 (first received 14 December 2017).

\section{OxCKD1 2012 \{published data only\}}

O'Callaghan CA. OxCKD1 - Empowering healthy lifestyle choices in chronic kidney disease (OxCKD1). clinicaltrials.gov/show/ nct01552317 (first received 13 March 2012).

STICK 2015 \{published data only\}

O'Donnell MJ, Smyth A. Sodium Intake in Chronic Kidney Disease (STICK). clinicaltrials gov/ct2/show/NCT02458248 (first received 1 Jun 2015).

\section{SUBLIME 2020 \{published data only\}}

Humalda JK, Klaassen G, De Vries H, Meuleman Y, Laverman GD, Bos WJ, et al. The 'sublime' approach: Cost-efficacy of a novel self-management approach for dietary sodium restriction in CKD patients [abstract no: SP351]. Nephrology Dialysis Transplantation 2016;31(Suppl 1):i206-7. [EMBASE: 72326453]

Humalda JK, Klaassen G, de Vries H, Meuleman Y, Verschuur LC, Straathof EJ, et al. A self-management approach for dietary sodium restriction in patients with CKD: a randomized controlled trial. American Journal of Kidney Diseases 2020;75(6):847-56. [MEDLINE: 31955921]

\section{SUPER 2016 \{published data only\}}

Mills KT. Sodium Lowering and Urinary Protein Reduction Trial (SUPER) [Effect of dietary sodium reduction in kidney disease patients with albuminuria]. clinicaltrials.gov/ct2/show/ NCT02945969 (first received 26 October 2016).

\section{Additional references}

\section{Aburto 2013}

Aburto NJ, Ziolkovska A, Hooper L, Elliott P, Cappuccio FP, Meerpohl JJ. Effect of lower sodium intake on health: systematic review and meta-analyses. BMJ 2013;346:f1326. [MEDLINE: 23558163]

\section{Allen 1997}

Allen TJ, Waldron MJ, Casley D, Jerums G, Cooper ME. Salt restriction reduces hyperfiltration, renal enlargement, and albuminuria in experimental diabetes. Diabetes 1997;46(1):19-24. [MEDLINE: 8971091]

\section{Al-Solaiman 2009}

Al-Solaiman Y, Jesri A, Zhao Y, Morrow JD, Egan BM. LowSodium DASH reduces oxidative stress and improves vascular function in salt-sensitive humans. Journal of Human Hypertension 2009;23(12):826-35. [MEDLINE: 19404315]

\section{Ang 1999}

Ang KS, Benarbia S, Boulahrouz R, Stanescu C, Charasse C, Le Cacheux P, et al. Arterial hypertension in the hemodialysis patient. A model of salt-sensitive hypertension in man [L'hypertension arterielle du patient hemodialyse. Un modele d'hypertension sensible au sel chez l'homme]. Archives des Maladies du Coeur et des Vaisseaux 1999;92(8):1023-6. [MEDLINE: 10486658]

\section{Bakris 2000}

Bakris GL, Williams M, Dworkin L, Elliott WJ, Epstein M, Toto R, et al. Preserving renal function in adults with hypertension and diabetes: a consensus approach. National Kidney Foundation Hypertension and Diabetes Executive Committees Working Group. American Journal of Kidney Diseases 2000;36(3):646-61. [MEDLINE: 10977801]

\section{Bland 1996}

Bland JM, Altman DG. The use of transformation when comparing two means. BMJ 1996;312(7039):1153. [MEDLINE: 8620137]

\section{Cole 2019}

Cole NI, Swift PA, He FJ, MacGregor GA, Suckling RJ. The effect of dietary salt on blood pressure in individuals receiving chronic dialysis: a systematic review and meta-analysis of randomised controlled trials. Journal of Human Hypertension 2019;33(4):319-26. [MEDLINE: 30413764]

\section{Elliot 2006}

Elliot P, Brown I. Sodium intakes around the world: background document prepared for the forum and technical meeting on reducing salt intake in populations (Paris 5-7th October 2006). Geneva: WHO Press, 2006. [ISBN: 978924159593 5]

\section{Essig 2008}

Essig M, Escoubet B, de Zuttere D, Blanchet F, Arnoult F, Dupuis E, et al. Cardiovascular remodelling and extracellular fluid excess in early stages of chronic kidney disease. Nephrology Dialysis Transplantation 2008;23(1):239-48. [MEDLINE: 17704109]

\section{Garofalo 2018}

Garofalo C, Borrelli S, Provenzano M, De Stefano T, Vita C, Chiodini $\mathrm{P}$, et al. Dietary salt restriction in chronic kidney disease: a meta-analysis of randomized clinical trials. Nutrients 2018;10(6):732. [MEDLINE: 29882800]

\section{GBD 2019}

Institute for Health Metrics and Evaluation (IHME). GBD Compare. Seattle, WA: IHME, University of Washington. 2019. www.vizhub.healthdata.org/gbd-compare (Accessed 8 May 2021). 


\section{Go 2004}

Go AS, Chertow GM, Fan D, McCulloch CE, Hsu CY. Chronic kidney disease and the risks of death, cardiovascular events, and hospitalization [Erratum in: N Engl J Med. 2008;18(4):4]. New England Journal of Medicine 2004;351(13):1296-305. [MEDLINE: 15385656]

\section{GRADE 2008}

Guyatt GH, Oxman AD, Vist GE, Kunz R, Falck-Ytter Y, AlonsoCoello $P$, et al. GRADE: an emerging consensus on rating quality of evidence and strength of recommendations. BMJ 2008;336(7650):924-6. [MEDLINE: 18436948]

\section{GRADE 2011}

Guyatt G, Oxman AD, Akl EA, Kunz R, Vist G, Brozek J, et al. GRADE guidelines: 1. Introduction-GRADE evidence profiles and summary of findings tables. Journal of Clinical Epidemiology 2011;64(4):383-94. [MEDLINE: 21195583]

\section{Graudal 2020}

Graudal NA, Hubeck-Graudal T, Jurgens G. Effects of low sodium diet versus high sodium diet on blood pressure, renin, aldosterone, catecholamines, cholesterol, and triglyceride. Cochrane Database of Systematic Reviews 2020, Issue 12. Art. No: CD004022. [DOI: 10.1002/14651858.CD004022.pub5]

\section{Guerin 2001}

Guerin AP, Blacher J, Pannier B, Marchais SJ, Safar ME, London GM. Impact of aortic stiffness attenuation on survival of patients in end-stage renal failure. Circulation 2001;103(7):987-92. [MEDLINE: 11181474]

\section{He 2003}

He FJ, MacGregor GA. How far should salt intake be reduced? Hypertension 2003;42(6):1093-9. [MEDLINE: 14610100]

\section{He 2013}

He FJ, Li J, MacGregor GA. Effect of longer-term modest salt reduction on blood pressure. Cochrane Database of Systematic Reviews 2013, Issue 4. Art. No: CD004937. [DOI: 10.1002/14651858.CD004937.pub2]

\section{Hernandez 2018}

Hernandez AV, Emonds EE, Chen BA, Loayza JA, Pasupuleti V, Roman-Morillo YM, et al. Systematic review and meta-analysis of the effects of low sodium salt substitutes on cardiovascular outcomes [abstract]. Journal of the American College of Cardiology 2018;71(11):A1749. [EMBASE: 621787030]

\section{Higgins 2003}

Higgins JP, Thompson SG, Deeks JJ, Altman DG. Measuring inconsistency in meta-analyses. BMJ 2003;327(7414):557-60. [MEDLINE: 12958120]

\section{Higgins 2008}

Higgins JP, White IR, Anzures-Cabrera J. Meta-analysis of skewed data: combining results reported on log-transformed or raw scales. Statistics in Medicine 2008;27(29):6072-92. [MEDLINE: 18800342]

\section{Higgins 2011}

Higgins JP, Green S (editors). Cochrane Handbook for Systematic Reviews of Interventions Version 5.1.0 (updated March 2011). The Cochrane Collaboration, 2011. Available from www.cochrane-handbook.org.

\section{Hooper 2002}

Hooper L, Bartlett C, Davey Smith G, Ebrahim S. Systematic review of long term effects of advice to reduce dietary salt in adults. BMJ 2002;325(7365):628. [MEDLINE: 12242173]

\section{Hunsicker 2004}

Hunsicker LG. The consequences and costs of chronic kidney disease before ESRD. Journal of the American Society of Nephrology 2004;15(5):1363-4. [MEDLINE: 15100382]

\section{Jones-Burton 2006}

Jones-Burton C, Mishra SI, Fink JC, Brown J, Gossa W, Bakris GK, et al. An in-depth review of the evidence linking dietary salt intake and progression of chronic kidney disease. American Journal of Nephrology 2006;26(3):268-75. [MEDLINE: 16763384]

\section{Kayikcioglu 2009}

Kayikcioglu M, Tumuklu M, Ozkahya M, Ozdogan O, Asci G, Duman S, et al. The benefit of salt restriction in the treatment of end-stage renal disease by haemodialysis. Nephrology Dialysis Transplantation 2009;24(3):956-62. [MEDLINE: 19004849]

\section{KDIGO 2013}

Levin A, Stevens PE, Bilous RW, Coresh J, De Francisco AL, De Jong PE, et al. Kidney disease: Improving global outcomes (KDIGO) CKD work group. KDIGO 2012 clinical practice guideline for the evaluation and management of chronic kidney disease. Kidney International Supplements 2013;3(1):1-150. [EMBASE: 369856107]

\section{Korhonen 2000}

Korhonen MH, Jarvinen RM, Sarkkinen ES, Uusitupa MI. Effects of a salt-restricted diet on the intake of other nutrients. American Journal of Clinical Nutrition 2000;72(2):414-20. [MEDLINE: 10919936]

\section{Law 2009}

Law MR, Morris JK, Wald NJ. Use of blood pressure lowering drugs in the prevention of cardiovascular disease: metaanalysis of 147 randomised trials in the context of expectations from prospective epidemiological studies. BMJ 2009;338:b1665. [MEDLINE: 19454737]

\section{Malta 2018}

Malta D, Petersen K S, Johnson C, Trieu K, Rae S, Jefferson K, et al. High sodium intake increases blood pressure and risk of kidney disease. From the Science of Salt: A regularly updated systematic review of salt and health outcomes (August 2016 to March 2017). Journal of Clinical Hypertension 2018;20(12):1654-65. [MEDLINE: 30402970]

\section{McMahon 2012a}

McMahon EJ, Campbell KL, Mudge D, Bauer JD. Achieving salt restriction in chronic kidney disease. International Journal of Nephrology 2012:720429. [MEDLINE: 23320173] 


\section{Mozaffarian 2014}

Mozaffarian D, Fahimi S, Singh GM, Micha R, Khatibzadeh S, Engell RE, et al. Global sodium consumption and death from cardiovascular causes. New England Journal of Medicine 2014;371(7):624-34. [MEDLINE: 25119608]

\section{Nerbass 2018}

Nerbass FB, Calice-Silva V, Pecoits-Filho R. Sodium intake and blood pressure in patients with chronic kidney disease: a salty relationship. Blood Purification 2018;45(1-3):166-72. [MEDLINE: 29478050]

\section{NKF 2002}

National Kidney Foundation. K/DOQI clinical practice guidelines for chronic kidney disease: evaluation, classification, and stratification. American Journal of Kidney Diseases 2002;39(2 Suppl 1):S1-266. [MEDLINE: 11904577]

\section{Osanai 2002}

Osanai T, Fujiwara N, Saitoh M, Sasaki S, Tomita H, Nakamura M, et al. Relationship between salt intake, nitric oxide and asymmetric dimethylarginine and its relevance to patients with end-stage renal disease. Blood Purification 2002;20(5):466-8. [MEDLINE: 12207094]

\section{Qian 2018}

Qian Q. Salt, water and nephron: mechanisms of action and link to hypertension and chronic kidney disease. Nephrology 2018;23 Suppl 4:44-9. [MEDLINE: 30298656]

\section{Ritz 2009}

Ritz E, Koleganova N, Piecha G. Role of sodium intake in the progression of chronic kidney disease. Journal of Renal Nutrition 2009;19(1):61-2. [MEDLINE: 19121773]

\section{Rupp 1978}

Rupp JW, Stone RA, Gunning BE. Sodium versus sodium fluid restriction in hemodialysis: control of weight gains and blood pressures. American Journal of Clinical Nutrition 1978;31(10):1952-5. [MEDLINE: 707354]

\section{Schunemann 2011a}

Schünemann HJ, Oxman AD, Higgins JP, Vist GE, Glasziou P, Guyatt GH. Chapter 11: Presenting results and 'Summary of findings' tables. In: Higgins JP, Green S (editors). Cochrane Handbook for Systematic Reviews of Interventions Version 5.1.0 [updated March 2011]. The Cochrane Collaboration, 2011. Available from www.cochrane-handbook.org.

\section{Schunemann 2011b}

Schünemann HJ, Oxman AD, Higgins JP, Deeks JJ, Glasziou P, Guyatt GH. Chapter 12: Interpreting results and drawing conclusions. In: Higgins JP, Green S (editors). Cochrane Handbook for Systematic Reviews of Interventions Version 5.1.0 [updated March 2011]. The Cochrane Collaboration, 2011. Available from www.cochrane-handbook.org.

\section{Siebenhofer 2016}

Siebenhofer A, Jeitler K, Berghold A, Horvath K, Posch N, Poggenberg $\mathrm{S}$, et al. Long-term effects of weight-reducing diets in people with hypertension. Cochrane Database of Systematic Reviews 2016, Issue 3. Art. No: CD008274. [DOI: 10.1002/14651858.CD008274.pub3]

\section{Suckling 2010}

Suckling RJ, He FJ, MacGregor GA. Altered dietary salt intake for preventing and treating diabetic kidney disease. Cochrane Database of Systematic Reviews 2010, Issue 12. Art. No: CD006763. [DOI: 10.1002/14651858.CD006763.pub2]

\section{Svetkey 1999}

Svetkey LP, Simons-Morton D, Vollmer WM, Appel LJ, Conlin PR, Ryan DH, et al. Effects of dietary patterns on blood pressure: subgroup analysis of the Dietary Approaches to Stop Hypertension (DASH) randomized clinical trial. Archives of Internal Medicine 1999;159(3):285-93. [MEDLINE: 9989541]

\section{Todd 2010}

Todd AS, Macginley RJ, Schollum JB, Johnson RJ, Williams SM, Sutherland WH, et al. Dietary salt loading impairs arterial vascular reactivity. American Journal of Clinical Nutrition 2010;91(3):557-64. [MEDLINE: 20107199]

\section{Trieu 2015}

Trieu K, Neal B, Hawkes C, Dunford E, Campbell N, RodriguezFernandez R, et al. Salt reduction initiatives around the world a systematic review of progress towards the global target. PLoS ONE [Electronic Resource] 2015;10(7):e0130247. [MEDLINE: 26201031]

\section{Verhave 2004}

Verhave JC, Hillege HL, Burgerhof JG, Janssen WM, Gansevoort RT, Navis GJ, et al. Sodium intake affects urinary albumin excretion especially in overweight subjects. Journal of Internal Medicine 2004;256(4):324-30. [MEDLINE: 15367175]

\section{WHO 2012}

World Health Organization. Guideline: sodium intake for adults and children. www.who.int/nutrition/publications/guidelines/ sodium_intake_printversion.pdf 2012.

\section{References to other published versions of this review McMahon 2012b}

McMahon EJ, Campbell KL, Bauer JD, Mudge DW. Altered dietary salt intake for chronic kidney disease. Cochrane Database of Systematic Reviews 2012, Issue 9. Art. No: CD010070. [DOI: 10.1002/14651858.CD010070]

\section{McMahon 2015}

McMahon EJ, Campbell KL, Bauer JD, Mudge DW. Altered dietary salt intake for people with chronic kidney disease. Cochrane Database of Systematic Reviews 2015, Issue 2. Art. No: CD010070. [DOI: 10.1002/14651858.CD010070.pub2]

* Indicates the major publication for the study 
CHARACTERISTICS OF STUDIES

Characteristics of included studies [ordered by study ID]

BalanceWise-HD 2013

\section{Study characteristics}

\begin{tabular}{|c|c|}
\hline Methods & $\begin{array}{l}\text { - Study design: parallel, open-label RCT } \\
\text { - Time frame: September } 2009 \text { to September } 2012 \\
\text { - Duration (weeks): total (32); interventions (16) }\end{array}$ \\
\hline Participants & 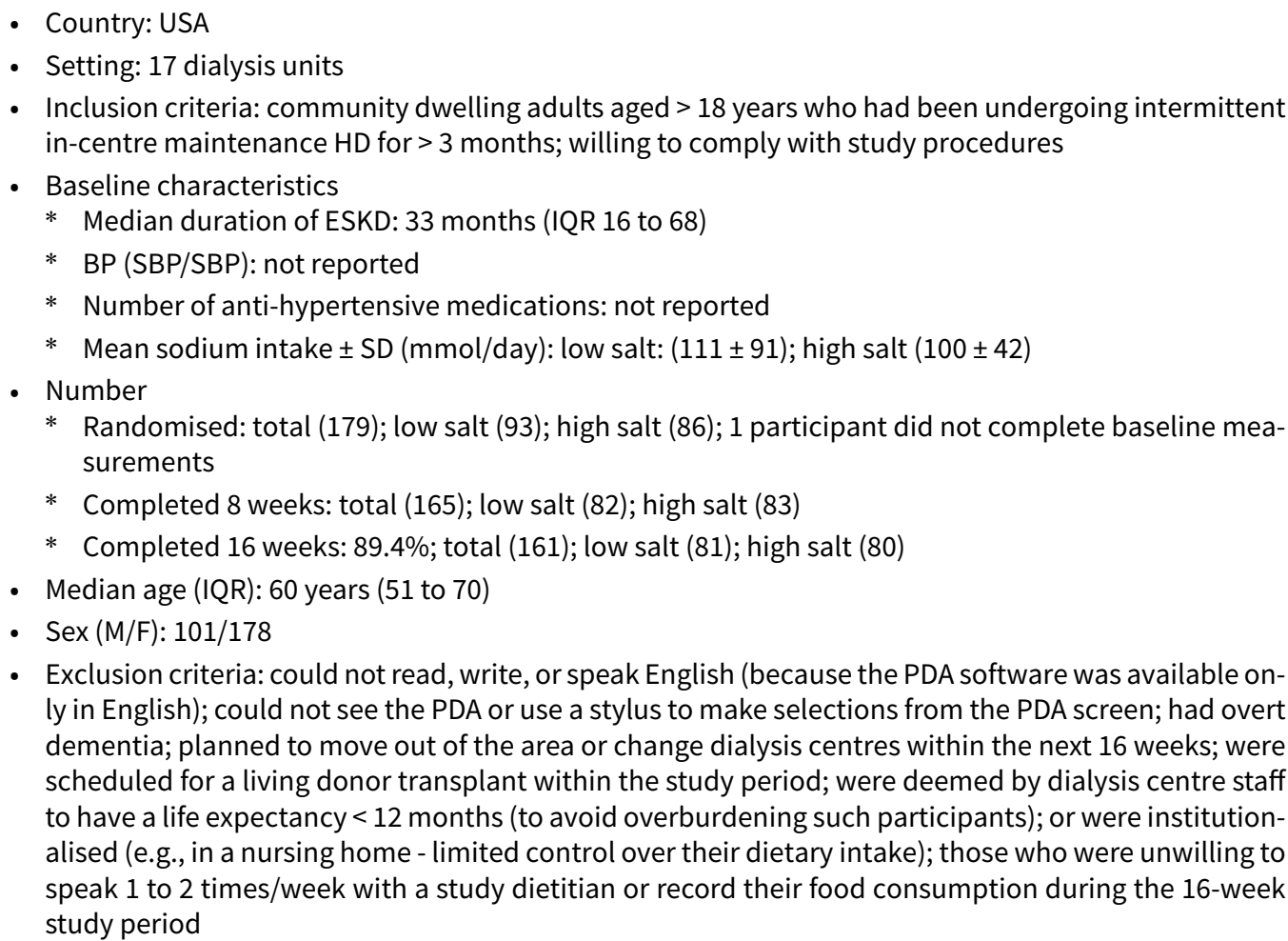 \\
\hline
\end{tabular}

- Individualised dietary education (by dietitian, twice/week for 8 weeks; weekly for weeks 9 to 12 and fortnightly for weeks 13 to 16 ) technology-based dietary self-monitoring (recorded meals); feedback on sodium intake; plus 6 dietary educational modules on different aspects of the standard HD dietary regimen

- Duration: 16 weeks

High salt group

- Attention control: 6 dietary educational modules on different aspects of the standard HD dietary regimen

- Duration: 16 weeks

Co-interventions

- Nil

\begin{tabular}{ll}
\hline Outcomes & Inter-dialytic weight gain \\
- Sodium intake: 24 -hour recall (3 days)
\end{tabular}

Notes Notes: 8-week follow-up data used for analysis


BalanceWise-HD 2013 (Continued)

- Funding: University of Pittsburgh

- Additional data: provided by authors

- Trial registration: https://clinicaltrials.gov/ct2/show/NCT01125202

\section{Risk of bias}

Bias Authors' judgement Support for judgement

Random sequence genera- Low risk tion (selection bias)
Randomised. Change from baseline reported

Quote: "Within each dialysis centre, participants were then randomised using a permuted block algorithm developed by the study statistician."

Quote: "Median Kt/V differed somewhat between the groups with attention control group participants being better dialyzed. Otherwise, no significant differences were observed in baseline characteristics of the intervention and attention control group participants."

\begin{tabular}{lll}
\hline $\begin{array}{l}\text { Allocation concealment } \\
\text { (selection bias) }\end{array}$ & Low risk & $\begin{array}{l}\text { Randomisation occurred after participants were recruited and baseline mea- } \\
\text { surements collected as above }\end{array}$ \\
\hline $\begin{array}{l}\text { Blinding of participants } \\
\text { and personnel (perfor- } \\
\text { mance bias) }\end{array}$ & Unclear risk & Open-label study \\
All outcomes & \\
\hline
\end{tabular}

Blinding of outcome as- Unclear risk

Outcomes were objective. Study staff performed measurements sessment (detection bias)

All outcomes

\section{Incomplete outcome data Low risk} (attrition bias)

All outcomes

\begin{abstract}
$16 \%$ attrition; 8-week sodium intake data used and this was mostly complete (a lot of missing data at week 16)

Quote: "Of the 191 individuals enrolling, 31 (16.2\%) did not complete the study. Three individuals withdrew before randomisation, and 3 were excluded post hoc ( 1 for confusion, 1 was a family relative of another participant, and 1 due to residence in an institutional setting). Of those who continued beyond the baseline assessment, 14 intervention participants and 11 attention control participants did not complete the study for the following reasons: 10 withdrew voluntarily (6 intervention, 4 control); 5 discontinued the study due to illness; 3 died; 3 relocated to a nonparticipating dialysis centre; 2 were admitted to an institutional setting; and 2 were transferred to home HD." "Some participants (16 intervention and 11 attention control) have missing sodium data due to missing dietary recalls, and some have missing IDGWA data due to missing haemodialysis sessions."
\end{abstract}

\begin{tabular}{lll}
\hline $\begin{array}{l}\text { Selective reporting (re- } \\
\text { porting bias) }\end{array}$ & Low risk & Study was registered online and the pre-specified outcomes were reported \\
\hline Bias from confounders & Unclear risk & $\begin{array}{l}\text { Confounding factors not measured/described. Baseline imbalances: Change } \\
\text { from baseline reported }\end{array}$ \\
\hline Other & Low risk & Funding: University of Pittsburgh \\
\hline
\end{tabular}

\section{BalanceWise-PD 2011}

\section{Study characteristics}

Altered dietary salt intake for people with chronic kidney disease (Review) 
BalanceWise-PD 2011 (Continued)

\begin{tabular}{|c|c|}
\hline Methods & $\begin{array}{l}\text { - Study design: open-label, parallel RCT } \\
\text { - Time frame: } 2007 \\
\text { - Duration: } 16 \text { weeks }\end{array}$ \\
\hline Participants & 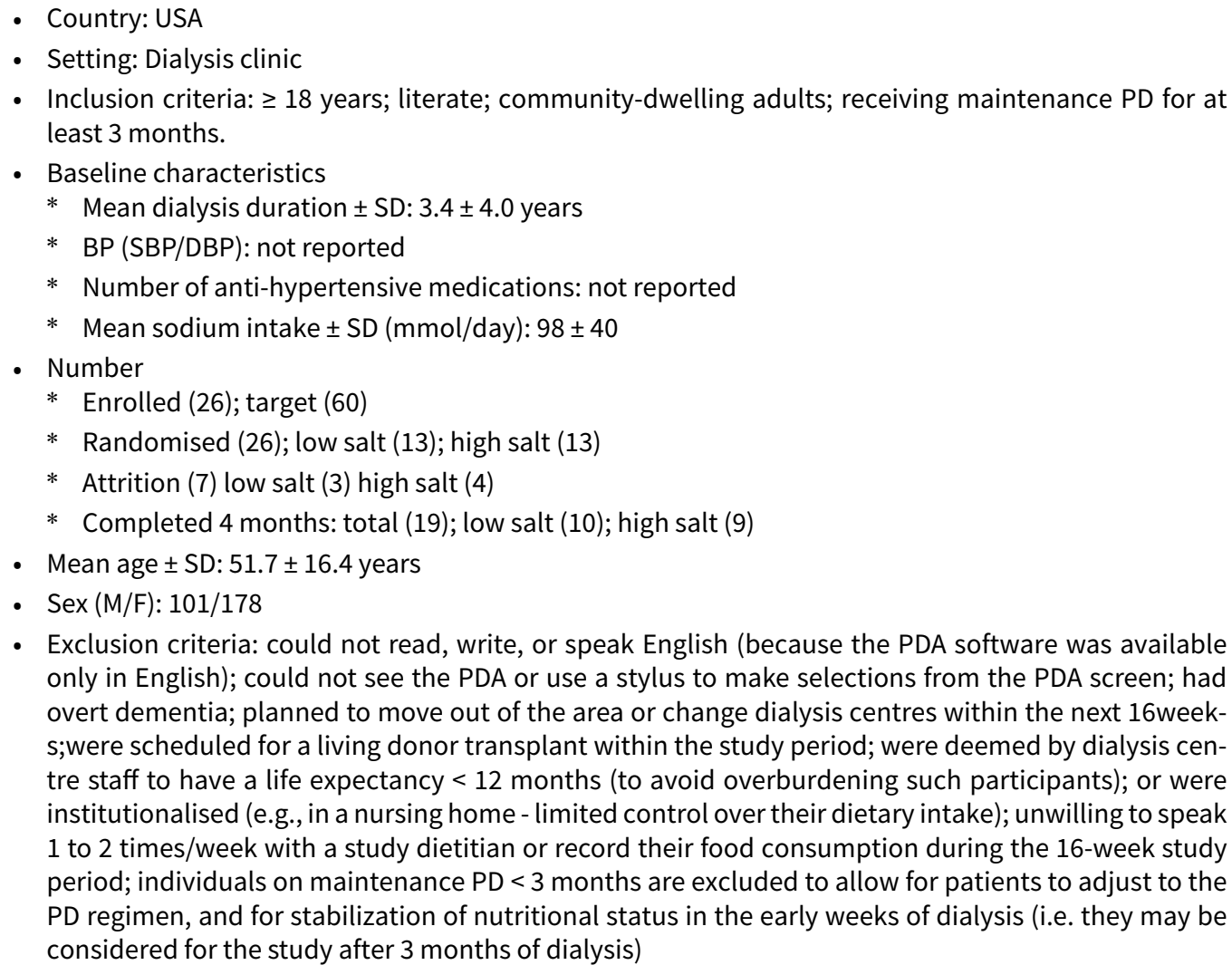 \\
\hline
\end{tabular}

Low salt group
- Dietary counselling based on Social Cognitive Theory, paired with PDA-based dietary self-monitoring
- Duration: 16 weeks

High salt group

- Attention control: standard PD education

- Duration: 16 weeks

Co-interventions

- Nil

$\begin{array}{ll}\text { - Butcomes } & \text { Bitting and standing (self-recorded); standing used for analysis as less missing data } \\ \text { - Fluid } \\ \text { - Weight (self-recorded) } \\ \text { - Sodium intake: } 24 \text {-hour recall (3 days) }\end{array}$

Notes

- Additional data: provided by authors

- Trial registration: https://clinicaltrials.gov/ct2/show/NCT00447317

\section{Risk of bias}


BalanceWise-PD 2011 (Continued)

Random sequence genera- Low risk tion (selection bias)
Quote: "In the BalanceWise-PD study, 2 dialysis units participated. Within dialysis centres, participants were stratified according to where they were dialyzed using CAPD versus CCPD, and then randomised within strata." (From email correspondence 23rd July 2019)

Baseline values not provided, but change from baseline reported

\begin{tabular}{lll}
\hline $\begin{array}{l}\text { Allocation concealment } \\
\text { (selection bias) }\end{array}$ & Low risk & Randomisation on sequentially assigned participant identification numbers \\
\hline $\begin{array}{l}\text { Blinding of participants } \\
\text { and personnel (perfor- }\end{array}$ & Unclear risk & Open-label study \\
mance bias) & \\
All outcomes & \\
\hline
\end{tabular}

Blinding of outcome as- High risk Open-label study; outcomes self-recorded sessment (detection bias)

All outcomes

$\begin{array}{ll}\begin{array}{l}\text { Incomplete outcome data } \\ \text { (attrition bias) }\end{array} & \text { High risk } \\ \text { All outcomes } & \begin{array}{l}\text { Considerable missing data; BP }>30 \%, \text { weight } 28 \% \text {, urine } ~ 50 \% \text { missing. } 19 \% \\ \text { attrition }(5 / 26) \text { but reasons well explained and unlikely to be due to allocation }\end{array} \\ & \begin{array}{l}\text { Quote: "Five participants were lost to follow-up, due to transfer to another } \\ \text { dialysis facility }(n=2), \text { transfer to haemodialysis }(n=1), \text { prolonged hospitalisa- } \\ \text { tion }(n=1), \text { or death }(n=1) . "\end{array}\end{array}$

\begin{tabular}{lll}
\hline $\begin{array}{l}\text { Selective reporting (re- } \\
\text { porting bias) }\end{array}$ & Low risk & Study was registered online and the pre-specified outcomes were reported \\
\hline Bias from confounders & Unclear risk & $\begin{array}{l}\text { Confounding factors not measured/described. Baseline imbalances: Change } \\
\text { from baseline reported }\end{array}$ \\
\hline Other & Low risk & $\begin{array}{l}\text { Funding: University of Pittsburgh; National Institute of Diabetes and Digestive } \\
\text { and Kidney Diseases (NIDDK) }\end{array}$ \\
\hline
\end{tabular}

Catto 1973

\section{Study characteristics}

\begin{tabular}{ll}
\hline Methods & Study design: double-blind cross-over RCT \\
- Time frame: not reported \\
- Duration: 4 months total; 2-month interventions \\
\hline Participants & Country: UK \\
- Setting: dialysis unit \\
- Inclusion criteria: not reported \\
- Baseline characteristics \\
$*$ CKD: HD \\
$*$ BP (SBP/DBP): not reported \\
$*$ Number of anti-hypertensive medications: not reported \\
$*$ Sodium excretion (mmol/day): not measured/reported \\
- Number: randomised (19); analysed (17) \\
- Mean age \pm SD (years): not reported \\
- Sex (M/F): randomised (12/7) completed $(10 / 11 ; 6 / 7)$
\end{tabular}


Catto 1973 (Continued)

- Exclusion criteria: not reported

Low salt group
Interventions
- Usual salt intake plus placebo
High salt group
- Usual salt intake and slow sodium twice/week (140 mmol) during dialysis (14 tablets over 7 hours;
from 1 hour before to 6 hours after starting dialysis)
- Duration: 2 months
- Muscle cramps frequency and severity: self-recorded during and 2 hours post-dialysis; averaged from
- 15 dialysis sessions
for analysis)
- Weight: pre- and post-dialysis
- Preferred therapy
- Sodium intake: not measured

Notes

- Additional data: could not contact authors

- Trial registration not available.

\section{Risk of bias}

\begin{tabular}{lll}
\hline Bias & Authors' judgement & Support for judgement \\
\hline $\begin{array}{l}\text { Random sequence genera- } \\
\text { tion (selection bias) }\end{array}$ & Unclear risk & "Randomised". Further information not provided \\
\hline $\begin{array}{l}\text { Allocation concealment } \\
\text { (selection bias) }\end{array}$ & Unclear risk & Double-blind, likely concealed, but not described \\
\hline $\begin{array}{l}\text { Blinding of participants } \\
\text { and personnel (perfor- } \\
\text { mance bias) }\end{array}$ & Low risk & Double-blind \\
All outcomes & & \\
\hline
\end{tabular}

Blinding of outcome as- Low risk Likely that outcome assessors were blinded

sessment (detection bias)

All outcomes

$\begin{array}{ll}\begin{array}{l}\text { Incomplete outcome data } \\ \text { (attrition bias) }\end{array} & \text { Low risk } \\ \text { All outcomes } & \text { Quote:“One patient taking the placebo died from acute bacterial endocardi- } \\ & \text { tis and another was withdrawn from the trial while receiving the sodium chlo- } \\ \text { ride preparation." "The patient withdrawn from the trial, a 22-year-old bache- } & \text { lor, had a long history of erratic behaviour and hypertension that was difficult } \\ \text { to control adequately; he was not able to keep to a standard diet or to control } & \text { his fluid intake and his weight gain between dialyses was excessive. Though } \\ \text { his blood pressure at the time was no higher than it had been on many previ- } & \text { ous occasions it was considered that the additional sodium intake was not jus- } \\ \text { tified." }\end{array}$

\begin{tabular}{|c|c|c|}
\hline $\begin{array}{l}\text { Selective reporting (re- } \\
\text { porting bias) }\end{array}$ & Unclear risk & $\begin{array}{l}\text { Pre-specified study protocol not available. Inter-dialytic weight gain not re- } \\
\text { ported (but mean pre- and post- dialysis weights reported). Two-month inter- } \\
\text { vention meaning participants would have had } 17-18 \text { dialysis sessions, but only } \\
15 \text { analysed and further information not specified beyond }\end{array}$ \\
\hline
\end{tabular}


Catto 1973 (Continued)

Quote: "The results obtained from 15 dialyses on a particular treatment were analysed."

\begin{tabular}{lll}
\hline Carry-over effect & Low risk & Sufficient intervention duration to avoid carry-over effect (2 months) \\
\hline Bias from confounders & Unclear risk & $\begin{array}{l}\text { Dietary and medication confounders not described; actual sodium intake or } \\
\text { excretion not described }\end{array}$ \\
\hline Other & Low risk & No competing interests declared. Pharmaceutical company supplied tablets \\
\hline
\end{tabular}

de Brito-Ashurst 2013

\section{Study characteristics}

\begin{tabular}{|c|c|}
\hline Methods & $\begin{array}{l}\text { - Study design: parallel, open-label RCT } \\
\text { - Time frame: June } 2008 \text { to July } 2009 \\
\text { - Duration: } 6 \text { month intervention }\end{array}$ \\
\hline Participants & $\begin{array}{l}\text { - Country: UK } \\
\text { - Setting: tertiary renal unit based in acute care hospital in East London } \\
\text { - Inclusion criteria: eGFR }<60 \mathrm{~mL} / \mathrm{min} \text {; mean } \mathrm{BP}>130 / 80 \mathrm{~mm} \text { Hg on at least } 2 \text { clinic visits or taking } \\
\text { antihypertensive medication; Bangladeshi origin; Attending predialysis clinic } \\
\text { - Baseline characteristics (mean } \pm \mathrm{SD}) \\
\text { * } \mathrm{CKD} \text {; mean eGFR } \pm \mathrm{SD}\left(\mathrm{mL} / \mathrm{min} / 1.73 \mathrm{~m}^{2}\right) \text { : low salt }(41 \pm 17) \text {; high salt }(42 \pm 15) \\
\text { * Mean BP } \pm \mathrm{SD}(\mathrm{SBP} / \mathrm{DBP} \mathrm{mm} \mathrm{Hg}) \text { : low salt }(149 \pm 15 / 85 \pm 6) \text {; high salt }(156 \pm 11 / 85 \pm 6) \\
\text { * Median number of anti-hypertensive medications: } 3 \text { (range } 2 \text { to } 4) \\
\text { * Mean sodium excretion } \pm \mathrm{SD}(\mathrm{mmol} / \text { day): total }(261 \pm 50) \text {; low salt: }(263 \pm 54) \text {; high salt }(259 \pm 47) \\
\text { - Number: low salt }(25) \text {; high salt }(23) \\
\text { - Mean age } \pm \mathrm{SD} \text { (years): low salt }(56 \pm 11) \text {; high salt }(61 \pm 9) \\
\text { - Sex (M/F): } 28 / 20 \\
\text { - Exclusion criteria: on dialysis; } \mathrm{BMI}<20 \text { or }>35 \mathrm{~kg} / \mathrm{m}^{2} \text {; urinary incontinence; cognitive impairment or } \\
\text { mental problems impairing ability to participate }\end{array}$ \\
\hline
\end{tabular}

Interventions

Low salt group

- Reduced sodium intake by ongoing individualised dietary education (in person and phone calls) and cooking lessons

- Duration: 26 weeks

High salt group

- Sodium intake: usual care (general low salt advice sent with doctor's letter)

- Duration: 26 week

Co-interventions

- Nil

Outcomes

- 24-hour BP

- Total body water by body composition monitor

- Measurement of sodium intake: 24 -hour urine 
de Brito-Ashurst 2013 (Continued)

- Measurement of confounders

* 24-hour urinary potassium and creatinine

* Body weight change

* Physical activity levels measured using a pedometer

Notes

- Additional data: provided by authors.

- Trial registration: https://clinicaltrials.gov/ct2/show/NCT00702312

\section{Risk of bias}

Bias Authors' judgement Support for judgement

Random sequence genera- Low risk tion (selection bias)

Allocation concealment $\quad$ Unclear risk
(selection bias)

(selection bias)

\begin{tabular}{|c|c|c|}
\hline $\begin{array}{l}\text { Blinding of participants } \\
\text { and personnel (perfor- } \\
\text { mance bias) } \\
\text { All outcomes }\end{array}$ & Unclear risk & $\begin{array}{l}\text { Unblinded; objective outcomes unlikely to be affected by performance bias; } \\
\text { dietary behaviour may have differed due to lack of blinding }\end{array}$ \\
\hline
\end{tabular}

Blinding of outcome as- Low risk sessment (detection bias)

All outcomes
Quote: "Randomisation to treatment was conducted by the study statistician using computer-generated random blocks with block sizes between four and eight"

\section{Quote: "Group assignment given to the researcher"}

Further information not provided

Unblinded; objective outcomes unlikely to be affected by performance bias; dietary behaviour may have differed due to lack of blinding
Outcomes were objective and not immediately available, analysis was performed blinded.

Quote: "Neither participants nor the dietitian administering the intervention could be blinded to treatment allocation. Data analysis was conducted by the study statistician who was blinded to treatment allocation."

Blinding of participants: no, blinding of investigators: no; blinding of outcomes assessors: no, blinding of data assessors: yes
Incomplete outcome data Low risk

(attrition bias)

All outcomes
Reasons for attrition unlikely to be related to allocation. 56 participants enrolled; 8 withdrew (14\% attrition); unwilling to complete: 24 -hour urine collection (3), BP monitoring (2), attend dietary education (1) lost to follow-up: death (1); emigration (1)

Attrition by allocation: low salt group (3); high salt group (5)

Selective reporting (re- Low risk No evidence of outcomes missing from report
porting bias)

\begin{tabular}{ll}
\hline Bias from confounders $\quad$ Unclear risk & Intervention is described as salt restriction \\
& Quote: "in addition to standard hypertension medication management" but \\
unclear whether changes to medication occurred (or were measured) during & follow up. Major confounders (potassium intake, body weight change, physical \\
activity) measured and reported as 'unchanged'. Baseline imbalances: Change \\
from baseline reported
\end{tabular}

Other Low risk Funding: PhD scholarship from charitable trust

Quote: "this study was funded by a PhD fellowship grant from the trustees of Barts and The London Charitable Foundation. The analysis, interpretation of data, generation of the manuscript and decision to submit for publication were carried out independently of the funding body" 
de Vries 2016

\section{Study characteristics}

\begin{tabular}{|c|c|}
\hline Methods & $\begin{array}{l}\text { - Study design: cross-over RCT } \\
\text { - Time frame: January } 2012 \text { to May } 2014 \\
\text { - Study duration (weeks): total (12); interventions (6); no run-in or washout }\end{array}$ \\
\hline Participants & 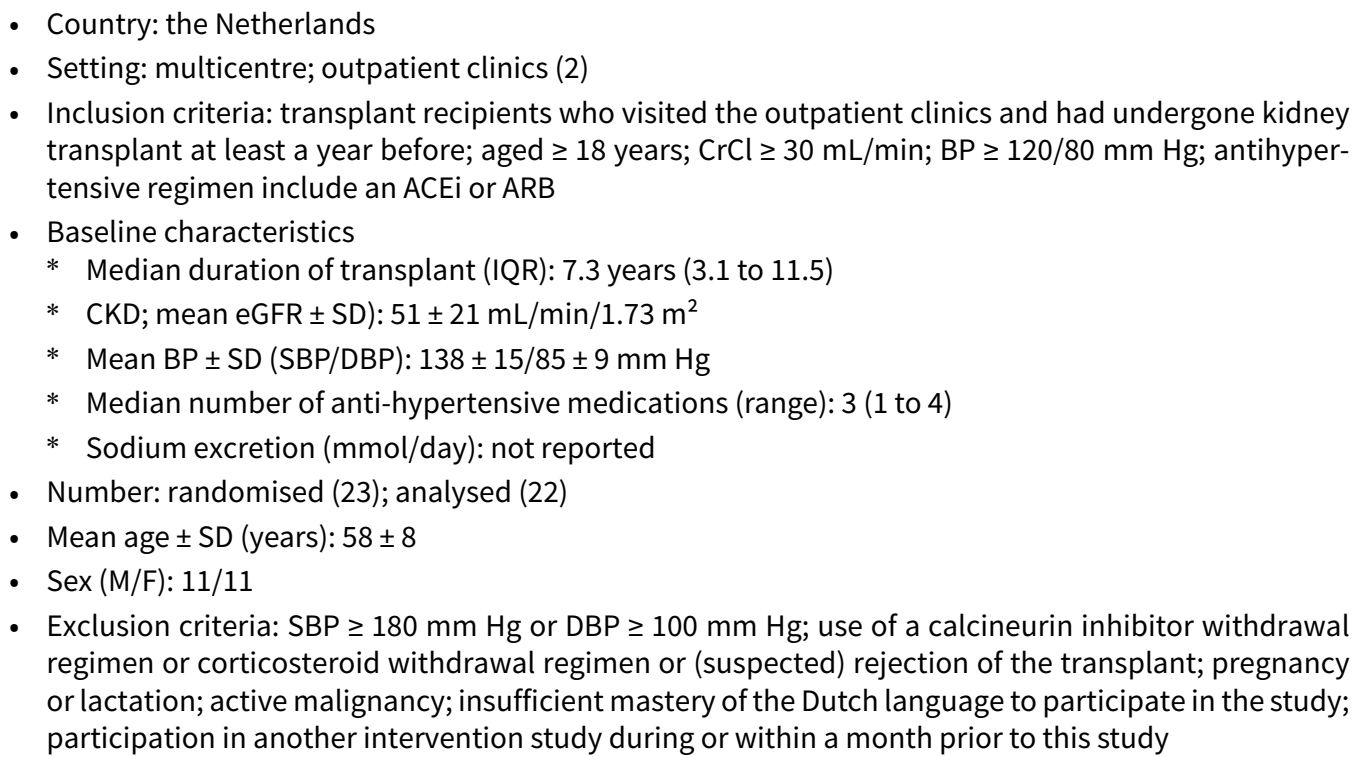 \\
\hline
\end{tabular}

Interventions

Low salt group

- Target sodium intake: $50 \mathrm{mmol} /$ day (individualised counselling by research physicians)

- Duration: 6 weeks

High salt group

- Target sodium intake: $150 \mathrm{mmol} / \mathrm{day}$ (instructed to maintain usual diet)

- Duration: 6 weeks

Other information

- Participants were instructed to maintain an isocaloric diet and stable protein intake; immunosuppressive regimen was kept stable throughout the study; antihypertensive medication kept stable unless patients experienced severe orthostatic complaints.

- Feedback on sodium intake given after each 24-hour urine collection

- Clinic BP (1-minute intervals for 15 minutes with a semiautomatic device while the patient was left
alone in a room in a semisupine position)
- 24 -hour urinary albumin, urea, calcium, potassium, and creatinine excretion
$\cdot \mathrm{CrCl}$
$\cdot \mathrm{eGFR}$
- $\mathrm{SCr}$, sodium, potassium, urea, total cholesterol, NT-proBNP, renin and aldosterone
- Measurement of sodium intake: 24 -hour urine (at 3 and 6 weeks of each intervention)

Notes

- Trial registration: https://www.trialregister.nl/trial/3785

- Additional data: requested from authors

\section{Risk of bias}


de Vries 2016 (Continued)

\begin{tabular}{|c|c|c|}
\hline Bias & Authors' judgement & Support for judgement \\
\hline $\begin{array}{l}\text { Random sequence genera- } \\
\text { tion (selection bias) }\end{array}$ & Low risk & $\begin{array}{l}\text { Quote: "For allocation, a computer-generated list of random numbers was } \\
\text { used." }\end{array}$ \\
\hline $\begin{array}{l}\text { Allocation concealment } \\
\text { (selection bias) }\end{array}$ & Unclear risk & Insufficient information to permit judgement \\
\hline $\begin{array}{l}\text { Blinding of participants } \\
\text { and personnel (perfor- } \\
\text { mance bias) } \\
\text { All outcomes }\end{array}$ & Unclear risk & Dietary interventions were open label \\
\hline $\begin{array}{l}\text { Blinding of outcome as- } \\
\text { sessment (detection bias) } \\
\text { All outcomes }\end{array}$ & Unclear risk & Insufficient information to permit judgement \\
\hline $\begin{array}{l}\text { Incomplete outcome data } \\
\text { (attrition bias) } \\
\text { All outcomes }\end{array}$ & Low risk & $\begin{array}{l}\text { Of the } 23 \text { who were randomly assigned, } 1 \text { patient withdrew halfway through } \\
\text { the low-sodium period because of orthostatic hypotension (This participant } \\
\text { was included in the orthostatic hypotension outcome). May have reduced the } \\
\text { effect on BP, but only } 1 / 23 \text { participants }\end{array}$ \\
\hline $\begin{array}{l}\text { Selective reporting (re- } \\
\text { porting bias) }\end{array}$ & Low risk & No indication of selective reporting \\
\hline Carry-over effect & Low risk & $\begin{array}{l}\text { Adequate intervention duration to reduce risk of carry over effect ( } 6 \text { weeks fol- } \\
\text { low-up) }\end{array}$ \\
\hline Bias from confounders & Unclear risk & $\begin{array}{l}\text { Antihypertensive dose reduction ( } 5 / 23 \text { in low salt group) likely to reduce effect } \\
\text { on BP; Potassium not significantly changed }\end{array}$ \\
\hline \multirow[t]{2}{*}{ Other } & Low risk & $\begin{array}{l}\text { Quote:"Dr Krediet was supported by the innovation grant IP-11.40 of the Dutch } \\
\text { Kidney Foundation." }\end{array}$ \\
\hline & & $\begin{array}{l}\text { Quote: "Financial Disclosure: The other authors declare that they have no rele- } \\
\text { vant financial interests." }\end{array}$ \\
\hline
\end{tabular}

Doulton 2007

\section{Study characteristics}

\begin{tabular}{ll}
\hline Methods & Study design: double-blind, cross-over RCT \\
& - Time frame: not reported \\
\hline Participants & Duration of study (weeks): total (8); interventions (4); no run in or washout \\
\hline & - Country: UK \\
- Setting: single centre & Bnclusion criteria: HD/HDF for ESKD $>3$ months; clinically stable \\
& $*$ CKD: HD \\
& $*$ BP (SBP/DBP): $122 \pm 5 / 69 \pm 2$ mm Hg \\
& $*$ Sodium excretion (mmol/day): not reported \\
- Number: target enrolment (20); randomised (not reported); analysed (13) & Mean age \pm SD: $60 \pm 5$ years \\
- Sex (M/F): $10 / 3$
\end{tabular}


Doulton 2007 (Continued)

- Exclusion criteria: significant intercurrent illness; SBP > 240 mm Hg or DBP > 120 mm Hg at enrolment; unstable BP whilst on HD; sodium profiled HD or HDF

\begin{tabular}{|c|c|}
\hline Interventions & $\begin{array}{l}\text { Low salt group } \\
\text { - Target sodium intake: } 100 \mathrm{mmol} / \text { day; dietary education (verbal and leaflet, administered by experi- } \\
\text { enced renal dietitian) plus placebo } \\
\text { - Duration: } 4 \text { weeks } \\
\text { High salt group } \\
\text { - Target sodium intake } 170 \text { to } 200 \mathrm{mmol} / \text { day; slow sodium ( } 90 \mathrm{mmol} / \text { day) } \\
\text { - Duration: } 4 \text { weeks }\end{array}$ \\
\hline Outcomes & $\begin{array}{l}\text { - Pre-dialysis SBP } \\
\text { - Post-dialysis ambulatory BP (24-hour) } \\
\text { - Thirst score } \\
\text { - Intradialytic weight gain } \\
\text { - Systemic vascular resistance } \\
\text { - Asymmetric dimethylarginine } \\
\text { - Measurement of sodium intake: 3-day food diary }\end{array}$ \\
\hline Notes & $\begin{array}{l}\text { - Additional data: unable to contact study authors } \\
\text { - Abstract only available. Mean values only reported (variation not reported) but P values used to im- } \\
\text { pute confidence intervals } \\
\text { - Trial registration: https://clinicaltrials.gov/ct2/show/study/NCT00141609 Study listed as completed } \\
\text { October 2006; Last updated May } 142007\end{array}$ \\
\hline
\end{tabular}

\section{Risk of bias}

\begin{tabular}{|c|c|c|}
\hline Bias & Authors' judgement & Support for judgement \\
\hline $\begin{array}{l}\text { Random sequence genera- } \\
\text { tion (selection bias) }\end{array}$ & Unclear risk & $\begin{array}{l}\text { "Randomised". Further information not provided. Baseline values not provid- } \\
\text { ed }\end{array}$ \\
\hline $\begin{array}{l}\text { Allocation concealment } \\
\text { (selection bias) }\end{array}$ & Low risk & $\begin{array}{l}\text { Double blind; allocation concealment not described; likely to have been con- } \\
\text { cealed }\end{array}$ \\
\hline $\begin{array}{l}\text { Blinding of participants } \\
\text { and personnel (perfor- } \\
\text { mance bias) } \\
\text { All outcomes }\end{array}$ & Low risk & "Double blind". Slow sodium versus placebo. No details of placebo matching. \\
\hline
\end{tabular}

\begin{tabular}{|c|c|c|}
\hline $\begin{array}{l}\text { Blinding of outcome as- } \\
\text { sessment (detection bias) }\end{array}$ & Low risk & $\begin{array}{l}\text { "Double blind". Further information not provided. Some risk of unblinding } \\
\text { with outcome measurement }\end{array}$ \\
\hline
\end{tabular}

\begin{tabular}{lll} 
All outcomes & \\
\hline $\begin{array}{l}\text { Incomplete outcome data } \\
\text { (attrition bias) } \\
\text { All outcomes }\end{array}$ & Unclear risk & $\begin{array}{l}\text { Attrition not provided. 13 completed; target 20 enrolled. Actual enrolment not } \\
\text { provided }\end{array}$ \\
\hline $\begin{array}{l}\text { Selective reporting (re- } \\
\text { porting bias) }\end{array}$ & Low risk & $\begin{array}{l}\text { Study was pre-registered online and the pre-specified outcomes were report- } \\
\text { ed. All outcomes reported in abstract }\end{array}$ \\
\hline $\begin{array}{l}\text { Carry-over effect } \\
\text { Low risk }\end{array}$ & $\begin{array}{l}\text { Adequate intervention duration to reduce risk of carry over effect (4 weeks fol- } \\
\text { low-up) }\end{array}$
\end{tabular}


Doulton 2007 (Continued)

Bias from confounders Unclear risk Measurement of dietary or medication confounders not described; Target weight kept stable during the study; alterations to dialysis prescription not specified

Other Low risk Funding: British Heart Foundation

DUAAAL 2011

\section{Study characteristics}

\begin{tabular}{|c|c|}
\hline Methods & $\begin{array}{l}\text { - Study design: double blind, cross-over RCT } \\
\text { - Time frame: April } 2006 \text { to October } 2009 \\
\text { - Study duration (weeks): total (30); run-in (6); interventions (6); no washout }\end{array}$ \\
\hline Participants & 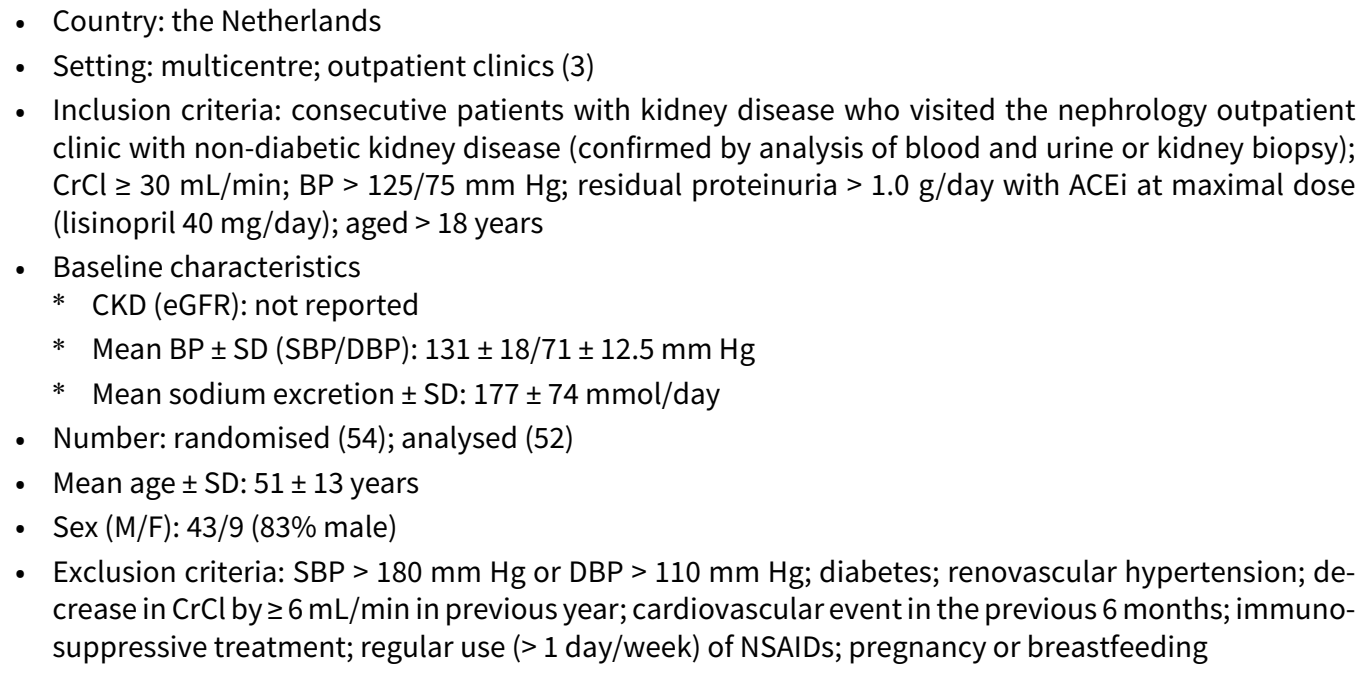 \\
\hline
\end{tabular}

Interventions

Low salt group

- Target sodium intake: $50 \mathrm{mmol} /$ day (individualised counselling by dietician)

- Duration: 12 weeks

High salt group

- Sodium intake: usual diet

- Duration: 12 weeks

Co-interventions

- Each participant was on lisinopril $40 \mathrm{mg} /$ day for entire study and went through four interventions for six weeks each in random order ( ${ }^{*}$ used for analysis)

* Usual salt, placebo*

* Usual salt valsartan $320 \mathrm{mg} /$ day

* High salt, placebo*

* High salt valsartan $320 \mathrm{mg} /$ day

Other information

- Run-in: 6 weeks; no dietary intervention

- No other RAAS blockers. Additional antihypertensive drugs such as beta-blockers, alpha-blockers, calcium channel blockers, and diuretics were allowed and kept stable during the study 
DUAAAL 2011 (Continued)
Outcomes
- 24-hour proteinuria
- Clinic BP (supine)
- Clinical evaluation of oedema
- Weight
- Serum markers (electrolytes, lipids, proteins, creatinine)
- Urinary electrolytes and $\mathrm{CrCl}$
- Measurement of sodium intake: 24-hour urine
- Measurement of confounders
* Medication intake measured by pill counts (not relevant to dietary interventions)
* Protein intake measured from urea excretion (Maroni formula)

\begin{tabular}{ll}
\hline Notes & - Trial registration: http://www.isrctn.com/ISRCTN50137410 \\
& - Additional data: provided by authors
\end{tabular}

\section{Risk of bias}

\begin{tabular}{lll}
\hline Bias & Authors' judgement & Support for judgement \\
\hline $\begin{array}{l}\text { Random sequence genera- } \\
\text { tion (selection bias) }\end{array}$ & Low risk & $\begin{array}{l}\text { Quote: "An independent pharmacist randomised these sequences, using a } \\
\text { computer program" }\end{array}$ \\
\hline $\begin{array}{l}\text { Allocation concealment } \\
\text { (selection bias) }\end{array}$ & Unclear risk & Insufficient information to permit judgement \\
\hline $\begin{array}{l}\text { Blinding of participants } \\
\begin{array}{l}\text { and personnel (perfor- } \\
\text { mance bias) }\end{array}\end{array}$ & Unclear risk & $\begin{array}{l}\text { Dietary interventions were open label but outcomes were objective and un- } \\
\text { likely to be influenced by performance bias }\end{array}$ \\
\hline
\end{tabular}

\begin{tabular}{|c|c|c|}
\hline $\begin{array}{l}\text { Blinding of outcome as- } \\
\text { sessment (detection bias) } \\
\text { All outcomes }\end{array}$ & Unclear risk & Insufficient information to permit judgement \\
\hline $\begin{array}{l}\text { Incomplete outcome data } \\
\text { (attrition bias) } \\
\text { All outcomes }\end{array}$ & Low risk & $\begin{array}{l}\text { Quote: "Additionally, we analysed the data for all } 54 \text { patients who were includ- } \\
\text { ed (intention to treat). As the effect estimates and confidence intervals were } \\
\text { very similar and the statistical and clinical conclusions did not change, we } \\
\text { have not shown these data" } \\
54 \text { randomised, } 2 \text { withdrew after randomisation; } 52 \text { included in analysis }\end{array}$ \\
\hline $\begin{array}{l}\text { Selective reporting (re- } \\
\text { porting bias) }\end{array}$ & Low risk & $\begin{array}{l}\text { Study was pre-registered online and the pre-specified outcomes were report- } \\
\text { ed }\end{array}$ \\
\hline Carry-over effect & Low risk & Adequate intervention duration to reduce risk of carry-over effect \\
\hline Bias from confounders & High risk & $\begin{array}{l}\text { Medication changes reported and did not occur during placebo phases. Com- } \\
\text { parison of usual intake versus low sodium intervention increases risk of di- } \\
\text { etary confounders - reduction in body weight, potassium excretion and urinary } \\
\text { urea in low salt phase suggests potential confounding }\end{array}$ \\
\hline Other & Unclear risk & $\begin{array}{l}\text { Funding: study supported by Novartis; declaration of non-involvement by fun- } \\
\text { der } \\
\text { Quote: "Funding: Unrestricted grant from Novartis. No role in the design and } \\
\text { conduct of the study; collection, management, analysis, and interpretation of } \\
\text { the data; and preparation, review, or approval of the manuscript" }\end{array}$ \\
\hline
\end{tabular}




\section{Study characteristics}

\begin{tabular}{|c|c|}
\hline Methods & $\begin{array}{l}\text { - Study design: parallel, open-label RCT } \\
\text { - Time frame: June } 2011 \text { to August } 2014 \\
\text { - Duration of study: } 6 \text { months }\end{array}$ \\
\hline Participants & 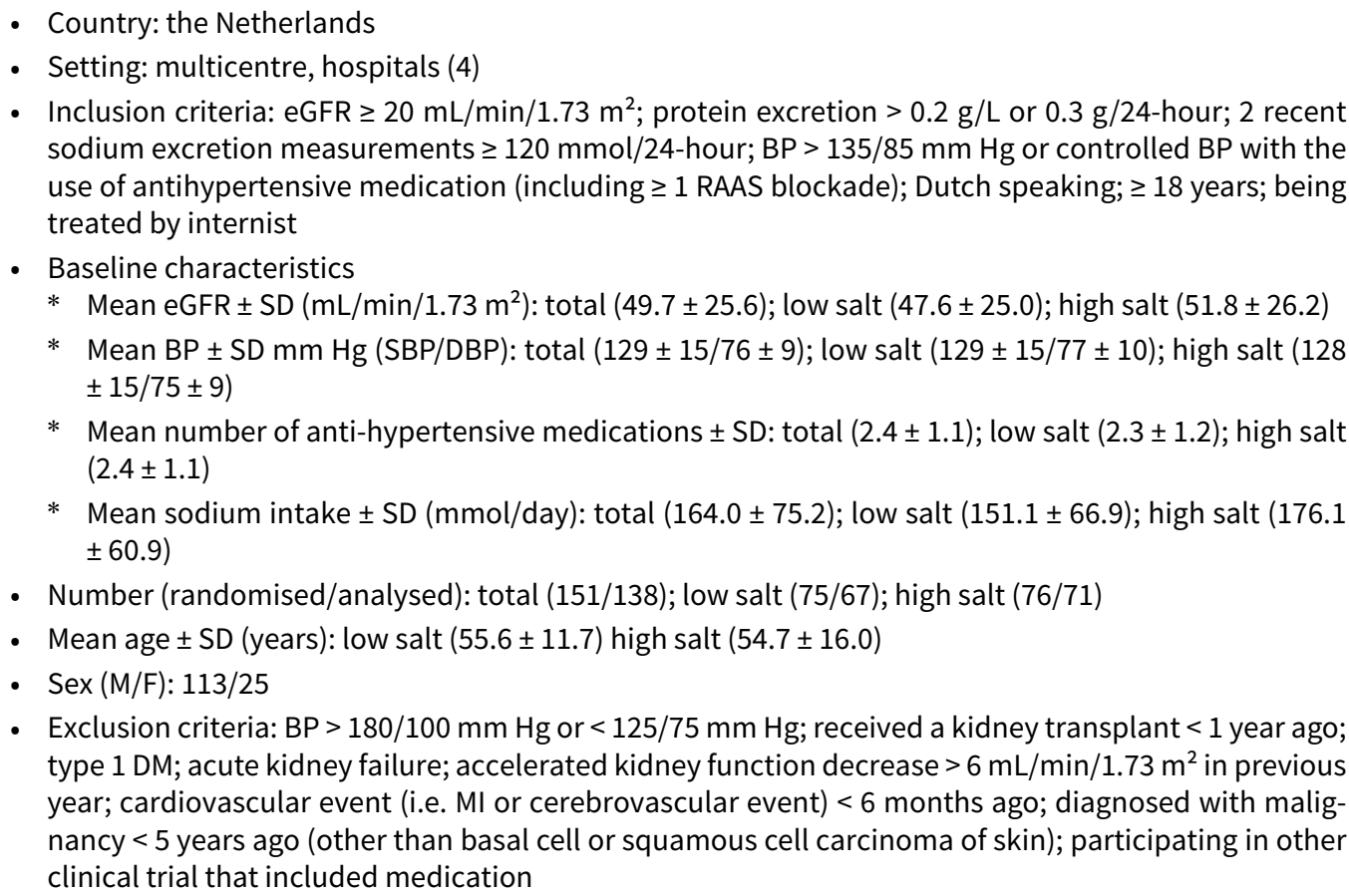 \\
\hline
\end{tabular}

\begin{tabular}{ll}
\hline Interventions & Low salt group \\
- Education, motivational interviewing, coaching, self-monitoring of BP and sodium \\
- Duration: 3 months \\
High salt group \\
- Usual care \\
- BP(24-hour \& clinic) \\
- 24 -hour proteinuria \\
- eGFR \& CrCl \\
- Measurement of sodium intake: 24-hour urine \\
- Measurement of confounders \\
$*$ Body weight change \\
- Participants followed up at 3 months (t1) and 6 months (t2), 3 month follow up (t1) used for analysis \\
- Registered at: NTR2917 \\
- Values at end of 3 months (t1) used as change from baseline not available for each group; intention to \\
treat analysis values adjusted for baseline values used \\
- Additional data: provided by authors
\end{tabular}

\section{Risk of bias}


ESMO 2017 (Continued)

Random sequence genera- Low risk tion (selection bias)
Quote: "A medical information specialist allocated patients to the intervention or control condition using a computer-based block randomisation procedure. The number of patients in each condition was predefined, and different sizes of blocks were used to prevent too many patients being consecutively assigned to the same condition."

\begin{tabular}{|c|c|c|}
\hline $\begin{array}{l}\text { Allocation concealment } \\
\text { (selection bias) }\end{array}$ & Low risk & $\begin{array}{l}\text { Quote: "Only the medical information specialist knew the block sizes. There- } \\
\text { after, researchers and patients were notified of the allocation." }\end{array}$ \\
\hline
\end{tabular}

\begin{tabular}{|c|c|c|}
\hline $\begin{array}{l}\text { Blinding of participants } \\
\text { and personnel (perfor- } \\
\text { mance bias) } \\
\text { All outcomes }\end{array}$ & Unclear risk & $\begin{array}{l}\text { Outcomes were objective and unlikely to be influenced by performance bias } \\
\text { Blinding of participants: no; Blinding of Investigators: no; Blinding of Out- } \\
\text { comes assessors: not reported; Blinding of Data assessors: not reported }\end{array}$ \\
\hline
\end{tabular}

Blinding of outcome as- Unclear risk Insufficient information to permit judgement
sessment (detection bias) All outcomes

\section{Incomplete outcome data Low risk} (attrition bias)

All outcomes

\section{Reasons for attrition unlikely to be related to allocation. Both intention to treat} and sensitivity analyses performed

Details: between allocation to baseline, $13 / 151$ withdrew ( 8 in intervention group \& 5 in control; not included in intention-to-treat analysis). Between baseline to 3-month follow up, 21/138 withdrew: 8 from intervention group (health problems (4),too busy (1), too much burden (1), participation other study (1); 13 from control group (too much burden and no gain (6), health problems (2), too busy (2), negative experience phlebotomy (1), lost interest (1), no response (1))

\begin{tabular}{|c|c|c|}
\hline $\begin{array}{l}\text { Selective reporting (re- } \\
\text { porting bias) }\end{array}$ & Low risk & $\begin{array}{l}\text { Study was pre-registered online and the pre-specified outcomes were report- } \\
\text { ed }\end{array}$ \\
\hline \multirow[t]{5}{*}{ Bias from confounders } & High risk & $\begin{array}{l}\text { Body weight change: measured; significant reduction in intervention group } \\
(1.5 \mathrm{~kg} \text { ) but may be due to fluid (not measured) }\end{array}$ \\
\hline & & $\begin{array}{l}\text { Quote: "An explanation for our intervention effect could be that the weight re- } \\
\text { duction was not sodium specific, but due to weight loss goals that } 21(31 \%) \\
\text { participants set in addition to sodium goals." }\end{array}$ \\
\hline & & $\begin{array}{l}\text { Physical activity: not measured; antihypertensive dose: measured; reported } \\
\text { not significantly changed; potassium excretion measured and not significantly } \\
\text { changed }\end{array}$ \\
\hline & & $\begin{array}{l}\text { Baseline imbalances: results not reported as change from baseline for each } \\
\text { group but were adjusted for baseline values. Some differences between } \\
\text { groups in baseline values (higher sodium excretion in control) }\end{array}$ \\
\hline & & $\begin{array}{l}\text { Crude analyses and analyses performed adjusting for baseline values had sim- } \\
\text { ilar results. }\end{array}$ \\
\hline Other & Low risk & $\begin{array}{l}\text { Funding: Grants from The Netherlands Organization for Health Research De- } \\
\text { velopment - Medical Sciences, the Dutch Kidney Foundation; Conflict of inter- } \\
\text { est: nil }\end{array}$ \\
\hline
\end{tabular}

\section{Study characteristics}


ESPECIAL 2014 (Continued)

Methods

- Study design: parallel, open-label RCT

- Time frame: March 2012 to March 2013

- Duration of study (weeks): total (16); run in (8); intervention (8)

\section{Participants}

- Country: South Korea

- Setting: multicentre, outpatient renal clinics (7)

- Inclusion criteria: aged 19 to 75 years; diagnosis of hypertension or use of antihypertensive medication, MDRD study eGFR $\geq 30 \mathrm{~mL} / \mathrm{min} / 1.73 \mathrm{~m}^{2}$, verified at least twice to have ACR $\geq 30 \mathrm{mg} / \mathrm{g}$ in a spot urine sample with interval of 1 week or more in recent 6 months

- Baseline characteristics

* CKD: Stage 3 to 4 non-dialysed, non-transplanted

* Mean eGFR $\pm \mathrm{SD}\left(\mathrm{mL} / \mathrm{min} / 1.73 \mathrm{~m}^{2}\right)$ : total $(67.3 \pm 24.6)$; low salt $(68.4 \pm 23.6)$; high salt $(66.2 \pm 25.6)$

* Mean baseline BP \pm SD mm Hg (SBP/DBP): total $(130.9 \pm 11.8 / 79.4 \pm 9.1)$; low salt $(131.0 \pm 11.0 / 79.7$ $\pm 8.2)$; high salt $(130.8 \pm 12.4 / 79.2 \pm 9.9)$

* Mean baseline sodium intake \pm SD (mmol): total (155 \pm 70$)$; low salt $(155 \pm 70)$; high salt $(156 \pm 71)$

- Number (randomised/analysed: total (256/245) low salt (125/119); high salt (131/126)

- Mean age \pm SD: $49.5 \pm 13.3$ years

- $\operatorname{Sex}(\mathrm{M} / \mathrm{F}): 122 / 123$

- Exclusion criteria: $\mathrm{SBP} / \mathrm{DBP}>160 / 100 \mathrm{~mm} \mathrm{Hg}$; pregnant; serum potassium level > $5.5 \mathrm{mEq} / \mathrm{L}$ at screening period; malignancy; acute cerebral infarction; acute MI; unstable angina; $\mathrm{PCI}$ or CABG in recent 6 months; DM; allergy to olmesartan; involved in other clinical study in recent 1 month or are participated in screening period; taking medications of corticosteroid or immunosuppressant in a screening period

- Low salt diet: target $100 \mathrm{mmol} /$ day via dietary education from dietician (one 30 minute phone call every week)

- Duration: 8 weeks

High salt group

- Education for low salt diet will be conducted as in office with brief communication with a patient and a physician

- Duration: 8 weeks

Co-interventions

- During run-in (8 weeks), all RAAS blocking agents and diuretic medications were ceased and switched to antihypertensive agents of different categories \& all participants were prescribed olmesartan medoxomil (40mg/day)

Outcomes

- BP (measured at clinics, number of measurements not recorded)

- 24-hour albuminuria

- 24-hour urinary creatinine

- Spot urine ACR

- $\mathrm{Hb}$

- Sodium intake measurement

* 24-hour UNa

* Food frequency questionnaire

- Measurement of confounders

* 24-hour urinary potassium

* Body weight change 
ESPECIAL 2014 (Continued)

Notes
- Other information

* Before randomisation, the participants who displayed poor medication adherence to olmesartan (used $\leq 60 \%$ of the prescribed medication) were removed from the study

* $>25 \%$ reduction of salt intake was recommended in both groups

- Registered at: NCT00702312

- Values for change from week 8 (end of run-in) to week 16 (end of intervention) used for analysis

- Additional data: provided by authors

\section{Risk of bias}

\begin{tabular}{lll}
\hline Bias & Authors' judgement & Support for judgement \\
\hline $\begin{array}{ll}\text { Random sequence genera- } \\
\text { tion (selection bias) }\end{array}$ & Low risk & $\begin{array}{l}\text { Quote: "Randomly assigned (1:1) to either conventional education or intensive } \\
\text { education for LSD with computerized block randomisation (block size six) and } \\
\text { balanced according to institution and sex." }\end{array}$ \\
\hline
\end{tabular}

\begin{tabular}{lll}
\hline $\begin{array}{l}\text { Allocation concealment } \\
\text { (selection bias) }\end{array}$ & Low risk & $\begin{array}{l}\text { Quote: "It was not feasible to mask participants to allocation, but clinicians } \\
\text { were masked to group assignment". }\end{array}$ \\
\hline $\begin{array}{l}\text { Blinding of participants } \\
\begin{array}{l}\text { and personnel (perfor- } \\
\text { mance bias) }\end{array}\end{array}$ & Unclear risk & $\begin{array}{l}\text { Outcomes were objective and unlikely to be influenced by performance bias; } \\
\text { blinding of participants: no; blinding of Investigators: yes; blinding of out- } \\
\text { comes assessors: no; blinding of data assessors: unclear }\end{array}$ \\
\hline
\end{tabular}

\begin{tabular}{|c|c|c|}
\hline $\begin{array}{l}\text { Blinding of outcome as- } \\
\text { sessment (detection bias) } \\
\text { All outcomes }\end{array}$ & Low risk & $\begin{array}{l}\text { Most outcomes were objective and not immediately available (24-hour urinary } \\
\text { markers) }\end{array}$ \\
\hline
\end{tabular}

\begin{tabular}{ll}
\hline $\begin{array}{l}\text { Incomplete outcome data } \\
\text { (attrition bias) }\end{array}$ & Low risk \\
All outcomes & $\begin{array}{l}\text { 11/256 (4\%) withdrew. Intervention group: } 6 \text { withdrawn (withdrew consent (1), } \\
\text { adverse events }\end{array}$ \\
& $\begin{array}{l}\text { (2), continuous user of steroids (1), missed education (1), follow-up loss (1)); } \\
\text { control group: } 5 \text { withdrawn (withdrew consent (1), adverse events (1), diag- } \\
\text { nosed DM (1), education error (1),follow-up loss (1)); attrition balanced be- } \\
\text { tween groups and unlikely to introduce bias }\end{array}$
\end{tabular}

\begin{tabular}{|c|c|c|}
\hline $\begin{array}{l}\text { Selective reporting (re- } \\
\text { porting bias) }\end{array}$ & Low risk & $\begin{array}{l}\text { Study was pre-registered online and the pre-specified outcomes were report- } \\
\text { ed }\end{array}$ \\
\hline
\end{tabular}

\begin{tabular}{|c|c|c|}
\hline Bias from confounders & Unclear risk & $\begin{array}{l}\text { Potassium: measured but only reported at baseline; body weight: measured, } \\
\text { not reported by group (total change calculated from Ahn } 2018=0.1 \pm 2.2 \text { ); pro- } \\
\text { tein intake not significantly changed; Physical activity: measured at baseline } \\
\text { but not follow up; No changes to medications }\end{array}$ \\
\hline
\end{tabular}

Quote: "During the 16 weeks, no medications were changed, other than olmesartan medoxomil,"

Quote: "During the study period, hyperkalaemia (range of 5.6-6.2 mEq/L) was detected in five participants $(2.0 \%)$ after olmesartan treatment. However, all of the hyperkalaemic events were developed before randomisation and corrected with dietary potassium restriction and cation exchange resin"

Baseline imbalances: some baseline differences, but unlikely to impact findings and change from baseline values was used for analysis. Details: significant difference at baseline in exercise minutes (intervention group median 0.0 (IQR $0.0 ; 180.0)$; control group $120.0(0.0 ; 240.0), P=0.001)$ and BUN

\begin{tabular}{|c|c|c|}
\hline Other & Unclear risk & $\begin{array}{l}\text { Funding: This study was funded by Daiichi Sankyo Korea Co. Ltd. And Dae- } \\
\text { woong Pharmaceutical Co. Ltd. Olmesartan medoxomil was provided by the }\end{array}$ \\
\hline
\end{tabular}


same pharmaceutical companies for all participants. Conflict of interest: none reported

Quote: "the finding that the baseline 24-hour urinary sodium excretion amount was relatively low compared with the mean value of the Korean population on the basis of the 2011 Korea Health Statistics (18) can be explained by the possibility that somewhat routine LSD education was already applied and emphasized in study populations according to the guidelines for patients with hypertension and proteinuria."

Fine 1997

\section{Study characteristics}

\begin{tabular}{ll}
\hline Methods & Study design: double-blind, cross-over RCT \\
- Time frame: not reported \\
- Study duration (weeks): total (18); run in/washout (3); intervention (6) \\
\hline Participants & Country: Canada \\
- Setting: renal outpatient clinic \\
- Inclusion criteria: CAPD $>4$ months \\
- Baseline data \\
$*$ GFR: not reported \\
$*$ Baseline BP: not reported, 10 were hypertensive \\
$*$ Mean duration of dialysis: $15 \pm 15$ months \\
- Number: 20 \\
- Mean age \pm SD: $61 \pm 13$ years \\
- Sex (M/F): $14 / 6$ \\
Exclusion criteria: DBP $>100$ mm Hg; difficulty staying oedema-free; medication noncompliance; con- \\
dialysate in $75 \%$ on more of their usual cycles; large geographical distance between unit and the pa- \\
tient's home
\end{tabular}

Interventions

Low salt diet

- Usual diet plus placebo

- Duration: 6 weeks

High salt diet

- Sodium intake: usual diet plus $60 \mathrm{mmol}$ sodium capsule

- Duration: 6 weeks

Other information

- Co-interventions: none

- Dialysate sodium $132 \mathrm{mmol} / \mathrm{L}$ in all participants

Outcomes

- Clinic BP (self-recorded, 3 weekly)

- Weight (self-recorded, twice weekly)

- Measurement of sodium intake

* 24-hour urine + dialysate collection

* 3-day food record

* Change in dialysate regimen self-recorded 
Fine 1997 (Continued)

- Measurement of confounders

* Medication changes discussed for hypertensive patients but not the CAPD group and measurement not described

* Measurement of other dietary confounders not described

* Adherence to study medication not described

- Values at the end of the intervention used

Notes $\quad$ Funding: Baxter Healthcare Corporation and Kidney Foundation of Canada, Manitoba Branch

\section{Risk of bias}

\begin{tabular}{lll}
\hline Bias & Authors' judgement & Support for judgement \\
\hline $\begin{array}{l}\text { Random sequence genera- } \\
\text { tion (selection bias) }\end{array}$ & Low risk & $\begin{array}{l}\text { Quote: "By pharmacy". Further information not provided; however, low risk of } \\
\text { bias due to study design }\end{array}$ \\
\hline $\begin{array}{l}\text { Allocation concealment } \\
\text { (selection bias) }\end{array}$ & Low risk & "Double blind" and medications packaged by pharmacy. Probably concealed \\
\hline $\begin{array}{l}\text { Blinding of participants } \\
\text { and personnel (perfor- } \\
\text { mance bias) }\end{array}$ & Low risk \\
All outcomes & & Quote: "Physician, patient, and study nurse were blinded" \\
\hline
\end{tabular}

Blinding of outcome as- Unclear risk Quote: "Patients recorded own weights and BP". Objective outcome; however, sessment (detection bias) introduced attrition and could have unblinded allocation

All outcomes

Incomplete outcome data Unclear risk (attrition bias)

All outcomes

\begin{abstract}
12/32 withdrew (37.5\%). Large degree of attrition, even in both groups and well-explained, however self-measurement of BP led to some attrition. Details: 32 participants enrolled, 12 withdrew (6 in each intervention), 20 completed and were included for analysis. Reasons for attrition

Quote: "Twelve patients. six on salt pills and six on placebo, could not complete both arms of the study for the following reasons: gastrointestinal symptoms (5), itch (1), depression (1), poor record keeping (1), patient decision for no identifiable reason (2), and patient concern about their BP based on single BP readings (2). In one of these two patients, the diastolic BP did not exceed 85 , and in the second patient systolic BP did not exceed 160 . Their data have been excluded. Twenty patients completed the entire study. The high dropout rate warrants further discussion. This protocol placed considerable demands on these patients. beyond the usual rigours of home dialysis, and in our view, five to six of the dropouts were related to a general apathy that developed during the study. The gastrointestinal symptoms may in part be related to the highly artificial manner in which the salt was given, but the strict design of the study mandated the procedure. To our surprise, two of the five patients whose gastrointestinal intolerance led to withdrawal from the study developed those symptoms when taking placebo."
\end{abstract}

\begin{tabular}{lll}
\hline $\begin{array}{l}\text { Selective reporting (re- } \\
\text { porting bias) }\end{array}$ & Low risk & No evidence of reporting bias \\
\hline Carry-over effect & Low risk & Sufficient washout \\
\hline Bias from confounders & Unclear risk & $\begin{array}{l}\text { Measurement of dietary confounders not described. Medication changes not } \\
\text { well reported. Quote: "None of the hypertensive patients had to adjust their } \\
\text { medications during the salt period." }\end{array}$ \\
\hline
\end{tabular}


Fine 1997 (Continued)
Other
High risk
Funding: Baxter Healthcare Corporation

Keven 2006

\section{Study characteristics}

\begin{tabular}{|c|c|}
\hline Methods & $\begin{array}{l}\text { - Study design: parallel RCT } \\
\text { - Time frame: January } 2004 \text { to December } 2004 \\
\text { - Study duration (weeks): total (12); intervention (12) }\end{array}$ \\
\hline Participants & $\begin{array}{l}\text { - Country: Turkey } \\
\text { - Setting: not reported } \\
\text { - Inclusion criteria: underwent kidney transplant between } 1993 \text { and } 2002 \text { and continuing care at time } \\
\text { of screening; stable allograft function at the time of evaluation }(\mathrm{SCr}<2.5 \mathrm{mg} / \mathrm{dL}) \text {; on antihypertensive } \\
\text { treatment; residing in geographic proximity to the institution } \\
\text { - Baseline characteristics } \\
\text { * Duration of transplant (years): low salt ( } 5.3 \pm 3.1) \text {; high salt }(7.2 \pm 3.9) \\
\text { * Mean baseline BP } \pm \mathrm{SD} \mathrm{mm} \mathrm{Hg}(\mathrm{SBP} / \mathrm{DBP}) \text { : low salt }(146 \pm 21 / 89 \pm 8) \text {; high salt }(140 \pm 16 / 86 \pm 8) \\
\text { * Mean sodium excretion } \pm \mathrm{SD}(\mathrm{mmol} / \text { day): total }(190 \pm 57) \text {; low salt }(191 \pm 17) \text {; high salt }(190 \pm 75) \\
\text { - Number: low salt (18); high salt }(14) \\
\text { - Mean age } \pm \mathrm{SD} \text { (years): low salt }(40 \pm 14) \text {; high salt ( } 43 \pm 9) \\
\text { - Sex (M/F): } 25 / 7 \\
\text { - Exclusion criteria: evidence of renal artery stenosis on Doppler ultrasonography }\end{array}$ \\
\hline
\end{tabular}

\begin{tabular}{ll}
\hline Interventions & Low salt group \\
- Target sodium intake: 80 to $100 \mathrm{mmol} / \mathrm{day}$ (counselling by dietician) \\
- Duration: 12 weeks \\
High salt group \\
- Sodium intake: assumed usual diet (information not provided) \\
- Duration: 12 weeks \\
Co-interventions \\
- Antihypertensive treatment (including dose/number of drugs) adjusted if SBP $>140$ or $<100 \mathrm{~mm} \mathrm{Hg}$, \\
and/or DBP $>90$ mm Hg or $<70$ mm Hg as assessed by a blinded physician \\
\hline - Clinic BP (sitting, after 5 minutes rest) \\
- Serum markers (electrolytes, creatinine) \\
- Measurement of sodium intake: 24 -hour urine \\
\hline Outcomes
\end{tabular}

\section{Risk of bias}

\begin{tabular}{lll}
\hline Bias & Authors' judgement & Support for judgement \\
\hline $\begin{array}{l}\text { Random sequence genera- } \\
\text { tion (selection bias) }\end{array}$ & Unclear risk & $\begin{array}{l}\text { "Randomised". Further information not provided. Considerable difference in } \\
\text { baseline BP likely to underestimate effect of intervention with parallel design }\end{array}$ \\
\hline
\end{tabular}


Keven 2006 (Continued)

Allocation concealment Unclear risk Insufficient information to permit judgement
(selection bias)

\begin{tabular}{|c|c|c|}
\hline $\begin{array}{l}\text { Blinding of participants } \\
\text { and personnel (perfor- } \\
\text { mance bias) } \\
\text { All outcomes }\end{array}$ & Unclear risk & $\begin{array}{l}\text { Open-label dietary intervention however outcomes were objective and unlike- } \\
\text { ly to be influenced by performance bias }\end{array}$ \\
\hline $\begin{array}{l}\text { Blinding of outcome as- } \\
\text { sessment (detection bias) } \\
\text { All outcomes }\end{array}$ & Unclear risk & Insufficient information to permit judgement \\
\hline $\begin{array}{l}\text { Incomplete outcome data } \\
\text { (attrition bias) } \\
\text { All outcomes }\end{array}$ & Low risk & $\begin{array}{l}\text { Attrition reasons explained; however, attrition for each group not provided. } \\
35 \text { participants began study, } 3 \text { withdrew (noncompliance with study visits (1), } \\
\text { long-term hospitalisation secondary to chronic diarrhoea (1), development of } \\
\text { chronic allograft nephropathy (1)) }\end{array}$ \\
\hline
\end{tabular}

\begin{tabular}{|c|c|c|}
\hline $\begin{array}{l}\text { Selective reporting (re- } \\
\text { porting bias) }\end{array}$ & Unclear risk & $\begin{array}{l}\text { No evidence of reporting bias; however, study registration could not be locat- } \\
\text { ed }\end{array}$ \\
\hline
\end{tabular}

\begin{tabular}{|c|c|c|}
\hline Bias from confounders & High risk & $\begin{array}{l}\text { Confounding factors not measured/described (body weight, potassium, an- } \\
\text { tihypertensive medication changes ( } 7 \text { in low salt group; } 1 \text { in high salt group). } \\
\text { Highly likely that other dietary factors may have confounded results with un- } \\
\text { blinded, usual intake versus low sodium, study design. Baseline imbalances: } \\
\text { SBP/DBP was } 6 / 3 \mathrm{~mm} \text { Hg higher in low salt versus high salt group at baseline } \\
\text { which may have masked the effect on BP as change from baseline was not re- } \\
\text { ported }\end{array}$ \\
\hline
\end{tabular}

\begin{tabular}{lll}
\hline Other & Unclear risk & Funding: not reported \\
\hline
\end{tabular}

Konishi 2001

\section{Study characteristics}

\begin{tabular}{ll}
\hline Methods & Study design: cross-over RCT \\
- Time frame: 1998 to 2002 \\
- Duration of study (weeks): total (3); run in (1); interventions (1); no washout \\
\hline Participants & - Country: Japan \\
- Setting: single centre, Osaka City General Hospital \\
- Baseline characteristics \\
$*$ GFR: not reported \\
$*$ BP: not reported \\
- Number: 38 \\
- Mean age \pm SD: $45 \pm 15$ years \\
- Sex: $14 / 27$ \\
- Exclusion criteria: other kidney or heart disease; taking any medication \\
Low salt group \\
- Sodium intake: 87 mmol/day (meals provided) \\
- Duration: 1 week \\
High salt group
\end{tabular}


Konishi 2001 (Continued)

- Sodium intake: $209 \mathrm{mmol} / \mathrm{day}$ (meals provided)

- Duration: 1 week

Other information

- Study diets contained the same amount of protein (1.2 g/kg body weight/day) and calories (35 kcal/ $\mathrm{kg} /$ day)

- Participants were asked to maintain usual levels of physical activity and to refrain from drugs for 1 week before and during the study

- Co-interventions: none

\begin{tabular}{ll}
\hline Outcomes & 24-hour BP (hourly measurements) \\
- 24-hour proteinuria \\
- Serum markers (electrolytes, renin, aldosterone) \\
- Renal plasma flow, $\mathrm{CrCl}$ \\
- Measurement of sodium intake: 24-hour urine (3 days) \\
- Measurement of confounders: assumed medications recorded from medical charts \\
\hline Notes & - Funding: not reported \\
& Additional data: provided by authors
\end{tabular}

\section{Risk of bias}

\begin{tabular}{|c|c|c|}
\hline Bias & Authors' judgement & Support for judgement \\
\hline $\begin{array}{l}\text { Random sequence genera- } \\
\text { tion (selection bias) }\end{array}$ & Unclear risk & Insufficient information to permit judgement \\
\hline $\begin{array}{l}\text { Allocation concealment } \\
\text { (selection bias) }\end{array}$ & Unclear risk & Insufficient information to permit judgement \\
\hline $\begin{array}{l}\text { Blinding of participants } \\
\text { and personnel (perfor- } \\
\text { mance bias) } \\
\text { All outcomes }\end{array}$ & Unclear risk & $\begin{array}{l}\text { Information not provided however outcomes were objective and unlikely to be } \\
\text { influenced by performance bias }\end{array}$ \\
\hline $\begin{array}{l}\text { Blinding of outcome as- } \\
\text { sessment (detection bias) } \\
\text { All outcomes }\end{array}$ & Low risk & $\begin{array}{l}\text { Information not provided. However, given nature of outcomes (objective and } \\
\text { results not available immediately) }\end{array}$ \\
\hline $\begin{array}{l}\text { Incomplete outcome data } \\
\text { (attrition bias) } \\
\text { All outcomes }\end{array}$ & Unclear risk & Insufficient information to permit judgement \\
\hline $\begin{array}{l}\text { Selective reporting (re- } \\
\text { porting bias) }\end{array}$ & Unclear risk & $\begin{array}{l}\text { No evidence of reporting bias; however, study registration could not be locat- } \\
\text { ed }\end{array}$ \\
\hline Carry-over effect & Unclear risk & Short interventions with no washout - carry over effect may be present \\
\hline Bias from confounders & Unclear risk & $\begin{array}{l}\text { Standardised meals were provided reducing risk of dietary confounders, but } \\
\text { as confounders (e.g. potassium intake, weight loss) were not discussed, risk } \\
\text { of bias is unclear. Medications not reported but protocol was to refrain from } \\
\text { medications }\end{array}$ \\
\hline Other & Unclear risk & Funding not reported \\
\hline
\end{tabular}


Kwakernaak 2014

\section{Study characteristics}

Methods

- Study design: cross-over RCT

- Time frame: October 2009 to December 2012

- Study duration (weeks): total (30); run in (6); interventions (6); no washout
- Country: the Netherlands

- Setting: multi-centre; outpatient clinics (3)

- Inclusion criteria: consecutive patients with type 2 DM and presence of diabetic kidney disease (as diagnosed by the patient's own nephrologist on the basis of medical history and analysis of blood and urine); presence of albuminuria (defined as albuminuria $>30 \mathrm{mg} /$ day or urinary albumin concentration $>20 \mathrm{mg} / \mathrm{L}$ or urinary ACR $>2.5 \mathrm{mg} / \mathrm{mmol}$ for men and $>3.5 \mathrm{mg} / \mathrm{mmol}$ for women) at time of screening and after completion of the run-in period; aged $\geq 18$ years; $\mathrm{CrCl} \geq 30 \mathrm{~mL} / \mathrm{min}$ with $<6 \mathrm{~mL}$ / min decline in the previous year

- Baseline characteristics

* Mean GFR \pm SD: $65 \pm 25 \mathrm{~mL} / \mathrm{min} / 1.73 \mathrm{~m}^{2}$

* $\mathrm{BP}(\mathrm{SBP} / \mathrm{DBP})$ : not reported

* Mean BMI \pm SD: $32 \pm 5 \mathrm{~kg} / \mathrm{m}^{2}$

* Median time since DM diagnosis (IQR): 9 years (5 to 19$)$

* Median number antihypertensives (range): 1 (0-3)

- Number: randomised (45); analysed (45)

- Mean age \pm SD: $65 \pm 9$ years

- $\operatorname{Sex}(\mathrm{M} / \mathrm{F}): 38 / 7$

- Exclusion criteria: SBP of $\geq 180 \mathrm{~mm} \mathrm{Hg}$; DBP $\geq 110 \mathrm{~mm} \mathrm{Hg}$; overt nephrotic syndrome at baseline; second primary kidney disease in addition to diabetic kidney disease; type $1 \mathrm{DM}$; renovascular hypertension; a cardiovascular or cerebrovascular event within 3 months before inclusion; serum potassium $\geq$ $6.0 \mathrm{mmol} / \mathrm{L}$; transplantation or immunosuppressive treatment; contraindication for the use of lisinopril or hydrochlorothiazide; pregnancy or lactation; noncompliance with medication; inability to provide informed consent
Low salt group

- Target sodium intake: $50 \mathrm{mmol} /$ day (individualised counselling by dietician)

- Duration: 12 weeks

High salt group

- Sodium intake: usual diet (target $200 \mathrm{mmol} /$ day)

- Duration: 12 weeks

Co-interventions

- Each participant was on lisinopril $40 \mathrm{mg} /$ day for entire study and went through four interventions for six weeks each in random order ( ${ }^{*}$ used for analysis)

* Usual salt, placebo*

* Usual salt, hydrochlorothiazide $50 \mathrm{mg} /$ day

* High salt, placebo*

* High salt, hydrochlorothiazide $50 \mathrm{mg} /$ day

Other information

- During the 6 week run-in period, patients were titrated to maximum dose of ACEi (lisinopril $40 \mathrm{mg} /$ day), whereas all other RAAS blockers and diuretics were discontinued

- No dietary intervention during the run-in period

- Additional antihypertensive drugs, such as alpha blockers, beta blockers, and calcium-channel blockers, were allowed when dosage was stable throughout the trial 
Kwakernaak 2014 (Continued)
Outcomes
- 24-hour albuminuria and proteinuria
- Clinic BP (semi-supine)
- Weight
- Serum markers (electrolytes, lipids, proteins, creatinine)
- Urinary markers, $\mathrm{CrCl}$
- Measurement of sodium intake: 24-hour urine
- Measurement of confounders
* Medication intake measured by pill counts
* Urea \& potassium excretion

\begin{tabular}{ll}
\hline Notes & Funding: Unfunded \\
& - Trial registration: http://www.trialregister.nl/trialreg/admin/rctview.asp?TC=2366 \\
& - Additional data: additional data not requested
\end{tabular}

\section{Risk of bias}

\begin{tabular}{lll} 
Bias & Authors' judgement & Support for judgement \\
\hline $\begin{array}{ll}\text { Random sequence genera- } \\
\text { tion (selection bias) }\end{array}$ & Low risk & $\begin{array}{l}\text { Quote: "Independent pharmacist used a computer program to randomise pa- } \\
\text { tients in blocks of two. No stratification was needed as the trial has a crossover } \\
\text { design. An independent pharmacist randomised treatment sequences. Pa- } \\
\text { tients were sequentially enrolled according to moment of recruitment. The } \\
\text { randomisation code remained secret during the entire trial" }\end{array}$
\end{tabular}

$\begin{array}{ll}\begin{array}{l}\text { Allocation concealment } \\ \text { (selection bias) }\end{array} & \begin{array}{l}\text { Quote“...drug intervention was double blind, whereas the dietary intervention } \\ \text { was open label”. "All patients, investigators, and health-care providers were } \\ \text { masked, apart from the pharmacist who did the randomisation. On comple- } \\ \text { tion of the trial, the principal investigator (AJK) provided the pharmacist and } \\ \text { the medical ethics committee with a written statement that the trial was com- } \\ \text { pleted, after which masking ended” }\end{array} \\ \end{array}$

\begin{tabular}{|c|c|c|}
\hline $\begin{array}{l}\text { Blinding of participants } \\
\text { and personnel (perfor- } \\
\text { mance bias) }\end{array}$ & Unclear risk & $\begin{array}{l}\text { Dietary interventions were open label but outcomes were objective and un- } \\
\text { likely to be influenced by performance bias }\end{array}$ \\
\hline All outcomes & & $\begin{array}{l}\text { Blinding of participants: yes for drug, no for diet; blinding of investigators: yes } \\
\text { for drug, no for diet; blinding of outcomes assessors: yes for drug, no for diet; } \\
\text { blinding of data assessors: yes for drug, no for diet }\end{array}$ \\
\hline
\end{tabular}

$\begin{array}{lll}\begin{array}{l}\text { Blinding of outcome as- } \\ \text { sessment (detection bias) }\end{array} & \text { Unclear risk } & \begin{array}{l}\text { The drug intervention was double blind, whereas the dietary intervention was } \\ \text { open label }\end{array}\end{array}$
sessment (detection bias) open label

All outcomes

\begin{tabular}{ll}
\hline $\begin{array}{l}\text { Incomplete outcome data } \\
\text { (attrition bias) }\end{array}$ & Low risk \\
All outcomes & $\begin{array}{l}45 \text { randomised; } 2 \text { excluded after randomisation, due to onset of malignancy } \\
\text { and } 1 \text { non-adherence to sodium restriction; all } 45 \text { included in intention-to- } \\
\text { treat analysis }\end{array}$
\end{tabular}

\begin{tabular}{|c|c|c|}
\hline $\begin{array}{l}\text { Selective reporting (re- } \\
\text { porting bias) }\end{array}$ & Low risk & $\begin{array}{l}\text { Study was pre-registered online and the pre-specified outcomes were report- } \\
\text { ed }\end{array}$ \\
\hline Carry-over effect & Low risk & $\begin{array}{l}\text { Quote: "Use of } 6 \text {-week treatment periods was based on previous studies from } \\
\text { our department in patients with non-diabetic nephropathy, showing that } \\
\text { changes in albuminuria generally stabilise } 3-4 \text { weeks after the change in thera- } \\
\text { py" }\end{array}$ \\
\hline
\end{tabular}

\begin{tabular}{|c|c|c|}
\hline Bias from confounders & Unclear risk & $\begin{array}{l}\text { Potassium: urinary excretion measured and reported unchanged; body weight } \\
\text { change: measured and } 2 \mathrm{~kg} \text { significant reduction with low salt; physical activ- }\end{array}$ \\
\hline
\end{tabular}




\begin{tabular}{ll}
\hline Other Low risk & $\begin{array}{l}\text { Quote: "No funding was received for this trial. The sponsor of this trial is the } \\
\text { University Medical Centre Groningen, Netherlands." } \\
\text { Conflict of interest: nil }\end{array}$ \\
\hline
\end{tabular}

LOWSALT CKD 2012

\section{Study characteristics}

\begin{tabular}{|c|c|}
\hline Methods & $\begin{array}{l}\text { - Study design: cross-over, double blind RCT } \\
\text { - Time frame: September } 2011 \text { to July } 2012 \\
\text { - Duration of study (weeks): total (6); run in/washout (1); interventions (2) }\end{array}$ \\
\hline Participants & $\begin{array}{l}\text { - Setting: single centre } \\
\text { - Country: Australia } \\
\text { - Inclusion criteria: eGFR } 15-59 \text {; SBP } 130 \text { to } 169 \mathrm{~mm} \mathrm{Hg} \text {; DBP > } 70 \mathrm{~mm} \mathrm{Hg} \text {; } \geq 18 \text { years } \\
\text { - Baseline characteristics } \\
\text { * CKD: Stage } 3 \text { to } 4 \text { non-dialysed, non-transplanted } \\
\text { * Mean BP } \pm \text { SD mm Hg (SBP/DBP): low salt ( } 149 \pm 15 / 85 \pm 6) \text {; high salt }(156 \pm 11 / 85 \pm 6) \\
\text { * Mean sodium excretion } \pm \text { SD: } 132 \pm 57 \text { mmol/day } \\
\text { - Number: } 20 \\
\text { - Mean age } \pm \text { SD: } 68.5 \pm 11.0 \text { years } \\
\text { - Sex (M/F): } 15 / 5 \\
\text { - Exclusion criteria: receiving KRT (dialysis or transplant) or likely to within study period; salt-wasting } \\
\text { CKD (as diagnosed by nephrologist); prescribed > } 1680 \text { mg sodium bicarbonate and unable to cease } \\
\text { therapy for } 6 \text { weeks; pregnant or breastfeeding; life expectancy < } 6 \text { months; current involvement in } \\
\text { other intervention; unable to comprehend study protocol }\end{array}$ \\
\hline
\end{tabular}

Interventions

Low salt group

- Sodium intake goal: 60 to $80 \mathrm{mmol} /$ day achieved by dietary education from trained dietician, plus placebo tablets

- Duration: 2 weeks

High salt group

- Sodium intake: low salt diet (goal 60 to $80 \mathrm{mmol} /$ day) achieved by dietary education plus $120 \mathrm{mmol}$ of sodium capsules

- Duration: 2 weeks

Other information

- Aimed to keep intake of other nutrients stable

- Co-interventions: none

- Values and the end of the intervention used; for some outcomes standard deviations were imputed so that effect size matched actual effect size of paired data

$\begin{array}{ll}\text { Outcomes } & \text { 24-hour BP (every } 20 \text { min during the day and } 30 \text { min at night) } \\ \text { - } 24 \text {-hour proteinuria and albuminuria } \\ \text { - Pulse wave velocity } \\ \text { - Augmentation index (pulse wave analysis) } \\ \text { - eGFR }\end{array}$


- Fluid status (bio-impedance spectroscopy using Body Composition Monitor)

- 24-hour urine output

- Weight

- NT-proBNP (via blood sample)

- Thirst (via xerostomia Index)

- CRP and adipokines

- Stimulation of RAAS (blood sample)

- Taste test study

- Barriers and enablers to adherence measured via beliefs about dietary compliance scale and attitudes to dietary recommendations questionnaires

- Sodium intake measurement

* 24-hour urine

* Midstream urine sample

* Semi-quantitative dietary history forms (verified by study dieticians)

* Food-frequency questionnaire

- Measurement of confounders

* 24-hour urinary potassium and urea

* Body weight change

* Dietary history (verified by study dieticians) to assess protein, sodium and energy intake

* Daily self-record of study medication intake

Notes

- Authors on this review (EM, KC) were investigators in the LowSALT CKD Study. The risk of bias was not assessed by these authors

- Additional data: provided by authors

- Trial registration: ACTRN12611001097932

\section{Risk of bias}

\section{Bias}

\section{Authors' judgement Support for judgement}

Random sequence genera- Low risk Randomisation was performed by an external statistical consultant
tion (selection bias)

\begin{tabular}{|c|c|c|}
\hline $\begin{array}{l}\text { Allocation concealment } \\
\text { (selection bias) }\end{array}$ & Low risk & $\begin{array}{l}\text { Quote: "Study medication was packaged offsite and labelled with the study } \\
\text { numbers and intervention order" }\end{array}$ \\
\hline
\end{tabular}

Blinding of participants Low risk
and personnel (perforQuote: "Participants, investigators, and outcome assessors were blinded to mance bias)

All outcomes

\section{Blinding of outcome as- Low risk} sessment (detection bias)

All outcomes the allocation"

\author{
Quote: "Participants, investigators, and outcome assessors were blinded to \\ the results of all outcomes." \\ Quote: "Data analysis was initially performed blinded to treatment order and \\ then was performed unblinded to confirm treatment order" \\ Blinding of participants: all outcomes \\ Blinding of investigators and outcome assessors: serum and urinary markers, \\ 24-hour BP and clinic BP blinded; arterial stiffness (pulse wave velocity and \\ analysis) unblinded \\ Blinding of data assessors: initial data analysis performed blinded to alloca- \\ tion and urinary sodium data
}


LowSALT CKD 2012 (Continued)

Incomplete outcome data Low risk 25\% attrition (5/25)

(attrition bias)

All outcomes

Attrition balanced between intervention periods and reasons for attrition well documented and unrelated to study results. Those who withdrew from the study did not differ in age or sex but had significantly higher weight and body mass index values compared with those who completed the study. 25 participants randomised; 5 withdrew; visit schedule too demanding (3), hospital admission unrelated to study (1), symptoms related to pre-existing medical condition (1). Some data missing for some outcomes but these are well justified

Quote: "One patient had missing data for urinary measures (sample not collected, $n=1$ ), and two for fluid measurement (presence of a pacemaker contraindicating measurement $[n=1]$; data loss $[n=1])$."

\begin{tabular}{|c|c|c|}
\hline $\begin{array}{l}\text { Selective reporting (re- } \\
\text { porting bias) }\end{array}$ & Low risk & $\begin{array}{l}\text { Study was pre-registered online and the pre-specified outcomes were report- } \\
\text { ed. Data for all outcomes available for inclusion in review }\end{array}$ \\
\hline
\end{tabular}

\begin{tabular}{ll}
\hline Carry-over effect $\quad$ Low risk & "To test for ... variation due to treatment order ... analysis of covariance was \\
conducted" No relationship found significant difference. Data analysed for car- \\
ry over effect
\end{tabular}

\begin{tabular}{ll}
\hline Bias from confounders $\quad$ Low risk & $\begin{array}{l}\text { Major confounding factors measured (potassium intake, energy intake, protein } \\
\text { intake, body weight, medication changes) and assessed for potential impact } \\
\text { on outcomes. Medication changes may have affected outcomes, although like- } \\
\text { ly to underestimate effect size }\end{array}$ \\
\hline
\end{tabular}

\begin{tabular}{ll}
\hline Other & Low risk \\
& $\begin{array}{l}\text { Funding by hospital trust and not-for-profit organisation. Funding: research } \\
\text { Kidney Health Australia. Study foods provided by Freedom Foods, Norco, Real }\end{array}$ \\
& $\begin{array}{l}\text { Foods, Carman's Fine Foods, Sanitarium Health \& Wellbeing Company, Rosel- } \\
\text { la, and Diego's }\end{array}$ \\
\end{tabular}

Mulhauser 1996

\section{Study characteristics}

\begin{tabular}{|c|c|}
\hline Methods & $\begin{array}{l}\text { - Study design: double-blind, parallel RCT } \\
\text { - Time frame: } 4 \text { years } \\
\text { - Study duration (weeks): total (10); run-in (6) intervention (4) }\end{array}$ \\
\hline Participants & 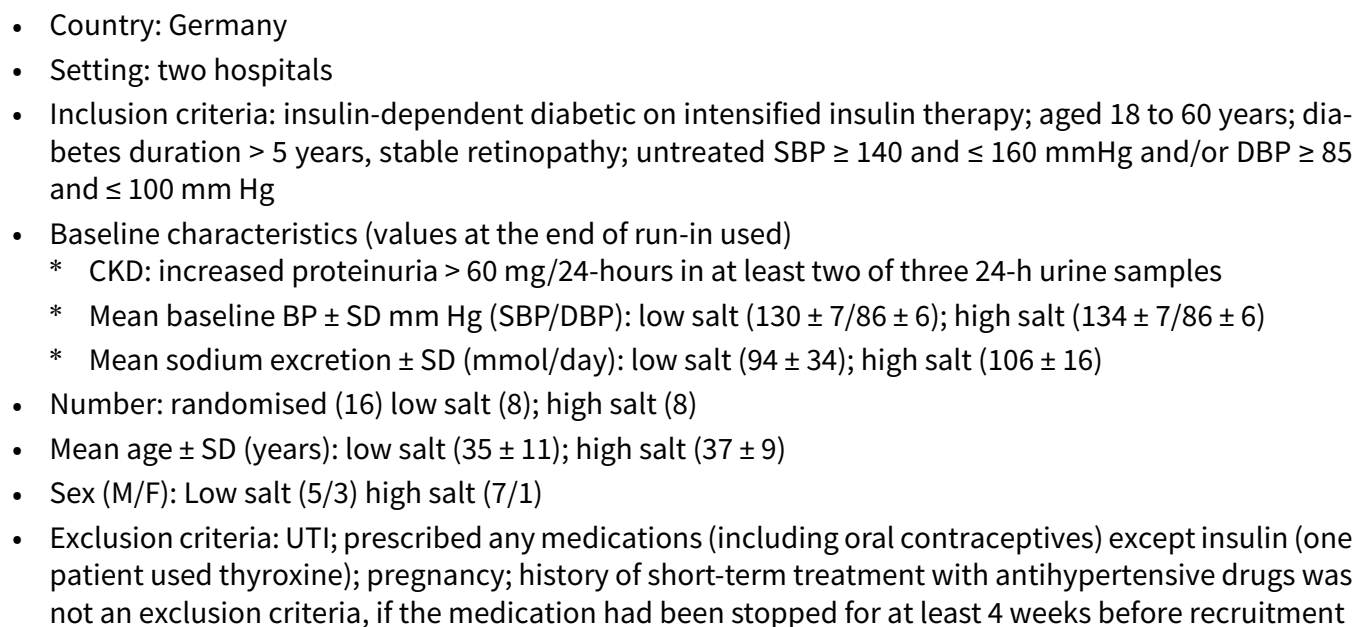 \\
\hline
\end{tabular}


Mulhauser 1996 (Continued)

\begin{tabular}{|c|c|}
\hline Interventions & $\begin{array}{l}\text { Low salt group } \\
\text { - Sodium restriction and placebo (group 1) } \\
\text { - Duration: } 4 \text { weeks } \\
\text { High salt group } \\
\text { - Sodium restriction and sodium tablets (group 2) } \\
\text { - Duration: } 4 \text { weeks } \\
\text { Other } \\
\text { - Run-in: 4-week usual diet followed by 2-week sodium restriction (by dietitian and nutritionists; re- } \\
\text { duced sodium bread provided) } \\
\text { - Co-interventions: none }\end{array}$ \\
\hline Outcomes & $\begin{array}{l}\text { - Clinic BP (mean of four sitting and four supine measurements, taken after } 10 \text { minutes rest) } \\
\text { - } \text { - Plame BP (as per clinic BP) } \\
\text { II) } \\
\text { - } \text { eGFR was assessed by the clearance of inulin and RPF by the clearance of PAH } \\
\text { - Renal vascular resistance (mean arterial BP x } 100 \text { x (1-haematocrit) divided by RPF filtration fraction } \\
\text { (GFR divided by RPF) } \\
\text { - Total exchangeable body sodium (weeks } 8 \text { and } 12 \text { ) (whole body counter method in three patients, and } \\
\text { modified isotope dilution method in } 13 \text { patients) } \\
\text { - Blood volume } \\
\text { - Plasma volume } \\
\text { - Erythrocyte volume } \\
\text { - Measurement of sodium intake: } 24-h o u r \text { urine; } 3 \text { day food diary } \\
\text { - Measurement of confounders: protein intake was calculated from } 24-h \text { urinary nitrogen excretion }\end{array}$ \\
\hline Notes & $\begin{array}{l}\text { - Additional data: unable to contact authors } \\
\text { - Trial registration: none found }\end{array}$ \\
\hline
\end{tabular}

\section{Risk of bias}

\begin{tabular}{lll}
\hline Bias & Authors' judgement & Support for judgement \\
\hline $\begin{array}{l}\text { Random sequence genera- } \\
\text { tion (selection bias) }\end{array}$ & Unclear risk & $\begin{array}{l}\text { Not described; some baseline differences but analyses adjusted for baseline } \\
\text { values }\end{array}$ \\
\hline $\begin{array}{l}\text { Allocation concealment } \\
\text { (selection bias) }\end{array}$ & Low risk & "Double blind" and medications packaged by pharmacy. Probably concealed \\
\hline $\begin{array}{l}\text { Blinding of participants } \\
\text { and personnel (perfor- } \\
\text { mance bias) } \\
\text { All outcomes }\end{array}$ & Low risk & Double blind \\
\hline
\end{tabular}

Blinding of outcome as- Low risk $\quad$ Outcome assessors were blinded
sessment (detection bias)
All outcomes

\footnotetext{
Incomplete outcome data Low risk (attrition bias)

No attrition reported after randomisation; no missing data reported
}

All outcomes 
Mulhauser 1996 (Continued)

Selective reporting (re- High risk Pre-specified study protocol not available. Many outcomes could not be porting bias) analysed using t-test (despite values indicating the data were not normally distributed), P values were not reported, adjustment for multiple comparisons occurred but not clear if this applied to all outcomes. Change (from end of run in to end of intervention) reported for BP only, unclear while other outcomes are reported only as values at the end of the intervention.

Bias from confounders Unclear risk

Participants were not on anti-hypertensive medications; known dietary confounders measured and reported unchanged; weight stable

Baseline imbalances: change from baseline not reported. Unable to determine if this would have impacted findings based on information given

Other Unclear risk

Funding: The study has been supported by Cassella Riedel, Frankfurt, Germany, and by the E Klockner Stiftung, Duisburg, Germany. Unclear of role of funding bodies

Power 2010

\section{Study characteristics}

\begin{tabular}{ll}
\hline Methods & Study design: RCT, parallel \\
- & Time frame: August 2008 to December 2009 \\
& - Duration (weeks): run-in (12), intervention (36) \\
\hline Participants & Country: UK \\
- Setting: hospital \\
- Inclusion criteria: not reported \\
Baseline characteristics \\
$*$ CKD: HD \\
$*$ BP (SBP/DBP): not reported \\
$*$ Sodium excretion (mmol/day): not reported \\
- Number: randomised (50); analysed (31) \\
- Mean age \pm SD (years): $65.1 \pm 12.4$ \\
- Sex (M/F): $84 \%$ male \\
\hline
\end{tabular}

- Sodium intake: restriction to $2.3 \mathrm{~g} /$ day with dietetic input

- Duration: 36 weeks

High salt group

- Further information not provided

- Duration: not reported

Other information

- Other groups

* Low dialysate sodium alone: target $3 \mathrm{mM}$ below patient's mean serum level by graded reduction: $1 \mathrm{mM} / 2$ weeks

* Low dialysate \& sodium restriction 
Power 2010 (Continued)

- Run-in period: dialysate sodium 140 mM, unrestricted diet

\begin{tabular}{ll}
\hline Outcomes & Ambulatory BP (every 6 weeks midpoint of dialysis week) \\
& - Anti-hypertensive dose \\
& - Dialysis symptom index (including cramps) \\
- Sodium gradient (NaG) (difference dialysate - serum $\mathrm{Na})$ \\
\hline Notes & - Abstract-only publication \\
& Additional data: requested
\end{tabular}

\section{Risk of bias}

\begin{tabular}{|c|c|c|}
\hline Bias & Authors' judgement & Support for judgement \\
\hline $\begin{array}{l}\text { Random sequence genera- } \\
\text { tion (selection bias) }\end{array}$ & Unclear risk & Insufficient information to permit judgement \\
\hline $\begin{array}{l}\text { Allocation concealment } \\
\text { (selection bias) }\end{array}$ & Unclear risk & Insufficient information to permit judgement \\
\hline $\begin{array}{l}\text { Blinding of participants } \\
\text { and personnel (perfor- } \\
\text { mance bias) } \\
\text { All outcomes }\end{array}$ & Unclear risk & Open-label study \\
\hline $\begin{array}{l}\text { Blinding of outcome as- } \\
\text { sessment (detection bias) } \\
\text { All outcomes }\end{array}$ & Unclear risk & Insufficient information to permit judgement \\
\hline $\begin{array}{l}\text { Incomplete outcome data } \\
\text { (attrition bias) } \\
\text { All outcomes }\end{array}$ & High risk & $\begin{array}{l}38 \% \text { attrition ( } 50 \text { entered, } 31 \text { analysed; reasons not described; attrition by allo- } \\
\text { cation not stated); unclear if there are missing outcome data }\end{array}$ \\
\hline $\begin{array}{l}\text { Selective reporting (re- } \\
\text { porting bias) }\end{array}$ & High risk & $\begin{array}{l}\text { Pre-specified study protocol not available. Results on ambulatory BP and an- } \\
\text { ti-hypertensive dose for control versus sodium restriction groups not reported } \\
\text { Note: abstract-only publication (requested additional results from study au- } \\
\text { thors but have not received a response) }\end{array}$ \\
\hline Bias from confounders & Unclear risk & $\begin{array}{l}\text { Measurement of confounders not described } \\
\text { Baseline imbalances: baseline values not reported }\end{array}$ \\
\hline Other & Low risk & Disclosure of financial relationships "nothing to describe" \\
\hline
\end{tabular}

Rodrigues Telini 2014

\section{Study characteristics}

\begin{tabular}{ll}
\hline Methods & Study design: parallel, open-label RCT \\
& - Time frame: April 2007 to February 2009 \\
& Duration of study: 16 weeks \\
\hline Participants & - Country: Brazil \\
& - Setting: single centre, university hospital
\end{tabular}


- Inclusion criteria: $\geq 18$ years; HD for at least 90 days; diagnosed with inflammation (CRP levels $\geq 0.7$ $\mathrm{mg} / \mathrm{dL}$, based on median of CRP levels in a sample of $119 \mathrm{HD}$ patients in the dialysis unit)

- Baseline characteristics

* Median dialysis duration in months (IQR): low salt $(30.90$ (8.75, 105.5); high salt (49.50 (26.0; 58.0)

* Mean BP \pm SD mm Hg (SBP/DBP): total (146 $\pm 17 / 85.89 \pm 11.92)$; low salt $(149 \pm 13.70 / 87.24 \pm 10.99)$; high salt $(142 \pm 19.30 / 84.31 \pm 13.06)$

* Mean sodium intake from 3 day record \pm SD (converted to mmol/day): total $(159 \pm 26)$; low salt (157 $\pm 25)$; high salt $(162 \pm 27)$

- Number

* Randomised: total (53); low salt (30); high salt (23)

* Completed/analysed: total (39); low salt (21); high salt (18)

- Mean age \pm SD (years): total $(57.95 \pm 12.9)$; low salt $(56.00 \pm 11.91)$; high salt $(60.22 \pm 13.96)$

- Sex (M/F): total (27/12); low salt (12/9); high salt (15/18)

- Exclusion criteria: acute inflammatory processes; chronic inflammatory diseases; antibiotic use within the past 2 months; malignancies; central venous catheter use

\begin{tabular}{|c|c|}
\hline Interventions & $\begin{array}{l}\text { Low salt group } \\
\text { - Sodium intake: restriction aiming for a } 2 \mathrm{~g} \text { reduction; dietary counselling by nutritionist } \\
\text { - Duration: } 16 \text { weeks } \\
\text { High salt group } \\
\text { - Usual sodium intake } \\
\text { - Duration: } 16 \text { weeks } \\
\text { Other information: } \\
\text { - All patients were dialysed } 3 \text { times/week, for } 3.5 \text { to } 4 \text { hours/session using low-flux polysulfone dialysers } \\
\text { and dialysate with bicarbonate buffer and a sodium concentration of } 138 \mathrm{mEq} / \mathrm{L} \\
\text { - Prescribed dialysis doses (Kt/V) were at least } 1.4\end{array}$ \\
\hline Outcomes & $\begin{array}{l}\text { - BP: average of the last } 10 \text { routine predialysis measurements } \\
\text { - Fluid status by bio-impedance analysis performed } 30 \text { minutes after dialysis sessions } \\
\text { - Serum levels of albumin, sodium, creatinine, urea, glucose, cholesterol, HDL cholesterol, triglycerides, } \\
\text { and bicarbonate, CRP, tumour necrosis factor-a, and interleukin- } 6 \\
\text { - HCT and Hb } \\
\text { - Body weight change } \\
\text { - Sodium intake: } 3-\text { day food record }\end{array}$ \\
\hline Notes & $\begin{array}{l}\text { - Registered at: CRSSTD: } 2904970 ; \text { https://clinicaltrials.gov/ct2/show/NCT01458808 } \\
\text { - Change from baseline not reported, therefore values at end of intervention (week 16) used } \\
\text { - Additional data: requested }\end{array}$ \\
\hline
\end{tabular}

\section{Risk of bias}

\begin{tabular}{lll}
\hline Bias & Authors' judgement & Support for judgement \\
\hline $\begin{array}{l}\text { Random sequence genera- } \\
\text { tion (selection bias) }\end{array}$ & Unclear risk & $\begin{array}{l}\text { Not described. Imbalance in group numbers (30 randomised to high salt; 23 to } \\
\text { low salt) }\end{array}$ \\
\hline $\begin{array}{l}\text { Allocation concealment } \\
\text { (selection bias) }\end{array}$ & Unclear risk & Insufficient information to permit judgement \\
\hline $\begin{array}{l}\text { Blinding of participants } \\
\text { and personnel (perfor- } \\
\text { mance bias) }\end{array}$ & Unclear risk & $\begin{array}{l}\text { Open-label study but outcomes were objective and unlikely to be influenced } \\
\text { by performance bias }\end{array}$ \\
\hline
\end{tabular}


Rodrigues Telini 2014 (Continued)

All outcomes

Blinding of outcome as-
sessment (detection bias) $\quad$ Unclear risk Insufficient information to permit judgement

All outcomes

Incomplete outcome data Unclear risk
(attrition bias)

All outcomes

$26 \%$ attrition $(14 / 53)$

Quote: "During the follow-up, 9 of 30 subjects in group A and 5 of 23 in group B were excluded because of acute infections. Therefore, 39 patients (21 in group A and 18 in group B) completed the study period."

Selective reporting (re- Low risk No evidence of selective reporting
porting bias)

Bias from confounders High risk
Potassium: not measured; body weight change; physical activity: not mea- sured; antihypertensive dose: reported not significantly different between groups.

Reported energy and protein intake not changed

Baseline imbalances: no significant differences at baseline, but there are clinically significant differences in the mean values. Change from baseline not reported, therefore baseline imbalances can bias estimated effect size when using values at the end of the intervention. SBP/DBP is $7 / 3 \mathrm{~mm} \mathrm{Hg}$ higher at baseline in intervention than control. Using end of intervention mean change is $1.7 /-3.78$, using change from baseline $8.2 /-0.8$

Other Low risk Funding: São Paulo Research Foundation; Conflict of interest: None declared

Ruilope 1992a

\section{Study characteristics}

\begin{tabular}{|c|c|}
\hline Methods & $\begin{array}{l}\text { - Study design: cross-over RCT } \\
\text { - Time frame: not reported } \\
\text { - Duration of study (weeks): total (6); run in (4); interventions (1); no washout }\end{array}$ \\
\hline Participants & $\begin{array}{l}\text { - Country: Spain } \\
\text { - Setting: Hypertension unit } \\
\text { - Inclusion criteria: mild kidney insufficiency, essential hypertension } \\
\text { - Baseline characteristics } \\
\text { * Mean BP } \pm \text { SD (SBP/DBP): } 158.2 \pm 29.1 / 99.9 \pm 8.9 \mathrm{~mm} \mathrm{Hg} \\
\text { * GFR: not reported } \\
\square \text { "Mild renal insufficiency", diagnostic criteria (not reported); nephrosclerosis (4); other clinical } \\
\text { criteria (10) } \\
\text { * Mean sodium excretion } \pm \text { SD: } 156.3 \pm 101.4 \mathrm{mmol} / \text { day } \\
\text { - Number: } 14 \\
\text { - Mean age } \pm \text { SD: } 63.5 \pm 22.4 \text { years } \\
\text { - Sex: not reported } \\
\text { - Exclusion criteria: no other concurrent medical illness }\end{array}$ \\
\hline
\end{tabular}

Low salt group
Interventions
$\begin{aligned} & \text { Sodium intake: } 68 \mathrm{mmol} / \text { day }(17 \mathrm{mmol} \text { dietary intake }+51 \mathrm{mmol} \text { supplement }) \text {. Further information } \\ & \text { not provided }\end{aligned}$


Ruilope 1992a (Continued)

$$
\text { - Duration: } 1 \text { week }
$$

High salt group

- Sodium intake: $187 \mathrm{mmol} /$ day (17 mmol dietary intake + $170 \mathrm{mmol}$ supplement). Further information not provided

- Duration: 1 week

Other details

- Run in (4 weeks) "no patient received medication"

- Dietary intake target $60 \mathrm{mmol}$ potassium/day

- Co-interventions: $240 \mathrm{mg}$ verapamil through both interventions

\begin{tabular}{ll}
\hline Outcomes & 24-hour BP (every 20 to $30 \mathrm{~min})$ \\
& - Clinic BP \\
- Weight \\
- $\mathrm{CrCl}$ \\
- $\mathrm{SCr}$ \\
- Measurement of sodium intake: 24-hour urine \\
- Measurement of confounders: urinary potassium \\
\hline Notes & - Funding: not reported
\end{tabular}

\section{Risk of bias}

\begin{tabular}{lll}
\hline Bias & Authors' judgement & Support for judgement \\
\hline $\begin{array}{l}\text { Random sequence genera- } \\
\text { tion (selection bias) }\end{array}$ & Unclear risk & "Randomised", no further information provided \\
\hline
\end{tabular}

Allocation concealment $\quad$ Unclear risk Insufficient information to permit judgement
(selection bias)

\begin{tabular}{|c|c|c|}
\hline $\begin{array}{l}\text { Blinding of participants } \\
\text { and personnel (perfor- }\end{array}$ & Unclear risk & $\begin{array}{l}\text { Information not provided, but outcomes were objective and unlikely to be in- } \\
\text { fluenced by performance bias }\end{array}$ \\
\hline
\end{tabular}
mance bias)

All outcomes

\begin{tabular}{lll}
\hline $\begin{array}{l}\text { Blinding of outcome as- } \\
\text { sessment (detection bias) } \\
\text { All outcomes }\end{array}$ & Unclear risk & Insufficient information to permit judgement \\
\hline $\begin{array}{l}\text { Incomplete outcome data } \\
\text { (attrition bias) } \\
\text { All outcomes }\end{array}$ & Unclear risk & Insufficient information to permit judgement \\
\hline $\begin{array}{l}\text { Selective reporting (re- } \\
\text { porting bias) }\end{array}$ & Unclear risk & No evidence of reporting bias; however, study registration not available \\
\hline $\begin{array}{l}\text { Carry-over effect } \\
\text { Bias from confounders }\end{array}$ & High risk & $\begin{array}{l}\text { Addition of antihypertensive medication on study day 1; short study duration } \\
\text { and lack of washout meant that carry over effect was likely }\end{array}$ \\
\hline Other & $\begin{array}{l}\text { Unable to assess using information provided; no indication of medication ad- } \\
\text { herence; difference in sodium intake larger than intended suggesting some } \\
\text { protocol deviation. }\end{array}$ \\
\hline \hline
\end{tabular}


Saran 2017

\section{Study characteristics}

$\begin{array}{ll}\text { Methods } & \text { - Study design: open-label, cross-over RCT } \\ \text { - Time frame: May } 2009 \text { to May } 2013 \\ \text { - Duration of study (weeks): total (12); interventions (4); washout (2) }\end{array}$

\begin{tabular}{|c|c|}
\hline Participants & 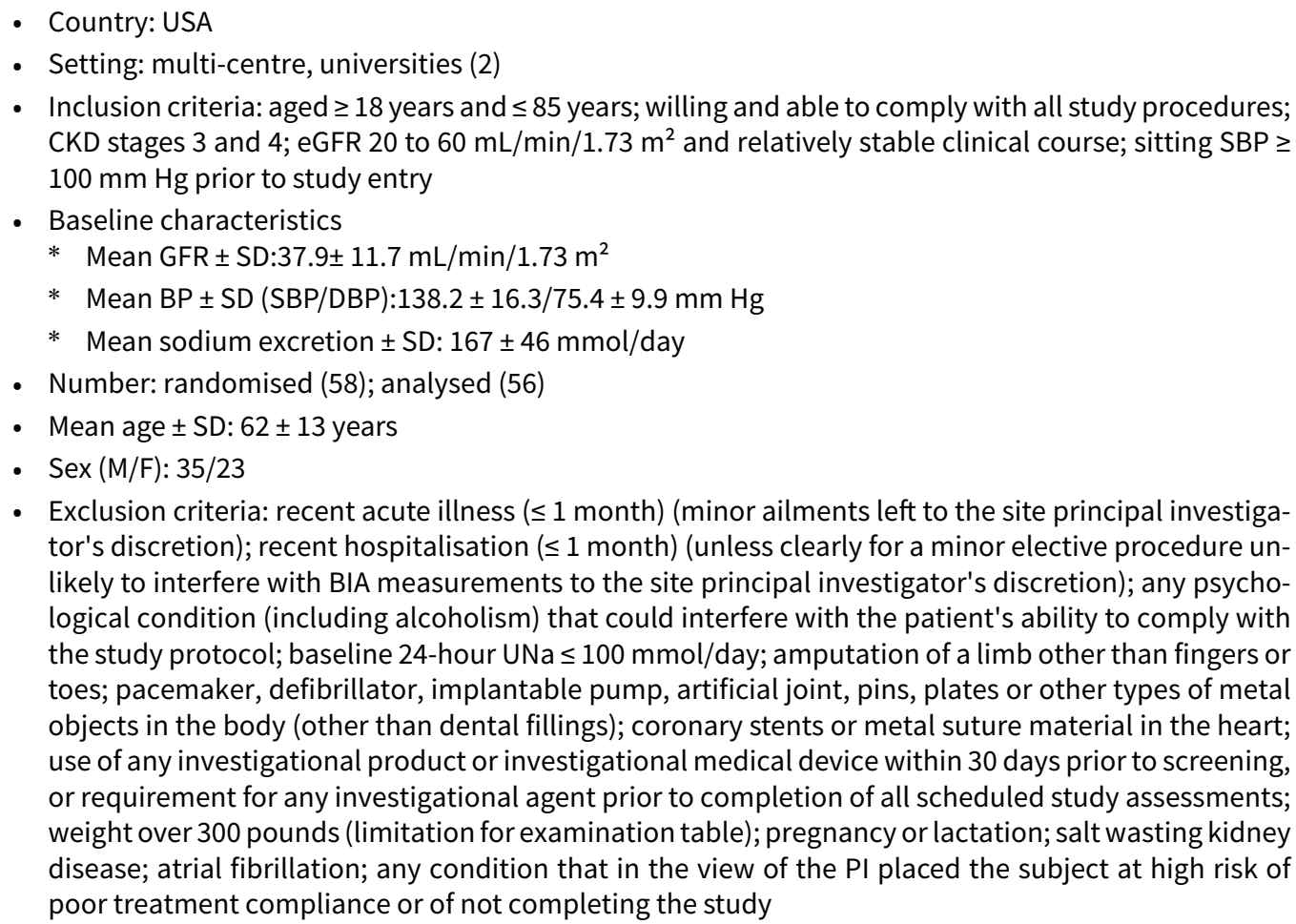 \\
\hline
\end{tabular}

Interventions

Low salt group

- Sodium intake: restriction, goal $2000 \mathrm{mg}$ sodium, dietary counselling by dietitian

- Duration: 4 weeks

High salt group

- Salt intake: usual intake

- Duration: 4 weeks

Other information

- Study participants were advised to maintain isocaloric diets and stable intake of total and saturated fat, potassium intake of 2 to $3 \mathrm{~g} /$ day, and phosphorus intake of $<1 \mathrm{~g} /$ day during both study phases. They were instructed to maintain their usual levels of alcohol, caffeine, and nicotine, and continue their usual level of physical activity

\begin{tabular}{ll}
\hline Outcomes & - 24-hour albuminuria \\
- Ambulatory \& clinic BP \\
- Fluid status (BIS; whole body and segmental techniques) \\
- Weight \\
- eGFR \\
- SCr, sodium \& potassium \\
- Urinary creatinine \& potassium
\end{tabular}


Saran 2017 (Continued)

- Sodium intake: 24 -hour urinary sodium

$\begin{array}{ll}\text { Notes } & \text { Funding: Renal Research Institute and grant from the National Center for Research Resources (NCRR) } \\ \text { - Additional data: requested } \\ \text { - Trial registration: https://clinicaltrials.gov/ct2/show/record/NCT00974636 }\end{array}$

\section{Risk of bias}

\begin{tabular}{lll}
\hline Bias & Authors' judgement & Support for judgement \\
\hline $\begin{array}{l}\text { Random sequence genera- } \\
\text { tion (selection bias) }\end{array}$ & Unclear risk & Insufficient information to permit judgement \\
\hline $\begin{array}{l}\text { Allocation concealment } \\
\text { (selection bias) }\end{array}$ & High risk & $\begin{array}{l}\text { Quote: "Randomization was performed using sealed envelopes at each site." } \\
\text { However allocation sequence not followed }\end{array}$ \\
& $\begin{array}{l}\text { Quote: "Of the } 21 \text { patients enrolled at UNC, six were given treatment in the re- } \\
\text { verse sequence from the randomised assignment for unknown reasons." }\end{array}$ \\
\hline $\begin{array}{l}\text { Blinding of participants } \\
\text { and personnel (perfor- } \\
\text { mance bias) } \\
\text { All outcomes }\end{array}$ & High risk & $\begin{array}{l}\text { Quote: "Study investigators were blinded to assigned treatment, which was } \\
\text { only known to study dieticians and coordinators" }\end{array}$ \\
& $\begin{array}{l}\text { Blinding of participants: no; blinding of investigators: yes; blinding of out- } \\
\text { comes assessors: unclear; blinding of data assessors: unclear }\end{array}$ \\
& $\begin{array}{l}\text { Lack of blinding may have led to protocol deviation } \\
\text { Quote: "Of the } 21 \text { patients enrolled at UNC, six were given treatment in the re- } \\
\text { verse sequence from the randomised assignment for unknown reasons. In ad- } \\
\text { dition, four patients who were initially randomised to the SRD in phase } 1 \text { had } \\
\text { poor compliance and, in violation of the protocol, were encouraged to contin- } \\
\text { ue the SRD in phase } 2 . "\end{array}$
\end{tabular}

Blinding of outcome as- Unclear risk Insufficient information to permit judgement

sessment (detection bias)

All outcomes

\begin{tabular}{|c|c|c|}
\hline $\begin{array}{l}\text { Incomplete outcome data } \\
\text { (attrition bias) } \\
\text { All outcomes }\end{array}$ & High risk & $\begin{array}{l}3 \text { participants withdrew } 2 \text { Illness unrelated to intervention; } 1 \text { for personal rea- } \\
\text { sons (some data included for the latter). Incomplete outcome data as evi- } \\
\text { denced by supplementary table S3 (e.g. different in number for SBP \& DBP, on- } \\
\text { ly } 10 / 21 \text { participants at one of the sites with urinary albumin), have contacted } \\
\text { authors for further information }\end{array}$ \\
\hline
\end{tabular}

\begin{tabular}{lll}
\hline $\begin{array}{l}\text { Selective reporting (re- } \\
\text { porting bias) }\end{array}$ & Unclear risk & $\begin{array}{l}\text { No evidence of reporting bias in terms of outcomes not reported; incomplete } \\
\text { outcome data evident for some outcomes and unexplained }\end{array}$ \\
\hline Carry-over effect & Low risk & $\begin{array}{l}\text { 2-week washout; analysed both treatment orders \& found no treatment order } \\
\text { effect }\end{array}$ \\
\hline
\end{tabular}

Bias from confounders Unclear risk Potassium: measured, have requested data. Body weight change: measured, significant change \& higher than body water loss, may have influenced outcomes

Physical activity: not measured

Antihypertensive dose: measured \& change reported. Quote: "At enrolment, 48 patients were taking at least one antihypertensive medication, with $77 \%$ taking two or more and $48 \%$ taking three or more. During the study, 12 patients discontinued 27 medications; eight patients discontinued 15 medications during the SRD phase compared with six patients (and 12 medications) during 
the usual diet phase. The majority (75\%) of the changes during the usual diet phase occurred during phase 2 , after the SRD phase."

Other High risk
Funding: Renal Research Institute and grant from the National Center for Re-
search Resources (NCRR)

Conflict of interest: Two study authors (N Levin and P Kotanko) hold stock in Fresenius Medical Care, which makes the machine used to assess the primary outcome. Protocol deviation: "Of the 21 patients enrolled at UNC, six were given treatment in the reverse sequence from the randomised assignment for unknown reasons. In addition, four patients who were initially randomised to the SRD in phase 1 had poor compliance and, in violation of the protocol, were encouraged to continue the SRD in phase 2."

\section{ViRTUE-CKD 2016}

\section{Study characteristics}

\begin{tabular}{|c|c|}
\hline Methods & $\begin{array}{l}\text { - Study design: cross-over RCT (dietary intervention open-label) } \\
\text { - Time frame: January } 2012 \text { to March } 2015 \\
\text { - Study duration (weeks): total (38); run in (6); interventions (8); no washout }\end{array}$ \\
\hline Participants & $\begin{array}{l}\text { - Country: the Netherlands } \\
\text { - Setting: multi-centre; hospitals (3) } \\
\text { - Inclusion criteria: nondiabetic patients with stages } 1 \text { to } 3 \mathrm{CKD} \text {; residual albuminuria }>300 \mathrm{mg} / \text { day } \\
\text { despite single-agent RAAS blockade; } \mathrm{CrCl}>30 \mathrm{~mL} / \mathrm{min} \text { and }<6 \mathrm{~mL} / \mathrm{min} \text { decline in the previous year; } \\
\text { parathyroid hormone values }<1.5 \text { times the upper limit of normal; serum calcium (adjusted for serum } \\
\text { albumin) } 2.0 \text { to } 2.6 \mathrm{mmol} / \mathrm{L} ; \text { serum phosphate } \leq 1.5 \mathrm{mmol} / \mathrm{L} \text {; age }>18 \text { years } \\
\text { - Baseline characteristics } \\
\text { * Mean GFR } \pm \mathrm{SD}: 69.5 \pm 23.5 \mathrm{~mL} / \mathrm{min} / 1.73 \mathrm{~m}^{2} \\
\text { * BP (SBP/DBP): not reported } \\
\text { * Mean sodium excretion } \pm \mathrm{SD}: 175 \pm 64 \mathrm{mmol} / \text { day } \\
\text { - Number: randomised ( } 45) \text {; analysed ( } 45) \\
\text { - Mean age } \pm \mathrm{SD}: 52 \pm 13 \text { years } \\
\text { - Sex (M/F): } 33 / 12 \\
\text { - Exclusion criteria: DM; uncontrolled hypertension; hyperkalaemia (potassium }>6.0 \text { mmol/L); cardio- } \\
\text { vascular event in the previous } 6 \text { months; heart failure (NYHA class III-IV); epilepsy; liver disease; ac- } \\
\text { tive malignancy; bowel disorder resulting in fat malabsorption; treatment with vitamin analogue in } \\
\text { the previous } 3 \text { months; regular use ( }>2 \text { doses/week) of NSAID; use of immunosuppressive treatment; } \\
\text { digoxin or psychiatric medication; drug or alcohol abuse; noncompliance with the study diet or study } \\
\text { medication; pregnancy or breastfeeding; BP }>180 / 100 \text { mm Hg after maximum } 18 \text { weeks run-in period }\end{array}$ \\
\hline
\end{tabular}

Interventions

Low salt group

- Target sodium intake: $50 \mathrm{mmol} / \mathrm{day}$ (individualised counselling by dietician)

- Duration: 16 weeks

High salt group

- Target sodium intake: usual diet $(200 \mathrm{mmol} /$ day $)$

- Duration: 16 weeks

Co-interventions 
- Each participant was on ramipril at $10 \mathrm{mg} /$ day for entire study and went through four interventions for eight weeks each in random order ( ${ }^{*}$ used for analysis)

* Usual salt, placebo*

* Usual salt, paricalcitol $2 \mathrm{mg} /$ day

* High salt, placebo*

* High salt, paricalcitol $2 \mathrm{mg} /$ day

Other information

- Anti-hypertensive regimen reduced where participants reported symptomatic hypotension \& restored if $\mathrm{BP}>140 / 90 \mathrm{~mm} \mathrm{Hg}$

\begin{tabular}{ll}
\hline Outcomes & - 24 -hour albuminuria \\
- Clinic BP (semi-supine) \\
- Weight \\
- Serum markers (electrolytes, lipids, proteins, creatinine) \\
- Measurement of sodium intake: 24-hour urine \\
- Measurement of confounders \\
& $*$ Urea \& potassium excretion
\end{tabular}

$\begin{array}{ll}\text { Notes } & \text { Funding: unfunded } \\ \text { - Additional data: provided by authors } \\ \text { - Registered at: http://www.trialregister.nl/trialreg/admin/rctview.asp?TC=2898 }\end{array}$

\section{Risk of bias}

\section{Bias}

Authors' judgement Support for judgement

Random sequence genera- Low risk tion (selection bias)
Quote: "To prevent systematic errors resulting from the crossover design, the order of the treatment periods was randomised (1:1:1:1) for each patient. Four different treatment sequences were defined." "Randomization of these sequences was performed externally by the pharmaceutical company that delivered the study medication (AbbVie)".

Allocation concealment Low risk
(selection bias)

Quote: "Computer-generated randomisation was performed by AbbVie. The investigators (C.A.K. and G.F.v.B.) enrolled participants. Patients received study medication containers labelled with a unique number representing the randomly allocated sequence, whereby all participants and involved investigators and care providers remained blinded to the study medication type (paricalcitol or placebo) throughout the entire study. Assignment of the treatment order was not disclosed until the study database was locked. The dietary intervention was open label."

\begin{tabular}{|c|c|c|}
\hline $\begin{array}{l}\text { Blinding of participants } \\
\text { and personnel (perfor- }\end{array}$ & Unclear risk & $\begin{array}{l}\text { Dietary intervention was open label but outcomes were objective and unlikely } \\
\text { to be influenced by performance bias }\end{array}$ \\
\hline All outcomes & & $\begin{array}{l}\text { Blinding of participants: yes for medication, no for diet; blinding of investiga- } \\
\text { tors: yes for medication, no for diet; blinding of outcomes assessors: yes for } \\
\text { medication, no for diet; blinding of data assessors: yes for medication, no for } \\
\text { diet }\end{array}$ \\
\hline
\end{tabular}

\begin{tabular}{lll}
\hline $\begin{array}{l}\text { Blinding of outcome as- } \\
\text { sessment (detection bias) } \\
\text { All outcomes }\end{array}$ & Unclear risk & $\begin{array}{l}\text { Lab personnel assessing proteinuria were not aware of allocation; study per- } \\
\text { sonnel that assessed BP, weight, oedema were aware of allocation. }\end{array}$ \\
\hline $\begin{array}{l}\text { Incomplete outcome data } \\
\text { (attrition bias) }\end{array}$ & Low risk & $\begin{array}{l}3 \text { patients excluded after randomisation, however all included in intention-to- } \\
\text { treat analysis }\end{array}$ \\
\hline
\end{tabular}


ViRTUE-CKD 2016 (Continued)

All outcomes

\begin{tabular}{|c|c|c|}
\hline $\begin{array}{l}\text { Selective reporting (re- } \\
\text { porting bias) }\end{array}$ & Low risk & $\begin{array}{l}\text { Study was pre-registered online and the pre-specified outcomes were report- } \\
\text { ed }\end{array}$ \\
\hline
\end{tabular}

\begin{tabular}{lll}
\hline Carry-over effect & Low risk & Quote: "8-week period was long enough to minimize potential carryover" \\
\hline Bias from confounders & Unclear risk & $\begin{array}{l}\text { Potassium: measured and reported no change; body weight change: } 2 \text { kg } \\
\text { weight loss with sodium restriction, difficult to determine if due to fluid; phys- } \\
\text { ical activity: not reported; antihypertensive medications: no changes to med- } \\
\text { ication reported during placebo period }\end{array}$
\end{tabular}

Other Low risk Funding: AbbVie (Chicago, IL) funded the study medication (paricalcitol and
placebo)

Quote: "This trial was supported by a consortium grant from the Dutch Kidney Foundation (NIGRAM Consortium grant CP10.11).H.J.L.H. is supported by a grant from The Netherlands Organization for Scientific Research (Veni and Vidi grants). M.H.d.B. is supported by personal grants from the Dutch Kidney Foundation (grant no. KJPB.08.07) and the Netherlands Organization for Scientific Research (Veni grant). The funding source had no role in the design and conduct of the study; collection, management, analysis, and interpretation of the data; or preparation, review, or approval of the manuscript."

Vogt 2008

\section{Study characteristics}

\begin{tabular}{|c|c|}
\hline Methods & $\begin{array}{l}\text { - Study design: cross-over RCT } \\
\text { - Time frame: March } 2004 \text { to June } 2006 \\
\text { - Duration of study (weeks): total (36); interventions (6); no washout }\end{array}$ \\
\hline Participants & $\begin{array}{l}\text { - Country: the Netherlands } \\
\text { - Setting: outpatient renal clinic } \\
\text { - Inclusion criteria: stable proteinuria }>2 \mathrm{~g} / \text { day and }<10 \mathrm{~g} / \text { day; stable kidney function }(<6 \mathrm{~mL} / \mathrm{min} / \text { year } \\
\text { decline); aged } 18 \text { to } 70 \text { years } \\
\text { - Baseline characteristics } \\
* \mathrm{CKD}: \mathrm{CrCl} \geq 30 \mathrm{~mL} / \mathrm{min} \\
\text { * Mean BP } \pm \mathrm{SD}(\mathrm{SBP} / \mathrm{DBP}): 131 \pm 18 / 71 \pm 12.5 \mathrm{~mm} \mathrm{Hg} \\
\text { - Number: } 34 \\
\text { - Mean age } \pm \mathrm{SD}: 50 \pm 12 \text { years } \\
\text { - Sex (M/F): } 25 / 9 \\
\text { - Exclusion criteria: mean arterial BP }>100 \mathrm{~mm} \text { Hg; serum potassium }>5.5 \mathrm{mmol} / \mathrm{L} \text {; CVD (MI, un- } \\
\text { stable angina, percutaneous transluminal coronary angioplasty, CABG, or stroke within the last } 6 \\
\text { months); contraindication for AT1-antagonist or diuretic use; diabetes; frequent users of NSAID }>2 \\
\text { doses/week) }\end{array}$ \\
\hline
\end{tabular}

Interventions

Low salt group

- Target salt intake: $50 \mathrm{mmol}$ sodium/day (individualised counselling by dietician)

- Duration: 6 weeks

High salt group

- Target salt intake: $200 \mathrm{mmol}$ sodium/day

- Duration: 6 weeks 
Vogt 2008 (Continued)

Other details

- Additional antihypertensive drugs except for RAAS-blocking agents or diuretics were allowed for BP control and kept stable during the study

- Co-interventions: 6 weeks each with placebo, losartan, losartan plus hydrochlorothiazide on highsodium diet or low-sodium diet in random order during 18 weeks. After 18 weeks, participants changed diet and the three 6 -week periods were repeated. Placebo on high and low Na diet used for this review

- 24-hour proteinuria
- Clinic BP (semi-supine)
- Serum markers (creatinine, urea, cholesterol, triglycerides, total protein, albumin)
- NT-pro BNP
- Renin, aldosterone
- Uric acid
- Plasma vascular endothelial growth factor C
- Kidney Injury Molecule 1
- N-acetyl-beta-D-glucosaminidase
- Measurement of sodium intake: 24-hour urine
- Measurement of confounders: Urinary urea, weight

Notes

- Funding: supported by Merck Sharp \& Dohme (grant MSGP NETH-15-01)

- Additional data: provided by authors

\section{Risk of bias}

\begin{tabular}{|c|c|c|}
\hline Bias & Authors' judgement & Support for judgement \\
\hline $\begin{array}{l}\text { Random sequence genera- } \\
\text { tion (selection bias) }\end{array}$ & Low risk & $\begin{array}{l}\text { Randomisation was conducted by pharmacists using a computer generated } \\
\text { model }\end{array}$ \\
\hline $\begin{array}{l}\text { Allocation concealment } \\
\text { (selection bias) }\end{array}$ & Unclear risk & Insufficient information to permit judgement \\
\hline $\begin{array}{l}\text { Blinding of participants } \\
\text { and personnel (perfor- } \\
\text { mance bias) } \\
\text { All outcomes }\end{array}$ & Unclear risk & $\begin{array}{l}\text { Dietary interventions were open label; outcomes were objective and unlikely } \\
\text { to be affected by performance bias }\end{array}$ \\
\hline $\begin{array}{l}\text { Blinding of outcome as- } \\
\text { sessment (detection bias) } \\
\text { All outcomes }\end{array}$ & Unclear risk & Insufficient information to permit judgement \\
\hline $\begin{array}{l}\text { Incomplete outcome data } \\
\text { (attrition bias) } \\
\text { All outcomes }\end{array}$ & Low risk & $\begin{array}{l}\text { Low }(3 \%) \text { attrition and unlikely to introduce bias. } 35 \text { were randomised, one } \\
\text { withdrew }\end{array}$ \\
\hline $\begin{array}{l}\text { Selective reporting (re- } \\
\text { porting bias) }\end{array}$ & Low risk & No evidence of reporting bias \\
\hline Carry-over effect & Low risk & Sufficient intervention duration to avoid carry-over effect \\
\hline Bias from confounders & High risk & $\begin{array}{l}\text { Reduction in body weight (unable to determine if fluid change) and urinary } \\
\text { urea in low salt phase may have confounded results. Change in medication not } \\
\text { reported but protocol was to keep stable during the study }\end{array}$ \\
\hline
\end{tabular}


Vogt 2008 (Continued)

Other Low risk
Quote: "The original RCT was supported by Merck Sharp \& Dohme (grand MSGP NETH-15-01). The second study was supported by an unrestricted grant from Novartis (CVAL489ANL08). The funding bodies had no role in study design, data collection, data analysis or data interpretation." (From Gant 2017)

ACEi - angiotensin-converting-enzyme inhibitor; ACR - albumin:creatinine ratio; ANP - atrial natriuretic peptide; ARB - angiotensin receptor blocker; BMI - body mass index; BP - blood pressure; BUN - blood urea nitrogen; CABG - coronary artery bypass graft; CAPD - continuous ambulatory peritoneal dialysis; $\mathrm{CKD}$ - chronic kidney disease; $\mathrm{CrCl}$ - creatinine clearance; $\mathrm{CRP}$ - C-reactive protein; CVD - cardiovascular disease; DBP - diastolic BP; DM - diabetes mellitus; eGFR - estimated glomerular filtration rate; ESKD - end-stage kidney disease; Hb haemoglobin; HCT - haematocrit; HD - haemodialysis; HDF - haemodiafiltration; IgA - immunoglobulin A; IQR - interquartile range; KRT - kidney replacement therapy; MAP - mean arterial pressure; MDRD - Modification of Diet in Renal Disease; MI - myocardial infarction; $\mathrm{Na}$ - sodium; NSAID - nonsteroidal anti-inflammatory drug; NT-proBNP - N-terminal pro-brain natriuretic peptide; NYHA - New York Heart Association; NSAID - non-steroidal anti-inflammatory drug/s; PAH - para-aminohippuric acid; PCI - percutaneous coronary arterial intervention; PD - peritoneal dialysis; PDA - personal digital assistant; RAAS - renin-angiotensin-aldosterone system; RCT - randomised controlled trial; RPF - renal plasma flow; SBP - systolic BP; SCr - serum creatinine; SD - standard deviation; UNa - urinary sodium excretion; UTI - urinary tract infection

\section{Characteristics of excluded studies [ordered by study ID]}

\section{Study Reason for exclusion}

Chanwikrai 2012 Wrong intervention: not comparing two or more levels of salt intake; RCT where all groups are advised on low salt and low protein diet

Clark-Cutaia 2016

DD 2017

De Nicola 2000
Wrong duration: < 1 week; RCT of sodium restriction in dialysis patients with 5-day follow up

Wrong intervention: concomitant intervention not stable between arms; RCT comparing diuretics versus sodium restriction in CKD

Wrong duration: < 1 week; RCT of differing dialysate sodium concentrations with 68-hour follow up
Wrong intervention: concomitant intervention not stable between arms; cross-over RCT with 5 arms in proteinuric patients: ramipril at $5 \mathrm{mg} /$ day with usual furosemide dosage and usual sodium intake; ramipril at $10 \mathrm{mg}$ /day with usual furosemide dosage and usual sodium intake; valsar$\tan$ at $160 \mathrm{mg} /$ day with usual furosemide dosage and usual sodium intake; combined ramipril at 5 $\mathrm{mg}$ and valsartan at $80 \mathrm{mg} /$ day with usual furosemide dosage and usual sodium intake; combined ramipril at $5 \mathrm{mg}$, valsartan at $80 \mathrm{mg} /$ day with increased furosemide dosage \& participants asked to avoid excess sodium

\section{HHK 2018}

Wrong intervention: concomitant intervention not stable between arms; RCT of multiple behaviour change (physical activity, weight loss, restriction of sodium and phosphate additives)
Wrong intervention: not comparing two levels of salt intake; cross-over RCT of high versus low salt ( 1 week), then 2 weeks of ACEi. Comparisons are made only for ACEi versus high salt arms
Wrong intervention: concomitant intervention not stable between arms; RCT comparing supportive educative nursing intervention to reduce BP versus usual care in HD patients. Intervention goals included sodium restriction, fluid restriction/limiting weight gain between dialysis sessions and medication adherence

\section{Li $2013 f$}

Wrong population: cluster RCT comparing education program to reduce sodium plus provision of a salt substitute versus control in rural Chinese villages (not a CKD population); sodium excretion measured at follow up only
This study was stopped early and withdrawn 2015 (no reasons provided) 


\section{Study Reason for exclusion}

Suckling 2016

Wrong population: RCT of sodium restriction in participants with impaired glucose tolerance and type 2 diabetes mellitus; excludes those with impaired kidney function

ACEi - angiotensin-converting-enzyme inhibitor; BP - blood pressure; CKD - chronic kidney disease; eGFR - estimated glomerular filtration rate; HD - haemodialysis; RCT - randomised controlled trial

Characteristics of ongoing studies [ordered by study ID]

NCT03373500

\begin{tabular}{|c|c|}
\hline Study name & Effect of dietary salt reduction on blood pressure in kidney transplant recipients \\
\hline Methods & $\begin{array}{l}\text { - Study design: open-label, parallel RCT } \\
\text { - Duration of study: } 9 \text { months }\end{array}$ \\
\hline Participants & $\begin{array}{l}\text { - Sample size: } 66 \\
\text { - CKD: transplant recipients } \\
\text { - Inclusion criteria: patients who have received a kidney transplant } \geq 6 \text { months previously who have } \\
\text { a SBP > } 130 \mathrm{~mm} \mathrm{Hg} \text { and/or } \mathrm{DBP}>80 \mathrm{~mm} \mathrm{Hg} \text {, or are receiving treatment for hypertension } \\
\text { - Exclusion criteria: } \mathrm{BP}<120 / 80 \text { on } \mathrm{BP} \text { treatment; } \mathrm{BP}>160 / 100 \text {; variation in creatinine }>20 \% \text { over } \\
\text { preceding } 2 \text { months; secondary hypertension due to a cause other than CKD; heart failure (left ven- } \\
\text { tricular ejection fraction < } 30 \% \text { or NYHA class II - IV); MI within } 6 \text { months; stroke within } 6 \text { months; } \\
\text { current diagnosis of cancer; liver disease; bilateral arterio-venous fistulae; evidence of significant } \\
\text { active infection; pregnant or breastfeeding; hyponatraemia (Na < } 130 \mathrm{mmol} / \mathrm{L} \text { ) or hypernatraemia } \\
\text { (Na > } 150 \mathrm{mmol} / \mathrm{L}) \text {; histologically confirmed episode of rejection within } 6 \text { months; steroids dose } \\
\text { change in preceding } 2 \text { months; unable to give full informed consent; Initial 24-hour urinary } \mathrm{Na}< \\
80 \mathrm{mmol} / 24 \text { hours }\end{array}$ \\
\hline
\end{tabular}

Interventions

Low salt group

- Intensive dietary advice to achieve a low salt diet, targeting a dietary salt intake of $<5 \mathrm{~g} /$ day ( 80 $\mathrm{mmol} / \mathrm{day})$

High salt group

- Usual care

Outcomes

- Office SBP \& DBP (9 months) (primary outcome)

- Ambulatory BP (9 months)

- Endothelial function, measured by digital pulse wave analysis (9 months)

- Arterial stiffness, measured by digital pulse wave analysis (9 months)

- Proteinuria (9 months)

- Biomarkers of fibrosis (9 months): TGF- $\beta 1,2$ \& 3; CTGF \& EDA + Fibronectin

- $48 \mathrm{hr}$ sodium excretion

\begin{tabular}{ll}
\hline Starting date & October 11, 2017 \\
\hline Contact information & Principal Investigator: Pauline Swift \\
\hline Notes & $\begin{array}{l}\text { Trial registration: https://clinicaltrials.gov/ct2/show/NCT03373500 Estimated completion date } \\
\text { June } 2019\end{array}$
\end{tabular}


OxCKD1 2012

\begin{tabular}{|c|c|}
\hline Study name & OxCKD1 2012 - Empowering healthy lifestyle choices in chronic kidney disease (OxCKD1 2012) \\
\hline Methods & $\begin{array}{l}\text { - Study design: open-label, parallel RCT } \\
\text { - Duration of study: } 11 \text { months }\end{array}$ \\
\hline Participants & $\begin{array}{l}\text { - Sample size: } 201 \\
\text { - } \text { Inclusion criteria: willing and able to give informed consent for participation in the study; aged } \geq \\
18 \text { years; clinically acceptable laboratory data available to confirm the CKD diagnosis; able (in the } \\
\text { opinion of the investigators) and willing to comply with all study requirements; willing to allow } \\
\text { his or her General Practitioner and consultant, if appropriate, to be notified of participation in the } \\
\text { study } \\
\text { - Exclusion criteria: pregnant, lactating or planning pregnancy during the course of the study; any } \\
\text { other significant disease or disorder which, in the opinion of the investigator, may either put the } \\
\text { participants at risk because of participation in the study, or may influence the result of the study, } \\
\text { or the participant's ability to participate in the study; inability to understand English or special } \\
\text { communication needs because the interventions will use English and is not funded to deal with } \\
\text { special communication needs; known salt losing kidney disease }\end{array}$ \\
\hline
\end{tabular}

\begin{tabular}{|c|c|}
\hline Interventions & $\begin{array}{l}\text { Low salt group } \\
\text { - Practical advice on cutting down on salt using information booklets, text messages, emails, tele- } \\
\text { phone calls, and a website } \\
\text { High salt group } \\
\text { - Usual care }\end{array}$ \\
\hline Outcomes & $\begin{array}{l}\text { - Salt intake as assessed by } 24 \text {-hour urine Na excretion and dietary salt analysis (month } 1 \text { ) } \\
\text { - BP (month } 1,3 \text { and } 11 \text { ) } \\
\text { - Urine protein (month } 1,3 \text { and } 11 \text { ) }\end{array}$ \\
\hline Starting date & April 2012 \\
\hline Notes & $\begin{array}{l}\text { Trial registration: https://clinicaltrials.gov/ct2/show/NCT01552317 Listed as Completed November } \\
\text { 2014. Emailed study authors on } 11 \text { July } 2019 \text { to ask if results are available. }\end{array}$ \\
\hline
\end{tabular}

\section{STICK 2015}

\begin{tabular}{ll}
\hline Study name & Sodium intake in chronic kidney disease (STICK) \\
\hline Methods & Study design: open-label, parallel RCT \\
& Duration of study: 24 months \\
\hline Participants & Sample size: 105 \\
- & CKD: CKD (MDRD eGFR of 30 to $60 \mathrm{~mL} / \mathrm{min} / 1.73 \mathrm{~m}^{2}$ on $\geq 2$ occasions $\geq 3$ months apart) \\
- & Inclusion criteria: Aged $\geq 40$ years; $\mathrm{most}$ recent eGFR measurement within 3 months; $\mathrm{SBP}<160 \mathrm{~mm}$ \\
& Hg and DB $<95 \mathrm{~mm} \mathrm{Hg}$ on 3 office BP readings at time of screening and confirmed by a study am- \\
& bulatory BP before randomisation of $<150 / 90 \mathrm{~mm}$ Hg; no change in antihypertensive or diuretic \\
& medications (including dose) for 3 months before screening visit; consumption of moderate sodi- \\
& um intake at screening, defined as an estimated daily Na intake of $>2.3 \mathrm{~g} /$ day estimated from food \\
frequency questionnaire completed during the screening visit; self-reported willingness to mod-
\end{tabular}


- Exclusion criteria: AKI in the preceding 3 months, defined as doubling of baseline SCr or rapidly declining eGFR over the preceding 6 months, defined as a decline in eGFR of $\geq 10 \mathrm{~mL} / \mathrm{min} / 1.73$ $\mathrm{m}^{2}$ in those with established CKD; any of the following renal conditions: glomerular disease due to post-infectious glomerulonephritis, IgA nephropathy, thin basement membrane disease, Henoch-Schonlein purpura, proliferative glomerulonephritis, membranous nephropathy (including lupus nephritis), rapidly progressive glomerulonephritis, minimal change disease, or focal segmental glomerulosclerosis; prior or planned kidney transplantation; prior, current or planned dialysis; medical diagnosis known to be associated with abnormal renal sodium excretion, including Bartter syndrome, SIADH, diabetes insipidus, or serum sodium $<125 \mathrm{mmol}$; severe heart failure (defined as left ventricular ejection fraction $\leq 30 \%$ or NYHA class III/IV symptoms); high-dose loop or thiazide diuretic therapy, exceeding a total daily dose of frusemide $80 \mathrm{mg}$, bumetanide $2 \mathrm{mg}$, hydrochlorothiazide $50 \mathrm{mg}$, bendroflumethiazide $2.5 \mathrm{mg}$, indapamide $2.5 \mathrm{mg}$, metolazone $2.5 \mathrm{mg}$ or the use of both a loop and thiazide diuretic; current use of NSAIDs for $\geq 3$ days/week (low-dose aspirin $<100 \mathrm{mg} /$ day is not an exclusion); unable to follow educational advice of the research team; prescribed high-salt diet, low-salt diet or sodium bicarbonate; symptomatic postural hypotension or receiving treatment for postural hypotension; current or recent use (within 1 month) of immunosuppressive medications including tacrolimus, cyclosporin, azathioprine or mycophenolate mofetil; pregnancy or lactation; unable to comply with 24-hour urinary collections, or medical condition making collection of 24-hour urinary collection difficult (e.g. severe urinary incontinence); Participant unlikely to comply with study procedures or follow-up visits due to severe co-morbid illness or other factor (e.g. inability to travel for follow-up visits, drug or alcohol misuse) in opinion of research team; cognitive impairment defined as a known diagnosis of dementia, or inability to provide informed consent due to cognitive impairment in the opinion of the investigator; $\mathrm{BMI}<20 \mathrm{~kg} / \mathrm{m}^{2}$ or BMI $>40 \mathrm{~kg} / \mathrm{m}^{2}$; participating in another clinical trial or previous allocation in this study

- In addition to usual care, those randomised to the intervention arm will receive specific counselling on behavioural and environmental factors that promote sodium reduction after randomisation and at all specified post-randomisation visits, targeting sodium intake of $<100 \mathrm{mmol} /$ day $(<2.3 \mathrm{~g} /$ day). A research dietitian will develop the specific components of the intervention, based on standardised approaches to education interventions

High salt group

- Usual care

\section{Outcomes}

- 24-hour urinary $\mathrm{CrCl}$ (change from baseline to final follow-up)

- eGFR (MDRD formula)

- eGFR (CKD-EPI formula)

- Rates of requirement for KRT

- 24-hour urinary protein

- Increase in risk category for prognosis of CKD as measured by the KDIGO 2012 CKD classification table

- 24-hour UNa

- 24-hour ambulatory BP

- Composite outcome of risk category for prognosis of CKD (increase in risk), requirement for renal replacement therapy or death as measured by the KDIGO 2012 CKD classification table

- Functional status as measured by the assessment functional status questionnaire

\begin{tabular}{ll}
\hline Starting date & March 2016 \\
\hline Contact information & Principal Investigator: Martin J O'Donnell, MB PhD MRCPI National University of Ireland Galway \\
& Principal Investigator: Andrew Smyth, MB PhD National University of Ireland Galway \\
\hline
\end{tabular}


STICK 2015 (Continued)

Notes

Trial registration: https://clinicaltrials.gov/ct2/show/NCT02458248 Study listed as Active, not recruiting; Estimated Primary Completion Date: August 2020

SUBLIME 2020

Study name SodiUm Burden Lowered by Lifestyle Intervention: Self-Management and E-health Technology
(SUBLIME)

\begin{tabular}{|c|c|}
\hline Methods & $\begin{array}{l}\text { - Study design: open-label, parallel RCT } \\
\text { - Duration of study: } 9 \text { months }\end{array}$ \\
\hline Participants & $\begin{array}{l}\text { - Sample size: } 99 \\
\text { - CKD: stage } 1 \text { to } 3, \mathrm{CKD} 4 \text { if eGFR } \geq 25 \mathrm{~mL} / \mathrm{min} / 1.73 \mathrm{~m}^{2} \text {, (or a kidney transplant recipient) } \\
\text { - Inclusion criteria: } \geq 18 \text { years; } \mathrm{UNa} \text { during at least the last } 2 \text { subsequent visits }>130 \mathrm{mmol} / \text { day, or } 1 \\
\text { last UNa }>150 \mathrm{mmol} / \text { day; } \mathrm{SBP}>135 \mathrm{~mm} \mathrm{Hg} \text {, DBP }>85 \mathrm{mmHg} \text { or a well-controlled BP by treatment } \\
\text { with antihypertensives including RAAS-blockade (ACEi or ARB); sufficient command of the Dutch } \\
\text { language; access and ability to use the Internet } \\
\text { - Exclusion criteria: eGFR }<25 \mathrm{~mL} / \mathrm{min} / 1.73 \mathrm{~m}^{2} \text { or an anticipated need for predialysis work-up with- } \\
\text { in the time frame of the study; unstable disease: defined as rapid, persistent, progressive kidney } \\
\text { function loss (e.g. }>6 \mathrm{~mL} / \mathrm{min} / 1.73 \mathrm{~m}^{2} \text { per year), not from acute, intermittent origin; SBP }>170 \\
\mathrm{~mm} \mathrm{Hg} \text { or DBP }>100 \mathrm{~mm} \mathrm{Hg} \text { during medical treatment; } \mathrm{SBP}<95 \mathrm{~mm} \mathrm{Hg} \text { not responding to with- } \\
\text { drawal of antihypertensives; cardiovascular event (MI, cerebrovascular accident) }<6 \text { months ago; } \\
\text { kidney transplantation }<1 \text { year ago; medical conditions that are likely to interfere with comple- } \\
\text { tion of the study (such as progressive malignancy or other debilitating illness) at the discretion of } \\
\text { the nephrologist; Every patient who has participated in the ESMO study (regardless whether in- } \\
\text { tervention or control) cannot participate in the current study; current participation in any clinical } \\
\text { trial that might interfere with SUBLIME trial }\end{array}$ \\
\hline
\end{tabular}

\begin{tabular}{ll}
\hline Interventions & Low salt group \\
- Behavioural; 2 group meetings with fellow-patients, motivational interviewing, e-coaching and \\
ICT-based self-regulation as add-on to regular care for 9 months \\
High salt group \\
- Usual care; 9 months \\
- 24 -hour UNa \\
- BP \\
- Psychological well-being \\
- Psychological well-being will be assessed with multiple choice questionnaires in all 150 partici- \\
pants. \\
- Cost-effectiveness (derived from questionnaires on health care use, contacts with health care pro- \\
fessionals, change in medication in all participants). \\
Cardiorenal biomarkers
\end{tabular}

\begin{tabular}{ll}
\hline Starting date & June 2014 \\
\hline Contact information & Study Chair: Gerjan J Navis, MD PhD University Medical Center Groningen \\
& Principal Investigator: Paul JM Van der Boog, MD PhD Leiden University Medical Center \\
& Principal Investigator: Sandra Van Dijk, PhD Leiden University Medical Center \\
\hline Notes & Trial registration: https://clinicaltrials.gov/ct2/show/study/NCT02132013 Study listed as completed \\
& December 2015 (last updated May 2016); Emailed on 12/6/19 re: availability of results
\end{tabular}


SUPER 2016

\begin{tabular}{ll}
\hline Study name & Sodium lowering and Urinary ProtEin Reduction trial (SUPER) \\
\hline Methods & - Study design: open-label, parallel RCT. \\
- & Duration of study: 8 weeks \\
\hline Participants & Sample size: 150 (estimated) \\
- & CKD: eGFR $<90 \mathrm{~mL} / \mathrm{min} / 1.73 \mathrm{~m}^{2}$ but $>30 \mathrm{~mL} / \mathrm{min} / 1.73 \mathrm{~m}^{2}$ \\
- & Inclusion criteria: $\geq 21$ years; $\mathrm{ACR}>30 \mathrm{mg} / \mathrm{g}$ \\
- & Exclusion criteria: albuminuria $\geq 1.5 \mathrm{~g} / \mathrm{g}$ or kidney structural change; prior kidney transplant based \\
& on self-report; immunosuppression or other immunotherapy within the past 6 months prior to \\
& enrolment based on patient self-report; history of cancer other than non-melanoma skin cancer \\
& within two years prior to enrolment based on patient self-report; History of polycystic kidney dis- \\
& ease; currently receiving dialysis treatment; history of HIV; current pregnancy, breastfeeding or \\
& plans to become pregnant during the study; consumption of $\geq 14$ alcoholic drinks/week or con- \\
sumption of $\geq 6$ drinks/occasion; current participation in another lifestyle intervention trial; cur- \\
rent residence or planned residence make it difficult to meet trial requirements; other concerns \\
regarding ability to meet trial requirements, at the discretion of the principal investigator
\end{tabular}

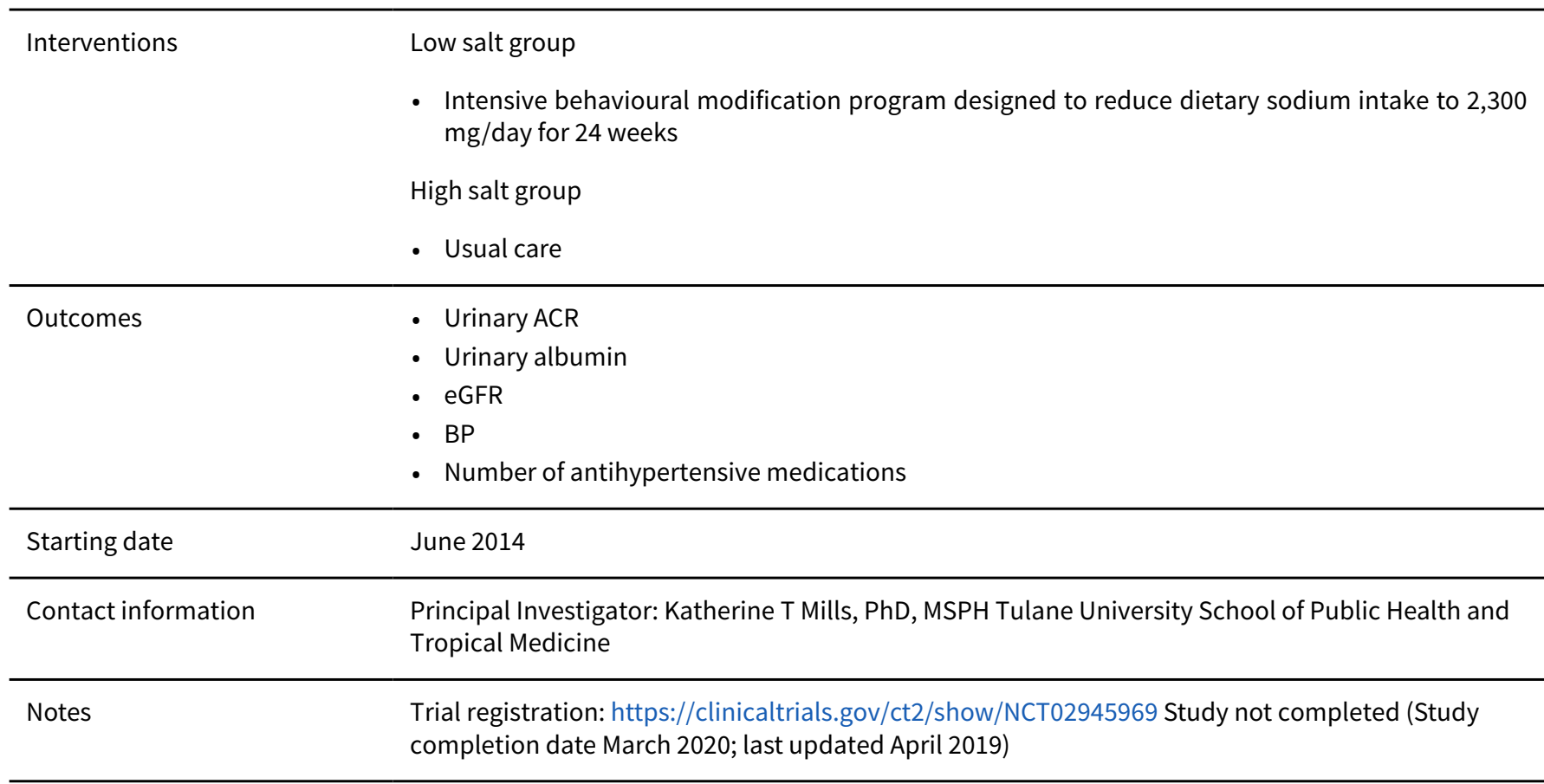

ACR - albumin-creatinine ratio; AKI - acute kidney injury; ACEi - angiotensin-converting enzyme inhibitors; ARB - angiotensin-receptor blockers; BMI - body mass index; BP - blood pressure; CKD - chronic kidney disease; $\mathrm{CrCl}$ - creatinine clearance; DBP - diastolic blood pressure; eGFR - estimated glomerular filtration rate; KRT - kidney replacement therapy; MDRD - Modification of Diet in Renal Disease; MI - myocardial infarction; Na - sodium; NSAID/s - nonsteroidal anti-inflammatory drug/s; NYHA - New York Heart Association; RAAS - reninangiotensin-aldosterone system; RCT - randomised controlled trial; SBP - systolic blood pressure; SCr - serum creatinine; UNa - urinary sodium excretion

\section{DATA AND ANALYSES}




\section{Comparison 1. CKD stage}

\begin{tabular}{|c|c|c|c|c|}
\hline $\begin{array}{l}\text { Outcome or sub- } \\
\text { group title }\end{array}$ & No. of studies & $\begin{array}{l}\text { No. of partici- } \\
\text { pants }\end{array}$ & Statistical method & Effect size \\
\hline $\begin{array}{l}\text { 1.1 Sodium intake/ex- } \\
\text { cretion }\end{array}$ & 18 & 1383 & Mean Difference (IV, Random, 95\% CI) & $-73.51[-92.76,-54.27]$ \\
\hline 1.1.1 CKD & 12 & 1048 & Mean Difference (IV, Random, 95\% Cl) & $-83.81[-104.54,-63.08]$ \\
\hline 1.1.2 Dialysis & 4 & 259 & Mean Difference (IV, Random, 95\% CI) & $-27.17[-48.59,-5.76]$ \\
\hline 1.1.3 Post-transplant & 2 & 76 & Mean Difference (IV, Random, 95\% CI) & $-96.99[-148.10,-45.89]$ \\
\hline $\begin{array}{l}1.2 \text { Systolic blood } \\
\text { pressure }\end{array}$ & 19 & 1261 & Mean Difference (IV, Random, 95\% CI) & $-6.91[-8.82,-4.99]$ \\
\hline 1.2.1 CKD & 12 & 1036 & Mean Difference (IV, Random, 95\% CI) & $-6.10[-8.11,-4.08]$ \\
\hline 1.2.2 Dialysis & 5 & 149 & Mean Difference (IV, Random, 95\% CI) & $-6.32[-11.04,-1.60]$ \\
\hline 1.2.3 Post-transplant & 2 & 76 & Mean Difference (IV, Random, 95\% Cl) & $-11.94[-15.77,-8.11]$ \\
\hline $\begin{array}{l}\text { 1.3 Diastolic blood } \\
\text { pressure }\end{array}$ & 19 & 1257 & Mean Difference (IV, Random, 95\% CI) & $-3.91[-4.80,-3.02]$ \\
\hline 1.3.1 CKD & 12 & 1032 & Mean Difference (IV, Random, 95\% CI) & $-3.47[-4.28,-2.65]$ \\
\hline 1.3.2 Dialysis & 5 & 149 & Mean Difference (IV, Random, 95\% CI) & $-3.46[-6.39,-0.54]$ \\
\hline 1.3.3 Post-transplant & 2 & 76 & Mean Difference (IV, Random, 95\% CI) & $-7.13[-9.46,-4.79]$ \\
\hline $\begin{array}{l}\text { 1.4 Proteinuria [ln mg/ } \\
\text { d] }\end{array}$ & 6 & & Mean Difference (IV, Random, 95\% CI) & $-0.41[-0.58,-0.25]$ \\
\hline 1.4.1 CKD & 6 & & Mean Difference (IV, Random, 95\% CI) & $-0.41[-0.58,-0.25]$ \\
\hline $\begin{array}{l}\text { 1.5 Albuminuria [ln } \\
\mathrm{mg} / \mathrm{d}]\end{array}$ & 6 & & Mean Difference (IV, Random, 95\% CI) & $-0.44[-0.58,-0.30]$ \\
\hline 1.5.1 CKD & 5 & & Mean Difference (IV, Random, 95\% CI) & $-0.47[-0.60,-0.34]$ \\
\hline 1.5.2 Post-transplant & 1 & & Mean Difference (IV, Random, 95\% CI) & $-0.03[-0.63,0.57]$ \\
\hline $\begin{array}{l}1.6 \mathrm{eGFR}[\mathrm{mL} / \mathrm{min} / 1.73 \\
\left.\mathrm{m}^{2}\right]\end{array}$ & 7 & 559 & Mean Difference (IV, Random, 95\% CI) & $-0.82[-2.31,0.66]$ \\
\hline 1.6.1 CKD & 6 & 515 & Mean Difference (IV, Random, 95\% CI) & $-1.00[-2.85,0.85]$ \\
\hline 1.6.2 Post-transplant & 1 & 44 & Mean Difference (IV, Random, 95\% CI) & $-0.50[-3.00,2.00]$ \\
\hline $\begin{array}{l}1.7 \text { Creatinine clear- } \\
\text { ance }\end{array}$ & 7 & 529 & Mean Difference (IV, Random, 95\% CI) & $-4.70[-6.94,-2.47]$ \\
\hline 1.7.1 CKD & 6 & 485 & Mean Difference (IV, Random, 95\% CI) & $-5.06[-7.40,-2.72]$ \\
\hline 1.7.2 Post-transplant & 1 & 44 & Mean Difference (IV, Random, 95\% CI) & $-1.00[-8.50,6.50]$ \\
\hline
\end{tabular}




\begin{tabular}{|c|c|c|c|c|}
\hline $\begin{array}{l}\text { Outcome or sub- } \\
\text { group title }\end{array}$ & No. of studies & $\begin{array}{l}\text { No. of partici- } \\
\text { pants }\end{array}$ & Statistical method & Effect size \\
\hline 1.8 Serum creatinine & 7 & 519 & Mean Difference (IV, Random, 95\% CI) & $4.46[0.08,8.83]$ \\
\hline 1.8.1 CKD & 6 & 487 & Mean Difference (IV, Random, 95\% CI) & $4.86[0.95,8.76]$ \\
\hline 1.8.2 Post-transplant & 1 & 32 & Mean Difference (IV, Random, 95\% CI) & $-11.00[-32.30,10.30]$ \\
\hline 1.9 Filtration fraction & 2 & 160 & Mean Difference (IV, Random, 95\% CI) & $-0.40[-0.87,0.07]$ \\
\hline 1.9.1 CKD & 2 & 160 & Mean Difference (IV, Random, 95\% CI) & $-0.40[-0.87,0.07]$ \\
\hline 1.10 Weight & 12 & 759 & Mean Difference (IV, Random, 95\% CI) & $-1.32[-1.94,-0.70]$ \\
\hline 1.10.1 CKD & 8 & 634 & Mean Difference (IV, Random, 95\% CI) & $-1.47[-2.42,-0.53]$ \\
\hline 1.10.2 Dialysis & 3 & 81 & Mean Difference (IV, Random, 95\% CI) & $-0.67[-1.37,0.04]$ \\
\hline 1.10.3 Post-transplant & 1 & 44 & Mean Difference (IV, Random, 95\% CI) & $-2.00[-3.00,-1.00]$ \\
\hline $\begin{array}{l}1.11 \text { Inter-dialytic } \\
\text { weight gain }\end{array}$ & 2 & 187 & Mean Difference (IV, Random, 95\% CI) & $-0.11[-0.28,0.06]$ \\
\hline 1.11.1 Dialysis & 2 & 187 & Mean Difference (IV, Random, 95\% CI) & $-0.11[-0.28,0.06]$ \\
\hline $\begin{array}{l}1.12 \text { Extracellular fluid } \\
\text { volume }\end{array}$ & 3 & 187 & Mean Difference (IV, Random, 95\% CI) & $-0.87[-1.17,-0.58]$ \\
\hline 1.12.1 CKD & 2 & 148 & Mean Difference (IV, Random, 95\% CI) & $-0.89[-1.20,-0.59]$ \\
\hline 1.12.2 Dialysis & 1 & 39 & Mean Difference (IV, Random, 95\% CI) & $-0.30[-1.87,1.27]$ \\
\hline $\begin{array}{l}\text { 1.13 Presence of oede- } \\
\text { ma }\end{array}$ & 2 & 191 & Risk Ratio (M-H, Random, 95\% Cl) & $0.52[0.31,0.90]$ \\
\hline 1.13.1 CKD & 2 & 191 & Risk Ratio (M-H, Random, 95\% Cl) & $0.52[0.31,0.90]$ \\
\hline $\begin{array}{l}1.14 \text { Plasma renin ac- } \\
\text { tivity }\end{array}$ & 2 & 142 & Mean Difference (IV, Random, 95\% CI) & $1.08[0.51,1.65]$ \\
\hline 1.14.1 CKD & 2 & 142 & Mean Difference (IV, Random, 95\% CI) & $1.08[0.51,1.65]$ \\
\hline $\begin{array}{l}\text { 1.15 Aldosterone } \\
\text { (plasma or serum) }\end{array}$ & 2 & 142 & Mean Difference (IV, Random, 95\% CI) & $6.20[3.82,8.58]$ \\
\hline 1.15.1 CKD & 2 & 142 & Mean Difference (IV, Random, 95\% CI) & $6.20[3.82,8.58]$ \\
\hline $\begin{array}{l}1.16 \text { Reduction in anti- } \\
\text { hypertensive dose }\end{array}$ & 7 & 664 & Risk Ratio (M-H, Random, 95\% Cl) & $2.45[0.98,6.08]$ \\
\hline 1.16.1 CKD & 5 & 588 & Risk Ratio (M-H, Random, 95\% Cl) & $1.53[0.62,3.78]$ \\
\hline 1.16.2 Post-transplant & 2 & 76 & Risk Ratio (M-H, Random, 95\% Cl) & $7.52[1.45,39.04]$ \\
\hline $\begin{array}{l}1.17 \text { Symptomatic hy- } \\
\text { potension }\end{array}$ & 6 & 478 & Risk Ratio (M-H, Random, 95\% Cl) & $6.70[2.40,18.69]$ \\
\hline
\end{tabular}




\begin{tabular}{lllll}
\hline $\begin{array}{l}\text { Outcome or sub- } \\
\text { group title }\end{array}$ & No. of studies & $\begin{array}{l}\text { No. of partici- } \\
\text { pants }\end{array}$ & Statistical method & Effect size \\
\hline 1.17 .1 CKD & 5 & 433 & Risk Ratio (M-H, Random, 95\% Cl) & $6.26[2.08,18.81]$ \\
\hline 1.17 .2 Post-transplant & 1 & 45 & Risk Ratio (M-H, Random, 95\% Cl) & $10.54[0.62,180.07]$ \\
\hline 1.18 Total cholesterol & 7 & 473 & Mean Difference (IV, Random, 95\% Cl) & $-0.11[-0.31,0.10]$ \\
\hline 1.18 .1 CKD & 5 & 390 & Mean Difference (IV, Random, 95\% Cl) & $-0.06[-0.30,0.19]$ \\
\hline 1.18 .2 Dialysis & 1 & 39 & Mean Difference (IV, Random, 95\% Cl) & $-0.42[-0.99,0.15]$ \\
\hline 1.18 .3 Post-transplant & 1 & 44 & Mean Difference (IV, Random, 95\% Cl) & $-0.08[-0.54,0.39]$ \\
\hline
\end{tabular}

\section{Analysis 1.1. Comparison 1: CKD stage, Outcome 1: Sodium intake/excretion}

\begin{tabular}{|c|c|c|c|c|c|c|c|c|c|c|}
\hline Study or Subgroup & \multicolumn{2}{|c|}{ Low salt } & \multicolumn{4}{|c|}{ High salt } & Weight & $\begin{array}{c}\text { Mean Difference } \\
\text { IV, Random, } 95 \% \text { CI [mmol/d] }\end{array}$ & \multicolumn{2}{|c|}{$\begin{array}{c}\text { Mean Difference } \\
\text { IV, Random, } 95 \% \text { CI [mmol/d] }\end{array}$} \\
\hline \multicolumn{11}{|l|}{ 1.1.1 CKD } \\
\hline Ruilope 1992a & 72.6 & 39.1 & 14 & 214.4 & 83.5 & 14 & $4.6 \%$ & $-141.80[-190.10,-93.50]$ & — & \\
\hline Mulhauser 1996 & 92 & 33 & 8 & 199 & 52 & 8 & $4.9 \%$ & $-107.00[-149.68,-64.32]$ & $\longrightarrow$ & \\
\hline Kwakernaak 2014 & 148 & 65 & 45 & 224 & 73 & 45 & $5.6 \%$ & $-76.00[-104.56,-47.44]$ & $\because$ & \\
\hline Vogt 2008 & 90 & 57.4 & 33 & 200 & 57.4 & 33 & $5.7 \%$ & $-110.00[-137.70,-82.30]$ & $\rightarrow$ & \\
\hline ViRTUE-CKD 2016 & 104 & 59 & 43 & 170 & 61 & 44 & $5.8 \%$ & $-66.00[-91.22,-40.78]$ & $=$ & \\
\hline Saran 2017 & 112.7 & 66.145 & 56 & 170 & 66.145 & 56 & $5.8 \%$ & $-57.30[-81.80,-32.80]$ & 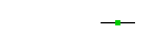 & \\
\hline DUAAAL 2011 & 106 & 50.5 & 52 & 189 & 57.7 & 52 & $6.0 \%$ & $-83.00[-103.84,-62.16]$ & $\rightarrow$ & \\
\hline ESMO 2017 & 138.3 & 53.2 & 67 & 176.9 & 55.6 & 71 & $6.1 \%$ & $-38.60[-56.75,-20.45]$ & - & \\
\hline de Brito-Ashurst 2013 & -122.5 & 40.4688 & 25 & -13 & 12.113 & 23 & $6.1 \%$ & $-109.50[-126.12,-92.88]$ & $=$ & \\
\hline ESPECIAL 2014 & -35.4 & 64.4 & 119 & -9 & 54.5 & 126 & $6.2 \%$ & $-26.40[-41.38,-11.42]$ & $\rightarrow$ & \\
\hline LowSALT CKD 2012 & 75 & 22.0162 & 19 & 168 & 22.0162 & 19 & $6.2 \%$ & $-93.00[-107.00,-79.00]$ & $\rightarrow$ & \\
\hline Konishi 2001 & 48 & 14 & 38 & 166 & 37 & 38 & $6.3 \%$ & $-118.00[-130.58,-105.42]$ & - & \\
\hline Subtotal (95\% CI) & & & 519 & & & 529 & $69.4 \%$ & $-83.81[-104.54,-63.08]$ & & \\
\hline \multicolumn{11}{|c|}{ Heterogeneity: $\mathrm{Tau}^{2}=1174.25 ; \mathrm{Chi}^{2}=135.98, \mathrm{df}=11(\mathrm{P}<0.00001) ; \mathrm{I}^{2}=92 \%$} \\
\hline \multicolumn{11}{|l|}{ 1.1.2 Dialysis } \\
\hline Fine 1997 & 155 & 108 & 20 & 207 & 88 & 20 & $3.9 \%$ & $-52.00[-113.06,9.06]$ & & \\
\hline BalanceWise-PD 2011 & -8.13 & 28.7826087 & 10 & 1.913043478 & 56 & 9 & $5.0 \%$ & $-10.04[-50.75,30.66]$ & 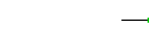 & \\
\hline Rodrigues Telini 2014 & 114.3 & 21.9 & 21 & 156.7 & 21.7 & 18 & $6.2 \%$ & $-42.40[-56.12,-28.68]$ & - & \\
\hline BalanceWise-HD 2013 & -3.08695652 & 44.65217 & 82 & 10.30435 & 43.08696 & 79 & $6.2 \%$ & $-13.39[-26.94,0.16]$ & & \\
\hline Subtotal $(95 \%$ CI) & & & 133 & & & 126 & $21.4 \%$ & $-27.17[-48.59,-5.76]$ & & \\
\hline \multicolumn{11}{|c|}{ Heterogeneity: $\mathrm{Ta}^{2}=276.17 ; \mathrm{Chi}^{2}=10.02, \mathrm{df}=3(\mathrm{P}=0.02) ; \mathrm{I}^{2}=70 \%$} \\
\hline \multicolumn{11}{|c|}{ Test for overall effect: $\mathrm{Z}=2.49(\mathrm{P}=0.01)$} \\
\hline \multicolumn{11}{|l|}{ 1.1.3 Post-transplant } \\
\hline Keven 2006 & 106 & 48 & 18 & 237 & 113 & 14 & $3.8 \%$ & $-131.00[-194.21,-67.79]$ & & \\
\hline de Vries 2016 & 87 & 55.8422 & 22 & 164 & 55.8422 & 22 & $5.4 \%$ & $-77.00[-110.00,-44.00]$ & & \\
\hline Subtotal $(95 \%$ CI) & & & 40 & & & 36 & $9.2 \%$ & $-96.99[-148.10,-45.89]$ & & \\
\hline \multirow{2}{*}{\multicolumn{11}{|c|}{$\begin{array}{l}\text { Heterogeneity: } \mathrm{Tau}^{2}=796.22 ; \mathrm{Chi}^{2}=2.20, \mathrm{df}=1(\mathrm{P}=0.14) ; \mathrm{I}^{2}=55 \% \\
\text { Test for overall effect: } \mathrm{Z}=3.72(\mathrm{P}=0.0002)\end{array}$}} \\
\hline & & & & & & & & & & \\
\hline Total $(95 \%$ CI) & & & 692 & & & 691 & $100.0 \%$ & $-73.51[-92.76,-54.27]$ & & \\
\hline \multicolumn{11}{|c|}{ Heterogeneity: $\mathrm{Tau}^{2}=1496.22 ; \mathrm{Chi}^{2}=248.56, \mathrm{df}=17(\mathrm{P}<0.00001) ; \mathrm{I}^{2}=93 \%$} \\
\hline Test for overall effect: $Z$ & $\begin{array}{l}.49(\mathrm{P}<0.00001) \\
\mathrm{c}^{2} \mathrm{Ch} \mathrm{j}^{2}=16.10 . \mathrm{df}=\end{array}$ & I & & & & & & & $-200 \quad-100$ & $\begin{array}{c}100 \\
100\end{array}$ \\
\hline
\end{tabular}


Analysis 1.2. Comparison 1: CKD stage, Outcome 2: Systolic blood pressure

\begin{tabular}{|c|c|c|c|c|c|c|c|c|c|c|}
\hline \multirow{3}{*}{$\begin{array}{l}\text { Study or Subgroup } \\
1.2 .1 \mathrm{CKD}\end{array}$} & \multicolumn{3}{|c|}{ Low salt } & \multicolumn{3}{|c|}{ High salt } & \multirow[b]{2}{*}{ Weight } & \multirow{2}{*}{$\begin{array}{c}\text { Mean Difference } \\
\text { IV, Random, } 95 \% \text { CI }[\mathrm{mm} \mathrm{Hg}]\end{array}$} & \multirow{2}{*}{\multicolumn{2}{|c|}{$\begin{array}{c}\text { Mean Difference } \\
\text { IV, Random, 95\% CI [mm Hg }\end{array}$}} \\
\hline & Mean [mm Hg] & SD [mm Hg] & Total & Mean [mm Hg] & SD $[\mathrm{mm} \mathrm{Hg}]$ & Total & & & & \\
\hline & & & & & & & & & & \\
\hline Ruilope 1992a & 146.1 & 20.2 & 14 & 148 & 21.2 & 14 & $1.4 \%$ & $-1.90[-17.24,13.44]$ & — & — \\
\hline Mulhauser 1996 & -1.7 & 8.3132 & 8 & 3.2 & 6.9376 & 8 & $4.3 \%$ & $-4.90[-12.40,2.60]$ & $\rightarrow$ & \\
\hline DUAAAL 2011 & 123 & 16.3975 & 52 & 134 & 16.3975 & 52 & $5.3 \%$ & $-11.00[-17.30,-4.70]$ & $\because$ & \\
\hline Saran 2017 & 137 & 15.7468 & 49 & 147.8 & 15.7468 & 49 & $5.3 \%$ & $-10.80[-17.04,-4.56]$ & $\rightarrow$ & \\
\hline Vogt 2008 & 137 & 11.9197 & 33 & 143 & 11.9197 & 33 & $5.8 \%$ & $-6.00[-11.75,-0.25]$ & $\rightarrow-$ & \\
\hline Konishi 2001 & 115 & 11.2 & 38 & 121.6 & 13.1 & 38 & $6.1 \%$ & $-6.60[-12.08,-1.12]$ & - & \\
\hline ViRTUE-CKD 2016 & 123 & 12 & 43 & 129 & 14 & 44 & $6.1 \%$ & $-6.00[-11.48,-0.52]$ & - & \\
\hline LowSALT CKD 2012 & 144.9 & 8.2285 & 20 & 154.6 & 8.2285 & 20 & $6.6 \%$ & $-9.70[-14.80,-4.60]$ & - & \\
\hline Kwakernaak 2014 & 141 & 10.4869 & 45 & 147 & 10.4869 & 45 & $7.6 \%$ & $-6.00[-10.33,-1.67]$ & $\rightarrow-$ & \\
\hline ESPECIAL 2014 & -1.7 & 14.6 & 119 & -0.6 & 15.1 & 126 & $8.4 \%$ & $-1.10[-4.82,2.62]$ & - & \\
\hline ESMO 2017 & 125 & 9.8 & 67 & 127 & 10.1 & 71 & $9.0 \%$ & $-2.00[-5.32,1.32]$ & & \\
\hline de Brito-Ashurst 2013 & -8.6 & 5.2977 & 25 & -0.6 & 5.2977 & 23 & $9.5 \%$ & $-8.00[-11.00,-5.00]$ & - & \\
\hline Subtotal $(95 \% \mathrm{CI})$ & & & 513 & & & 523 & $75.5 \%$ & $-6.10[-8.11,-4.08]$ & $\Delta$ & \\
\hline \multicolumn{11}{|c|}{ Heterogeneity: $\mathrm{Tau}^{2}=5.51 ; \mathrm{Chi}^{2}=20.96, \mathrm{df}=11(\mathrm{P}=0.03) ; \mathrm{I}^{2}=48 \%$} \\
\hline \multicolumn{11}{|c|}{ Test for overall effect: $\mathrm{Z}=5.93(\mathrm{P}<0.00001)$} \\
\hline \multicolumn{11}{|l|}{ 1.2.2 Dialysis } \\
\hline BalanceWise-PD 2011 & 2.7 & 27.8 & 7 & -4.9 & 19.5 & 7 & $0.6 \%$ & $7.60[-17.56,32.76]$ & & \\
\hline Rodrigues Telini 2014 & 147.5 & 18.25 & 21 & 149.22 & 20.44 & 18 & $2.0 \%$ & $-1.72[-13.97,10.53]$ & - & - \\
\hline Doulton 2007 & 119 & 12.9412 & 11 & 129 & 12.9412 & 11 & $2.5 \%$ & $-10.00[-20.82,0.82]$ & & \\
\hline Catto 1973 & 136.9 & 14.8432 & 17 & 140.2 & 15.6678 & 17 & $2.7 \%$ & $-3.30[-13.56,6.96]$ & - & - \\
\hline Fine 1997 & 135 & 11.8191 & 20 & 144 & 11.8191 & 20 & $4.4 \%$ & $-9.00[-16.33,-1.67]$ & $=$ & \\
\hline Subtotal $(95 \% \mathrm{CI})$ & & & 76 & & & 73 & $12.2 \%$ & $-6.32[-11.04,-1.60]$ & & \\
\hline \multirow{2}{*}{\multicolumn{11}{|c|}{$\begin{array}{l}\text { Heterogeneity: } \mathrm{Tau}^{2}=0.00 ; \mathrm{Chi}^{2}=3.01, \mathrm{df}=4(\mathrm{P}=0.56) ; \mathrm{I}^{2}=0 \% \\
\text { Test for overall effect: } \mathrm{Z}=2.63(\mathrm{P}=0.009)\end{array}$}} \\
\hline & & & & & & & & & & \\
\hline \multicolumn{11}{|l|}{ 1.2.3 Post-transplant } \\
\hline Keven 2006 & 116 & 11 & 18 & 132 & 13 & 14 & $3.6 \%$ & $-16.00[-24.50,-7.50]$ & — & \\
\hline de Vries 2016 & 129 & 5.9227 & 22 & 140 & 5.9227 & 22 & $8.7 \%$ & $-11.00[-14.50,-7.50]$ & $=$ & \\
\hline Subtotal (95\% CI) & & & 40 & & & 36 & $12.3 \%$ & $-11.94[-15.77,-8.11]$ & 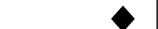 & \\
\hline \multirow{2}{*}{\multicolumn{11}{|c|}{$\begin{array}{l}\text { Heterogeneity: } \text { Tau }^{2}=1.51 ; \mathrm{Chi}^{2}=1.14, \mathrm{df}=1(\mathrm{P}=0.29) ; \mathrm{I}^{2}=12 \% \\
\text { Test for overall effect: } \mathrm{Z}=6.11(\mathrm{P}<0.00001)\end{array}$}} \\
\hline & & & & & & & & & & \\
\hline Total $(95 \%$ CI) & & & 629 & & & 632 & $100.0 \%$ & $-6.91[-8.82,-4.99]$ & 1 & \\
\hline \multicolumn{11}{|c|}{ Heterogeneity: $\mathrm{Tau}^{2}=7.70 ; \mathrm{Chi}^{2}=36.15, \mathrm{df}=18(\mathrm{P}=0.007) ; \mathrm{I}^{2}=50 \%$} \\
\hline \multirow{2}{*}{\multicolumn{9}{|c|}{$\begin{array}{l}\text { Test for overall effect: } \mathrm{Z}=7.08(\mathrm{P}<0.00001) \\
\text { Test for subgroup differences: } \mathrm{Chi}^{2}=7.17, \mathrm{df}=2(\mathrm{P}=0.03), \mathrm{I}^{2}=72.1 \%\end{array}$}} & $\begin{array}{ll}-50 & -25\end{array}$ & 25 \\
\hline & & & & & & & & & Favours low salt & Favours ! \\
\hline
\end{tabular}


Analysis 1.3. Comparison 1: CKD stage, Outcome 3: Diastolic blood pressure

\begin{tabular}{|c|c|c|c|c|c|c|c|c|c|c|}
\hline \multirow{2}{*}{$\begin{array}{l}\text { Study or Subgroup } \\
1.3 .1 \mathrm{CKD}\end{array}$} & \multicolumn{3}{|c|}{ Low salt } & \multicolumn{3}{|c|}{ High salt } & Weight & $\begin{array}{c}\text { Mean Difference } \\
\text { IV, Random, 95\% CI [mm Hg] }\end{array}$ & \multicolumn{2}{|c|}{$\begin{array}{c}\text { Mean Difference } \\
\text { IV, Random, } 95 \% \text { CI [mm Hg] }\end{array}$} \\
\hline & & & & & & & & & & \\
\hline Ruilope 1992a & 90.3 & 11.3 & 14 & 90.1 & 12.1 & 14 & $1.0 \%$ & $0.20[-8.47,8.87]$ & & \\
\hline Mulhauser 1996 & -3.1 & 3.2894 & 8 & 2.2 & 4.7846 & 8 & $4.1 \%$ & $-5.30[-9.32,-1.28]$ & $\longrightarrow-$ & \\
\hline DUAAAL 2011 & 73 & 10.4348 & 52 & 80 & 10.4348 & 52 & $4.1 \%$ & $-7.00[-11.01,-2.99]$ & —- & \\
\hline Konishi 2001 & 75 & 8 & 38 & 79 & 9 & 38 & $4.5 \%$ & $-4.00[-7.83,-0.17]$ & & \\
\hline Saran 2017 & 70.8 & 7.4201 & 47 & 77 & 7.4201 & 47 & $6.6 \%$ & $-6.20[-9.20,-3.20]$ & $\rightarrow-$ & \\
\hline ViRTUE-CKD 2016 & 74 & 7.0049 & 43 & 77 & 7.0049 & 44 & $6.8 \%$ & $-3.00[-5.94,-0.06]$ & 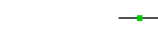 & \\
\hline Vogt 2008 & 83 & 6.093 & 33 & 86 & 6.093 & 33 & $6.8 \%$ & $-3.00[-5.94,-0.06]$ & - & \\
\hline ESPECIAL 2014 & 73.6 & 10.7768 & 119 & 76 & 10.7768 & 126 & $7.7 \%$ & $-2.40[-5.10,0.30]$ & $=$ & \\
\hline LowSALT CKD 2012 & 79.4 & 4.0336 & 20 & 83.3 & 4.0336 & 20 & $8.6 \%$ & $-3.90[-6.40,-1.40]$ & $\rightarrow$ & \\
\hline Kwakernaak 2014 & 78.6 & 5.8084 & 45 & 82 & 5.8084 & 45 & $9.1 \%$ & $-3.40[-5.80,-1.00]$ & - & \\
\hline ESMO 2017 & 74 & 6.5 & 67 & 76 & 6.7 & 71 & $10.1 \%$ & $-2.00[-4.20,0.20]$ & $\rightarrow$ & \\
\hline de Brito-Ashurst 2013 & -4 & 4.4 & 25 & -1 & 2.1 & 23 & $11.9 \%$ & $-3.00[-4.93,-1.07]$ & - & \\
\hline Subtotal (95\% CI) & & & 511 & & & 521 & $81.3 \%$ & $-3.47[-4.28,-2.65]$ & 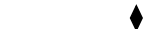 & \\
\hline \multicolumn{11}{|c|}{ Heterogeneity: $\mathrm{Tau}^{2}=0.00 ; \mathrm{Chi}^{2}=10.57, \mathrm{df}=11(\mathrm{P}=0.48) ; \mathrm{I}^{2}=0 \%$} \\
\hline \multicolumn{11}{|c|}{ Test for overall effect: $\mathrm{Z}=8.30(\mathrm{P}<0.00001)$} \\
\hline \multicolumn{11}{|l|}{ 1.3.2 Dialysis } \\
\hline BalanceWise-PD 2011 & 0.1 & 13.3 & 7 & -3.4 & 9.6 & 7 & $0.5 \%$ & $3.50[-8.65,15.65]$ & & \\
\hline Rodrigues Telini 2014 & 87.4 & 11.9 & 21 & 83.6 & 22.9 & 18 & $0.6 \%$ & $3.80[-7.94,15.54]$ & & \\
\hline Catto 1973 & 84.2 & 11.1324 & 17 & 85.8 & 11.5447 & 17 & $1.3 \%$ & $-1.60[-9.22,6.02]$ & & - \\
\hline Doulton 2007 & 66 & 5.9064 & 11 & 71 & 5.9064 & 11 & $2.9 \%$ & $-5.00[-9.94,-0.06]$ & & \\
\hline Fine 1997 & 77 & 7.6273 & 20 & 82 & 7.6273 & 20 & $3.1 \%$ & $-5.00[-9.73,-0.27]$ & & \\
\hline Subtotal $(95 \% \mathrm{CI})$ & & & 76 & & & 73 & $8.4 \%$ & $-3.46[-6.39,-0.54]$ & & \\
\hline \multicolumn{11}{|c|}{ Heterogeneity: $\mathrm{Tau}^{2}=0.00 ; \mathrm{Chi}^{2}=3.74, \mathrm{df}=4(\mathrm{P}=0.44) ; \mathrm{I}^{2}=0 \%$} \\
\hline \multicolumn{11}{|c|}{ Test for overall effect: $\mathrm{Z}=2.32(\mathrm{P}=0.02)$} \\
\hline \multicolumn{11}{|l|}{ 1.3.3 Post-transplant } \\
\hline Keven 2006 & 72 & 10 & 18 & 80 & 9 & 14 & $1.7 \%$ & $-8.00[-14.60,-1.40]$ & & \\
\hline de Vries 2016 & 79 & 4.2305 & 22 & 86 & 4.2305 & 22 & $8.6 \%$ & $-7.00[-9.50,-4.50]$ & $=-$ & \\
\hline Subtotal $(95 \% \mathrm{CI})$ & & & 40 & & & 36 & $10.3 \%$ & $-7.13[-9.46,-4.79]$ & & \\
\hline \multicolumn{11}{|c|}{ Heterogeneity: $\mathrm{Tau}^{2}=0.00 ; \mathrm{Chi}^{2}=0.08, \mathrm{df}=1(\mathrm{P}=0.78) ; \mathrm{I}^{2}=0 \%$} \\
\hline \multicolumn{11}{|c|}{ Test for overall effect: $\mathrm{Z}=5.97(\mathrm{P}<0.00001)$} \\
\hline Total $(95 \% \mathrm{CI})$ & & & 627 & & & 630 & $100.0 \%$ & $-3.91[-4.80,-3.02]$ & $\Delta$ & \\
\hline \multicolumn{11}{|c|}{ Heterogeneity: $\mathrm{Tau}^{2}=0.77 ; \mathrm{Chi}^{2}=22.84, \mathrm{df}=18(\mathrm{P}=0.20) ; \mathrm{I}^{2}=21 \%$} \\
\hline Test for overall effect: $Z$ & $3.62(\mathrm{P}<0.00001)$ & & & & & & & & $-20-10$ & 10 \\
\hline Test for subgroup differ & es: $\mathrm{Chi}^{2}=8.45, \mathrm{df}=$ & $2(\mathrm{P}=0.01), \mathrm{I}^{2}=$ & $76.3 \%$ & & & & & & Favours low salt & Favours hig \\
\hline
\end{tabular}

Analysis 1.4. Comparison 1: CKD stage, Outcome 4: Proteinuria [ln mg/d]

\begin{tabular}{|c|c|c|c|c|c|}
\hline & MD & SE & Weigh & $\begin{array}{c}\text { Mean Difference } \\
\text { IV, Random, 95\% CI }\end{array}$ & $\begin{array}{c}\text { Mean Difference } \\
\text { IV, Random, 95\% CI }\end{array}$ \\
\hline
\end{tabular}

\begin{tabular}{lrrrr}
\hline $\mathbf{1 . 4 . 1}$ CKD & & & & \\
LowSALT CKD 2012 & -0.5414 & 0.2241 & $9.0 \%$ & $-0.54[-0.98,-0.10]$ \\
ViRTUE-CKD 2016 & -0.33 & 0.1622 & $12.7 \%$ & $-0.33[-0.65,-0.01]$ \\
ESMO 2017 & -0.33 & 0.1042 & $17.5 \%$ & $-0.33[-0.53,-0.13]$ \\
DUAAAL 2011 & -0.71 & 0.0804 & $19.5 \%$ & $-0.71[-0.87,-0.55]$ \\
Kwakernaak 2014 & -0.37 & 0.0757 & $19.9 \%$ & $-0.37[-0.52,-0.22]$ \\
Vogt 2008 & -0.2485 & 0.0583 & $21.3 \%$ & $-0.25[-0.36,-0.13]$ \\
Subtotal (95\% CI) & & & $\mathbf{1 0 0 . 0} \%$ & $\mathbf{- 0 . 4 1}[-\mathbf{0 . 5 8}, \mathbf{- 0 . 2 5}]$
\end{tabular}

Heterogeneity: $\mathrm{Tau}^{2}=0.03 ; \mathrm{Chi}^{2}=22.73, \mathrm{df}=5(\mathrm{P}=0.0004) ; \mathrm{I}^{2}=78 \%$

Test for overall effect: $\mathrm{Z}=4.86(\mathrm{P}<0.00001)$

Total (95\% CI)

$100.0 \%-0.41[-0.58,-0.25]$

Heterogeneity: $\mathrm{Tau}^{2}=0.03 ; \mathrm{Chi}^{2}=22.73, \mathrm{df}=5(\mathrm{P}=0.0004) ; \mathrm{I}^{2}=78 \%$

Test for overall effect: $\mathrm{Z}=4.86(\mathrm{P}<0.00001)$

Test for subgroup differences: Not applicable

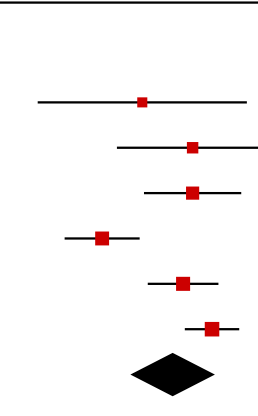


Analysis 1.5. Comparison 1: CKD stage, Outcome 5: Albuminuria [ln mg/d]

\begin{tabular}{|c|c|c|c|c|c|}
\hline Study or Subgroup & MD & SE & Weight & $\begin{array}{c}\text { Mean Difference } \\
\text { IV, Random, 95\% CI }\end{array}$ & $\begin{array}{c}\text { Mean Difference } \\
\text { IV, Random, 95\% CI }\end{array}$ \\
\hline
\end{tabular}

\begin{tabular}{lrrrr}
\hline $\mathbf{1 . 5 . 1}$ CKD & & & & \\
Saran 2017 & -0.2 & 0.2551 & $7.1 \%$ & $-0.20[-0.70,0.30]$ \\
ESPECIAL 2014 & -0.43 & 0.158224 & $15.5 \%$ & $-0.43[-0.74,-0.12]$ \\
Kwakernaak 2014 & -0.5447 & 0.1379 & $18.9 \%$ & $-0.54[-0.81,-0.27]$ \\
ViRTUE-CKD 2016 & -0.293 & 0.1376 & $18.9 \%$ & $-0.29[-0.56,-0.02]$ \\
LowSALT CKD 2012 & -0.5798769 & 0.0798343 & $34.3 \%$ & $-0.58[-0.74,-0.42]$ \\
Subtotal (95\% CI) & & & $\mathbf{9 4 . 8 \%}$ & $\mathbf{- 0 . 4 7}[-\mathbf{0 . 6 0}, \mathbf{- 0 . 3 4}]$
\end{tabular}

Heterogeneity: $\mathrm{Tau}^{2}=0.00 ; \mathrm{Chi}^{2}=4.91, \mathrm{df}=4(\mathrm{P}=0.30) ; \mathrm{I}^{2}=19 \%$

Test for overall effect: $\mathrm{Z}=7.17(\mathrm{P}<0.00001)$

\subsubsection{Post-transplant}

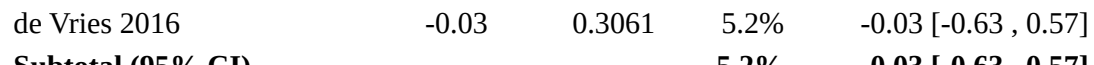

Subtotal (95\% CI) $\quad 5.2 \% \quad-0.03[-0.63,0.57]$

Heterogeneity: Not applicable

Test for overall effect: $\mathrm{Z}=0.10(\mathrm{P}=0.92)$

Total (95\% CI)

$100.0 \% \quad-0.44[-0.58,-0.30]$

Heterogeneity: Tau $^{2}=0.01 ; \mathrm{Chi}^{2}=7.09, \mathrm{df}=5(\mathrm{P}=0.21) ; \mathrm{I}^{2}=29 \%$

Test for overall effect: $\mathrm{Z}=6.05(\mathrm{P}<0.00001)$

Test for subgroup differences: $\mathrm{Chi}^{2}=2.00, \mathrm{df}=1(\mathrm{P}=0.16), \mathrm{I}^{2}=50.0 \%$

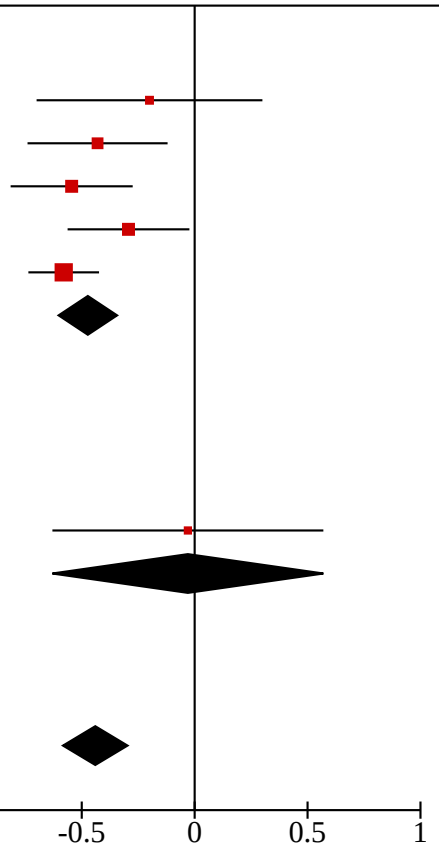

Favours low salt $\quad$ Favours high salt

Analysis 1.6. Comparison 1: CKD stage, Outcome 6: eGFR [mL/min/1.73 m²]

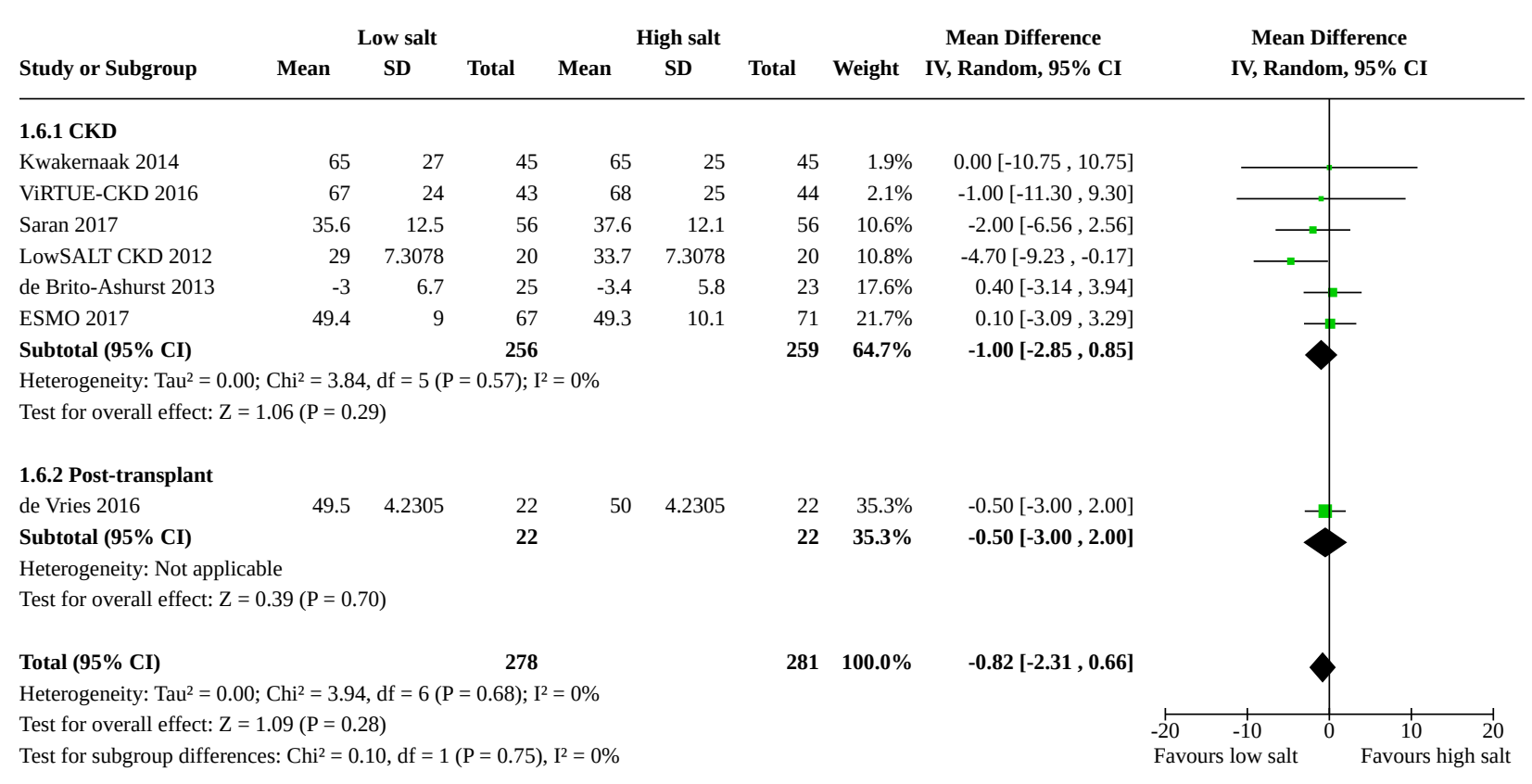




\section{Analysis 1.7. Comparison 1: CKD stage, Outcome 7: Creatinine clearance}

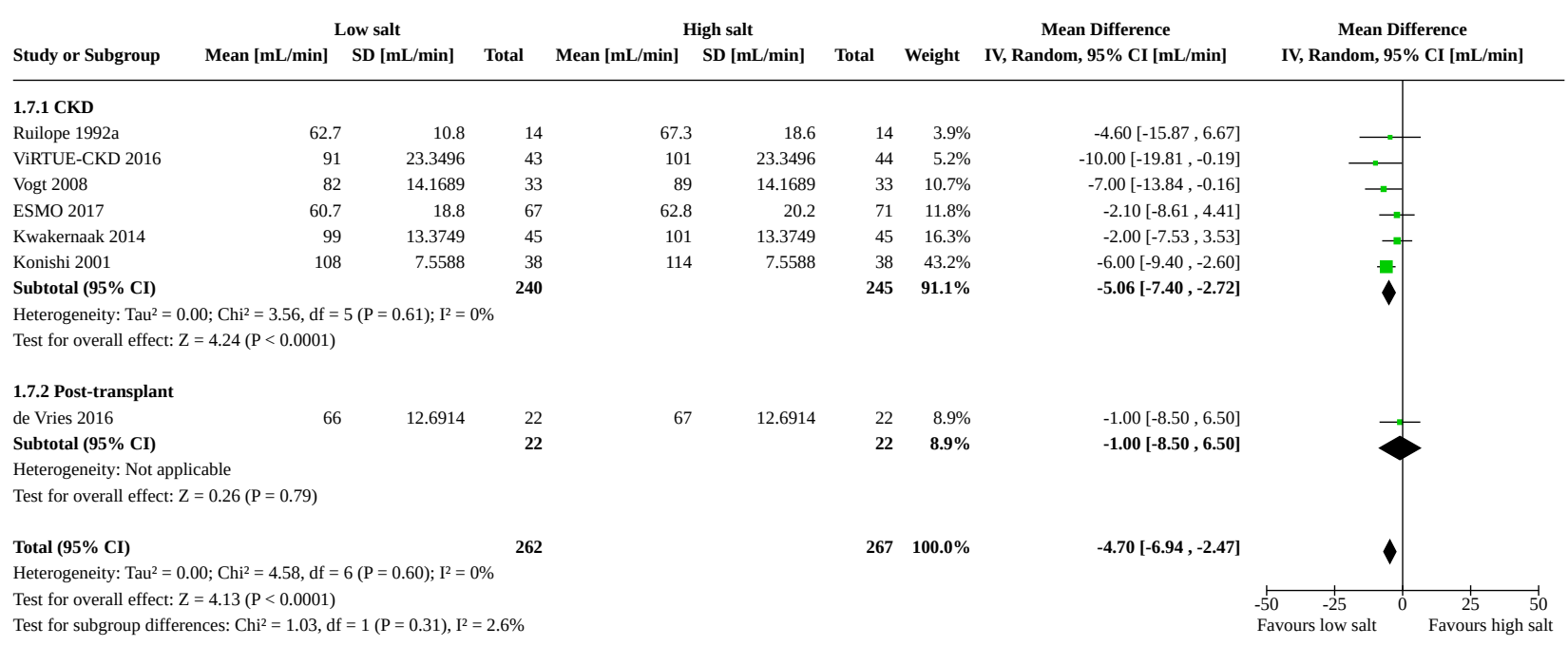

Analysis 1.8. Comparison 1: CKD stage, Outcome 8: Serum creatinine

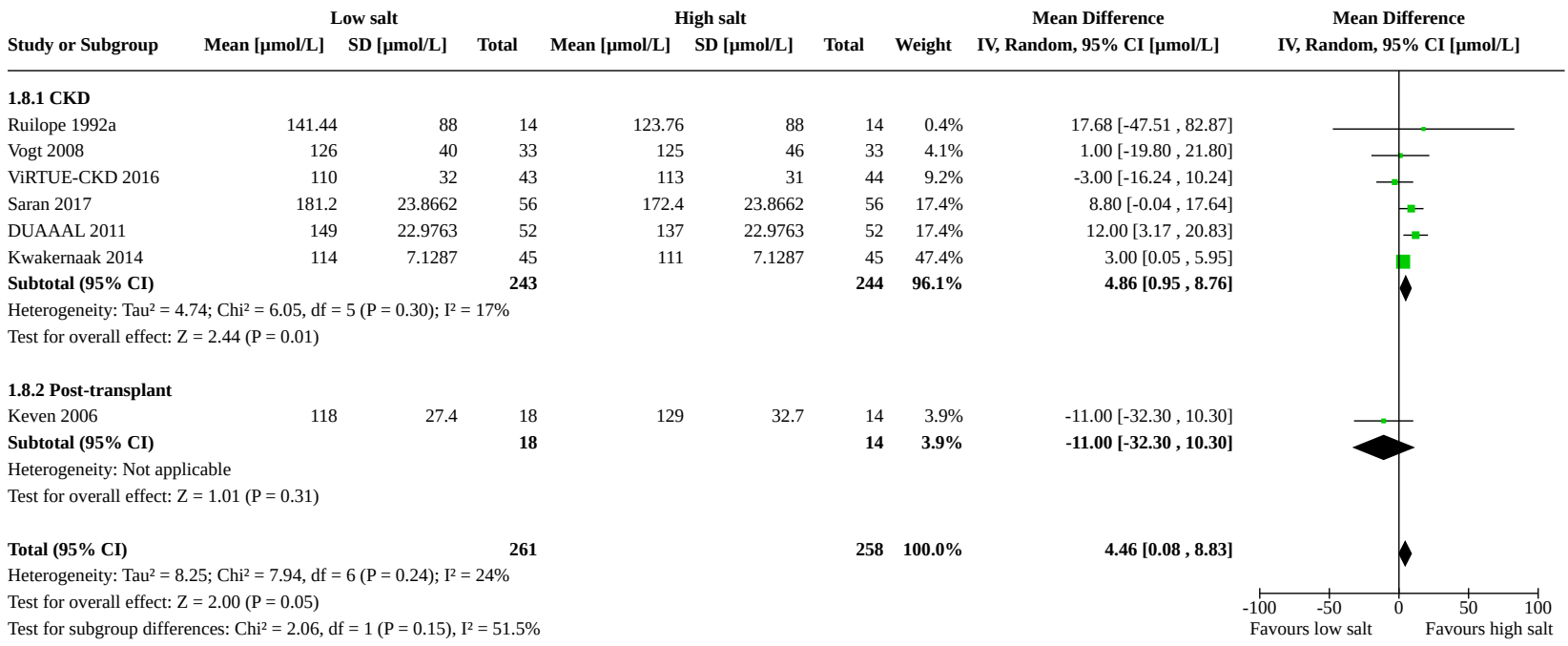

\section{Analysis 1.9. Comparison 1: CKD stage, Outcome 9: Filtration fraction}

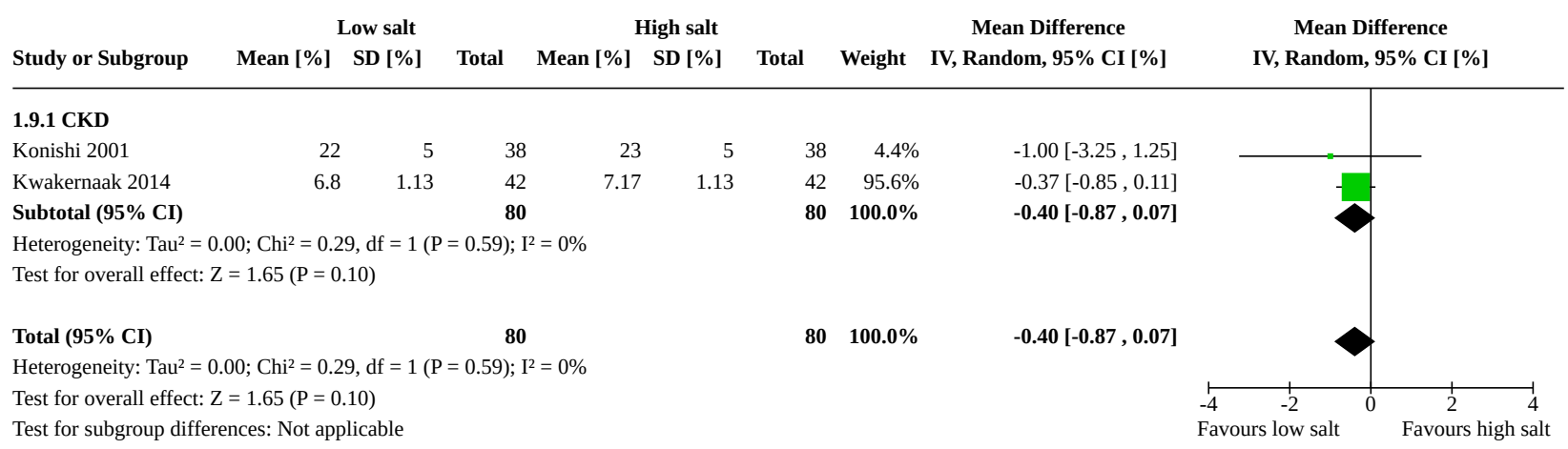




\section{Analysis 1.10. Comparison 1: CKD stage, Outcome 10: Weight}

\begin{tabular}{|c|c|c|c|c|c|c|c|c|c|c|}
\hline \multirow[b]{2}{*}{ Study or Subgroup } & \multicolumn{2}{|c|}{ Low salt } & \multicolumn{4}{|c|}{ High salt } & \multicolumn{2}{|r|}{ Mean Difference } & \multirow{2}{*}{\multicolumn{2}{|c|}{$\begin{array}{c}\text { Mean Difference } \\
\text { IV, Random, 95\% CI [kg] }\end{array}$}} \\
\hline & Mean [kg] & SD [kg] & Total & Mean [kg] & SD [kg] & Total & Weight & IV, Random, 95\% CI [kg] & & \\
\hline \multicolumn{11}{|l|}{ 1.10.1 CKD } \\
\hline ViRTUE-CKD 2016 & 90 & 17 & 43 & 88 & 18 & 13 & $0.3 \%$ & $2.00[-9.03,13.03]$ & & \\
\hline Vogt 2008 & 89 & 17.2 & 33 & 91 & 17.2 & 33 & $0.5 \%$ & $-2.00[-10.30,6.30]$ & & \\
\hline Kwakernaak 2014 & 100 & 18 & 45 & 102 & 18 & 45 & $0.7 \%$ & $-2.00[-9.44,5.44]$ & & \\
\hline Ruilope 1992a & 68.3 & 8.2 & 14 & 70.9 & 7.6 & 14 & $1.1 \%$ & $-2.60[-8.46,3.26]$ & & \\
\hline DUAAAL 2011 & 87 & 3.5372 & 52 & 89 & 3.5372 & 52 & $11.0 \%$ & $-2.00[-3.36,-0.64]$ & - & \\
\hline ESMO 2017 & 89.9 & 3.3 & 67 & 91.4 & 3.4 & 71 & $13.2 \%$ & $-1.50[-2.62,-0.38]$ & - & \\
\hline Saran 2017 & 92.9 & 2.5648 & 56 & 95.2 & 2.5648 & 56 & $15.0 \%$ & $-2.30[-3.25,-1.35]$ & - & \\
\hline LowSALT CKD 2012 & 86 & 0.6454 & 20 & 86.4 & 0.6454 & 20 & $21.3 \%$ & $-0.40[-0.80,0.00]$ & . & \\
\hline Subtotal (95\% CI) & & & 330 & & & 304 & $63.1 \%$ & $-1.47[-2.42,-0.53]$ & $\Delta$ & \\
\hline \multicolumn{11}{|c|}{ Heterogeneity: $\mathrm{Tau}^{2}=0.74 ; \mathrm{Chi}^{2}=18.62, \mathrm{df}=7(\mathrm{P}=0.009) ; \mathrm{I}^{2}=62 \%$} \\
\hline \multicolumn{11}{|c|}{ Test for overall effect: $\mathrm{Z}=3.06(\mathrm{P}=0.002)$} \\
\hline \multicolumn{11}{|l|}{ 1.10.2 Dialysis } \\
\hline Fine 1997 & 72 & 10 & 20 & 72 & 11 & 20 & $0.9 \%$ & $0.00[-6.52,6.52]$ & & \\
\hline BalanceWise-PD 2011 & -1.40615078 & 2.086546 & 8 & -1.13399 & 3.311258 & 7 & $3.9 \%$ & $-0.27[-3.12,2.58]$ & 一 & \\
\hline Doulton 2007 & 75.3 & 0.9482 & 13 & 76 & 0.9482 & 13 & $17.6 \%$ & $-0.70[-1.43,0.03]$ & $=$ & $=$ \\
\hline Subtotal (95\% CI) & & & 41 & & & 40 & $22.4 \%$ & $-0.67[-1.37,0.04]$ & 1 & \\
\hline \multicolumn{11}{|c|}{ Heterogeneity: $\mathrm{Tau}^{2}=0.00 ; \mathrm{Chi}^{2}=0.12, \mathrm{df}=2(\mathrm{P}=0.94) ; \mathrm{I}^{2}=0 \%$} \\
\hline \multicolumn{11}{|c|}{ Test for overall effect: $\mathrm{Z}=1.86(\mathrm{P}=0.06)$} \\
\hline \multicolumn{11}{|l|}{ 1.10.3 Post-transplant } \\
\hline de Vries 2016 & 81 & 1.6922 & 22 & 83 & 1.6922 & 22 & $14.5 \%$ & $-2.00[-3.00,-1.00]$ & - & \\
\hline Subtotal $(95 \% \mathrm{CI})$ & & & 22 & & & 22 & $14.5 \%$ & $-2.00[-3.00,-1.00]$ & $\Delta$ & \\
\hline \multicolumn{11}{|c|}{ Heterogeneity: Not applicable } \\
\hline \multicolumn{11}{|c|}{ Test for overall effect: $\mathrm{Z}=3.92(\mathrm{P}<0.0001)$} \\
\hline Total (95\% CI) & & & 393 & & & 366 & $100.0 \%$ & $-1.32[-1.94,-0.70]$ & $\theta$ & \\
\hline \multicolumn{11}{|c|}{ Heterogeneity: $\mathrm{Tau}^{2}=0.42 ; \mathrm{Chi}^{2}=23.89, \mathrm{df}=11(\mathrm{P}=0.01) ; \mathrm{I}^{2}=54 \%$} \\
\hline Test for overall effect: 2 & $19(\mathrm{P}<0.0001$ & & & & & & & -20 & -10 & 10 \\
\hline Test for subgroup differ & s: $\mathrm{Chi}^{2}=5.01$, & If $=2(P=0$ & 08), $\mathrm{I}^{2}=($ & $0.0 \%$ & & & & Fav & rs low salt & Favours \\
\hline
\end{tabular}

\section{Analysis 1.11. Comparison 1: CKD stage, Outcome 11: Inter-dialytic weight gain}

\begin{tabular}{|c|c|c|c|c|c|c|c|c|c|}
\hline Study or Subgroup & \multicolumn{2}{|r|}{ Low salt } & & $\begin{array}{l}\text { High salt } \\
\text { SD [kg] }\end{array}$ & Total & Weight & $\begin{array}{c}\text { Mean Difference } \\
\text { IV, Random, 95\% CI [kg] }\end{array}$ & $\begin{array}{c}\text { Mean Difference } \\
\text { IV, Random, 95\% CI [kg] }\end{array}$ \\
\hline \multicolumn{10}{|l|}{ 1.11.1 Dialysis } \\
\hline Doulton 2007 & 0.8 & 0.9482 & 13 & 1.1 & 0.9482 & 13 & $5.2 \%$ & $-0.30[-1.03,0.43]$ & \\
\hline BalanceWise-HD 2013 & 1.1 & 0.6 & 81 & 1.2 & 0.5 & 80 & $94.8 \%$ & $-0.10[-0.27,0.07]$ & \\
\hline Subtotal (95\% CI) & & & 94 & & & 93 & $100.0 \%$ & $-0.11[-0.28,0.06]$ & \\
\hline \multicolumn{9}{|c|}{ Heterogeneity: $\mathrm{Tau}^{2}=0.00 ; \mathrm{Chi}^{2}=0.27, \mathrm{df}=1(\mathrm{P}=0.60) ; \mathrm{I}^{2}=0 \%$} & Test for overall effect: $\mathrm{Z}=1.30(\mathrm{P}=0.19)$ \\
\hline Total $(95 \% \mathrm{CI})$ & & & 94 & & & 93 & $100.0 \%$ & $-0.11[-0.28,0.06]$ & \\
\hline \multicolumn{10}{|c|}{ Heterogeneity: $\mathrm{Tau}^{2}=0.00 ; \mathrm{Chi}^{2}=0.27, \mathrm{df}=1(\mathrm{P}=0.60) ; \mathrm{I}^{2}=0 \%$} \\
\hline Test for overall effect: Z & $1.30(\mathrm{P}=0.19$ & & & & & & & & -1 \\
\hline
\end{tabular}


Analysis 1.12. Comparison 1: CKD stage, Outcome 12: Extracellular fluid volume

\begin{tabular}{|c|c|c|c|c|c|c|c|c|c|}
\hline & & Low salt & & & Iigh salt & & & Mean Difference & Mean Difference \\
\hline Study or Subgroup & Mean [L] & SD [L] & Total & Mean [L] & SD [L] & Total & Weight & IV, Random, 95\% CI [L] & IV, Random, 95\% CI [L] \\
\hline
\end{tabular}

\subsubsection{CKD}

Saran 2017

LowSALT CKD 2012

$19.18 \quad 1.2419$

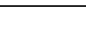

Subtotal (95\% CI)

19.20 .6123

18
74

$18 \quad 54.9 \%$

$-1.02[-1.48,-0.56]$

Heterogeneity: Tau$^{2}=0.00 ; \mathrm{Chi}^{2}=0.50, \mathrm{df}=1(\mathrm{P}=0.48) ; \mathrm{I}^{2}=0 \%$

$-0.80[-1.20,-0.40]$

Test for overall effect: $\mathrm{Z}=5.81(\mathrm{P}<0.00001)$

\subsubsection{Dialysis}

Rodrigues Telini 2014

$15.3 \quad 2.9$

21

$15.6 \quad 2.1$

$18 \quad 3.5 \%$

$-0.30[-1.87,1.27]$

Subtotal (95\% CI)

21

$18 \quad 3.5 \%$

$-0.30[-1.87,1.27]$

Heterogeneity: Not applicable

Test for overall effect: $\mathrm{Z}=0.37(\mathrm{P}=0.71)$

Total (95\% CI)

95

Heterogeneity: $\mathrm{Tau}^{2}=0.00 ; \mathrm{Chi}^{2}=1.03, \mathrm{df}=2(\mathrm{P}=0.60) ; \mathrm{I}^{2}=0 \%$

Test for overall effect: $\mathrm{Z}=5.78(\mathrm{P}<0.00001)$

Test for subgroup differences: $\mathrm{Chi}^{2}=0.53, \mathrm{df}=1(\mathrm{P}=0.47), \mathrm{I}^{2}=0 \%$

$92 \quad 100.0 \%$

$-0.87[-1.17,-0.58]$

V, Random, 95\% CI [L]

Analysis 1.13. Comparison 1: CKD stage, Outcome 13: Presence of oedema

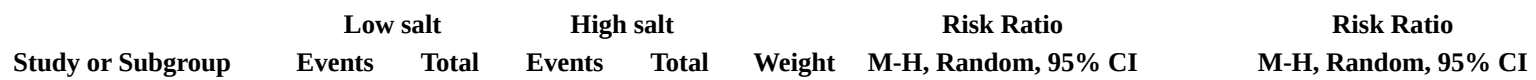

\subsubsection{CKD}

ViRTUE-CKD 2016

DUAAAL 2011

Subtotal (95\% CI)

Total events:

Events Total

M-H, Random, 95\% CI

Heterogeneity: $\mathrm{Tau}^{2}=0.00 ; \mathrm{Chi}^{2}=0.41, \mathrm{df}=1(\mathrm{P}=0.52) ; \mathrm{I}^{2}=0 \%$

Test for overall effect: $\mathrm{Z}=2.36(\mathrm{P}=0.02)$
Total (95\% CI)
95
$96 \quad 100.0 \%$
$0.52[0.31,0.90]$

$0.63[0.29,1.37]$

Total events:

$16 \quad 31$

Heterogeneity: $\mathrm{Tau}^{2}=0.00 ; \mathrm{Chi}^{2}=0.41, \mathrm{df}=1(\mathrm{P}=0.52) ; \mathrm{I}^{2}=0 \%$

Test for overall effect: $\mathrm{Z}=2.36(\mathrm{P}=0.02)$

Test for subgroup differences: Not applicable

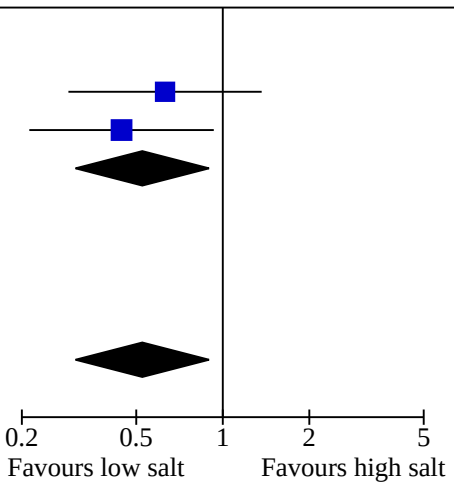

Analysis 1.14. Comparison 1: CKD stage, Outcome 14: Plasma renin activity

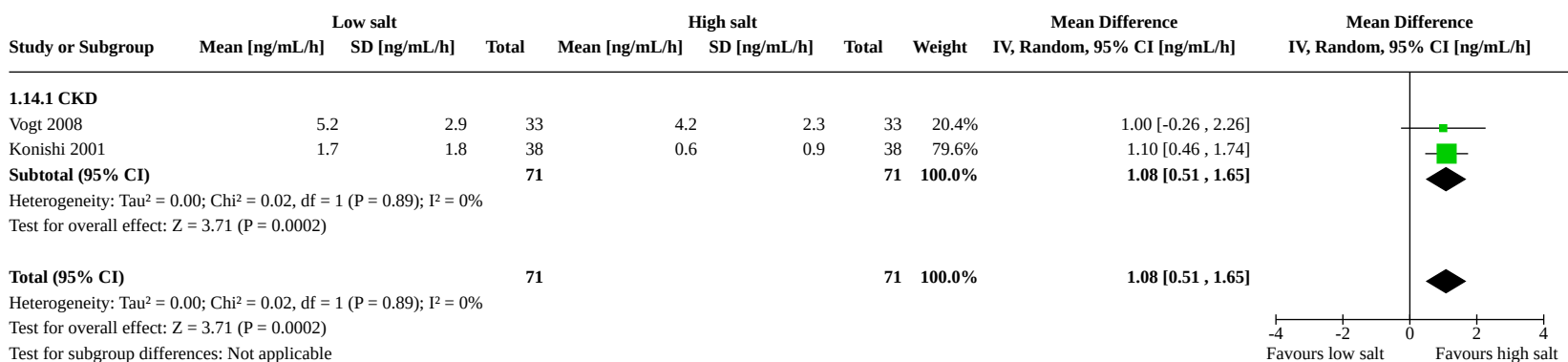


Analysis 1.15. Comparison 1: CKD stage, Outcome 15: Aldosterone (plasma or serum)

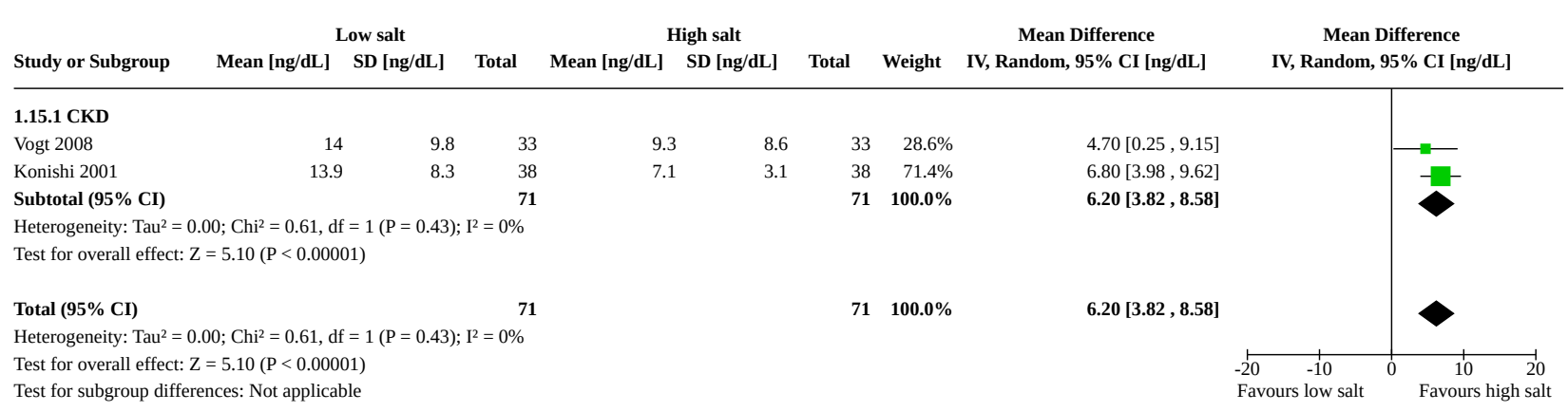

\section{Analysis 1.16. Comparison 1: CKD stage, Outcome 16: Reduction in antihypertensive dose}

\begin{tabular}{|c|c|c|c|c|c|c|c|}
\hline & Lov & & Hig & & & Risk Ratio & Risk Ratio \\
\hline Study or Subgroup & Events & Total & Events & Total & Weight & M-H, Random, 95\% CI & M-H, Random, 95\% CI \\
\hline
\end{tabular}

\begin{tabular}{lrrrrrr}
\hline 1.16.1 CKD & & & & & & \\
ESPECIAL 2014 & 0 & 119 & 0 & 126 & & Not estimable \\
DUAAAL 2011 & 0 & 52 & 0 & 52 & & Not estimable \\
ViRTUE-CKD 2016 & 0 & 43 & 0 & 44 & & Not estimable \\
LowSALT CKD 2012 & 3 & 20 & 1 & 20 & $15.9 \%$ & $3.00[0.34,26.45]$ \\
Saran 2017 & 8 & 56 & 6 & 56 & $56.4 \%$ & $1.33[0.49,3.59]$ \\
Subtotal (95\% CI) & & $\mathbf{2 9 0}$ & & $\mathbf{2 9 8}$ & $\mathbf{7 2 . 2 \%}$ & $\mathbf{1 . 5 3 [ 0 . 6 2 , ~ 3 . 7 8 ]}$ \\
Total events: & 11 & & 7 & & &
\end{tabular}

Heterogeneity: $\mathrm{Tau}^{2}=0.00 ; \mathrm{Chi}^{2}=0.44, \mathrm{df}=1(\mathrm{P}=0.50) ; \mathrm{I}^{2}=0 \%$

Test for overall effect: $\mathrm{Z}=0.93(\mathrm{P}=0.35)$

\subsubsection{Post-transplant}

$\begin{array}{lllllrl}\text { de Vries 2016 } & 2 & 22 & 0 & 22 & 8.9 \% & 5.00[0.25,98.52] \\ \text { Keven 2006 } & 7 & 14 & 1 & 18 & 18.9 \% & 9.00[1.25,64.89] \\ \text { Subtotal (95\% CI) } & & \mathbf{3 6} & & \mathbf{4 0} & \mathbf{2 7 . 8 \%} & \mathbf{7 . 5 2}[\mathbf{1 . 4 5}, \mathbf{3 9 . 0 4}]\end{array}$

$\begin{array}{lcc}\text { Total events: } & 9 & 1 \\ \text { Heterogeneity: } \mathrm{Tau}^{2}=0.00 ; \mathrm{Chi}^{2}=0.10, \mathrm{df}=1(\mathrm{P}=0.75) ; \mathrm{I}^{2}=0 \%\end{array}$

Test for overall effect: $\mathrm{Z}=2.40(\mathrm{P}=0.02)$

$\begin{array}{lllll}\text { Total }(95 \% \mathrm{CI}) & 326 & 338 & 100.0 \% & 2.45[0.98,6.08]\end{array}$

Total events:

$20 \quad 8$

Heterogeneity: $\mathrm{Tau}^{2}=0.13 ; \mathrm{Chi}^{2}=3.43, \mathrm{df}=3(\mathrm{P}=0.33) ; \mathrm{I}^{2}=12 \%$

Test for overall effect: $\mathrm{Z}=1.92(\mathrm{P}=0.05)$

Test for subgroup differences: $\mathrm{Chi}^{2}=2.76, \mathrm{df}=1(\mathrm{P}=0.10), \mathrm{I}^{2}=63.7 \%$ 


\section{Analysis 1.17. Comparison 1: CKD stage, Outcome 17: Symptomatic hypotension}

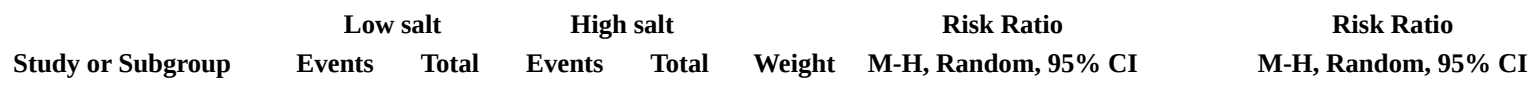

\subsubsection{CKD}

Saran 2017

DUAAAL 2011

LowSALT CKD 2012

Kwakernaak 2014

ViRTUE-CKD 2016

Subtotal (95\% CI)

Total events:

Heterogeneity: $\mathrm{Tau}^{2}=0.00 ; \mathrm{Chi}^{2}=0.24, \mathrm{df}=3(\mathrm{P}=0.97) ; \mathrm{I}^{2}=0 \%$

Test for overall effect: $\mathrm{Z}=3.27(\mathrm{P}=0.001)$

\subsubsection{Post-transplant}

de Vries 2016

Subtotal (95\% CI)

Total events:

53
23

0

22

$13.1 \%$

$10.54[0.62,180.07]$

ceneity: Not applicable

Test for overall effect: $\mathrm{Z}=1.63(\mathrm{P}=0.10)$

\section{Total (95\% CI)}

239

Total events:

26

$239 \quad 100.0 \%$

Heterogeneity: Tau $^{2}=0.00 ; \mathrm{Chi}^{2}=0.35, \mathrm{df}=4(\mathrm{P}=0.99) ; \mathrm{I}^{2}=0 \%$

Test for overall effect: $\mathrm{Z}=3.63(\mathrm{P}=0.0003)$

Test for subgroup differences: $\mathrm{Chi}^{2}=0.11, \mathrm{df}=1(\mathrm{P}=0.74), \mathrm{I}^{2}=0 \%$
Not estimable

$7.00[0.37,132.23]$

$7.00[0.38,127.32]$

$11.00[0.63,193.25]$

$5.12[1.19,22.01]$

$6.26[2.08,18.81]$

Analysis 1.18. Comparison 1: CKD stage, Outcome 18: Total cholesterol

\begin{tabular}{|c|c|c|c|c|c|c|c|c|c|}
\hline Study or Subgroup & \multicolumn{2}{|r|}{ Low salt } & Total & \multicolumn{2}{|r|}{ High salt } & Total & Weight & $\begin{array}{c}\text { Mean Difference } \\
\text { IV, Random, 95\% CI [mmol/L] }\end{array}$ & $\begin{array}{c}\text { Mean Difference } \\
\text { IV, Random, } 95 \% \mathrm{CI}[\mathrm{mmol} / \mathrm{L}]\end{array}$ \\
\hline \multicolumn{10}{|l|}{ 1.18.1 CKD } \\
\hline LowSALT CKD 2012 & 4.09 & 1.43 & 20 & 4.12 & 1.26 & 20 & $5.9 \%$ & $-0.03[-0.87,0.81]$ & \\
\hline Vogt 2008 & 5.9 & 1.1 & 33 & 6.1 & 1.7 & 33 & $8.6 \%$ & $-0.20[-0.89,0.49]$ & \\
\hline Kwakernaak 2014 & 4.5 & 1.5 & 45 & 4.6 & 1.4 & 45 & $11.5 \%$ & $-0.10[-0.70,0.50]$ & \\
\hline ViRTUE-CKD 2016 & 5.2 & 1.2 & 45 & 4.9 & 1 & 45 & $19.8 \%$ & $0.30[-0.16,0.76]$ & \\
\hline DUAAAL 2011 & 4.8 & 0.7 & 52 & 5.1 & 1.4 & 52 & $22.7 \%$ & $-0.30[-0.73,0.13]$ & - \\
\hline Subtotal $(95 \%$ CI) & & & 195 & & & 195 & $68.5 \%$ & $-0.06[-0.30,0.19]$ & \\
\hline \multicolumn{10}{|c|}{ Heterogeneity: $\mathrm{Tau}^{2}=0.00 ; \mathrm{Chi}^{2}=3.79, \mathrm{df}=4(\mathrm{P}=0.43) ; \mathrm{I}^{2}=0 \%$} \\
\hline \multicolumn{10}{|c|}{ Test for overall effect: $\mathrm{Z}=0.46(\mathrm{P}=0.65)$} \\
\hline \multicolumn{10}{|l|}{ 1.18.2 Dialysis } \\
\hline Rodrigues Telini 2014 & 3.419726 & 0.650896 & 21 & 3.837365 & 1.080948 & 18 & $12.6 \%$ & $-0.42[-0.99,0.15]$ & \\
\hline Subtotal (95\% CI) & & & 21 & & & 18 & $12.6 \%$ & $-0.42[-0.99,0.15]$ & \\
\hline \multicolumn{10}{|c|}{ Heterogeneity: Not applicable } \\
\hline \multicolumn{10}{|c|}{ Test for overall effect: $Z=1.43(P=0.15)$} \\
\hline \multicolumn{10}{|l|}{ 1.18.3 Post-transplant } \\
\hline de Vries 2016 & 4.99098 & 0.82752 & 22 & 5.06856 & 0.74994 & 22 & $18.9 \%$ & $-0.08[-0.54,0.39]$ & \\
\hline Subtotal $(95 \%$ CI) & & & 22 & & & 22 & $18.9 \%$ & $-0.08[-0.54,0.39]$ & \\
\hline \multicolumn{10}{|c|}{ Heterogeneity: Not applicable } \\
\hline \multicolumn{10}{|c|}{ Test for overall effect: $\mathrm{Z}=0.33(\mathrm{P}=0.74)$} \\
\hline Total (95\% CI) & & & 238 & & & 235 & $100.0 \%$ & $-0.11[-0.31,0.10]$ & \\
\hline \multicolumn{10}{|c|}{ Heterogeneity: $\mathrm{Tau}^{2}=0.00 ; \mathrm{Chi}^{2}=5.10, \mathrm{df}=6(\mathrm{P}=0.53) ; \mathrm{I}^{2}=0 \%$} \\
\hline Test for overall effect: 2 & $1.03(\mathrm{P}=0.30)$ & & & & & & & & -0.5 \\
\hline
\end{tabular}




\section{Comparison 2. Duration}

\begin{tabular}{|c|c|c|c|c|}
\hline $\begin{array}{l}\text { Outcome or subgroup ti- } \\
\text { tle }\end{array}$ & No. of studies & $\begin{array}{l}\text { No. of partici- } \\
\text { pants }\end{array}$ & Statistical method & Effect size \\
\hline $\begin{array}{l}2.1 \text { Sodium intake/excre- } \\
\text { tion }\end{array}$ & 18 & 1383 & $\begin{array}{l}\text { Mean Difference (IV, Random, 95\% } \\
\mathrm{CI})\end{array}$ & $-73.51[-92.76,-54.27]$ \\
\hline $\begin{array}{l}\text { 2.1.1 Short-term }(<4 \\
\text { weeks) }\end{array}$ & 3 & 142 & $\begin{array}{l}\text { Mean Difference (IV, Random, 95\% } \\
\mathrm{Cl})\end{array}$ & $\begin{array}{l}-111.29[-134.25 \\
-88.32]\end{array}$ \\
\hline $\begin{array}{l}2.1 .2 \text { Longer-term }(\geq 4 \\
\text { weeks) }\end{array}$ & 15 & 1241 & $\begin{array}{l}\text { Mean Difference (IV, Random, 95\% } \\
\mathrm{CI})\end{array}$ & $-64.53[-83.29,-45.78]$ \\
\hline 2.2 Systolic blood pressure & 19 & 1261 & $\begin{array}{l}\text { Mean Difference (IV, Random, 95\% } \\
\mathrm{CI})\end{array}$ & $-6.91[-8.82,-4.99]$ \\
\hline $\begin{array}{l}\text { 2.2.1 Short-term }(<4 \\
\text { weeks) }\end{array}$ & 3 & 144 & $\begin{array}{l}\text { Mean Difference (IV, Random, 95\% } \\
\mathrm{Cl})\end{array}$ & $-7.91[-11.53,-4.28]$ \\
\hline $\begin{array}{l}\text { 2.2.2 Longer-term ( } \geq 4 \\
\text { weeks) }\end{array}$ & 16 & 1117 & $\begin{array}{l}\text { Mean Difference (IV, Random, 95\% } \\
\mathrm{CI})\end{array}$ & $-6.82[-9.00,-4.64]$ \\
\hline $\begin{array}{l}2.3 \text { Diastolic blood pres- } \\
\text { sure }\end{array}$ & 19 & 1257 & $\begin{array}{l}\text { Mean Difference (IV, Random, 95\% } \\
\mathrm{CI})\end{array}$ & $-3.91[-4.80,-3.02]$ \\
\hline $\begin{array}{l}\text { 2.3.1 Short-term }(<4 \\
\text { weeks) }\end{array}$ & 3 & 144 & $\begin{array}{l}\text { Mean Difference (IV, Random, 95\% } \\
\mathrm{CI})\end{array}$ & $-3.70[-5.74,-1.67]$ \\
\hline $\begin{array}{l}\text { 2.3.2 Longer-term }(\geq 4 \\
\text { weeks) }\end{array}$ & 16 & 1113 & $\begin{array}{l}\text { Mean Difference (IV, Random, 95\% } \\
\mathrm{CI})\end{array}$ & $-3.99[-5.03,-2.94]$ \\
\hline 2.4 Creatinine clearance & 7 & 529 & $\begin{array}{l}\text { Mean Difference (IV, Random, 95\% } \\
\mathrm{CI})\end{array}$ & $-4.70[-6.94,-2.47]$ \\
\hline $\begin{array}{l}\text { 2.4.1 Short-term }(<4 \\
\text { weeks) }\end{array}$ & 2 & 104 & $\begin{array}{l}\text { Mean Difference (IV, Random, 95\% } \\
\mathrm{CI})\end{array}$ & $-5.88[-9.14,-2.63]$ \\
\hline $\begin{array}{l}\text { 2.4.2 Longer-term ( } \geq 4 \\
\text { weeks) }\end{array}$ & 5 & 425 & $\begin{array}{l}\text { Mean Difference (IV, Random, 95\% } \\
\mathrm{Cl})\end{array}$ & $-3.65[-6.72,-0.58]$ \\
\hline 2.5 Serum creatinine & 7 & 519 & $\begin{array}{l}\text { Mean Difference (IV, Random, 95\% } \\
\mathrm{CI})\end{array}$ & $4.46[0.08,8.83]$ \\
\hline $\begin{array}{l}\text { 2.5.1 Short-term }(<4 \\
\text { weeks) }\end{array}$ & 1 & 28 & $\begin{array}{l}\text { Mean Difference (IV, Random, 95\% } \\
\mathrm{CI})\end{array}$ & $17.68[-47.51,82.87]$ \\
\hline $\begin{array}{l}\text { 2.5.2 Longer-term ( } \geq 4 \\
\text { weeks) }\end{array}$ & 6 & 491 & $\begin{array}{l}\text { Mean Difference (IV, Random, 95\% } \\
\mathrm{CI})\end{array}$ & $4.40[-0.41,9.20]$ \\
\hline 2.6 Weight & 12 & 759 & $\begin{array}{l}\text { Mean Difference (IV, Random, 95\% } \\
\mathrm{CI})\end{array}$ & $-1.32[-1.94,-0.70]$ \\
\hline $\begin{array}{l}\text { 2.6.1 Short-term }(<4 \\
\text { weeks) }\end{array}$ & 2 & 68 & $\begin{array}{l}\text { Mean Difference (IV, Random, 95\% } \\
\mathrm{Cl})\end{array}$ & $-0.41[-0.81,-0.01]$ \\
\hline $\begin{array}{l}\text { 2.6.2 Longer-term ( } \geq 4 \\
\text { weeks) }\end{array}$ & 10 & 691 & $\begin{array}{l}\text { Mean Difference (IV, Random, 95\% } \\
\mathrm{Cl})\end{array}$ & $-1.53[-2.02,-1.04]$ \\
\hline
\end{tabular}


Analysis 2.1. Comparison 2: Duration, Outcome 1: Sodium intake/excretion

\begin{tabular}{|c|c|c|c|c|c|c|c|c|c|c|}
\hline Study or Subgroup & \multicolumn{2}{|c|}{ Low salt } & Total & \multicolumn{2}{|c|}{ High salt } & Total & Weight & $\begin{array}{c}\text { Mean Difference } \\
\text { IV, Random, 95\% CI [mmol/d] }\end{array}$ & \multicolumn{2}{|c|}{$\begin{array}{c}\text { Mean Difference } \\
\text { IV Random, } 95 \% \text { CUmmold }\end{array}$} \\
\hline \multicolumn{11}{|c|}{ 2.1.1 Short-term (<4 weeks) } \\
\hline Ruilope 1992a & 72.6 & 39.1 & 14 & 214.4 & 83.5 & 14 & $4.6 \%$ & $-141.80[-190.10,-93.50]$ & - & \\
\hline LowSALT CKD 2012 & 75 & 22.0162 & 19 & 168 & 22.0162 & 19 & $6.2 \%$ & $-93.00[-107.00,-79.00]$ & - & \\
\hline Konishi 2001 & 48 & 14 & 38 & 166 & 37 & 38 & $6.3 \%$ & $-118.00[-130.58,-105.42]$ & $=$ & \\
\hline Subtotal $(95 \%$ CI) & & & 71 & & & 71 & $17.1 \%$ & $-111.29[-134.25,-88.32]$ & & \\
\hline \multicolumn{11}{|c|}{ Heterogeneity: $\mathrm{Tau}^{2}=279.02 ; \mathrm{Chi}^{2}=8.72, \mathrm{df}=2(\mathrm{P}=0.01) ; \mathrm{I}^{2}=77 \%$} \\
\hline \multicolumn{11}{|c|}{ Test for overall effect: $\mathrm{Z}=9.50(\mathrm{P}<0.00001)$} \\
\hline \multicolumn{11}{|c|}{ 2.1.2 Longer-term ( $\geq 4$ weeks) } \\
\hline Keven 2006 & 106 & 48 & 18 & 237 & 113 & 14 & $3.8 \%$ & $-131.00[-194.21,-67.79]$ & . & \\
\hline Fine 1997 & 155 & 108 & 20 & 207 & 88 & 20 & $3.9 \%$ & $-52.00[-113.06,9.06]$ & & \\
\hline Mulhauser 1996 & 92 & 33 & 8 & 199 & 52 & 8 & $4.9 \%$ & $-107.00[-149.68,-64.32]$ & — & \\
\hline BalanceWise-PD 2011 & -8.13 & 28.7826087 & 10 & 1.913043478 & 56 & 9 & $5.0 \%$ & $-10.04[-50.75,30.66]$ & & - \\
\hline de Vries 2016 & 87 & 55.8422 & 22 & 164 & 55.8422 & 22 & $5.4 \%$ & $-77.00[-110.00,-44.00]$ & 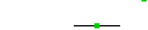 & \\
\hline Kwakernaak 2014 & 148 & 65 & 45 & 224 & 73 & 45 & $5.6 \%$ & $-76.00[-104.56,-47.44]$ & $\Longrightarrow$ & \\
\hline Vogt 2008 & 90 & 57.4 & 33 & 200 & 57.4 & 33 & $5.7 \%$ & $-110.00[-137.70,-82.30]$ & $\rightarrow$ & \\
\hline ViRTUE-CKD 2016 & 104 & 59 & 43 & 170 & 61 & 44 & $5.8 \%$ & $-66.00[-91.22,-40.78]$ & & \\
\hline Saran 2017 & 112.7 & 66.145 & 56 & 170 & 66.145 & 56 & $5.8 \%$ & $-57.30[-81.80,-32.80]$ & $\rightarrow$ & \\
\hline DUAAAL 2011 & 106 & 50.5 & 52 & 189 & 57.7 & 52 & $6.0 \%$ & $-83.00[-103.84,-62.16]$ & $\rightarrow$ & \\
\hline ESMO 2017 & 138.3 & 53.2 & 67 & 176.9 & 55.6 & 71 & $6.1 \%$ & $-38.60[-56.75,-20.45]$ & $=$ & \\
\hline de Brito-Ashurst 2013 & -122.5 & 40.4688 & 25 & -13 & 12.113 & 23 & $6.1 \%$ & $-109.50[-126.12,-92.88]$ & $\ldots$ & \\
\hline ESPECIAL 2014 & -35.4 & 64.4 & 119 & -9 & 54.5 & 126 & $6.2 \%$ & $-26.40[-41.38,-11.42]$ & - & \\
\hline Rodrigues Telini 2014 & 114.3 & 21.9 & 21 & 156.7 & 21.7 & 18 & $6.2 \%$ & $-42.40[-56.12,-28.68]$ & $\rightarrow$ & \\
\hline BalanceWise-HD 2013 & -3.08695652 & 44.65217 & 82 & 10.30435 & 43.08696 & 79 & $6.2 \%$ & $-13.39[-26.94,0.16]$ & & \\
\hline Subtotal $(95 \% \mathrm{CI})$ & & & 621 & & & 620 & $82.9 \%$ & $-64.53[-83.29,-45.78]$ & & \\
\hline \multicolumn{11}{|c|}{ Heterogeneity: $\mathrm{Tau}^{2}=1133.49 ; \mathrm{Chi}^{2}=140.19, \mathrm{df}=14(\mathrm{P}<0.00001) ; \mathrm{I}^{2}=90 \%$} \\
\hline \multicolumn{11}{|c|}{ Test for overall effect: $\mathrm{Z}=6.74(\mathrm{P}<0.00001)$} \\
\hline Total $(95 \%$ CI) & & & 692 & & & 691 & $100.0 \%$ & $-73.51[-92.76,-54.27]$ & & \\
\hline \multicolumn{11}{|c|}{ Heterogeneity: $\mathrm{Tau}^{2}=1496.22 ; \mathrm{Ch}^{2}=248.56, \mathrm{df}=17(\mathrm{P}<0.00001) ; \mathrm{I}^{2}=93 \%$} \\
\hline \multirow{2}{*}{\multicolumn{9}{|c|}{$\begin{array}{l}\text { Test for overall effect: } \mathrm{Z}=7.49(\mathrm{P}<0.00001) \\
\text { Test for subgroup differences: } \mathrm{Chi}^{2}=9.55, \mathrm{df}=1(\mathrm{P}=0.002), \mathrm{I}^{2}=89.5 \%\end{array}$}} & -100 & 100 \\
\hline & & & & & & & & & Favours low salt & Favours hi \\
\hline
\end{tabular}

\section{Analysis 2.2. Comparison 2: Duration, Outcome 2: Systolic blood pressure}

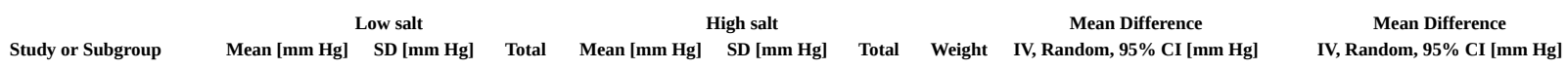

2.2.1 Short-term ( $<4$ weeks)

Konishi 2001

LowSALT CKD 2012

Subtotal (95\% CI)

Heterogeneity: $\mathrm{Tau}^{2}=0.00 ; \mathrm{Chi}^{2}=1.28, \mathrm{df}=2(\mathrm{P}=0.53) ; \mathrm{I}^{2}=0 \%$

$\begin{array}{rr}146.1 & 20.2 \\ 115 & 11.2 \\ 144.9 & 8.2285\end{array}$

Test for overall effect: $\mathrm{Z}=4.27(\mathrm{P}<0.0001)$

2.2.2 Longer-term ( $(4$ weeks)

BalanceWise-PD 2011

Rodrigues Telini 2014

Doulton 2007

Catto 1973

Keven 2006

Mulhauser 1996

Fine 1997

DUAAAL 2011

Saran 2017

Vogt 2008

ViRTUE-CKD 2016

Kwakernaak 2014

ESPECIAL 2014

de Vries 2016

ESMO 2017

de Brito-Ashurst 2013

Subtotal (95\% CI)

Heterogeneity: $\mathrm{Tau}^{2}=9.44 ; \mathrm{Chi}^{2}=34.35, \mathrm{df}=15(\mathrm{P}=0.003) ; \mathrm{I}^{2}=56 \%$

Test for overall effect: $Z=6.12(\mathrm{P}<0.00001)$

Total $(95 \%$ CI)

Heterogeneity: $\mathrm{Tau}^{2}=7.70 ; \mathrm{Chi}^{2}=36.15, \mathrm{df}=18(\mathrm{P}=0.007) ; \mathrm{I}^{2}=50 \%$

Test for overall effect: $\mathrm{Z}=7.08(\mathrm{P}<0.00001)$

Test for subgroup differences: $\mathrm{Chi}^{2}=0.25, \mathrm{df}=1(\mathrm{P}=0.62), \mathrm{I}^{2}=0 \%$

$\begin{array}{rrrrr}14 & 148 & 21.2 & 14 & 1.4 \% \\ 38 & 121.6 & 13.1 & 38 & 6.1 \% \\ 20 & 154.6 & 8.2285 & 20 & 6.6 \% \\ \mathbf{7 2} & & & \mathbf{7 2} & \mathbf{1 4 . 1 \%}\end{array}$

$6.1 \%$

$14.1 \%$

$\begin{array}{rrrr}-4.9 & 19.5 & 7 & 0.6 \% \\ 149.22 & 20.44 & 18 & 2.0 \% \\ 129 & 12.9412 & 11 & 2.5 \% \\ 140.2 & 15.6678 & 17 & 2.7 \% \\ 132 & 13 & 14 & 3.6 \% \\ 3.2 & 6.9376 & 8 & 4.3 \% \\ 144 & 11.8191 & 20 & 4.4 \% \\ 134 & 16.3975 & 52 & 5.3 \% \\ 147.8 & 15.7468 & 49 & 5.3 \% \\ 143 & 11.9197 & 33 & 5.8 \% \\ 129 & 14 & 44 & 6.1 \% \\ 147 & 10.4869 & 45 & 7.6 \% \\ -0.6 & 15.1 & 126 & 8.4 \% \\ 140 & 5.9227 & 22 & 8.7 \% \\ 127 & 10.1 & 71 & 9.0 \% \\ -0.6 & 5.2977 & 23 & 9.5 \% \\ & & 560 & 85.9 \%\end{array}$

$632 \quad 100.0 \%$

$1.90[-17.24,13.44]$ $-6.60[-12.08,-1.12]$ $-9.70[-14.80,-4.60]$ 


\section{Analysis 2.3. Comparison 2: Duration, Outcome 3: Diastolic blood pressure}

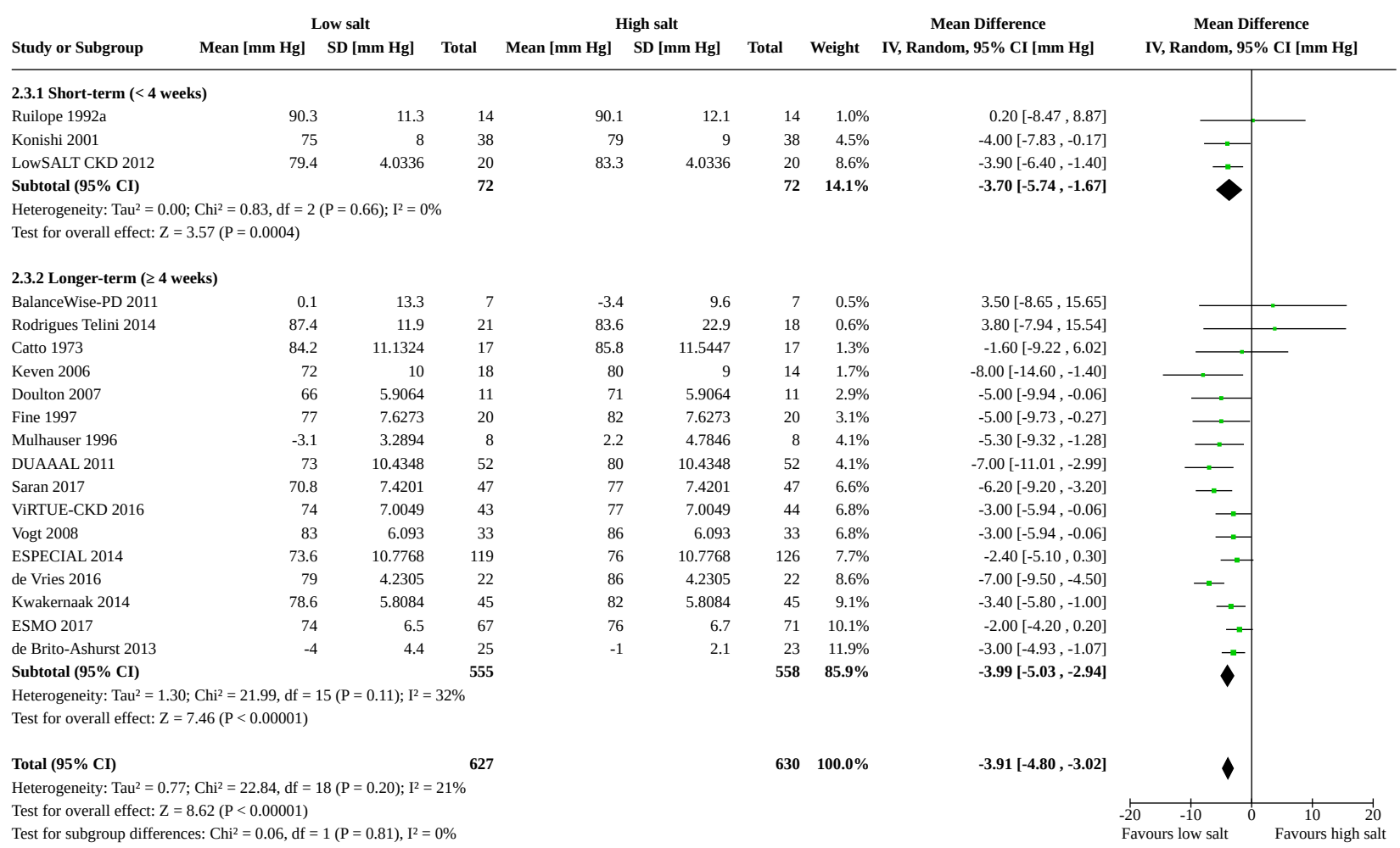

Analysis 2.4. Comparison 2: Duration, Outcome 4: Creatinine clearance

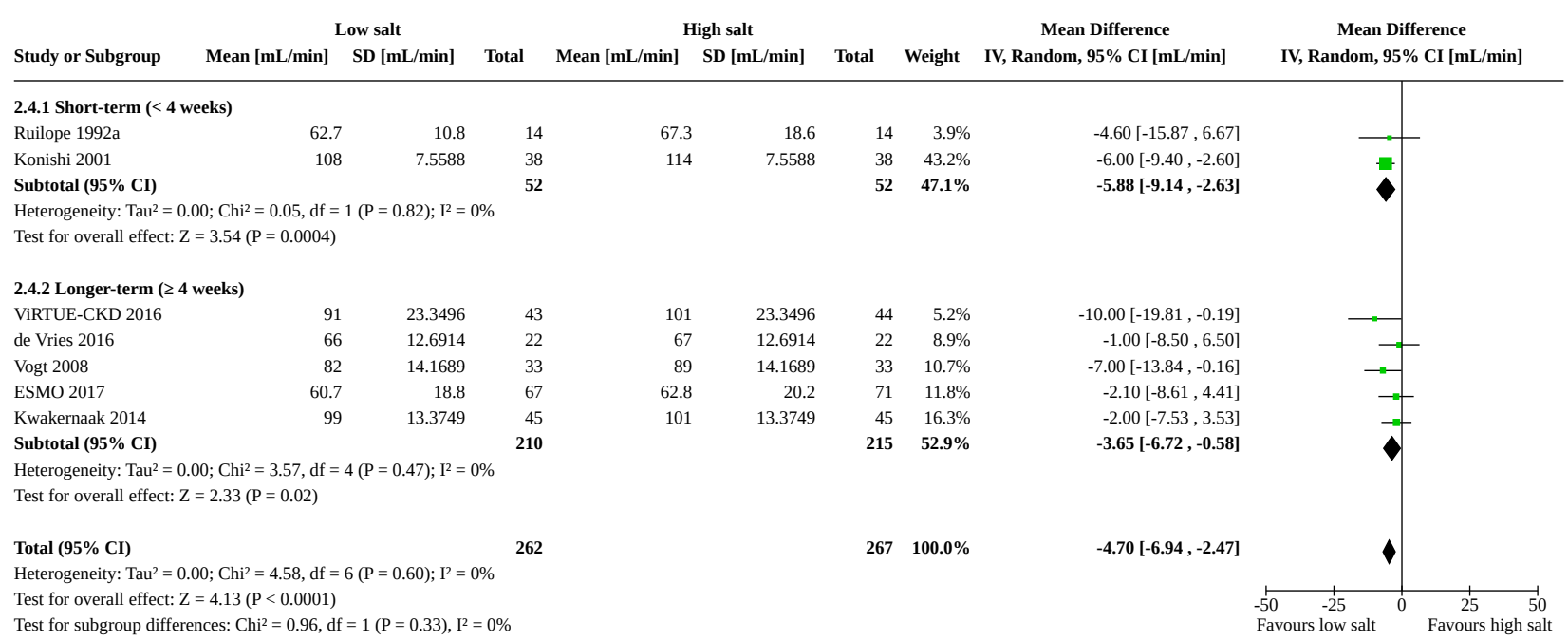


Analysis 2.5. Comparison 2: Duration, Outcome 5: Serum creatinine

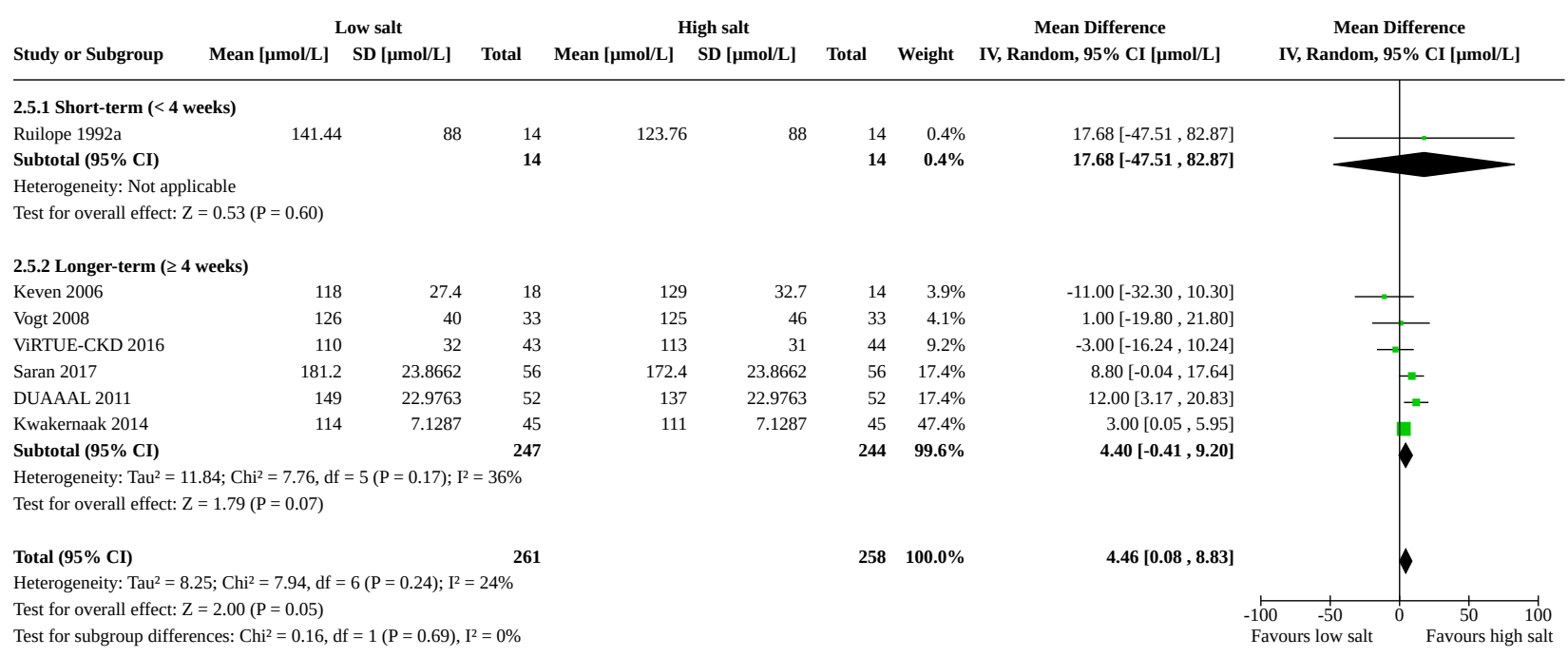

Analysis 2.6. Comparison 2: Duration, Outcome 6: Weight

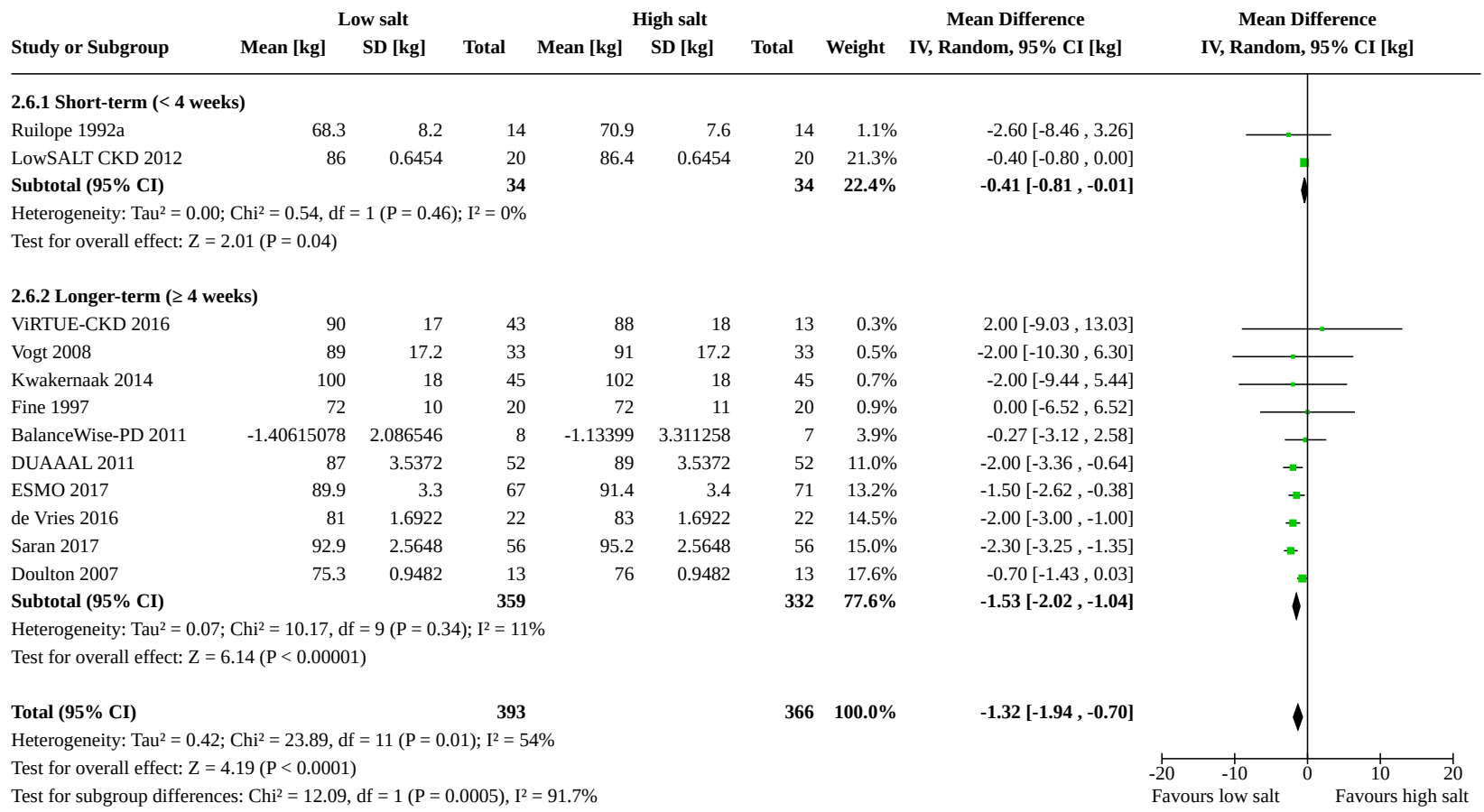

\section{APPENDICES}

Appendix 1. Electronic search strategies

\begin{tabular}{ll}
\hline Database & Search terms \\
\hline CENTRAL & 1 . sodium chloride:kw \\
\hline
\end{tabular}


2. ((sodium or salt) near/5 (low or high or alter ${ }^{\star}$ or reduce* or reducing or reduction or restrict ${ }^{\star}$ or intake or diet $^{\star}$ or increas* or decreas* or change* or changing)):ti,ab,kw

3. (\#1 OR\#2)

4. "renal replacement therapy":ti,ab,kw

5. ( $h^{\star}$ emodialysis or $h^{\star}$ emofiltration or $h^{\star}$ emodiafiltration):ti,ab,kw

6. dialysis:ti,ab,kw

7. (CAPD or CCPD or APD):ti,ab,kw

8. ("kidney disease" or "kidney diseases" or "renal disease" or "renal diseases"):ti,ab,kw

9. (chronic next kidney or chronic next renal):ti,ab,kw

10.((kidney next failure) or (renal next failure)):ti,ab,kw

11.("end-stage kidney" or "end-stage renal" or "endstage kidney" or "endstage renal"):ti,ab,kw

12.(ESRF or ESKF or ESRD or ESKD):ti,ab,kw

13. (CKF or CKD or CRF or CRD):ti,ab,kw

14.(predialysis or "pre-dialysis"):ti,ab,kw

15.(nephropath* or nephrit* or glomerulo*):ti,ab,kw

16. (glomerular next disease $\left.{ }^{\star}\right): \mathrm{ti}, \mathrm{ab}, \mathrm{kw}$

17. (\#4 OR \#5 OR \#6 OR \#7 OR \#8 OR \#9 OR \#10 OR \#11 OR \#12 OR \#13 OR \#14 OR \#15 OR \#16)

18.(\#3 AND \#17)

1. exp Sodium Chloride/

2. Diet, Sodium Restricted/

3. ((sodium or salt) adj5 (low or high or alter ${ }^{\star}$ or reduce $^{\star}$ or reduction or restrict ${ }^{\star}$ or intake or diet $^{\star}$ or increas ${ }^{\star}$ or decreas* or change* or changing)).tw.

4. or/1-3

5. Renal Replacement Therapy/

6. exp Renal Dialysis/

7. (hemodialysis or haemodialysis).tw.

8. (hemofiltration or haemofiltration).tw.

9. (hemodiafiltration or haemodiafiltration).tw.

10.dialysis.tw.

11.(CAPD or CCPD or APD).tw.

12.exp Kidney Diseases/

13. (kidney disease ${ }^{\star}$ or renal disease $\left.{ }^{\star}\right)$.tw.

14.(nephropath* or nephrit ${ }^{\star}$ or glomerulo* or glomerular disease $\left.{ }^{\star}\right)$.tw.

15.(end-stage renal or end-stage kidney or endstage renal or endstage kidney).tw.

16.(ESRF or ESKF or ESRD or ESKD).tw.

17. (chronic kidney or chronic renal).tw.

18. (CKF or CKD or CRF or CRD).tw.

19. (predialysis or pre-dialysis).tw.

20.or/5-19

21.and/4,20

1. Sodium Chloride/

2. Salt Intake/

3. Sodium Restriction/

4. Sodium Intake/

5. ((sodium or salt) adj5 (low or high or alter ${ }^{\star}$ or reduce ${ }^{\star}$ or reduction or restrict* or intake $^{\star}$ or diet $^{\star}$ or increas ${ }^{\star}$ or decreas* or change* or changing)).tw.

6. or/1-5

7. exp Renal Replacement Therapy/

8. (hemodialysis or haemodialysis).tw.

9. (hemofiltration or haemofiltration).tw. 


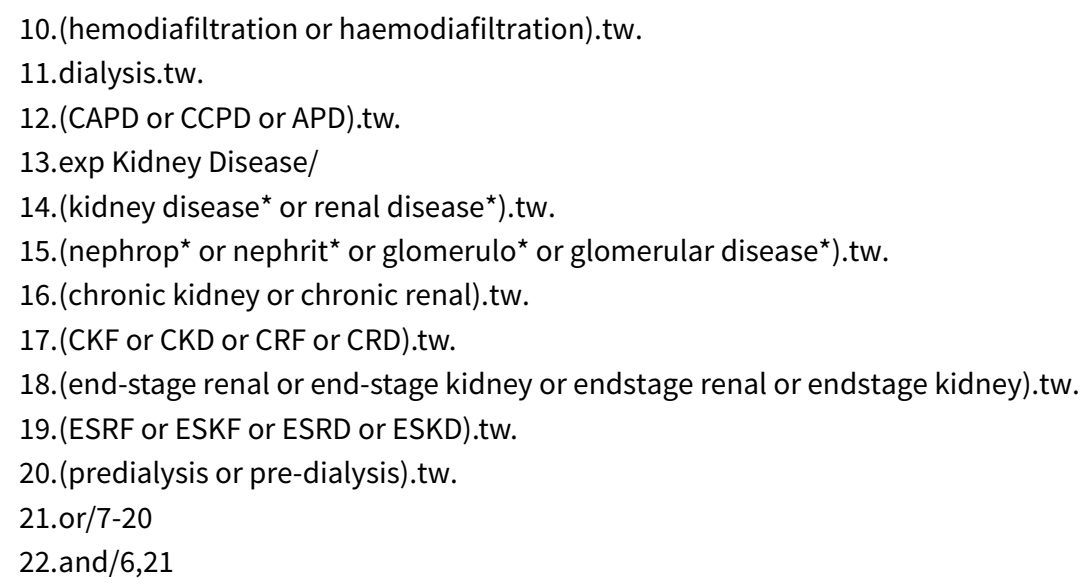

Appendix 2. Risk of bias assessment tool

\begin{tabular}{ll}
\hline Potential source of bias & Assessment criteria \\
\hline $\begin{array}{l}\text { Random sequence genera- } \\
\text { tion }\end{array}$ & $\begin{array}{l}\text { Low risk of bias: Random number table; computer random number generator; coin tossing; shuf- } \\
\text { fling cards or envelopes; throwing dice; drawing of lots; minimization (minimization may be imple- } \\
\text { mented without a random element, and this is considered to be equivalent to being random). }\end{array}$ \\
\cline { 2 - 2 } $\begin{array}{l}\text { Selection bias (biased alloca- } \\
\text { tion to interventions) due to } \\
\text { inadequate generation of a } \\
\text { randomised sequence }\end{array}$ & $\begin{array}{l}\text { High risk of bias: Sequence generated by odd or even date of birth; date (or day) of admission; se- } \\
\text { quence generated by hospital or clinic record number; allocation by judgement of the clinician; by } \\
\text { preference of the participant; based on the results of a laboratory test or a series of tests; by avail- } \\
\text { ability of the intervention. }\end{array}$
\end{tabular}

Unclear: Insufficient information about the sequence generation process to permit judgement.

\section{Allocation concealment}

Selection bias (biased allocation to interventions) due to inadequate concealment of allocations prior to assignment

Low risk of bias: Randomisation method described that would not allow investigator/participant to know or influence intervention group before eligible participant entered in the study (e.g. central allocation, including telephone, web-based, and pharmacy-controlled, randomisation; sequentially numbered drug containers of identical appearance; sequentially numbered, opaque, sealed envelopes).

High risk of bias: Using an open random allocation schedule (e.g. a list of random numbers); assignment envelopes were used without appropriate safeguards (e.g. if envelopes were unsealed or non-opaque or not sequentially numbered); alternation or rotation; date of birth; case record number; any other explicitly unconcealed procedure.

Unclear: Randomisation stated but no information on method used is available.

\section{Blinding of participants and personnel}

Performance bias due to knowledge of the allocated interventions by participants and personnel during the study
Low risk of bias: No blinding or incomplete blinding, but the review authors judge that the outcome is not likely to be influenced by lack of blinding; blinding of participants and key study personnel ensured, and unlikely that the blinding could have been broken.

High risk of bias: No blinding or incomplete blinding, and the outcome is likely to be influenced by lack of blinding; blinding of key study participants and personnel attempted, but likely that the blinding could have been broken, and the outcome is likely to be influenced by lack of blinding.

Unclear: Insufficient information to permit judgement 
(Continued)

\section{Blinding of outcome assess- ment}

Detection bias due to knowledge of the allocated interventions by outcome assessors.
Low risk of bias: No blinding of outcome assessment, but the review authors judge that the outcome measurement is not likely to be influenced by lack of blinding; blinding of outcome assessment ensured, and unlikely that the blinding could have been broken.

High risk of bias: No blinding of outcome assessment, and the outcome measurement is likely to be influenced by lack of blinding; blinding of outcome assessment, but likely that the blinding could have been broken, and the outcome measurement is likely to be influenced by lack of blinding.

Unclear: Insufficient information to permit judgement

\section{Incomplete outcome data}

Attrition bias due to amount, nature or handling of incomplete outcome data.
Low risk of bias: No missing outcome data; reasons for missing outcome data unlikely to be related to true outcome (for survival data, censoring unlikely to be introducing bias); missing outcome data balanced in numbers across intervention groups, with similar reasons for missing data across groups; for dichotomous outcome data, the proportion of missing outcomes compared with observed event risk not enough to have a clinically relevant impact on the intervention effect estimate; for continuous outcome data, plausible effect size (difference in means or standardized difference in means) among missing outcomes not enough to have a clinically relevant impact on observed effect size; missing data have been imputed using appropriate methods.

High risk of bias: Reason for missing outcome data likely to be related to true outcome, with either imbalance in numbers or reasons for missing data across intervention groups; for dichotomous outcome data, the proportion of missing outcomes compared with observed event risk enough to induce clinically relevant bias in intervention effect estimate; for continuous outcome data, plausible effect size (difference in means or standardized difference in means) among missing outcomes enough to induce clinically relevant bias in observed effect size; 'as-treated' analysis done with substantial departure of the intervention received from that assigned at randomisation; potentially inappropriate application of simple imputation.

Unclear: Insufficient information to permit judgement

\section{Selective reporting}

Reporting bias due to selective outcome reporting

Low risk of bias: The study protocol is available and all of the study's pre-specified (primary and secondary) outcomes that are of interest in the review have been reported in the pre-specified way; the study protocol is not available but it is clear that the published reports include all expected outcomes, including those that were pre-specified (convincing text of this nature may be uncommon).

High risk of bias: Not all of the study's pre-specified primary outcomes have been reported; one or more primary outcomes is reported using measurements, analysis methods or subsets of the data (e.g. subscales) that were not pre-specified; one or more reported primary outcomes were not prespecified (unless clear justification for their reporting is provided, such as an unexpected adverse effect); one or more outcomes of interest in the review are reported incompletely so that they cannot be entered in a meta-analysis; the study report fails to include results for a key outcome that would be expected to have been reported for such a study.

Unclear: Insufficient information to permit judgement

\section{Carry-over effect}

Bias due to treatment order in cross-over studies
Low risk of bias: Sufficient time between outcome assessments in the first and second periods to ensure carryover effects are not present; insufficient time between outcome assessments in the first and second periods but treatment order effect accounted for in the analysis (by inclusion of intervention-by-time period interactions)

High risk of bias: Insufficient time between outcome assessments in the first and second periods to ensure carryover effects are not present and treatment order effect not accounted for in analysis.

Unclear: Insufficient information to permit judgement

Confounding factors

Low risk of bias: Behavioural factors that are associated with the outcome and covary with dietary sodium (e.g., potassium intake, body weight, anti-hypertensive medication dosage) are un- 
(Continued)

Bias due to differences between groups other than sodium intake changed, or changes were similar between groups, or differences between groups unlikely to modify the intervention effect estimate.

High risk of bias: Changes in confounding factors or baseline imbalances likely to have modified intervention effect estimate

Unclear: Insufficient information to permit judgement

\section{Other bias}

Bias due to problems not covered elsewhere in the table
Low risk of bias: The study appears to be free of other sources of bias.

High risk of bias: Had a potential source of bias related to the specific study design used; stopped early due to some data-dependent process (including a formal-stopping rule); had extreme baseline imbalance; has been claimed to have been fraudulent; had some other problem.

Unclear: Insufficient information to assess whether an important risk of bias exists; insufficient rationale or evidence that an identified problem will introduce bias.

\section{WHAT'S NEW}

\begin{tabular}{lll}
\hline Date & Event & Description \\
\hline 17 June 2021 & New search has been performed & 13 additional studies included \\
\hline 17 June 2021 & $\begin{array}{l}\text { New citation required and conclusions } \\
\text { have changed }\end{array}$ & GRADE used to assess the evidence \\
& $\begin{array}{l}\text { Inclusion criteria modified 1) updated definition of CKD; 2) re- } \\
\text { moved eligibility criterion related to measurement of 24-hour } \\
\text { urine and achieving at least a 34 mmol difference. Previously ex- } \\
\text { cluded studies were re-assessed based on updated eligibility cri- } \\
\text { teria. }\end{array}$ \\
& $\begin{array}{l}\text { New analyses: proteinuria; albuminuria; inter-dialytic weight } \\
\text { gain }\end{array}$ \\
& New outcome: muscle cramps \\
& Used results from paired analyses where possible
\end{tabular}

\section{H I S T O R Y}

Protocol first published: Issue 9, 2012

Review first published: Issue 2, 2015

\section{CONTRIBUTIONSOFAUTHORS}

1. Review protocol: EM, KC, JB, DM

2. Study selection 2019 update: EM, KC; 2015 review: EM, KC, JB

3. Data extraction 2019 update: EM; 2015 review: EM, KC

4. Data analysis: EM

5. Quality assessment: EM, KC

6. GRADE assessment: EM, JK, JB

7. Interpret analysis: $\mathrm{EM}, \mathrm{KC}, \mathrm{JB}, \mathrm{DM}, \mathrm{JK}$

8. Write review: EM, KC, JB, DM, JK 


\section{DECLARATIONS OF INTEREST}

- Emma J McMahon: none known

- Katrina L Campbell: none known

- Judith D Bauer: none known

- David W Mudge: none known

- Jaimon T Kelly: JK reports consultancy fees from Amgen for travel and professional presentation unrelated to the submitted work.

\section{SOURCES OF SUPPORT}

\section{Internal sources}

- Princess Alexandra Hospital, Australia

Salary (DM, KC)

- University of Queensland, Australia

Salary (JB, EH)

\section{External sources}

- NHMRC/Australian Heart Foundation Early Career Fellowship (100085), Australia

\section{DIFFERENCES BETWEEN PROTOCOL AND REVIEW}

2015 review: Outcome sodium excretion was included.

2021 update: Inclusion criteria modified i) updated definition of CKD; ii) removed eligibility criterion related to measurement of 24-hour urine and achieving at least a $34 \mathrm{mmol}$ difference. Outcome added: muscle cramps.

\section{INDEX TERMS}

\section{Medical Subject Headings (MeSH)}

Antihypertensive Agents [administration \& dosage]; Blood Pressure [ ${ }^{*}$ drug effects] [physiology]; *Diet, Sodium-Restricted; Edema [prevention \& control]; Hypertension [drug therapy]; Randomized Controlled Trials as Topic; Renal Insufficiency, Chronic [ ${ }^{\star}$ diet therapy]; Selection Bias; Sodium Chloride, Dietary [*administration \& dosage]

\section{MeSH check words}

Humans 